UNIVERSIDADE DE SÃO PAULO

ESCOLA DE ENGENHARIA DE SÃO CARLOS

Programa de Pós-Graduação em Ciências da Engenharia Ambiental

CAROLINE MOÇO ERBA POMPEI

Filtros Ecológicos: um estudo da remoção de produtos farmacêuticos e de cuidados pessoais e do efeito da contaminação no biofilme. 


\section{Filtros Ecológicos: um estudo da remoção de produtos farmacêuticos e de cuidados pessoais e do efeito da contaminação no biofilme.}

Tese apresentada à Escola de Engenharia de São Carlos, Universidade de São Paulo, como parte dos requisitos para obtenção do título de doutor em Ciências da Engenharia Ambiental.

Orientadora: Profa. Dra. Eny Maria Vieira Co-orientadora: Profa. Dra. Andréa Tucci 
AUTORIZO A REPRODUÇÃO TOTAL OU PARCIAL DESTE TRABALHO, POR QUALQUER MEIO CONVENCIONAL OU ELETRÔNICO, PARA FINS DE ESTUDO E PESQUISA, DESDE QUE CITADA A FONTE.

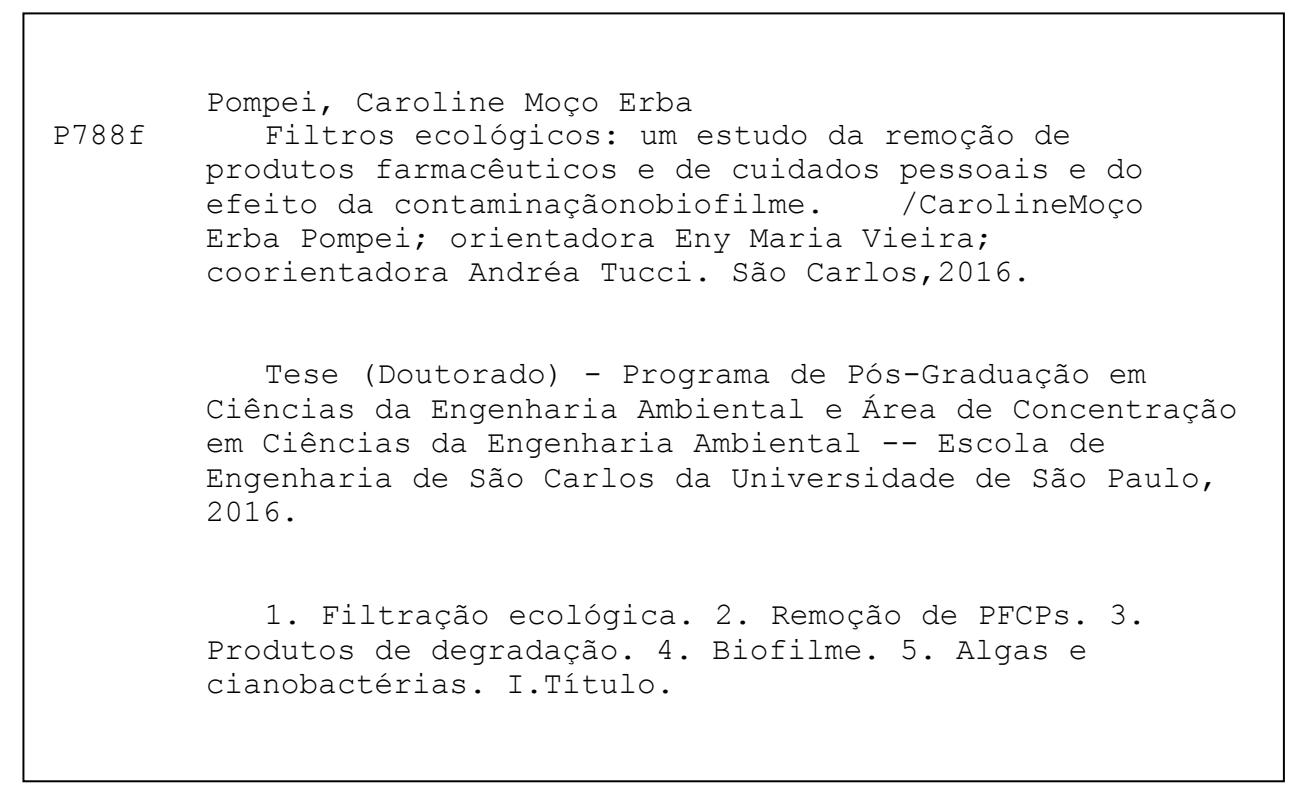




\section{FOLHA DE JULGAMENTO}

Candidata: Licenciada CAROLINE MOÇO ERBA POMPEI.

Título da tese: "Filtros ecológicos: um estudo da remoção de produtos farmacêuticos e de cuidados pessoais e do efeito da contaminação no biofilme".

Data da defesa: 12/08/2016.

\section{Comissão Julgadora:}

Profa. Dra. Eny Maria Vieira (Orientadora)

(Instituto de Química de São Carlos/IQSC)

Prof. Dr. Luiz Antônio Daniel

(Escola de Engenharia de São Carlos/EESC)

Prof. Dr. Edson Pereira Tangerino

(Universidade Estadual Paulista "Júlio de Mesquita Filho"/UNESP - Ilha Solteira)

Profa. Dra. Odete Rocha

(Universidade Federal de São Carlos/UFSCar)

Dr. Carlos Alexandre Galinaro

(Pós-Doutorando/CNPq)

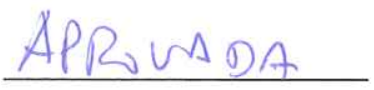

\section{Resultado:}

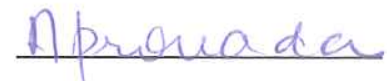


Dedico este trabalho aos meus pais, por acreditarem em mim e por me incentivarem do inicio ao fim, e ao meu marido, por caminhar cada passo desta conquista comigo, em tempos bons e ruins. 


\section{Agradecimentos}

Primeiramente sou grata a Deus, por me proporcionar e capacitar para mais esta etapa da vida. Sem Ele, nada disso seria possível.

Aos meus pais, Edson e Zulema Erba, exemplo de vida e determinação. Por todo o apoio e amor incondicional.

Ao meu marido Bruno Pompei, por me apoiar em todo o tempo, me incentivando sempre e que por muitas vezes "colocou a mão na massa", passando madrugadas comigo no laboratório me ajudando nas análises, nas coletas e por muitas vezes entender minha ausência durante viagens necessárias para desenvolver esta pesquisa.

À FAPESP pela bolsa de doutorado concedida, referente ao Processo número 2011/21666-1, e todo o apoio financeiro concedido, imprescindível para a concretização desta pesquisa.

A Capes pela bolsa de doutorado sanduiche $n^{\circ} .99999 .011120 / 2013-04$

A todos os professores, que participaram de toda esta etapa de construção do saber na minha vida. Em especial, aos professores que se envolveram ativamente com este projeto.

Ao Professor Dr. Edson Pereira Tangerino que me acompanhou desde o mestrado, me incentivou a entrar no doutorado, nunca mediu esforços para me ajudar e incentivar; dimensionou o sistema dos filtros e foi um dos principais responsáveis por eu chegar até aqui e talvez mesmo sem saber, muito me inspirou.

Em especial também a orientadora Professora Dra. Eny Maria Vieira pela confiança, por mais de 4 anos de trabalho e amizade, por todo o incentivo e apoio.

À co-orientadora Andréa Tucci que me acompanha desde a graduação, sou muito grata por todos os ensinamentos, trabalhos desenvolvidos e pela amizade e carinho que sempre teve comigo.

A todos os companheiros do laboratório LAQUAAE e do CRHEA. Aos técnicos de laboratório do CRHEA Amandio e Marcelo.

Agradeço em especial aos amigos que fiz na USP - EESC e na UFSCar, à amiga Mariangela Spadoto (M.M), Tiago Silva, Carlos, Elis, Daniele Schiavone, Thais Garcia.

Agradeço também todos os funcionários do CRHEA, em especial ao José Luiz, Nelson, Rogério, Cido e Regina. Igualmente a todos os funcionários do IQSC, em especial as secretárias Gislei e Veroneide e ao técnico Milton que confeccionou a estrutura dos filtros. 
A todos do Instituto de Botânica de São Paulo, da seção de Ficologia e também o pessoal do alojamento onde passei vários meses. Em especial ao Kleber, Camila, Watson, Andrea, João, Edna e Dinorah.

À Profa. Dra. Maria Valnice Boldrin Zanoni do Instituto de Química da Unesp de Araraquara, que permitiu a utilização do LC-MS/MS em seu laboratório, e em especial a técnica e amiga Dra. Bianca Ferreira da Silva.

Ao Professor Dr. José Carlos Fogo do Departamento de Estatística da UFScar por toda a ajuda com as análises estatísticas e ensinamentos.

À professora Iza Ferreira por todos os ensinamentos na lingua inglesa, e que além de ser a única professora de inglês que conseguiu me fazer gostar da lingua, é uma grande amiga.

À Professora Dra. Luiza Cintra Campos que me aceitou e recebeu na University College London (UCL) com tanto carinho e cuidado durante um ano; por todos os valiosos ensinamentos que com certeza levarei para a vida.

Igualmente agradeço a todos os funcionários da UCL, em especial aos técnicos de laboratório Judith Zhou, Catherine Unsworth, e Ilan; também a Melissa Canales por toda a ajuda com as bactérias isoladas do biofilme, a Tessia Evenor, Elaine Coutman, a Professora Dra. Lena Ciric que possibilitou as análises de sequenciamento genético de bactérias. A Dra. Kersti Karu do departamento de química da UCL pelos ensinamentos e ajuda com as análises químicas.

Também sou grata aos amigos que fiz em Londres, Clarissa Matos, ao amado casal Aracele Langer e Patrick, ao casal Pr. Phill Turner e Tabata Lima Turner, por todas as orações e amizade.

Aos amigos da vida, fora da universidade, Marilia Correa, Otávio Volpato, Cinthia e Daniel, Luciana, Iza Ferreira e Marcelo Ferreira, Karen Valim e Marcelo Martelli.

A todos que de alguma forma contribuíram para a conclusão deste doutorado, os meus sinceros agradecimentos. 
"Talvez não tenha conseguido fazer o melhor, mas lutei para que o melhor fosse feito. Não sou o que deveria ser, mas Graças a Deus, não sou o que era antes”.

(Marthin Luther King) 


\title{
RESUMO
}

\author{
Pompei, C.M.E. Filtros ecológicos: um estudo da remoção de produtos farmacêuticos e \\ de cuidados pessoais e do efeito da contaminação no biofilme. Tese (Doutorado) - Escola \\ de Engenharia de São Carlos, Universidade de São Paulo, São Carlos, SP, Brasil, 2016.
}

A contaminação do ambiente aquático e até mesmo da água de consumo por produtos farmaceuticos e de cuidados pessoais (PFCPs) é resultado das atividades antrópicas. Entre as tecnologias de tratamento de água, a filtração ecológica (modernização do termo filtro lento de areia) é atraente por ser um método natural de tratamento, de baixo custo e eficiência na remoção de patógenos e pode ser utilizada não só em grande escala, mas também domiciliar. $\mathrm{O}$ objetivo desta pesquisa foi avaliar a aplicabilidade dos filtros ecológicos abastecidos com água do Reservatório do Lobo, e a eficiência em remover produtos farmaceuticos e de cuidados pessoais. Além disso, foi avaliado o efeito da contaminação nas comunidades de algas e cianobactérias e de bactérias, presentes no biofilme dos filtros ecológicos. Os filtros ecológicos apresentaram boa remoção de coliformes fecais e Escherichia coli. Os PFCPs alvos deste estudo foram encontrados na água do Reservatório do Lobo em concentração da ordem de $\mu \mathrm{g} \mathrm{L}{ }^{-1}$. Os produtos de cuidados pessoais, metilparabeno e benzofenona3 ,estiveram presentes em todas as amostras de água coletadas e foram os compostos encontrados em maior concentração no reservatório. Dois produtos de degradação dos compostos originais diclofenaco e benzofenona-3 foram identificados na água do reservatório. A porcentagem média global de remoção dos PFCPs pelos filtros ecológicos foi de 81,09 \% de paracetamol, 91,07\% de diclofenaco, 97,33\% de naproxeno, 99,57\% de ibuprofeno, 70,81\% de metilparabeno e 71,69\% de benzofenona3. Foi observado efeito da contaminação na comunidade de algas e cianobactérias. Aulacoseiragranulata, Chroococcus minutus, Dolichospermum planctonicum e Microcystis aeruginosa foram as espécies de algas e cianobactérias consideradas como descritoras em comum para todas as contaminações e tempos de coleta. Lepocincles sp. foi a espécie que mais contribuiu em biovolume durante o período experimental. A ocorrência, abundância e frequência destas espécies indicam uma possível tolerância das mesmas aos PFCPs. O desempenho dos filtros ecológicos de uso doméstico não foi afetado pela presença de $2 \mu \mathrm{g} \mathrm{L}^{-1}$ de PFCPs na água afluente. As espécies Bacillus anthracis e Exiquobacterium sp. foram resistentes aos compostos aplicados no filtro 2. A concentração de biomassa nos filtros aumentou significativamente com o tempo de operação e foi expessa em uma função exponencial de crescimento, mas não houve diferença significativa entre o filtro controle e o contaminado.

Palavras-chave: Filtração ecológica; remoção de PFCPs; produtos de degradação; biofilme; algas e cianobactérias. 


\begin{abstract}
Pompei, C.M.E. Ecological filters: a study of the removal of pharmaceuticals and personal care compounds and the effect of the contamination in the biofilm. Thesis (Doctorate/PhD) - Escola de Engenharia de São Carlos, Universidade de São Paulo, São Carlos, SP, Brazil, 2016.
\end{abstract}

The contamination of the aquatic environment and even the water consumption with pharmaceutical and personal care products (PPCPs) is a result of human activities. Among the water treatment technologies, the ecological filtration (modern name for slow sand filter) is attractive because it is a natural treatment method, low cost and efficiency in removing pathogens and can be used not only in large scale, but also household. The objective of this research was to evaluate the applicability of ecological filters supplied with water from the Lobo Reservoir, and the efficiency in remove pharmaceuticals and personal care products. Furthermore, it was evaluated the effect of contamination in the communities of algae and cyanobacteria and bacteria, in the biofilm of the ecological filters. The ecological filters showed good removal of total coliforms and E. coli. The PPCPs aims of this study were found in the water from the Lobo Reservoir in order of $\mu \mathrm{L}^{-1}$ of concentration. The personal care products, methylparaben and benzophenone-3, were present in all water samples, and the compounds were found at higher concentration in the reservoir. Two degradation products of the original compounds diclofenac and benzophenone- 3 were identified in the water from reservoir. The overall average percentage of removal of PPCPs by ecological filters was $81,09 \%$ of paracetamol, $91,07 \%$ of diclofenac, $97,33 \%$ of naproxen, $99,57 \%$ of ibuprofen, $70,81 \%$ of methylparaben and $71,69 \%$ of benzophenone-3. It was observed an effect caused by contamination in the community of algae and cyanobacteria. Aulacoseira granulata, Chroococcus minutus, Dolichospermum planctonicum and Microcystis aeruginosa were the species of algae and cyanobacteria considered as descriptors in common for all contamination and collection times. Lepocincles sp. was the specie that most contributed in biovolume during the period. The occurrence, abundance and frequency of these species indicate a possible tolerance thereof to PPCPs. The performance of household ecological filters was not affected by the presence of $2 \mu \mathrm{g} \mathrm{L}^{-1}$ of PPCPs in affluent water. The species of bacteria Bacillus anthracis and Exiquobacterium sp. were resistant for the compound applied to the filter 2. The filter biomass concentration increased significantly with filter time and was summarised by an exponential growth function in both filters, but there was no substantial difference between the filter control and contaminated.

Key-words: Ecological filtration; removal ofPPCPs; degradation products; biofilm; algae and cyanobacteria. 


\section{Lista de abreviaturas e siglas}

ACC - Análise de correspondência canônica

ACP - Análise de componentes principais

ACoP - Análise de coordenadas principais

AINE - Anti-inflamatórios Não Esteroidais

ANOVA - Análise de Variancia Univariara

ANVISA - Agência Nacional de Vigilância Sanitária

BLAST - Basic Local Alignment search

BP-3 - Benzofenona-3

CE - Collision Energy

CEP - Cell Entrance Potential

Cloro-a - Clorofila-a

COD - Carbono Orgânico Dissolvido

COT - Carbono Orgânico Total

CRHEA - Centro de Recursos Hídricos e Estudos Ambientais

CU - Coeficiente de Uniformidade

CV - Coeficiente de Variação

CXP - Cell Exit Potential

DNA - DeoxyriboNucleic Acid

DP - Desvio Padrão

DP - Declustering Potential

DPs - Degradation products

EESC - Escola de Engenharia de São Carlos

EP - Entrance Potential

EPA - Environmental Protection Agency

ETEs - Estações de Tratamento de Esgoto

EUA - Estados Unidos da América

EURACHEM - Comitê Europeu para Análise Química

F1 - Filtro 1

F2 - Filtro 2

FAPESP - Fundação de Amparo a Pesquisa do Estado de São Paulo

FEco - Filtro Ecológico

FiME - Filtração em Múltiplas Etapas

FMix - Filtro com aplicação do mix dos compostos

H'- Diversidade

HPLC - Cromatografia liquida de alta eficiência

ICH - International Conference on Harmonisation

INMETRO - Instituto Nacional de Meteorologia, Qualidade e Tecnologia

ISO - Organização Internacional para Padronização

IUPAC - União Internacional de Química Pura e Aplicada

LC-MS/MS - Liquid chromatography-tandem mass spectrometry

LOD - Limite de detecção

LOQ - Limite de quantificação

MANOVA - Análise de Variância Multivariada

Mix - mistura dos seis produtos farmacêuticos e de cuidados pessoais

NMP - Número mais provável

n.d. - Não detectado

NCBI - National Centre for Biotechnology Information

$\mathrm{N}^{\mathrm{o}}$ - Número 
NT - Nitrogenio Total

NTU - Unidades Nefelométricas de Turbidez

OD - Oxigênio Dissolvido

OMS - Organização Mundial da Saúde

PCA - Principal Component Analysis

PCoA - Principal Coordinate Analysis

PCR - Polymerase Chain Reaction

PD - Produto de Degradação

PFCPs - Produtos Farmacêuticos e de Cuidados Pessoais

PFD - Pré-Filtração Dinâmica

PFP - Pré-Filtração em Pedregulhos

PPCPs - Pharmaceuticals and Personal Care Products

PT - Fósforo Total

PT - Produtos de Transformação

PVC - Polyvinyl chloride

QR - Quociente de Risco

QTRAP - Quadrupolo - ion trap linear

$\mathrm{R}$ - Riqueza

SPE - Solid Phase Extraction

STD - Sólidos Totais Dissolvidos

SUS - Sistema Único de Saúde

TPs - Transformation Products

uC - Unidade de cor

UE - União Europeia

UK - United Kingdom

USP - Universidade de São Paulo

UV - Ultravioleta

WHO - World Health Organization 


\section{Lista de Figuras}

\section{Contextualização e justificativa da pesquisa}

Figura 1: Esquema representativo do sistema de purificação ecológica da água

\section{Capítulo 1: Instalação piloto no tratamento de água por sistema de filtração ecológica.}

Figura 1: Mapa de localização de: A) sistema de filtração ecológica; B) local de captação de água na represa do Lobo

Figura 2: Esquema representativo do sistema de filtração ecológica. ................................................ 35

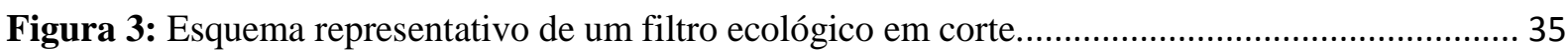

Figura 4: Temperatura média da água no afluente e efluente dos filtros ecológicos........................... 40

Figura 5: Condutividade elétrica média da água no afluente e efluente dos filtros ecológicos. ........... 40 Figura 6: Sólidos totais dissolvidos (STD) médio da água no afluente e efluente dos filtros ecológicos.

Figura 7: Valores médios de $\mathrm{pH}$ aferidos no afluente e efluente dos filtros ecológicos.

Figura 8: Valores médios de turbidez (NTU) aferidos no afluente e efluente dos filtros ecológicos. . 43 Figura 9: Valores médios de cor aparente $(\mathrm{uC})$ aferidos no afluente e efluente dos filtros ecológicos.

Figura 10: Valores médios de cor verdadeira (uC) aferidos no afluente e efluente dos filtros ecológicos

Figura 11: Valores médios de oxigênio dissolvido $\left(\mathrm{mg} \mathrm{L}^{-1}\right)$ aferidos no afluente e efluente dos filtros ecológicos

Figura 12: Valores médios de: a) coliformes totais e b) E. coli no afluente e no efluente dos filtros ecológicos, nas respectivas datas de coleta.

Figura 13: Porcentagem de remoção de coliformes totais e E. coli pelos filtros ecológicos............... 48

Figura 14: Correlação entre condutividade elétrica e STD no efluente dos filtros ecológicos............ 49

Figura 15: Correlação entre $\mathrm{pH}$ e temperatura da água no efluente dos filtros ecológicos................... 50

Figura 16: Correlação entre cor aparente e turbidez da água no efluente dos filtros ecológicos......... 51

Figura 17: Correlação entre pH e cor verdadeira da água no efluente dos filtros ecológicos............... 51

Capítulo 2: Identificação e quantificação de produtos farmacêuticos e de cuidados pessoais na represa do Lobo, remoção por filtros ecológicos e produtos de degradação identificados.

Figura 1: Filtros ecológicos e seus respectivos números. ${ }^{*}=$ Equipos utilizados para a aplicação dos PFCPs.

Figura 2: Cromatograma de íons totais obtido para a mistura dos analitos estudados....................... 72

Figura 3: Cromatogramas individuais para cada composto, ilustrando as três transições, sendo que: A) Paracetamol; B) Metilparabeno; C) Ibuprofeno; D) Diclofenaco; E) Naproxeno; F) Benzofenona-3.

Figura 4: Espectro de íons fragmentos do PD do diclofenaco nas amostras, e estrutura proposta (pelo autor) da via de degradação.

Figura 5: Espectro de íons fragmentos do PD de benzofenona-3 nas amostras, e estrutura proposta (pelo autor) da via de degradação. 
Figura 6: Perfis individuais (A) e perfis amostrais médios (B) para as contaminações com paracetamol.

Figura 7: Médias das porcentagens de remoção do paracetamol pelos filtros Controle, FEco e Mix, durante todas contaminações e diferentes tempos de coleta.

Figura 8: Perfis individuais (A) e perfis amostrais médios (B) para as contaminações com diclofenaco.

Figura 9: Médias das porcentagens de remoção do diclofenaco pelos filtros Controle, FEco e Mix, durante todas contaminações e diferentes tempos de coleta.

Figura 10: Perfis individuais (A) e perfis amostrais médios (B) para as contaminações com naproxeno.

Figura 11: Médias das porcentagens de remoção de naproxeno pelos filtros Controle, FEco e Mix, durante todas contaminações e diferentes tempos de coleta.

Figura 12: Perfis individuais (A) e perfis amostrais médios (B) para as contaminações com ibuprofeno.

Figura 13: Médias das porcentagens de remoção de ibuprofeno pelos filtros Controle, FEco e Mix, durante todas contaminações e diferentes tempos de coleta.

Figura 14: Perfis individuais (A) e perfis amostrais médios (B) para as contaminações com metilparabeno.

Figura 15: Médias das porcentagens de remoção de metilparabeno pelos filtros Controle, FEco e Mix, durante todas contaminações e diferentes tempos de coleta.

Figura 16: Perfis individuais (A) e perfis amostrais médios (B) para as contaminações com benzofenona-3.

Figura 17: Médias das porcentagens de remoção da benzofenona-3 pelos filtros Controle, FEco e Mix, durante todas contaminações e diferentes tempos de coleta.

\section{Capítulo 3: Comunidade de algas e cianobactérias em filtros ecológicos utilizados para o tratamento de água contaminada com produtos farmacêuticos e de cuidados pessoais.}

Figura 1: Desenvolvimento da alga Spyrogira sp. nos filtros ecológicos

Figura 2: Variação de riqueza de espécies em cada contaminação e filtros (de acordo com contaminante aplicado - Tabela 4 e tempo de coleta, onde "a"= antes da contaminação e "b" $=96$ horas após a contaminação).

Figura 3: Dendrograma de similaridade de espécies identificadas nos filtros ecológicos em todas as contaminações e diferentes tempos de coleta.

Figura 4: Variação do biovolume $\left(\mathrm{mm}^{3} \mathrm{~L}^{-1}\right)$ em cada filtro ecológico (siglas de acordo com Tabela 4), e no tempo de coleta na: A) primeira contaminação; B) segunda contaminação e C) terceira contaminação. Bacilla $=$ Bacillariophyceae; $\quad$ Crypto $=$ Cryptophyceae; $C y a n o=C y a n o b a c t e r i a ;$ Eugleno $=$ Euglenophyceae Zygne $=$ Zugnemaphyceae e Outros $=$ soma do biovolume das classes Chlorophyceae, Chrysophyceae, Dinophyceae, Xanthophyceae, Zygnemaphyceae - para A. Em B e C, Outros = soma do biovolume das classes Chlorophyceae, Chrysophyceae, Cryptophyceae, Dinophyceae, Xanthophyceae. 135

Figura 5: Valores do índice de diversidade (H': bits.ind-1) estimados com base no biovolume nas três contaminações e em cada filtro, antes (a) e após a contaminação (b), sendo que primeira letra refere-se ao tipo de tratamento aplicado, de acordo com a Tabela 4.

Figura 6: Gráfico de ACoP (Análise de Coordenadas Principais) das espécies significativas em todos os filtros (primeira letra refere-se ao tipo de tratamento aplicado, de acordo com a Tabela 4), nas três contaminações (1= primeira contaminação; $2=$ segunda contaminação; $3=$ terceira contaminação) 
realizadas e nos diferentes tempos de coleta $(a=$ antes da contaminação; $b=96$ horas após a contaminação).

Figura 7: Gráfico de ACoP (Análise de Coordenadas Principais) das espécies significativas em todos os filtros (primeira letra refere-se ao tipo de tratamento aplicado, de acordo com a Tabela 4), na primeira contaminação realizada e nos diferentes tempos de coleta.

Figura 8: Gráfico de ACoP (Análise de Coordenadas Principais) das espécies significativas em todos os filtros (primeira letra refere-se ao tipo de tratamento aplicado, de acordo com a Tabela 4), na segunda contaminação realizada e nos diferentes tempos de coleta

Figura 9: Gráfico de ACoP (Análise de Coordenadas Principais) das espécies significativas em todos os filtros (primeira letra refere-se ao tipo de tratamento aplicado, de acordo com a Tabela 4), na terceira contaminação realizada e nos diferentes tempos de coleta..

Figura 10: Gráfico biplot da ACC (eixos 1 e 2) das unidade amostrais referentes as três contaminações, em função das coletas realizadas nos filtros ecológicos de acordo com o tratamento (abreviações na Tabela 4) das espécies significativas da comunidade de algas e cianobactérias e as variáveis dos parâmetros de qualidade da água estudadas.

\section{Capítulo 4: Efeito da contaminação por produtos farmaceuticos e de cuidados pessoais no biofilme de filtros ecológicos para uso doméstico}

Figura 1: Modelo de um filtro ecológico doméstico em planta e seção transversal.

Figura 2: Filtros domésticos utilizados

Figura 3: Remoção de coliformes totais na fase 1(filtrações de 1 a 21) e na fase 2 (filtrações de 22 a 33) nos tempos de coleta (a) S1 e (b) S2; e remoção de E. coli nos tempos de coleta (c) S1 e (d) S2.

Figura 4: Remoção de COT na fase 1 (filtragens de 1 a 21) e na fase 2 (filtragens de 22 a 33) nos tempos de coleta (a) $\mathrm{S} 1 \mathrm{e}$ (b) $\mathrm{S} 2$

Figura 5: Gráfico de PCA (Análise dos Principais componentes) para as amostras das cepas isoladas em cada ponto de coleta de cada filtro, na fase 1 e 2 .

Figura 6: Gráfico das concentrações de biomassa aferidas a) no filtro 1 (F1) e b) no filtro 2 (F2)..1755 


\section{Lista de Tabelas}

\section{Contextualização e justificativa da pesquisa}

Tabela 1: Características físicas, químicas e informações sobre os fármacos estudados 6

Tabela 2: Características físicas, químicas e informações sobre os produtos de cuidados pessoais estudados.

\section{Capítulo 1: Instalação piloto no tratamento de água por sistema de filtração ecológica.}

Tabela 1: Valores médios de cadavariável avaliada, desvios padrão (DP) e valores de $\mathrm{P}$ referente ao teste-t que considerou afluente e efluente, medidos nos filtros ecológicos $(n=30)$.

Tabela 2: Valores calculados de desvio padrão (DP), e coeficiente de variação (CV) - expresso em porcentagem, a partir dos valores médios dos 22 filtros ecológicos de cada variável físico e químico de qualidade da água aferidas no efluente dos filtros.

Tabela 3: Valores médios de coliformes totais e $E$. coli aferidos no afluente, afluente diluído e efluente dos filtros ecológicos, com seus respectivos valores de $\mathrm{p}$ para o teste-t realizado $(n=13) \ldots . . .46$

Tabela 4: Valores de coeficiente de variação (CV) expressos em porcentagem, calculado entre os 22 filtros ecológicos em cada coleta realizada.

Capítulo 2: Identificação e quantificação de produtos farmacêuticos e de cuidados pessoais na represa do Lobo, remoção por filtros ecológicos e produtos de degradação identificados.

Tabela 1: Informações gerais e características dos compostos em estudo.

Tabela 2: Parâmetros ajustados para cada um dos compostos estudados e os deuterados.................... 70

Tabela 3: Alguns parâmetros avaliados para a validação do método analítico por LC-MS/MS. ....... 73

Tabela 4: Resultados de repetibilidade das amostras dopadas em 3 níveis de concentração.............. 75

Tabela 5: Concentrações dos compostos detectados nas amostras de água do reservatório do Lobo,

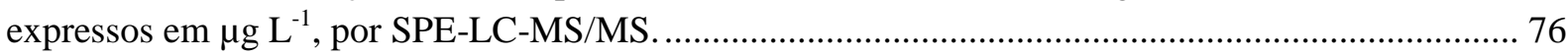

Tabela 6: Descrição de cada tratamento e respectivas unidades amostrais........................................ 81

Tabela 7: Redução percentual média na concentração de cada substância pelos filtros controle....... 82

Tabela 8: Percentual de redução média na concentração de cada substância pelos filtros FEco........ 83

Tabela 9: Percentual de redução média na concentração de cada substância pelos Filtros Mix......... 83

Tabela 10: Valores médios de concentração de paracetamol por tratamento e média geral, expressas em $\mu \mathrm{g} \mathrm{L} \mathrm{L}^{-1}$.

Tabela 11: Teste de esfericidade de Mauchly na contaminação com paracetamol............................. 85

Tabela 12: MANOVA para testar a hipótese da ausência do efeito da interação coleta $\square$ tratamento, nas contaminações com paracetamol.

Tabela 13: MANOVA para testar a hipótese da ausência do efeito de tratamento, nas contaminações

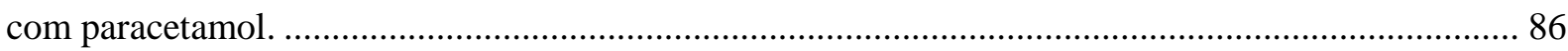

Tabela 14: MANOVA para testar a hipótese da ausência do efeito do tempo de coleta. ................... 86

Tabela 15: Valores médios da concentração de diclofenaco por tratamento e concentração média geral, expressas em $\mu \mathrm{g} \mathrm{L}{ }^{-1}$.

Tabela 16: Teste de esfericidade de Mauchly na contaminação com diclofenaco............................... 89

Tabela 17: MANOVA para testar a hipótese da ausência do efeito da interação tempo de coleta $\mathrm{x}$ tratamento, na contaminação com diclofenaco. 
Tabela 18: MANOVA para teste da hipótese de ausência do efeito de tratamento, nas contaminações com diclofenaco.

Tabela 19: MANOVA para testar a hipótese da ausência do efeito do tempo de coleta, nas contaminações com diclofenaco.

Tabela 20: Testes para comparações da concentração média de diclofenaco nos Tempo de Coleta. . 90

Tabela 21: Concentração média de naproxeno por tratamento e média geral, expressas em $\mu \mathrm{g} \mathrm{L}^{-1}$, em cada tempo de coleta.

Tabela 22: Teste de esfericidade de Mauchly, nas contaminações com naproxeno.

Tabela 23: MANOVA para testar a hipótese da ausência do efeito da interação coleta $x$ tratamento, nas contaminações com naproxeno.

Tabela 24: MANOVA para testar a hipótese da ausência do efeito de tratamento, na contaminação com naproxeno.

Tabela 25: MANOVA para testar a hipótese da ausência do efeito do tempo de coleta nas

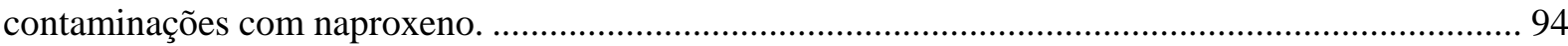

Tabela 26: Testes para comparações da concentração média de naproxeno nos tempo de coleta...... 94 Tabela 27: Concentração média de ibuprofeno por tratamento e média geral, expressas em $\mu \mathrm{g} \mathrm{L}{ }^{-1}$, em cada tempo de coleta.

Tabela 28: Teste de esfericidade de Mauchly nas contaminações com ibuprofeno.

Tabela 29: MANOVA para testar a hipótese da ausência do efeito da interação tempo de coleta $x$ tratamento, nas contaminações com ibuprofeno.

Tabela 30: MANOVA para testar a hipótese da ausência do efeito de tratamento, nas contaminações com ibuprofeno.

Tabela 31: MANOVA para testar a hipótese da ausência do efeito do tempo de coleta, nas contaminações com ibuprofeno.

Tabela 32: Concentração média do metilparabeno por tratamento e média geral, expressas em

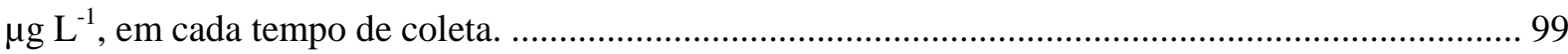

Tabela 33: Teste de esfericidade de Mauchly, nas contaminações com metilparabeno. .................... 100

Tabela 34: MANOVA para testar a hipótese da ausência do efeito da interação tempo de coleta $x$ tratamento, nas contaminações com metilparabeno.

Tabela 35: MANOVA para testar a hipótese da ausência do efeito do tratamento, nas contaminações com metilparabeno

Tabela 36: MANOVA para testar a hipótese da ausência do efeito do tempo de coleta.

Tabela 37: Concentração média da benzofenona-3 por tratamento e média geral, expressas em $\mu \mathrm{g} \mathrm{L}{ }^{-1}$, em cada tempo de coleta.

Tabela 38: Teste de esfericidade de Mauchly nas contaminações com benzofenona-3.................... 103

Tabela 39: MANOVA para testar a hipótese da ausência do efeito da interação tempo de coleta $x$ tratamento, nas contaminações com benzofenona-3.

Tabela 40: MANOVA para testar a hipótese da ausência do efeito de tratamento, nas contaminações com benzofenona-3.

Tabela 41: MANOVA para testar a hipótese da ausência do efeito do tempo de coleta, na contaminação com benzofenona-3.

Tabela 42: Testes para comparações da concentração média de benzofenona-3 nos tempo de coleta. 
Capítulo 3: Comunidade de algas e cianobactérias em filtros ecológicos utilizados para o tratamento de água contaminada com produtos farmacêuticos e de cuidados pessoais.

Tabela 1: Valor médio total e desvio padrão para os valores de: Temperatura (Temp) $\left({ }^{\circ} \mathrm{C}\right)$, Oxigênio Dissolvido (OD) $\left(\mathrm{mg} \mathrm{L}^{-1}\right), \mathrm{pH}$, Nitrogênio Total (NT) $\left(\mu \mathrm{g} \mathrm{L}^{-1}\right)$, Fósforo Total (PT) $\left(\mu \mathrm{g} \mathrm{L}^{-1}\right)$, e Clorofila-a (Cloro a) $\left(\mathrm{mg} \mathrm{L}^{-1}\right)$, aferidos durante as três contaminações............................................. 127

Tabela 2: Grupos taxonômicos registrados nos filtros ecológicos durante o período......................... 128

Tabela 3: Táxons registrados nos filtros ecológicos durante o período.............................................. 128

Tabela 4: Abreviações definidas para os filtros e seus respectivos PFCPs aplicados........................ 132

Tabela 5: Espécies descritoras da comunidade de algas e cianobactérias com base na porcentagem de contribuição em biovolume, nos filtros ecológicos (siglas conforme Tabela 4), na primeira contaminação.

Tabela 6: Espécies descritoras da comunidade de algas e cianobactérias com base na porcentagem de contribuição em biovolume, nos filtros ecológicos (siglas conforme Tabela 4), na segunda contaminação. 137

Tabela 7: Espécies descritoras da comunidade de algas e cianobactérias com base na porcentagem de contribuição em biovolume, nos filtros ecológicos (siglas conforme Tabela 4), na terceira contaminação.

Tabela 8: Coeficiente de correlação de Pearson entre as espécies significativas identificadas nos filtros ecológicos, nas três contaminações, nos dois primeiros eixos de ordenação $(n=48)$

Tabela 9: Coeficiente de correlação de Pearson entre as espécies significativas identificadas nos filtros ecológicos, na primeira contaminação, nos dois primeiros eixos de ordenação $(n=16)$.......... 141

Tabela 10: Coeficiente de correlação de Pearson entre as espécies significativas identificadas nos filtros ecológicos, na segunda contaminação, nos dois primeiros eixos de ordenação $(n=16)$......... 143

Tabela 11: Coeficiente de correlação de Pearson entre as espécies significativas identificadas nos filtros ecológicos, na terceira contaminação, nos dois primeiros eixos de ordenação $(n=16)$.......... 145

Tabela 12: Síntese dos resultados da Análise de Correspondência Canônica (ACC) realizada a partir de 6 variáveis ambientais e 37 espécies significativas $(n=48)$.

Tabela 13: Coeficiente canônico e correlações "intra-set" das seis variáveis ambientais com os eixos 1 e 2 da ACC, realizada com as 37 espécies significativas dos filtros ecológicos $(n=48)$.

Tabela 14: Coeficiente de correlação de Pearson entre as variáveis biológicas (37 espécies significativas) e as variáveis abióticas, nos dois primeiros eixos de ordenação $(n=48)$.

\section{Capítulo 4: Efeito da contaminação por produtos farmaceuticos e de cuidados pessoais no biofilme de filtros ecológicos para uso doméstico}

Tabela 1: Descrição das filtrações realizadas na fase 1 e fase 2.

Tabela 2: Sistema de operação dos filtros ecológicos domésticos nas fases 1 e 2.

Tabela 3: Valores médios dos parâmetros de qualidade de água aferidos durante as fases 1 e 2, e seus respectivos valores de $\mathrm{P}$, mostrando a relação entre afluente e efluente dos filtros.

Tabela 4: Presença e ausência de cada cepa de bactéria em seus respectivos ponto de coleta, nas fases 1 e 2 . 


\section{Sumário}

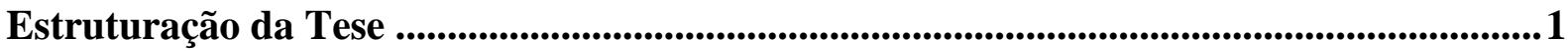

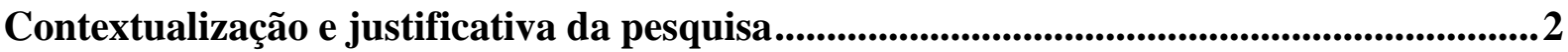

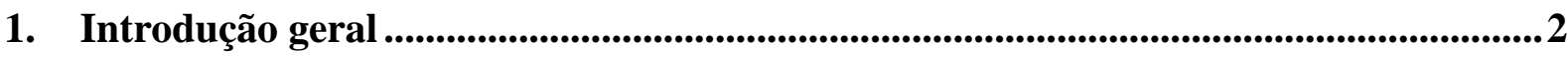

1.1. Produção e consumo mundiais de Produtos Farmacêuticos e de Cuidados Pessoais.............. 2

1.2. Características gerais dos produtos farmacêuticos e de cuidados pessoais ............................. 4

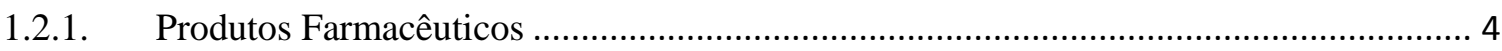

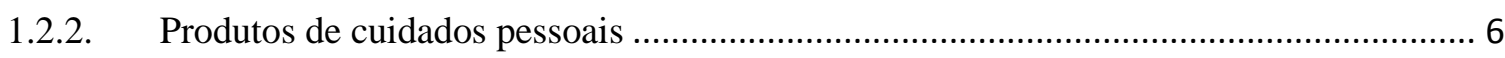

1.3. Contaminação dos ambientes aquáticos e águas de consumo por PFCPs e seus possíveis

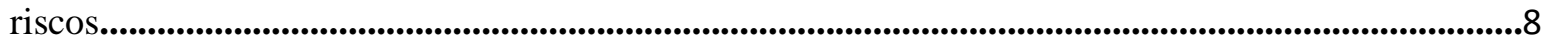

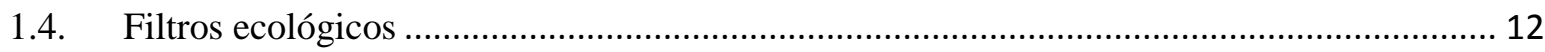

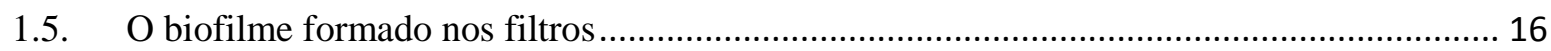

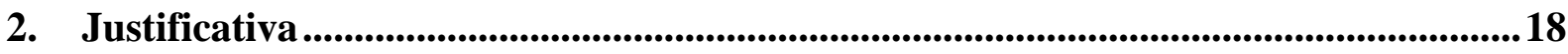

3. Referencias bibliográficas.............................................................................................................. 19

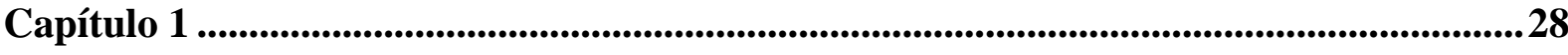

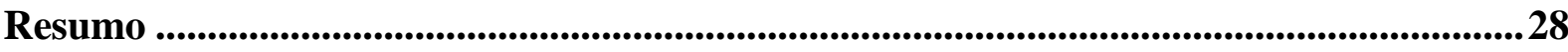

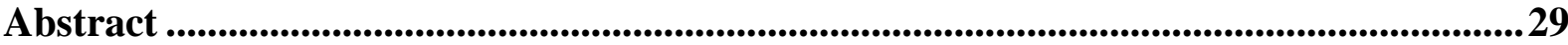

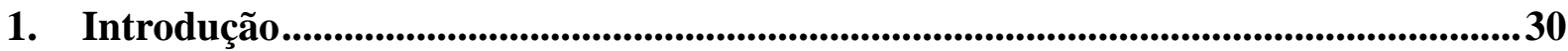

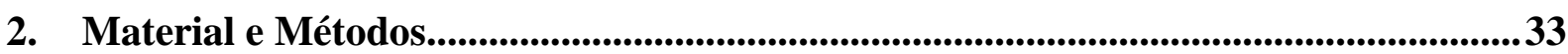

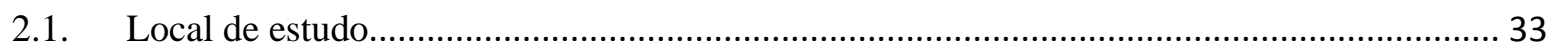

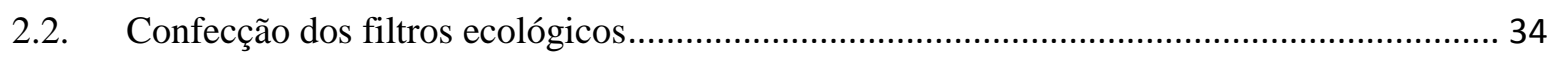

2.3. Coleta de amostras e análises das variáveis de qualidade de água ..................................... 36

3. Resultados e Discussões ......................................................................................................3 37

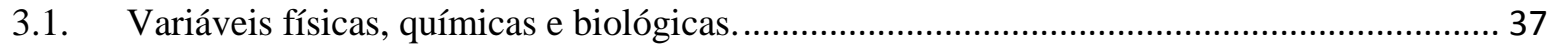

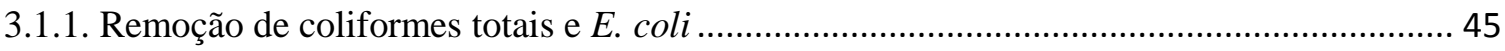

3.2. Relações entre os parâmetros físicos e químicos de qualidade da água .................................. 49

3.3. Aplicabilidade do sistema de filtração ecológica .................................................................. 51

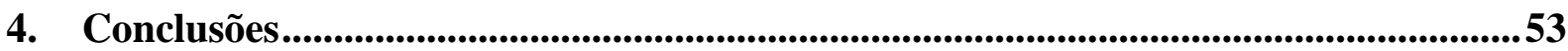

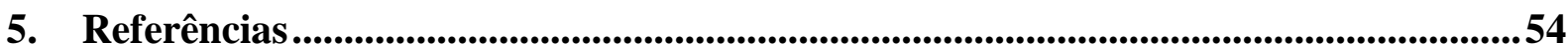

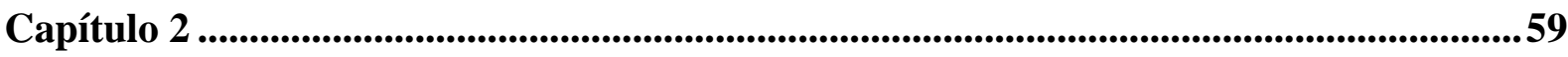

Resumo ........................................................................................................................................59

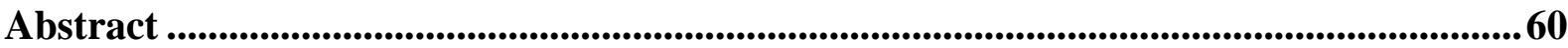




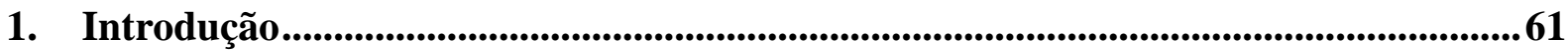

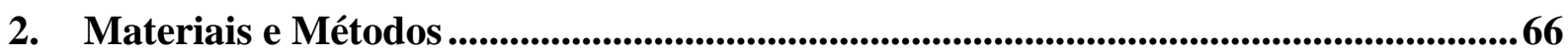

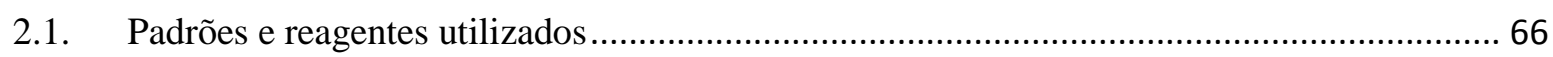

2.2. Aplicaçào dos PFCPs nos filtros ecológicos e coleta das amostras de água ..........................66

2.3. Método analítico utilizado para a identificação e a quantificação dos analitos...................... 67

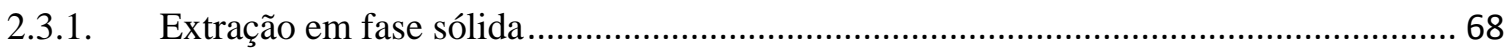

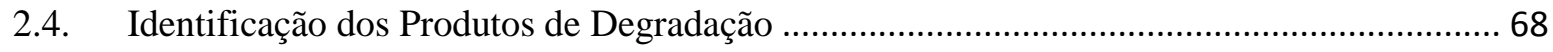

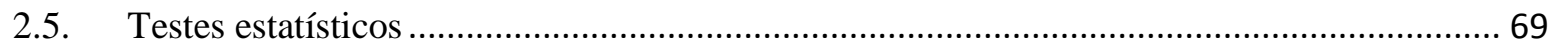

3. Resultados e discussões ..........................................................................................................69

3.1. Desenvolvimento, otimização e validação do método analítico. ............................................ 69

3.2. Identificação e quantificação dos produtos farmacêuticos e de cuidados pessoais na água do

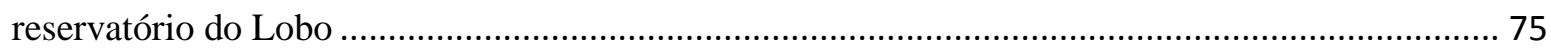

3.3. Identificação de produtos de degradação nas águas do reservatório do Lobo....................... 78

3.4. Remoção dos produtos farmacêuticos e de cuidados pessoais por filtros ecológicos ............ 81

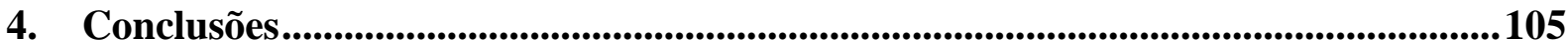

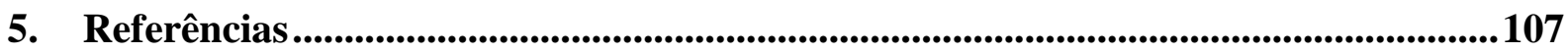

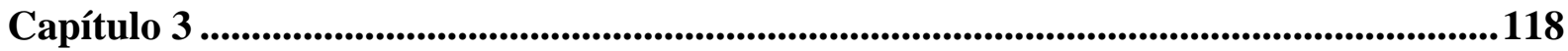

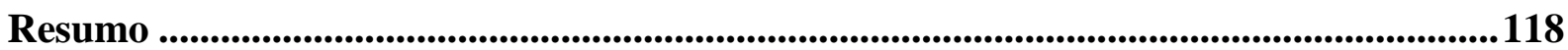

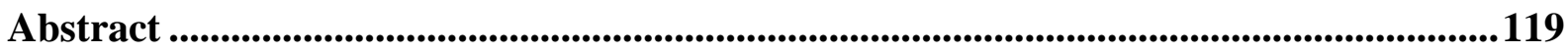

1. Introduçã

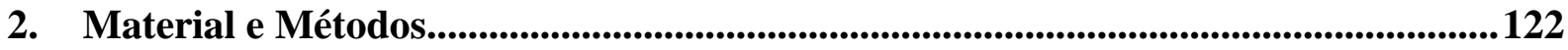

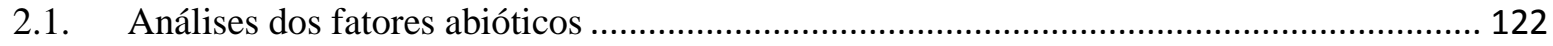

2.2. Análises qualitativas e quantitativas da comunidade de algas e cianobactérias.................. 122

2.2.1. Análise qualitativa da comunidade de algas e cianobactérias ..................................... 123

2.2.2. Análise quantitativa da comunidade de algas e cianobactérias ................................... 123

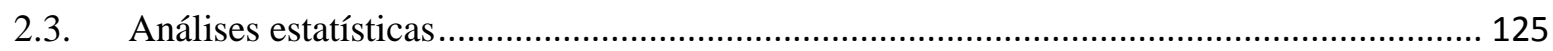

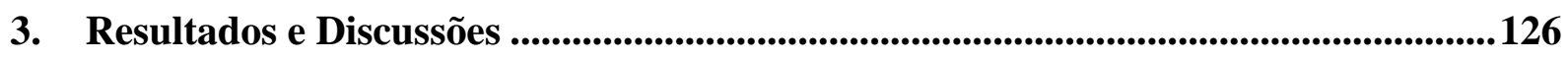

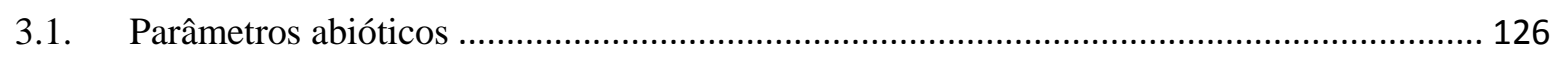

3.2. Comunidade de algas e cianobactérias no biofilme dos filtros ecológicos ......................... 128

3.3. Análises quantitativas da comunidade de algas e cianobactérias ......................................... 134

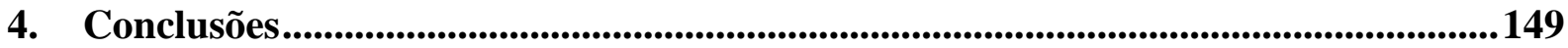

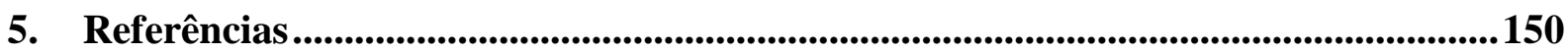

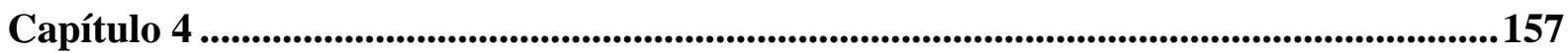

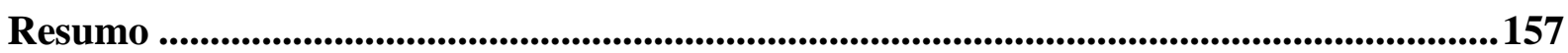




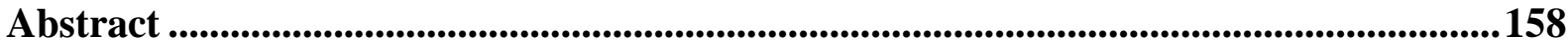

1. Introdução...................................................................................................................................... 159

2. Materiais e Métodos............................................................................................................161

2.1. Água bruta utilizada e descrição dos filtros ..................................................................... 161

2.2. Solução de produtos farmacêuticos e de cuidados pessoais adicionada a água buta ........... 163

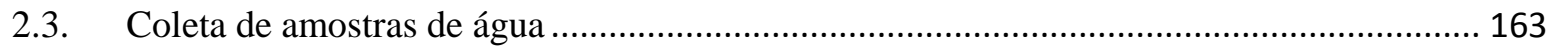

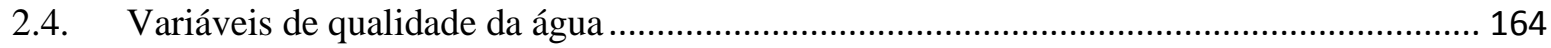

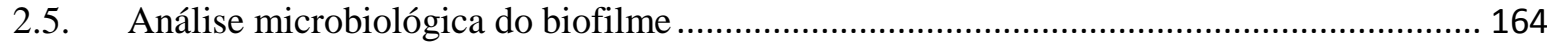

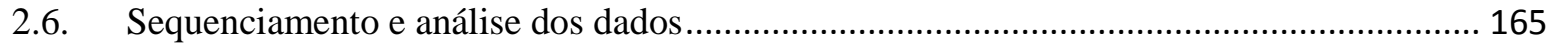

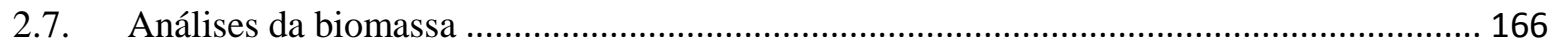

3. Resultados e Discussões ................................................................................................. 166

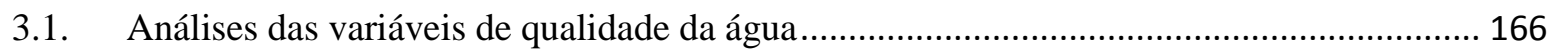

3.2. Comparação da composição bacteriana em filtros ecológicos domésticos, em dois modos

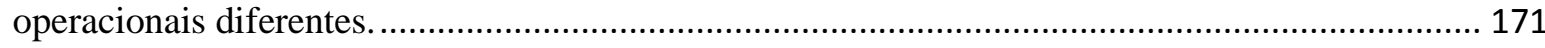

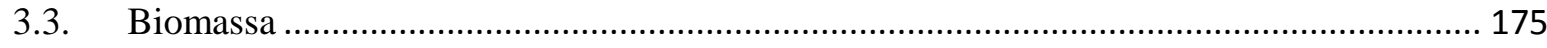

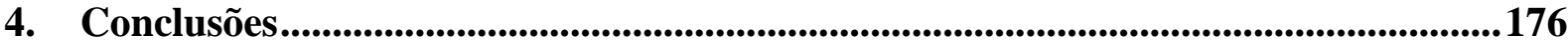

5. Referências Bibliográficas .....................................................................................177

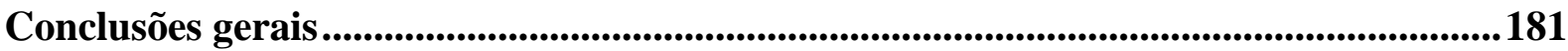

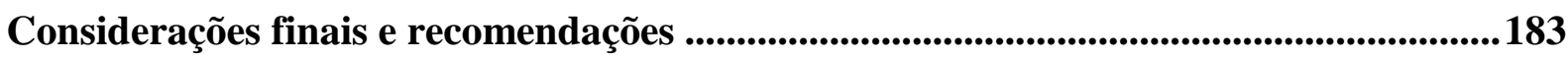

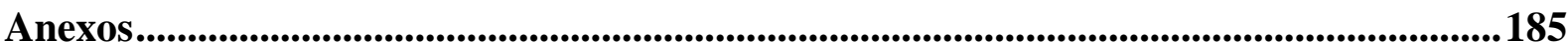




\section{Estruturação da Tese}

Esta tese está apresentada em formato de capítulos para facilitar a discussão dos resultados e o desmembramento em artigos científicos. Além destes, a tese contém uma parte inicial de contextualização e justificativa da pesquisa, onde é abordado o tema e o embasamento teórico da pesquisa, com as características de cada composto estudado, as consequências ambientais, contaminação de corpos d'água, águas de abastecimento e a filtração ecológica como alternativa na remoção de contaminantes emergentes. $\mathrm{O}$ capitulo 4 contém parte do estudo realizado durante o período de doutorado sanduiche em Londres, Inglaterra, na University College London, UCL.

Capítulo 1 - Instalação piloto no tratamento de água por sistema de filtração ecológica. O propósito do estudo descrito neste capítulo foi testar 22 filtros ecológicos confeccionados para tratar a água do reservatório do Lobo, Itirapina, São Paulo. Foram analisados parâmetros físicos, químicos e biológicos de qualidade da água, análise da existência de correlação entre as variáveis avaliados e a aplicabilidade deste sistema de tratamento de água.

Capítulo 2 - Identificação e quantificação de produtos farmacêuticos e de cuidados pessoais no Reservatório do Lobo, remoção por filtros ecológicos e produtos de degradação identificados. Neste capítulo procurou-se descrever os resultados obtidos durante o processo de desenvolvimento, otimização e validação do método analítico utilizado para identificar e quantificar os seis produtos farmacêuticos e de cuidados pessoais selecionados. Análise cromatográfica das amostras de água coletadas tanto da represa como do efluente de cada filtro, simulando uma contaminação real e avaliando-se assim a eficiência do sistema de purificação ecológica da água em remover os seis PFCPs da água. Também neste capitulo são apresentadosos resultados referentes aos PDs encontrados, propondo rotas de formação de novos compostos a partir dos originais.

Capítulo 3 - Comunidade de algas e cianobactérias em filtros ecológicos utilizados para o tratamento de água contaminada com produtos farmacêuticos e de cuidados pessoais. Este capítulo teve o propósito de identificar as espécies de algas e cianobactérias presentes nos filtros ecológicos destinados ao tratamento de água que foram contaminados com seis produtos farmacêuticos e de cuidados pessoais, aplicados individualmente e em conjunto, a fim de observar possíveis diferenças qualitativas e quantitativas na estrutura da comunidade dos filtros em decorrência das contaminações; determinar as espécies descritoras e avaliar a dinâmica estrutural da comunidade, relacionando com as características da água.

Capítulo 4 - Efeito da contaminação por produtos farmaceuticos e de cuidados pessoais no biofilme de filtros ecológicos para uso doméstico. Neste capítulo estão apresentados os resultados da pesquisa desenvolvida durante o doutorado sanduíche na University College London (UCL), sob supervisão da Profa. Dra. Luiza Cintra Campos. Foram avaliados dois filtros domésticos, do modelo BioSand Household Filter para tratamento de água. Foram operados de duas maneiras distintas: com pausas e sem pausas. Além disso, foram adicionados seis PFCPs em um dos filtros para avaliar os efeitos na composição do biofilme, com realização de sequenciamento genético para bactérias. 


\section{Contextualização e justificativa da pesquisa}

\section{Introdução geral}

\subsection{Produção e consumo mundiais de Produtos Farmacêuticos e de Cuidados Pessoais}

A produção e o consumo de produtos farmacêuticos e de cuidados pessoais estão em constante progresso, em acompanhamento aos avanços da medicina, ao surgimento de novas doenças, e procura da população pelo bem estar e qualidade de vida, e tambem dos usos veterinários.

O consumo mundial de fármacos é bastante significativo, um exemplo disso pode ser visto na União Européia (UE) onde aproximadamente 3.000 diferentes substâncias são usadas em medicamentos para consumo humano como analgésicos, anti-inflamatórios, conservantes, antibióticos, e muitos outros (PETROVIĆ et al., 2014). Também, um número expressivo dessas substâncias é utilizado em medicamentos de uso veterinário, como antibióticos e antiinflamatórios (PONEZI et al., 2007).

No Brasil houve um grande avanço industrial na década de cinquenta, que colocou o país na rota da modernização industrial. É dessa época a primeira grande transformação no setor farmacêutico. Foram assim, abertos caminhos para a atual situação do parque industrial farmacêutico brasileiro, confortável situação que se encontra o Brasil diante dos demais países desenvolvidos (FNFB 2, 2011).

Em todo o mundo, aproximadamente 3.000 compostos farmaceuticos são produzidos em grande escala, atingindo mais de 500 toneladas/ano. Destes, menos de $45 \%$ foram submetidos a algum tipo de ensaio toxicológico e menos de $10 \%$ foram estudados considerando-se qualquer tipo de efeito tóxico sobre organismos em desenvolvimento (MELLO-DA-SILVA e FRUCHTENGARTEN, 2005).

Atualmente, o Brasil está entre os 10 países que mais comercializam medicamentos. Por ano, o Ministério da Saúde investe R \$ 9 bilhões na compra de medicamentos que são distribuídos pelo SUS (Sistema Único de Saúde) (BRASIL, 2012).

O volume consumido globalmente de diclofenaco foi estimado em 940 toneladas por ano, com uma dose diária de 100 mg per capita (ZHANG et al., 2008). 
O ibuprofeno tem uma produção estimada anual global de várias quilo/toneladas, sendo o terceiro medicamento mais popular do mundo. Possui uma elevada dose terapêutica (600-1200 mg/d) (BUSER, POIGER e MULLER, 1999).

$\mathrm{Na}$ Espanha, o paracetamol foi considerado o analgésico não opióide mais vendido nos últimos anos (MARTINEZ BUENO et al., 2012).

A procura pelo bem-estar da população faz também, com que homens e mulheres dediquem muito mais tempo e esforço nos hábitos da higiene pessoal e da melhor aparência ao longo de suas vidas.

A preocupação com os perigos que a radiação ultravioleta pode causar na saúde humana tem gerado a procura, cada vez maior, por filtros solares, sejam eles em loções, em cremes, xampus, batons, entre outros. Para proteger os consumidores da radiação UV e aumentar a estabilidade dos produtos são adicionadas substâncias que atuam como filtro solar em concentrações de até $10 \%$, podendo variar de acordo com o composto específico ou com a determinação da agência reguladora de cada país (WEIHONG LI et al., 2007; SIQUEIRA, 2008). De acordo com a ANVISA (Agência Nacional de Vigilância Sanitária) no Brasil é permitido o uso de alguns filtros químicos em concentrações entre 3\% e 15\%. Na composição dos filtros solares pode ser encontrada a benzofenona-3.

Os parabenos sao usados como conservantes em produtos de cuidados pessoais, e podem ser utilizados em cosméticos para protegê-los contra o crescimento microbiano, resultando em proteção aos consumidores e na manutenção da integridade dos produtos (FDA, 2006).

No mercado mundial de higiene pessoal, perfumaria e cosméticos, conforme dados do Euromonitor de 2011, o Brasil ocupa a terceira posição, sendo Estados Unidos o primeiro e Japão o segundo. O Brasil é o primeiro mercado em perfumaria e desodorantes; segundo mercado em produtos para cabelos, produtos para higiene oral, masculinos, infantil, proteção solar; terceiro em produtos cosméticos; quarto em depilatórios; quinto em produtos para os cuidados da pele (ABIHPEC, 2012).

A Indústria Brasileira de higiene pessoal, perfumaria e cosméticos, composta por 2.282 empresas atuando no mercado, apresentou um crescimento médio deflacionado composto de $10 \%$ nos últimos 16 anos, tendo passado de um faturamento de $\mathrm{R} \$ 4,9$ bilhões em 1996 para R\$29,4 bilhões em 2011. Vários fatores têm contribuído para este crescimento do setor, dentre os quais se destaca o lançamento constante de novos produtos atendendo cada vez mais às necessidades do mercado, e o aumento da expectativa de vida, o que faz com que seja necessário conservar uma impressão de juventude (ABIHPEC, 2012). 


\subsection{Características gerais dos produtos farmacêuticos e de cuidados pessoais}

\subsubsection{Produtos Farmacêuticos}

Dentre os produtos farmacêuticos, encontram-se os Anti-inflamatórios Não Esteroidais (AINE). Estes, de um modo geral, consistem em um grupo variado de fármacos que têm em comum a capacidade de controlar a inflamação, de promover a analgesia, e de combater a hipertermia- embora não sejam muito utilizados para este fim.

No Brasil, esses são medicamentos de venda livre e estão em grande parte das associações medicamentosas disponíveis para venda, além de terem fácil acesso para consumo devido ao grande número de apresentações disponíveis no mercado. Isso acaba por caracterizar esta classe de medicamentos como a mais prescrita por médicos e dentistas, e consequentemente, uma das mais consumidas (EMERENCIANO et al., 2008).

Dentre os AINE, estudaram-se nesta pesquisa três medicamentos que são os mais vendidos e, portanto, os mais consumidos, sendo estes o diclofenaco sódico, o ibuprofeno e o naproxeno.

O diclofenaco pode apresentar-se nas formas sódica, potássica, resinada e colestiramina. Ele é amplamente usado para tratar inflamações e doenças reumáticas e dolorosas de origem não reumática, e tem sido encontrado em efluentes de muitas ETEs (Estações de Tratamento de Esgoto) (TERNES, 1998).

O diclofenaco é utilizado em 120 países, e é considerado o AINE mais utilizado no mundo. Existe há mais de 80 anos e se consolidou no mercado mundial como a droga mais amplamente vendida, devido ao grande número de prescrições, e livre venda em farmácias (EMERENCIANO, et al. 2008).

Embora este composto seja suscetível à fotodegradação por mecanismos complexos, dependendo das condições ambientais, é um dos compostos mais frequentemente encontrado nas águas superficiais em concentração acima de 1,2 $\mu \mathrm{g} \mathrm{L} \mathrm{L}^{-1}$ (BUSER, POIGER e MULLER, 1998; 1999; FENT et al.,2006).

O ibuprofeno possui propriedades físicas e químicas que apontam uma mobilidade bastante elevada no ambiente aquático e de fato, o ibuprofeno tem sido encontrado em efluentes de esgoto sanitário, industrial e rios (STUMPF et al., 1999). Um estudo realizado por Zuccato et al. (2000) sobre os sistemas de água e rios da Itália relata a presença do ibuprofeno na água ribeirinha, nos sedimentos e na água para consumo humano. Há uma 
preocupação crescente sobre a ocorrência, destino, e os possíveis efeitos dessas substâncias no meio ambiente (BUSER POIGER e MULLER, 1999).

Consta na bula deste medicamento que seu efeito inicia-se 30 minutos após a ingestão, prolongando-se de 4 a 6 horas, sendo metabolizado no fígado. A eliminação é completa 24 horas após a última dose e sua meia vida de eliminação é de 1,8 a 2 horas.

A concentração máxima do ibuprofeno encontrada em águas de superfície no Reino Unido foram de $5 \mu \mathrm{g} \mathrm{L}^{-1}$ com um valor estimado de quociente de risco (QR) de 0,01 (ASHTON et al., 2004). O ibuprofeno foi encontrado também na Espanha, em efluentes de esgoto sanitários, águas superficiais, e de consumo (RODIL et al., 2012).

Em um estudo feito por Pomati et al. (2004) com cultura de espécies isoladas, mostrou que o ibuprofeno na concentração de 1 a $1000 \mu \mathrm{g} \mathrm{L}^{-1}$ estimula o crescimento da cianobactéria Synechocystis sp. ao longo de cinco dias de exposição, sendo que o maior crescimento em densidade na cultura foi observado quando usou-se a concentração de $10 \mu \mathrm{g} \mathrm{L}^{-1}$. Em uma concentração de $1000 \mu \mathrm{g} \mathrm{L}^{-1}$ do fármaco ocorre inibição do crescimento da macrófita Lemna gibba, após sete dias de exposição.

Consta na bula de naproxeno que ele possui uma elevada dose terapêutica, de acordo com sua indicação (250 a $1250 \mathrm{mg} /$ dia). É rápido e completamente absorvido no sistema gastrointestinal após administração oral e sua metabolização ocorre no fígado. Aproximadamente $95 \%$ de uma dose de naproxeno são excretados na urina e pequenas quantidades, de aproximadamente $3 \%$, são excretadas nas fezes.

Este composto foi encontrado tanto em águas superficiais, como em efluentes de esgotos sanitário e industrial (TERNES, 1998; STUMPF et al., 1999; TERNES et al., 2001; RODIL et al., 2012); e água de consumo (RODIL et al., 2012).

Dentre os compostos farmacêuticos analgésicos, o paracetamol é um dos compostos farmacêuticos também selecionados para este estudo uma vez que ele é um dos mais utilizados para alívio de dores crônicas e é um dos melhores analgésicos disponíveis no mercado, inclusive é um dos analgésicos de distribuição gratuita no sistema público de saúde do Brasil; podendo fazer parte da composição de diversos medicamentos como por exemplo os indicados para gripes e sintomas de dengue, porém, alguns efeitos colaterais são associados a esta substância. O de maior destaque é a sua ação hepatotóxica para humanos e animais utilizados em testes de laboratório (SANTOS, 2003).

De acordo com informações da bula, após administração oral, o paracetamol é rápido e quase completamente absorvido pelo trato gastrintestinal. A concentração plasmática atinge seu pico em 30 a 60 minutos após a ingestão. Sua biotransformação ocorre no fígado. A meia- 
vida plasmática do paracetamol é cerca de 2 a 4 horas após doses terapêuticas e seu metabólito hidroxilado é tido como responsável por sua hepatotoxicidade. A Tabela 1 apresenta algumas características físicas, químicas e informações sobre os quatro produtos farmacêuticos estudados.

Tabela 1: Características físicas, químicas e informações sobre os fármacos estudados.

\begin{tabular}{|c|c|c|c|c|c|c|}
\hline Fármacos & $\begin{array}{c}\text { Utilização } \\
\text { médica/ação }\end{array}$ & $\begin{array}{c}\text { Fórmula } \\
\text { Molecular }\end{array}$ & $\begin{array}{c}\text { Massa } \\
\text { Molecular }\end{array}$ & $\begin{array}{l}\text { Ponto de } \\
\text { fusão }\end{array}$ & $\begin{array}{c}\begin{array}{c}\text { Solúvel } \\
\text { em água }\end{array} \\
\end{array}$ & Estrutura \\
\hline $\begin{array}{c}\text { Paracetamol } \\
\text { (Acetaminofenol) }\end{array}$ & $\begin{array}{c}\text { Uso } \\
\text { humano/analgésica }\end{array}$ & $\mathrm{C}_{8} \mathrm{H}_{9} \mathrm{NO}_{2}$ & $151,16 \mathrm{~g} \mathrm{~mol}^{-1}$ & $168-172{ }^{\circ} \mathrm{C}$ & Sim & \\
\hline $\begin{array}{l}\text { Diclofenaco } \\
\text { Sódico }\end{array}$ & $\begin{array}{l}\text { Uso humano/ } \\
\text { Anti-inflamatório, } \\
\text { analgésico, } \\
\text { antipirético }\end{array}$ & $\mathrm{C}_{14} \mathrm{H}_{10} \mathrm{Cl}_{2} \mathrm{NNaO}_{2}$ & $318,13 \mathrm{~g} \mathrm{~mol}^{-1}$ & $275-277^{\circ} \mathrm{C}$ & Sim & \\
\hline Naproxeno & $\begin{array}{l}\text { Uso humano e } \\
\text { veterinário/ Anti- } \\
\text { inflamatório, } \\
\text { analgésico, } \\
\text { antipirético }\end{array}$ & $\mathrm{C}_{14} \mathrm{H}_{14} \mathrm{O}_{3}$ & $230,26 \mathrm{~g} \mathrm{~mol}^{-1}$ & $152-155^{\circ} \mathrm{C}$ & Sim & \\
\hline Ibuprofeno & $\begin{array}{l}\text { Uso humano/ } \\
\text { Anti-inflamatório, } \\
\text { analgésico, } \\
\text { antipirético }\end{array}$ & $\mathrm{C}_{13} \mathrm{H}_{18} \mathrm{O}_{7}$ & $206,28 \mathrm{~g} \mathrm{~mol}^{-1}$ & $77-78^{\circ} \mathrm{C}$ & Não & \\
\hline
\end{tabular}

\subsubsection{Produtos de cuidados pessoais}

Os produtos de cuidados pessoais englobam diversos tipos de produtos, que podem estar relacionados desde a estética, necessidades básicas ou até mesmo para proteção, como é o caso dos protetores solares. Diversos compostos químicos são adicionados a estes produtos para sua fabricação.

A ANVISA publicou em 28 de agosto de 2000, a Resolução $\mathrm{n}^{\circ}$ 79, de forma a compatibilizar os regulamentos nacionais com os instrumentos harmonizados no âmbito do Mercosul, adotando-se como definição de cosméticos, produtos de higiene e perfumes: "Preparações constituídas por substâncias naturais ou sintéticas, de uso externo nas diversas partes do corpo humano, pele, sistema capilar, unhas, lábios, órgãos genitais externos, dentes e membranas mucosas da cavidade oral, com objetivo exclusivo ou principal de limpá-los, perfumá-los, alterar sua aparência e/ou corrigir odores corporais e/ou protegê-los ou ainda mantê-los em bom estado".

Dentre os compostos utilizados em produtos de cuidados pessoais, destacam-se os parabenos, que são utilizados como conservantes em diversos cosméticos, e a benzofenona-3, 
substância essencial na formulação de protetores solares. Características físicas, químicas e informações importantes sobre estes compostos encontram-se na Tabela 2.

Tabela 2: Características físicas, químicas e informações sobre os produtos de cuidados pessoais estudados.

\begin{tabular}{ccccccc}
\hline $\begin{array}{c}\text { Produtos de cuidados } \\
\text { pessoais }\end{array}$ & Utilização & $\begin{array}{c}\text { Fórmula } \\
\text { Molecular }\end{array}$ & $\begin{array}{c}\text { Massa } \\
\text { Molecular }\end{array}$ & $\begin{array}{c}\text { Ponto de } \\
\text { fusão }\end{array}$ & $\begin{array}{c}\text { Solúvel } \\
\text { em água }\end{array}$ & Estrutura \\
\hline Metilparabeno & $\begin{array}{c}\text { Conservante } \\
\text { de } \\
\text { cosméticos } \\
\text { e alimentos. }\end{array}$ & $\mathrm{C}_{8} \mathrm{H}_{8} \mathrm{O}_{3}$ & $152,15 \mathrm{~g} \mathrm{~mol}^{-1}$ & $125-128^{\circ} \mathrm{C}$ & $\mathrm{Sim}$ \\
$\begin{array}{c}\text { Benzofenona-3 } \\
\text { (Oxibenzona) }\end{array}$ & $\begin{array}{c}\text { Protetor } \\
\text { solar }\end{array}$ & $\mathrm{C}_{14} \mathrm{H}_{12} \mathrm{O}_{3}$ & $228,24 \mathrm{~g} \mathrm{~mol}^{-1}$ & $62-64{ }^{\circ} \mathrm{C}$ & $\mathrm{Não}$ & \\
\hline
\end{tabular}

A radiação solar, e especialmente a radiação ultravioleta (290 a 400 nm) são importante fator ambiental nocivo para a saúde humana. São vários os efeitos, tais como eritema, queimadura solar, bronzeamento, ou pigmentação, foto-envelhecimento, queratoses solares, cancro da pele (não melanoma e melanoma) e imunossupressão são atribuídos a radiações UV (MODI et al., 2011).

Os filtros solares químicos são compostos que absorvem UV, diminuindo assim a quantidade de radiação de energia solar que atinge a pele, e é o uso dos filtros solares que podem ajudar a evitar ou minimizar os efeitos nocivos da radiação solar sobre a pele (CHISVERT et al.,2000).

Dentre as substancias contidas em filtros solares que absorvem UV, pode-se citar a benzofenona. A Benzofenona-3 (BP-3) é uma cetona aromática comumente utilizada como filtro ultravioleta nos produtos de cuidados pessoais para proteger humanos e materiais de exposições perigosas a radiação UV, pode estar contidas também em sabonetes, perfumes, embalagens, dentre outros. É identificada na água como resultado de atividades recreativas e por meio do despejo de efluentes sanitário e indutrial (HAURI et al., 2003; KRUTMANN, 2006; GONG et al., 2015).

Os parabenos, ésteres do ácido p-hidroxibenzóico, são utilizados devido às suas propriedades antimicrobianas e antifúngicos, como conservantes necessários para que se mantenha a integridade de medicamentos, cosméticos e alimentos (ANDERSEN, 2008; SONI et al, 2005; LIN et al, 2009;. LIU et al 2014;. HAMANet al, 2015; GMUREK et al, 2015).

Os mais comuns atualmente são metil, etil, propil e butilparabeno, sendo que o metil é o mais hidrofílico e o butil é o mais lipossolúvel. Propriedades essas que os tornam fáceis e 
convenientes de serem usados na formulação não só de cosméticos, mas também de medicamentos e conservantes de alimentos (FDA, 2006).

Os cosméticos que contêm parabenos incluem maquiagem, hidratantes, produtos para cabelo, produtos para barbear, cremes de depilação e clareadores. Porém, a maioria das principais marcas de desodorantes e antitranspirantes, atualmente, não contem parabenos em suas formulações (DARBRE et al, 2004).

O metilparabeno é uma das substâncias controladas pela União Europeia (DEPA, 2013). Em contrapartida, não existem atualmente regulamentos sobre a presença de parabenos no ambiente ou, em particular, em águas superficiais, águas residuais ou solo. É o parabeno mais amplamente usado em aplicações comerciais e pode serutilizado puro ou como uma mistura com o propilparabeno a fim de melhorar o desempenho antimicrobiano (VELEGRAKI et al.,2015).

Está relatado na ficha de informações de segurança de produtos químicos da Sigma Aldrich (disponível no site da empresa) onde foi adquirido o composto padrão, que o metilparabeno enquadra-se como possuindo "toxicidade aguda e crônica para o ambiente aquático (Categoria 3)", indicados ainda pelo fabricante como "nocivo para os organismos aquáticos com efeitos duradouros”. É indicado o seu uso evitando a liberação para o ambiente.

Além disto, este composto, assim como os demais parabenos são listados como causadores de desregulação endócrina (LIU et al., 2014), podendo incentivar resposta cancerígena em nível celular (BOBERG et al., 2010). A Tabela 2 apresenta algumas características físicas, químicas e informações sobre os dois produtos de cuidados pessoais estudados.

\subsection{Contaminação dos ambientes aquáticos e águas de consumo por PFCPs e seus possíveis riscos}

Os fármacos de uso humano e veterinário podem atingir corpos d'água por diferentes rotas, como excreção através da urina e fezes após uso, eliminação direta de drogas domésticas, efluentes de estações de tratamento de esgotos (ETEs), efluentes industriais, descarte inadequado após expiração do prazo de validade, ou disposição inadequada em aterros (KUMMERER, 2009). 
Estudos demonstraram que várias dessas substâncias parecem ser persistentes no meio ambiente e não são completamente removidas nas ETEs (STUMPF et al., 1999; TERNES, et al., 1999). Esta situação é preocupante, em razão de que de 50 a $90 \%$ da dosagem do fármaco é excretada inalterada e persistente no ambiente (MULROY, 2001).

A grande maioria dos fármacos possui características lipofílicas e baixa biodegrabilidade no ambiente, e são estas propriedades que estão relacionadas a bioacumulação e persistência no ambiente (CHRISTENSEN,1998; apud PONEZI et al., 2007).

A ocorrência de fármacos no ambiente aquático esta intimamente relacionada ao estilo de vida da sociedade moderna, aos padrões de consumo e ao envelhecimento da população (CORTEZ, 2011).

Em relação aos produtos de cuidado pessoal, outra maneira de entrarem no meio ambiente se dá através de atividades recreativas. Os compostos de produtos como cosméticos, loções e protetores solares entram em água superficiais através do contato direto em atividades recreativas em rios e lagos (WEIHONG LI, et al., 2007, BALMERet al., 2005). A prática da higiene pessoal, ou seja, os banhos, a utilização dos produtos de higiene pessoal, também são uma forma da contaminação por estas substâncias.

Os primeiros estudos sobre a presença de fármacos no ambiente datam da década de 70 e foram realizados por Garrison et al., (1976) e Hignite e Azarnoff, (1977). Desde então, diversos estudos revelaram a presença de resíduos de fármacos em várias partes do mundo (MELO et al., 2009), com concentrações variando de $\mu \mathrm{g} \mathrm{L}^{-1}$ a $\mathrm{ng} \mathrm{L}^{-1}$ de anti-inflamatórios, antilipêmicos e betabloqueadores em ETE na Alemanha (TERNES, 1998), carbamazepina, ácido clofibrico e diclofenaco contaminando ETEs na Europa (França, Grécia, Itália e Suécia), sendo que alguns destes compostos estavam presentes também em água para consumo humano (HEBERER, 2002).

Em um estudo realizado na Galicia (Espanha), Rodil et al., (2012) estudaram a presença de 53 substâncias em águas superficiais, residuárias e de consumo na região. Destas, 50 foram encontradas. Dentre os farmacos, destacaram-se naproxeno, ibuprofeno, diclofenaco e atenolol, encontrados em água superficial, residuárias e também água de consumo humano. Dentre os filtros solares, a substância mais preocupante foi a benzofenona-4, por ter sido encontrada com frequência em água de consumo $\left(62 \mathrm{ng} \mathrm{L}^{-1}\right)$.

Além de estas substâncias terem sido encontradas em aguas superficiais, Sui et al., (2015) relatam contaminação em águas subterrâneas, sendo que dentre os anti-inflamatórios e 
analgésicos mais comumente encontrados incluem o ibuprofeno, diclofenaco e paracetamol por causa de seu grande consumo na vida diária.

Em uma pesquisa realizada no Canadá, o naproxeno foi encontrado em seis comunidades e oito dos 51 locais amostrados. O ibuprofeno foi detectado em cinco comunidades e nove dos 51 locais amostrados, e o diclofenaco foi encontrado em quatro comunidades e oito dos locais amostrados de $51 \mathrm{em}$ toda a província. Todos os antiinflamatórios citados estão na relação dos medicamentos mais prescritos nas comunidades em que foram encontrados (BOOKER e GARDNER, 2013).

A maioria dos estudos com filtros UV foi realizada na Europa e nos EUA, considerando que os dados provenientes de estudos semelhantes em países da Ásia e América Latina são escassos (WEIHONG LI et al., 2007).

Lambropoulou et al., (2002) encontraram 2-hidróxi-4-metoxibenzofenona e ácido octildimetil-p-aminobenzóico em níveis de $\mathrm{ng} \mathrm{mL}^{-1}$ em amostras de água de piscina, chuveiro e água do mar, de pessoas que tinham aplicado produtos cosméticos na pele antes de tomar banho.

Em um estudo realizado na Suíça, foi constatada a ocorrência de quatro diferentes substâncias presentes em filtros UV em esgotos sanitários e águas superficiais (BALMER et al., 2005 apud WEIHONG LI et al., 2007).

A benzofenona-3 já foi encontrada em rios (RODIL e MOEDER, 2008), lagos (POIGER et al., 2004; RODIL e MOEDER, 2008) e no oceano (DANOVARO et al., 2008).

Pedrouzo et al., (2009) validaram um método para determinação de onze substâncias encontradas em produtos de cuidado pessoal. Observaram que a maioria das substâncias estudadas foi encontrada nas águas superficiais sendo metilparabeno e propilparabeno os encontrados em maior concentração (5613 ng L ${ }^{-1}$ e $\left.1945 \mathrm{ng} \mathrm{L}^{-1}\right)$, respectivamente. Nas águas de efluentes, níveis significativamente baixos de algumas substâncias foram encontradas, sendo que a concentração da benzofenona-3 foi maior do que das outras substâncias estudadas.

Os relatos da presença do metilparabeno em efluentes de estações de tratamento de esgoto sanitário revelam que o composto não pode ser completamente eliminado através da utilização de tratamentos convencionais (HAMAN et al., 2015; GMUREK et al., 2015). Os parabenos foram também encontrados em fluidos humanos, tais como urina, sangue, e no leite materno, o qual está associado à aplicações dérmicas ou ingestão involuntária (LIU et al., 2014). 
O interesse crescente na determinação desses contaminantes ocorre pelo efeito e pelo fato de que não estão inseridos na legislação que regulamentam a qualidade da água para consumo humano (HERNANDÉZ et al., 2007; RODRIGUEZ-MOZAZ et al., 2007), o que requer pesquisas sobre a toxicidade e efeitos na biota aquática, do solo, e na saúde humana (HERNÁNDEZ et al., 2007).

Os fármacos são projetados para atingir órgãos ou rotas metabólicas e moleculares específicas tanto nos humanos como em animais, mas também possuem frequentemente efeitos colaterais relevantes. Quando introduzidos no ambiente, podem afetar os animais pelas mesmas rotas e atingir órgãos, tecidos, células ou biomoléculas com funções semelhantes à dos humanos (FENT et al.,2006); pois são moléculas biologicamente ativas.

O diclofenaco pode causar sérios efeitos em espécies de vertebrados em concentrações muito mais baixas do que o sugerido por concentrações agudas em testes de toxicidade crônica com espécies de invertebrados (FERRARI et al., 2003).

Em um dos mais extensos estudos em que foram investigados os efeitos dos medicamentos sobre as comunidades planctônicas, Richards et al. (2004) revelaram que uma mistura de ibuprofeno $\left(0,6 \mathrm{mg} \mathrm{L}^{-1}\right)$, fluoxetina $\left(1,0 \mathrm{mg} \mathrm{L}^{-1}\right)$ e ciprofloxacina $\left(1,0 \mathrm{mg} \mathrm{L}^{-1}\right)$ causou a diminuição da diversidade da comunidade zooplanctônica, e ao mesmo tempo, aumentou a abundância de outras espécies.

Em um estudo com Daphnia magna expostas ao ibuprofeno Heckmann et al., (2007) avaliaram a dinâmica das populações e observaram um efeito direto na reprodução, sendo que as mudanças na estrutura e no tamanho das populações parecem ser induzidas por um atraso na reprodução e pela redução da fecundidade.

Por estes e outros motivos, a simples presença dos fármacos em águas superficiais e subterrâneas demonstra a necessidade de estudos que determinem seus efeitos tóxicos e de interferência endócrina no meio ambiente (STUMPF et al., 1999).

No caso das substâncias encontradas em produtos de cuidado pessoal, mais especificamente a benzofenona e o metilparabeno, sabe-se que, Nagtegaal et al., (1997) apud Weihong Li et al., (2007), identificaram seis diferentes principios ativos presentes em filtros UV em peixes do Lago Maarfelder (Alemanha).

Uma pesquisa realizada pela bióloga molecular Phillippa Darbre, revelou que a estrutura química do éster dos parabenos encontrado nos tumores indica que este é originário de algum produto aplicado na pele, tais como desodorante axilar, cremes ou sprays para o corpo (DARBRE et al., 2004). 
De acordo com Gonzalez et al., (2006), um filtro solar disponível no comércio, contendo 4\% de benzofenona-3 (também referida como BP-3 ou BZ-3) foi aplicado topicamente em 25 voluntários por 5 dias, de manhã e à noite. Um grupo foi exposto à radiação UV e o outro não. Cerca de 3,7 \% da quantidade de BP-3 aplicada foi encontrada na urina. Não houve diferença significativa entre os dois grupos.

Estudos também revelaram que as benzofenonas hidroxiladas apresentaram atividade estrogênica in vitro sobre as células mamárias cancerígenas MCF-7(células sensíveis ao estrogênio) (SUZUKI et al., 2005).

Em outro estudo sobre filtros solares UV, Schlumpf et al., (2001) verificaram que, de cada seis amostras de leite materno avaliadas, cinco apresentaram resíduos de BP-3 e de metoxicinamato de octila (OMC) -outro composto presente em um filtro solar.

De acordo com Weihong Li et al., (2007), a preocupação com os efeitos secundários causados pelos PFCPs é crescente. Estes são motivo de preocupação pelos impactos ecológicos e ambientais, pois eles podem ser ativos em concentrações extremamente baixas. Podem interagir com outras moléculas orgânicas presentes no meio ambiente e para tanto não há previsão da ação dessas substâncias nos corpos hídricos, e às vezes podem se concentrar na cadeia alimentar, afetando especialmente os organismos aquáticos e causando impactos como, atraso no desenvolvimento dos peixes, na metamorfose de sapos e rãs, e uma variedade de reações, incluindo alterações do comportamento e reprodução.

Em razão deste cenário, a presença de resíduos de fármacos e outros compostos xenobióticos em águas superficiais e na água potável configura uma questão de saúde pública, uma vez que pouco se conhece a respeito do seu potencial efeito na saúde dos humanos associado com o consumo em longo prazo destes compostos na água potável (STACKELBERG et al., 2004).

\subsection{Filtros ecológicos}

Uma água limpa e "segura" é a meta mais importante de uma população, comunidade e economia saudável (POPE et al., 2012).

Os autores Mala-Jetmarova et al., (2015) fizeram um histórico a respeito dos sistemas de distribuição de água, com relatos desde a idade do bronze (Por volta de 3200-1100 aC) até os dias de hoje.

Ainda segundo Mala-Jetmarova et al., (2015) o registro mais antigo conhecido de tratamento de água vem de fontes indianas datada por volta de $2000 \mathrm{aC}$, porém o primeiro 
desenvolvimento da tecnologia de tratamento de água relevantes para abastecimento urbano encontra-se na civilização minóica no início da Idade do Bronze (cerca de 3.200-1.100 aC), onde cisternas de sedimentação foram utilizadas para a remoção de sólidos em suspensão e dispositivos de infiltração de terra cota cheias com carvão vegetal para a remoção de constituintes orgânicos e inorgânicos presentes na água (SKLIVANIOTIS e ANGELAKIS, 2006; MAYS et al., 2012).

O surgimento da filtração lenta em areia ocorreu em 1804 na Escócia, desenvolvida por John Gibs, melhorada por Robert Thom em 1827 que mais tarde foi contratado por James Simpson para a Companhia de Água Chelsea em 1829, quando os filtros lentos de areia estavam prontos para utilização em Londres (BAKER, 1949).

Mas a filtração lenta em areia só tornou-se reconhecida e foi difundida após o evento no verão de 1892, quando John Snow comparou o número de pessoas doentes por cólera e febre tifoide em duas cidades da Alemanha, Hamburgo e Altona, sendo que Altona já utilizava o sistema de tratamento por filtração lenta em areia e em Hamburgo, que registrou inúmeras pessoas doentes, ainda não (NAKAMOTO, 2008). Desde então, os filtros lentos de areia tornaram-se uma exigência legal para toda a água potável extraída do rio Tâmisa em 1852 (HUISMAN e WOOD, 1974).

Após, ocorreu o advento da filtração rápida que logo ganhou seu lugar em todo o mundo, a qual é muito utilizada no Brasil na atualidade.

Apesar de a filtração lenta em areia ter perdido sua popularidade por operar com baixa taxa de filtração, se comparada com a filtração rápida (NAKAMOTO, 2008) $\left(5 \mathrm{~m}^{3} / \mathrm{m}^{2}\right.$.dia contra $120 \mathrm{~m}^{3} / \mathrm{m}^{2}$.dia da filtração rápida) e por isso necessitar de espaço, Nakamoto, (2008) afirma que o sistema de filtração em areia tem bom rendimento em termos de área ocupada. $\mathrm{O}$ autor faz uma comparação entre duas cidades do Japão que utilizam cada um destes sistemas de tratamento e conclui que se considerando a área total ocupada, as estações praticamente se igualam.

Ainda dentre as desvantagens citadas por Nakamoto, (2008) a respeito da filtração rápida, o autor explica que o sistema não é capaz de eliminar por completo os agentes patogênicos, como Cryptosporidium, que atravessam o filtro e provocam diarreia aos consumidores. Além disso, o sistema não é capaz de eliminar o odor desagradável da água, o que faz com que se adicione o carvão ativado, consequentemente elevando o custo da água tratada. 
A partir da década de 1980 ressurgiu o interesse no sistema de filtração lenta em areia principalmente para aplicações em pequenas comunidades, mas até mesmo em médias, e em ambos os países industrializados e em desenvolvimento (HAIG et al., 2011).

O interesse pela filtração lenta em areia ressurgiu, pois dentre as diversas tecnologias de tratamento de água, mostra-se bastante atraente por não necessitar de aplicação de produtos químicos, não necessitar de mão de obra especializada e apresentar excelente remoção de organismos patogênicos incluindo os cistos de Giardia e oocistos de Cryptosporidium, além de compostos orgânicos complexos, como alguns fármacos (BELLAMY, 1985; HAARHOFF e CLEASBY, 1991; MELO, 2006; ERBA et al., 2014).

No Brasil, a relevância da filtração lenta em areia está consolidada no meio técnico, quer pela recente Portaria nº 2.914 (BRASIL, 2011) quer pela Agência de Proteção Ambiental dos EUA (EPA - Environmental Protection Agency), pois ambas estabelecem, embora com distintos requisitos de qualidade, a necessidade dessa etapa na distribuição de água captada em mananciais superficiais (LIBÂNIO, 2005).

O processo de filtração ecológica também possui desvantagens. Além da baixa taxa de filtração, existem limitações da aplicação deste sistema que se referem à qualidade da água afluente. De acordo com Sharpe et al. (1994), o uso da filtração lenta é indicada quando a turbidez da água é menor que 10 NTU.

No caso de situações diferentes desta, recomenda-se um pré-tratamento da água antes da utilização dos filtros lentos. Um exemplo de pré-tratamento da água é a inclusão de PréFiltração Dinâmica (PFD) e a Pré-Filtração em Pedregulhos (PFP), que em conjunto com a filtração lenta em areia, é denominada de Filtração em Múltiplas Etapas (FiME) (DI BERNANRDO et al., 1999).

De modo geral, os mecanismos responsáveis pela remoção das partículas no filtro lento podem ser divididos em três grupos, o que conduz a partícula em direção ao grão de areia (transporte) - físico; aqueles que operam para manter as partículas em contato com a superfície dos grãos de areia (aderência) - químico; e os processos microbiológicos, que são considerados de grande importância no processo (SÁ, 2006).

Conforme a água se infiltra através da areia, o material orgânico e os microrganismos são removidos tanto por ação mecânica (por exemplo, absorção, difusão, triagem e sedimentação) como por processos biológicos (por exemplo, a predação, morte natural e degradação metabólica) (HUISMAN, 1974; ELLIS e WOOD, 1985; HAARHOFF e CLEASBY, 1991; FOGEL et al., 1993; LLOYD, 1996; BAHGAT et al., 1999; HAIG et al., 2011). 
O filtro lento opera com baixa taxa (ou velocidade) de filtração, resultando em altos tempos de detenção na água acima do meio e no próprio meio. Em consequência desse tempo de detenção elevado, há o desenvolvimento de intensa atividade biológica nas camadas mais superficiais do meio filtrante (SÁ, 2006), esta camada biológica é conhecida como biofilme ou schmutzdecke.

Quando um filtro é colocado em operação, é necessário um período para o processo de maturação, ou seja, o estabelecimento da comunidade microbiológica. Este período é medido pela remoção dos coliformes pelo filtro, sendo este considerado maturado quando a remoção atinge o percentual próximo de 99\% (ELLIOTT et al., 2008; PALMATEER et al., 1999; BUZUNIS, 1993.).

É justamente pela presença deste biofilme no filtro lento de areia que Nakamoto (2008) diz que o nome filtração lenta é um equivoco e deve ser substituído por "sistema de purificação ecológica", pois o nome reflete o processo de purificação da água, incorporando o papel fundamental dos microrganismos (Figura 1).

Quando se utiliza o nome filtração ecológica, o próprio nome já sugere a fundamental importância da comunidade biológica, agregando valores ao sistema de tratamento por mostrar que é um sistema natural de purificação da água e, portanto, mais saudável.

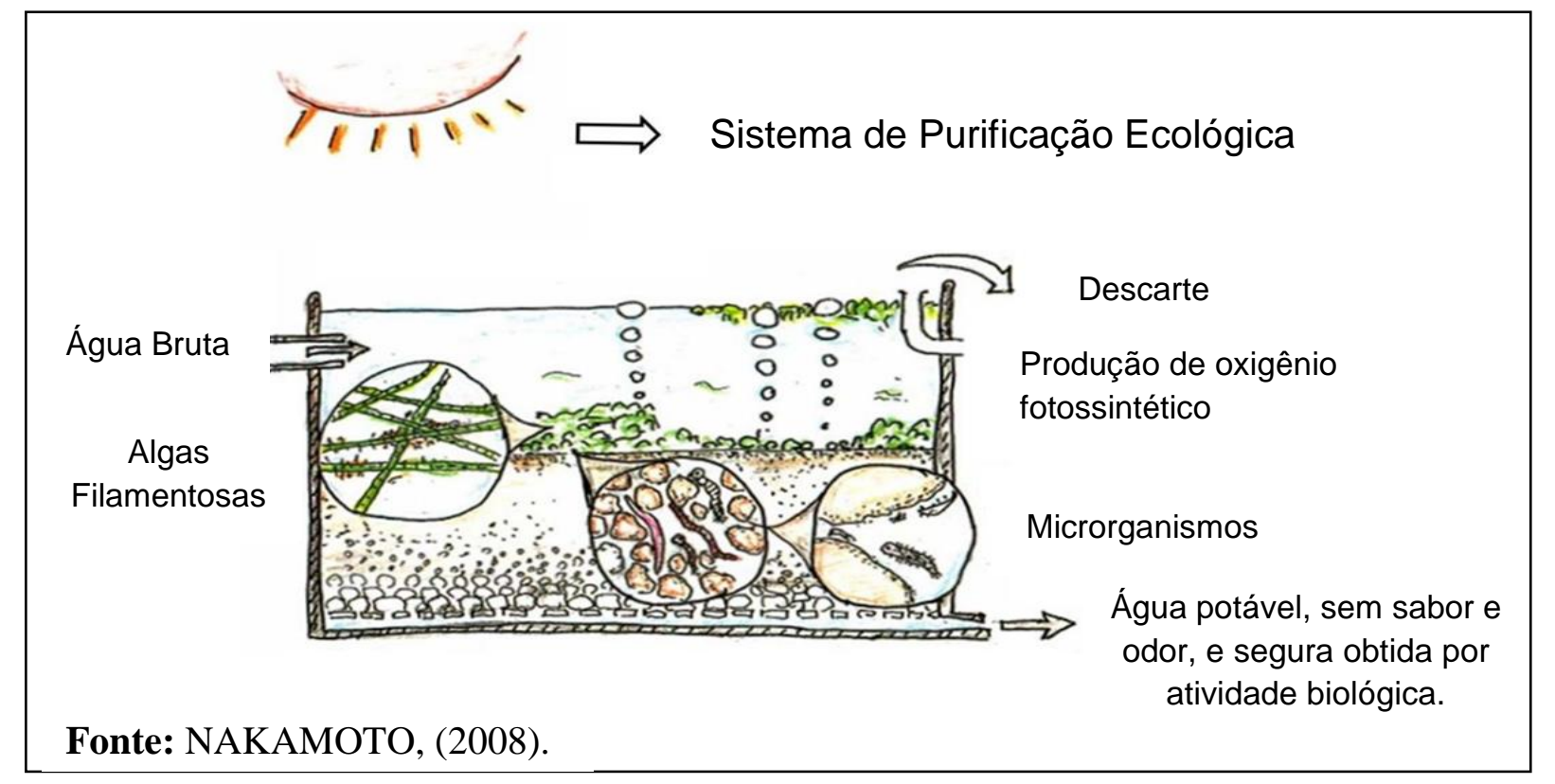

Figura 1: Esquema representativo do sistema de purificação ecológica da água. 


\subsection{O biofilme formado nos filtros}

O biofilme do filtro ecológico, conhecido também como schmutzdecke, é formado no topo da areia durante o processo de maturação (amadurecimento do filtro). Os organismos se formam não só sobre a areia do filtro, mas também nas paredes do mesmo.

De acordo com Huisman e Wood, (1974), o processo de purificação de água começana água sobrenadante. Os organismos presentes no filtro lento são em sua maioria algas, protozoários, bactérias e invertebrados (HAARHOFF e CLEASBY, 1991). Nakamoto, (2014) diz que o sucesso do sistema de purificação ecológica da água dá-se pela cadeia trófica completa que se forma nos filtros.

O "revestimento", ou biofilme sobre a areia continua através de alguns centímetros do leito de areia, as diferentes formas de vida predominam em diferentes profundidades, com a maior atividade próxima à superfície, onde o alimento é abundante (CAMPOS, 2002).

Em estudo realizado na Austrália por Bowles et al., 1983, os protozoários, as algas, rotíferos, e invertebrados eram abundantes no topo da areia de um filtro lento $(1 \mathrm{~cm})$, sendo que o número de microrganismos presentes decresceu rapidamente até uma profundidade de 8 $\mathrm{cm}$. Os pequenos flagelados foram os protozoários mais abundantes e as espécies ciliadas eram comumente encontradas.

McNair et al., (1987) examinaram o crescimento e a composição do schmutzdecke e encontraram quatro zonas: a zona A era composta de algas filamentosas e tinha uma espessura de aproximadamente $15 \mathrm{~mm}$; a zona B foi caracterizada por uma camada fina de algas unicelulares misturado com o sedimento e foi igualmente de aproximadamente $15 \mathrm{~mm}$ de espessura; a zona C continha acumulado sedimentos e contribuiu para uma espessura adicional de $15 \mathrm{~mm}$ para o schmutzdecke. A zona D consistia de uma fina camada de sedimentos e de poucas algas entre a superfície da areia.

Entre os mecanismos biológicos que ocorrem nos filtros lentos de areia, as atividades predatórias associadas com a maturidade do leito filtrante são sugeridas como sendo o processo principal responsável pela remoção e inativação dos patógenos microbianos durante a filtração (CAMPOS, 2002).

Dentre os vários grupos biológicos que compõem o biofilme de filtros ecológicos, as algas e cianobactérias desempenham papel fundamental na atividade biológica, pois compõem a base para a cadeia trófica. De acordo com Nakamoto, (2008) a comunidade fitoplanctônica forma uma "malha" sobre a areia do filtro, o que auxilia na retenção de impurezas. 
Embora tenha sido alvo de diversos estudos, é um sistema complexo ainda não totalmente compreendido e desvendado, o que limitou ainda mais a aplicação e utilização desta tecnologia. Os autores Haig et al., (2011) consideram os mecanismos biológicos de purificação dos filtros lentos em areia como uma "caixa preta", precisando ser mais investigados.

Haig et al., (2011) afirmam que uma limitação é que a maioria dos estudos foram realizados em microcosmos de escalas laboratoriais, com parâmetros cuidadosamente controlados, que não podem representar plenamente as complexas e diversificadas comunidades microbianas que formam o biofilme dos filtros lentos de areia em grande escala.

Com os avanços da biologia molecular, muitos estudos têm sido desenvolvidos utilizando sequenciamento genético e métodos avançados na investigação das bactérias que compõem o biofilme de filtros lentos de areia e Biosand filters (CALVO-BADO et al., 2003; WAKELIN et al., 2010; WAKELIN et al., 2011; HWANG et al., 2014; HAIG et al., 2015). Porém muitas perguntas ainda restam a respeito das algas e cianobactérias que formam a base de toda a cadeia trófica dos filtros ecológicos. 


\section{Justificativa}

Ainda hoje, muitas pessoas em todo o mundo sofrem com a falta de saneamento básico. Globalmente, estima-se que 1,9 bilhões de pessoas ou usam uma fonte de água imprópria e urbanizada, ou de uma fonte não tratada e contaminada por resíduos fecais (WHO, 2016).

Além dos patógenos, a questão da poluição ambiental relacionada à contaminação dos corpos hídricos, água de consumo e até mesmo águas subterrâneas por PFCPs tem sido objeto de estudo em todo o mundo (SUI et al., 2015), sendo estes classificados como poluentes emergentes.

O consumo de água nas atividades humanas varia muito entre diversos países. Não só o aumento populacional e a aceleração da economia ampliam os usos múltiplos, mas também o desenvolvimento cultural, que faz com que outras necessidades sejam incorporadas, resultando em impactos diversificados e de maior amplitude. Estes diversos usos da água e as permanentes necessidades estão relacionados ao crescimento populacional e as demandas industriais e agrícolas têm gerado permanente pressão sobre a qualidade dos recursos hídricos superficiais e subterrâneos (TUNDISI, 2005).

O uso de filtros ecológicos, terminologia moderna para filtro lento de areia, representam uma tecnologia em tratamento promissora em razão desta não necessitar da aplicação de produtos químicos, baixos custos de instalação e operacionais, bem como sua constatada eficiência na remoção de diversos compostos, inclusive de alguns fármacos (Erba et al., 2012).

A avaliação da remoção dos compostos selecionados aplicados isoladamente ou em mistura nos traz respostas do funcionamento do sistema simulando situações reais de utilização, uma vez que no meio ambiente uma mistura dos mais diversos compostos estão presentes. Deste modo, pode-se ter um sistema de tratamento de água eficiente, oferecendo à população de baixa renda o acesso à água potável uma alternativa viável e segura.

Os estudos modernos acerca da filtração lenta em areia, ou filtração ecológica, ou Biosand Household filters, estão focados em entender e descrever os processos que envolvem o biofilme formado no topo da areia. Diversos estudos foram realizados com bactérias, mas muito pouco foi investigado acerca das algas e cianobactérias que compõem a base da cadeia trófica do sistema ecológico de tratamento de água.

Além disso, os efeitos da aplicação de PFCPs na água a ser tratada pelos filtros e a resposta da comunidade de algas e cianobactérias ante a contaminação, nos traz contribuições importantes para compreender a essencial ação do biofilme no sistema de tratamento. 


\section{Referencias bibliográficas}

ABIHPEC. Associação Brasileira da Indústria de Higiene Pessoal, Perfumaria e Cosméticos. 2012. Panorama do setor 2011. Disponível em: <http://www.abihpec.org.br/2012/04/panorama-dosetor-2011/> Acesso em: 17 de out. 2012.

ANDERSEN, F.A. Final amended report on the safety assessment of methylparaben, ethylparaben, propylparaben, isopropylparaben, butylparaben, isobutylparaben, and benzylparaben as used in cosmetic products. International Journal of Toxicology. v. 27, p.1-82, 2008.

ANVISA, 2000. Agência Nacional de Vigilância Sanitária. Resolução RDC nº 79, de 28 de agosto de 2000. Disponível em: <http://www.anvisa.gov.br/cosmeticos/guia/html/79_2000.pdf> Acesso em 28 de out. de 2012.

ASHTON, D.; HILTON, M.; THOMAS, K.V. Investigating the environmental transport of human pharmaceuticals to streams in the United Kingdom. Science Total Environment. v. 333, p. 167184, 2004.

BAHGAT, M.; DEWEDAR, A.; ZAYED, A. Sand-filters used for wastewater treatment: buildup and distribution of microorganisms. Water Research. v. 33, p. 1949-1955, 1999.

BAKER, M. N. The Quest for Pure Water: The History of Water Purification from the Earliest Records to the Twentieth Century. New York, USA, 1949.

BALMER, M.E.; BUSER, H-R.; MULLER, M.D.; POIGER, T. Occurrence of Some Organic UV Filters in Wastewater, in Surface Waters, and in Fish from Swiss Lakes. Environmental Science \& Technology. v. 39, p. 953-962, 2005.

BELLAMY,W.D., HENDRICKS,D.W. e LONGSDON,G.S. "Slow and Filtration" Journal of the American Water Works Association, v.77(12), p. 62-66, 1985.

BOBERG, J.; TAXVIG, C.; CHRISTIANSEN, S.; HASS, U. Possible endocrine disrupting effects of parabens and their metabolites. Reproductive Toxicology, v. 30, p.301-12, 2010.

BOOKER, D.; GARDNER, M. Ontario First Nations pharmaceutical use. List of pharmaceuticals from the Non-Insured Health Benefits Directorate (NIHB). First Nations and Inuit Health Branch, Health Canada. Personal Communication, 2013.

BOWLES, D. A.; DREW, W. M.; HIRTH, G. The Application of Slow Sand Filtration Process to the Treatment of Small Town Water Supplies. Victoria, Australia: State Rivers and Water Supply Commission, 1983. 
BRASIL. Governo Federal. Pesquisa vai avaliar consumo e acesso a medicamentos por brasileiros. Disponível em: <http://www.brasil.gov.br/noticias/arquivos/2012/10/09/pesquisa-vaiavaliar-consumo-e-acesso-a-medicamentos-por-brasileiros> Acesso em: 11 de out. 2012.

BUSER, H. R; POIGER, T.; MULLER, M. D. Occurrence and environmental behavior of the chiral pharmaceutical drug Ibuprofen in surface waters and in wastewater. Environmental Science \&Technology, Easton, v. 33, n.15, p. 2529-2535, 1999.

BUSER, H. R; POIGER, T.; MULLER, M. D. Ocurrence and fate of the pharmaceutical drug diclofenaco in surface waters: rapid photodegradation in a lake. Environment Science \& Technology, Easton, v. 32, n. 22, p. 3449-3456, 1998.

BUZUNIS, B.J. Intermittently operated slow sand filtration: a new water treatment process. Master's Thesis, University of Calgary, Department of Civil Engineering, Calgary, Alberta, 1995.

CALVO-BADO, L.; PETTITT, T.; PARSONS, N.; PETCH, G.; MORGAN, J.; Spatial and temporal analysis of the microbial community in slow sand filters used for treating horticultural irrigation water. Applied and environmental microbiology. v. 69, p. $2116-2125,2003$.

CAMPOS, L.C.; SU, M.F.J.; GRAHAM, N.J.D.; SMITH, S.R. (2002). Biomass development in slow sand filters. Water research 36, 4543-4551.

CAMPOS, L.C. Modelling and Simulation of the Biological and Physical Processes of Slow Sand Filtration. PhD. Thesis, University of London, UK, 2002.

CHISVERT, A.; PASCUAL-MARTI, M. C.; SALVADOR, A. Determination of UV-filters in sunscreens by HPLC. Fresenius' Journal of Analytical Chemistry. v, 369, p. 638-641, 2000.

CORTEZ, F.S. Avaliação da toxicidade do fármaco triclosan através de ensaios ecotoxicológicos empregando organismos marinhos em água e sedimento marcado (spiked). Dissertação (Mestrado), Instituto de Pesquisas Energéticas e Nucleares da Universidade de São Paulo, São Paulo, SP, 2011.

DANOVARO, R.; BONGIOMI, L.; CORINALDESI, C.; GIOVANNELLI, C.; DAMIANI, E.; ASTOLFI, P.; GRECI, L.; PUSCEDDU, A. Environmental Health Perspectives, v.116, p. 441447, 2008.

DARBRE, P. D.; ALJARRAH, A.; MILLER, W. R.; COLDHAM, N. G.; SAUER, M. J. and POPE, G. S. Concentrations of parabens in human breast tumours. Journal of Applied Toxicology, v. 24, p. $5-13,2004$.

DEPA- Danish Environmental Protection Agency, Survey of Parabens e Part of the LOUSreview., 56p., 2013. 
DI BERNARDO; L.; BRANDÃO, C.C.S.; HELLER, L. Tratamento de águas de abastecimento por filtração em múltiplas etapas. PROSAB - Programa de Pesquisa em Saneamento Básico. Rio de Janeiro. ABES. 114p, 1999.

ELLIOTT, M.A.; STAUBER, C.E.; KOKSAL, F.; DIGIANO, F.A.; SOBSEY, M.D. Reductions of $E$. coli, echovirus type 12 and bacteriophages in an intermittently operated household-scale slow sand filter. Water Research. v. 42, p. 2662-2660, 2008.

ELLIS, K.V.; WOOD, W.E. Slow sand filtration. Critical Reviews in Environmental Control. v. 14, 315-354, 1985.

EMERENCIANO, D. P.; SILVA, H. F. O.; CARVALHO, G. C.; SOUZA, J. M.; CRUZ, M. F. C.; RIBEIRO, L. P. D.; MOURA, F. V. Controle de qualidade de medicamentos contendo diclofenaco sódico e potássico utilizando a espectroscopia no Infravermelho próximo NIR. In: CONGRESSO BRASILEIRO DE QUÍMICA, 48, 2008, Rio de Janeiro. Química na proteção ao meio ambiente e saúde. Rio de Janeiro: CBQ, 2008. Disponível em:

<http://www.abq.org.br/cbq/2008/trabalhos/4/4-483-4594.htm>. Acesso em: 16 maio 2009.

ERBA, C.M.; TANGERINO, E.P.; CARVALHO, S.L.; ISIQUE, W.D. Remoção de diclofenaco, ibuprofeno, naproxeno e paracetamol em filtro ecológico seguido por filtro de carvão granular biologicamente ativado. Engenharia Sanitária e Ambiental. v.17, n.2, p. 136-142, 2012.

ERBA, C. M.; TANGERINO, E.P.; ISIQUE, W. D.; CAMPOS, L. C. Removal of antiinflammatory compounds by ecological filtration. In: Nobutada Nakamoto, Nigel Graham, M. Robin Collins and Rolf Gimbel. (2014) (Org.). Progress in slow sand and alternative biofiltration process. 1ed.: IWA publishing. v. 5, cap 19, p. 147-152, 2014.

FDA - U.S. Food and Drug Administration. Parabens. 2006; Updated Outubro, 2007. Disponível em: $<$ http://www.fda.gov/Cosmetics/ProductandIngredientSafety/SelectedCosmeticIngredients/ucm 128042.htm> Acessado em Julho de 2011.

FENT, K; WESTON, A. A.; CAMINADA, D. Ecotoxicology of human pharmaceuticals. Aquatic Toxicology, v. 76, p.122-159, 2006.

FERRARI, B.; PAXEUS, N.; LO GIUDICE, R.; POLLIO, A.; GARRIC, J. Ecotoxicological impact of pharmaceuticals found in treated wasterwaters: study of carbamazepine, clofibric acid, and diclofenaco. Ecotoxicology and Environmental Safety, v. 55, n. 3, p. 359-370, 2003.

FNFB 2 - Formulário Nacional da Farmacopéia Brasileira, 2a Edição. p. 256, 2011.

FOGEL, D., ISAAC-RENTON, J., GUASPARINI, R., MOOREHEAD, W., and ONGERTH, J.Removing giardia and cryptosporidium by slow sand filtration. JAWWA, Research and Technology. p.77-84, 1993. 
GARRISON, A.W.; POPE, J. D.; ALLEN, F. R. Analysis of organic compounds in domestic wastewater. In: KEITH, C. H. (Ed.). Identification and analysis of organic pollutants in water. Michigan: Ann Arbor Science, p. 517-566, 1976.

GMUREK, M.; ROSSI, A.F.; MARTINS, R.C.; QUINTA-FERREIRA, R.M.; LEDAKOWICZ, S. Photodegradation of single and mixture of parabens - Kinetic, by-products identification and costefficiency analysis. Chemical Engeneering Journal. v. 276, p.303-314, 2015.

GONG, H.; KINGER, J.; DAMAZYN, K.; LI, X.; HUANG, S. A novel procedure for statistical inference and verification of gene regulatory subnetwork. BMC Bioinformatics. v. 16, suplemente 7,2015 .

GONZALES, H.; FARBROT, A.; LARKO, O.; WENNBERG, A-M. Percutaneous absorption of the sunscreen benzophenone-3 after repeated whole-body applications, with and without ultraviolet irradiation. British Journal of Dermatology. v. 154, p. 337-340.2006.

HAARHOFF, J. and CLEASBY, J.L. Biological and physical mechanisms in slow sand filtration. In Slow Sand Filtration, Logsdon, G.S.(Ed.), Task Committee on Slow Sand Filtration, ASCE, 1968, 1991.

HAIG, S.J., COLLINS, G., DAVIES, R.L., DOREA, C.C., QUINCE, C. Biological aspects of slow sand filtration: past, present and future. Water Science and Technology. v. 11, p. 468-472, 2011.

HAIG, S-J.; QUINCE, C.; DAVIES, R.L.; DOREA, C.C.; COLLINS, G. The relationship between microbial community evenness and function in slow sand filters. MBio v. 6(5), p. e00729-15, 2015.

HAMAN, C.; DAUCHY, X.; ROSIN, C.; MUNOZ, J-F. Occurrence, fate and behavior of parabens in aquatic environments: a review. Water Research. v. 68, p. 1-11, 2015.

HAURI, A., AMMSTRONG, G.L., HUTIN, Y. Unsafe health care injections. In: Ezzati M et al., eds. Comparative quantification of health risks: global and regional burden of disease due to selected major risk factors. Geneva, World Health Organization. 2003.

HEBERER, T. Occurrence, fate and removal of pharmaceuticals residues in the aquatic environment: a review of recent research data. Toxicology Letters, Amsterdam, v. 131, p. 5-17, 2002.

HECKMANN, L.; CALLAGHAN, A.; HOOPER, H. L.; CONNON, R.; HUTCHINSON, T. H.; MAUND, S. J.; SIBLY, R. M. Chronic toxicity of ibuprofen to Daphnia magna: effects on life history traits and population dynamics. Toxicology Letters, Amsterdam, v. 172,n. 1, p. 137-145, 2007.

HERNÁNDEZ, F.; SANCHO, J. V.; IBÁÑEZ, M.; GUERRERO, C. Antibiotic residue determination in environmental waters by LC-MS. Trends in Analytical Chemistry, Oxford, v. 26, n. 64 p. 66-485, 2007. 
HIGNITE, C.; AZARNOFF, D. L. Drugs and metabolites as environmental contaminants: chlorophenoxyisobutyrate and salicylic acid in sewage water effl uent. Life Sciences, Oxford, v. 20, n. 2, p. 337-342, 1977.

HUISMAN, L.; WOOD, W. Slow sand filtration. World Health Organization, Geneva, Switzerland, 1974.

HWANG, H.G.; KIM, M.S.; SHIN, S.M.; and HWANG, C.H. Risk Assessment of the Schmutzdecke of Biosand Filters: Identification of an Opportunistic Pathogen in schmutzdecke Developed by an Unsafe Water Source. Internationa. Journal of Environment Research Public Health.v.11, p. 2033-2048, 2014.

KRUTMANN, J. The interaction of UVA and UVB wavebands with particular emphasis on signalling. Progress in Biophysics and Molecular Biology, v. 92, p. 105-107, 2006.

KUMMERER, K. The presence of pharmaceuticals in the environment due to human use - present knowledge and future challenges. Journal of Environmental Management. v. 90, p. 2354-2366, 2009.

LAMBROPOULOU, D. A., SAKKAS, V. A., HELA, D. G., and ALBANIS, T. A. Application of soe in the monitoring of priority pesticides in the Kalamas River (N. W. Greece). Journal of Chromatography. v. 963, p. 107-116, 2002.

LIBÂNIO, M. Fundamentos de qualidade e tratamento de água. Campinas: Átomo, 444 p. 2005.

LIN, Y.; FERRONATO, C.; DENG, N.; WU, F.; CHOVELON, J-M. Photocatalytic degradation of methylparaben by $\mathrm{TiO} 2$ : multivariable experimental design and mechanism. Applied Catalysis $\mathrm{B}$ : Environmental. v. 88, p.32-41, 2009.

LIU, T.; LI, Y.; ZHAO, X.; ZHANG, M.; GU, W. Ethylparaben affects lifespan, fecundity, and the expression levels of ERR, EcR and YPR in Drosophila melanogaster. Journal of Insect

Physiology. v.71, p. 1-7, 2014.

LLOYD, B.J.The significance of protozoal predation and adsorption for the removal of bacteria by slow sand filtration. In Advances in Slow Sand and Alternative Biological Filtration. N.J.D. Graham and R. Collins (Eds.), John Wiley \& Sons, UK, 129-137, 1996.

MALA-JETMAROVA, H.; BARTON, A.; BAGIROV, A. A history of water distribution systems and their optimisation. Water Science \& Technology: Water Supply. v. 15, p. 224- 235, 2015.

MARTINEZ BUENO, M.J.; GOMEZ, M.J.; HERRERA, S.; HERMANO, M.D.; AGUERA, A.; FERNÁNDEZ-ALBA, A.R. (2012). Occurrence and persistence of organic emerging contaminants and priority pollutants in five sewage treatment plants of Spain: two years pilot survey monitoring. Environment Pollution. v. 164, p. 267-273, 2012. 
MAYS, L. W.; SKLIVANIOTIS, M.; ANGELAKIS, A. N. Water for human consumption through history. In: Evolution of Water Supply Through the Millennia (A. N. Angelakis, L. W. Mays, D. Koutsoyiannis \& N. Mamassis, eds). IWA Publishing, London, UK, 2012.

MCNAIR, R. D.; SIMS, R. C.; SORENSEN, D. L.; and HULBERT, M. Schmutzdecke characterization of clinoptilolite-amended slow sand filtration. Journal Am. Water Works Association. v. 79, p.74-81,1987.

MELLO, S. A. S.; TROVÓ, A. G.; BAUTITZ, I. R.; NOGUEIRA, R. F. P. Degradação de fármacos residuais por processos oxidativos avançados. Quimica Nova, São Carlos, v. 32, n. 1, p. 188-197. 2009.

MELLO-DA-SILVA, C. A., FRUCHTENGARTEN L. Riscos químicos ambientais à saúde da criança. Jornal de Pediatria, Porto Alegre, v. 81, n. 5, 205-211. 2005.

MELO, A. E. S. Avaliação da filtração lenta na remoção de células de Cylindrospermopsis raciborskii e saxitoxinas. Dissertação (Mestrado em Tecnologias Ambientais e Recursos Hídricos), Engenharia Civil e Ambiental, Universidade de Brasília, Brasília, 197 pag. 2006.

MODI, P. B.; VAIRALE, A. S.; SHERIKAR, A. V.; NALAMOTHU, V. A Stability indicating RPHPLC method for simultaneous determination of Oxybenzone, Avobenzone, Octocrylene, Methylparaben, Propylparaben in sunscreen formulations. IJPI's Journal of Analytical Chemistry. v. 1,p. 25-35, 2011.

MULROY, A. Monitoring and analysis of water and wastes. Water Environment Technology, Alexandria, v.13, n. 2 p. 32-36, 2001.

NAKAMOTO, N. Produza você mesmo uma água saborosa - sistema de purificação ecológica - revendo a tecnologia de produção de água potável.São Paulo: Ferrari. 210 p. 2008.

NAKAMOTO, N.; GRAHAM, N.; COLLINS, M.R. and GIMBEL, R. (Eds.) Progress in slow sand and alternative biofiltration process - Further developments and Applications. 1ed.: IWA publishing, 2014.

PALMATEER, G.; MANZ, D., JURKOVIC, A. Toxicant and parasite challenge of Manz intermittent slow sand filter. Environment Toxicology. v. 14, p. 217-255, 1999.

PEDROUZO M, BORRULL F, MARCE R.M., POCURULL E. Ultra-high-performance liquid chromatography-tandem mass spectrometry for determining the presence of eleven personal care products in surface and wastewaters. Journal of Chromatography A. v. 1216(42), p.6994-7000, 2009. 
PETROVIć, M.; ŠKRBIć, B.; ŽIVANčEV, J.; FERRANDO-CLIMENT, L.; BARCELÓ, D. Determination of 81 pharmaceutical drugs by high performance liquid chromatography coupled to mass spectrometry with hybrid triple quadrupole-linear ion trap in different types of water in Serbia. Science of the total Environment, v. 468-469, p. 415-428, 2014.

POIGER, T.; BUSER, H.R.; BALMER, M.E.; BERGQVIST, P-A.; MULLER, M.D. Occurrence of UV filter compounds from sunscreens in surface waters: regional mass balance in two Swiss lakes. Chemosphere. v. 55(7), p. 951-963, 2004.

POMATI, F.; NETTING, A.G.; CALAMARI, D.; NEILAN, B.A. Effects of erythromycin, tetracycline and ibuprofen on the growth of Synechocystis sp. and Lemna minor. Aquatic Toxicology. v. 67, p. 387-396, 2004.

PONEZI, A. N.; MARTA, D.; TEIXEIRA, C. Riscos ecológicos e humanos decorrentes da disposição de fármacos em matrizes ambientais. In: CONGRESSO BRASILEIRO DE ENGENHARIA SANITÁRIA E AMBIENTAL, 24. Anais. Rio de Janeiro: ABES, v. 1, p. 1-1, 2007.

POPE, J. M.; WEIR, M. H.; ROSE, J. B. History of water and health. In: Evolution of Water Supply Through the Millennia (A. N. Angelakis, L. W. Mays, D. Koutsoyiannis \& N. Mamassis, eds). IWA Publishing, London, UK, 2012.

RICHARDS, S .M.; WILSON, C. J.; JOHNSON, D. J.; CASTLE, D. M.; LAM, M.; MABURY, S. A; SIBLEY, P. K.; SOLOMON, K .R. Effects of pharmaceutical mixtures in aquatic microcosms. Environmental Toxicology and Chemistry, New York, n. 3, p. 1035-1042, 2004.

RODIL, R. and MOENDER, M. Development of a method for the determination of UV filters in water samples using stir bar sorptive extraction and thermal desorption-gas chromatography-mass spectrometry. Journal of Chromatography A. v. 1179, p. 81-88, 2008.

RODIL, R.; QUINTANA, J.B.; CONCHA-GRANA, E.; LOPEZ-MAHIA, P.; LORENZOMUNIATEGUI, S.; RODRIGUEZ-PRADA, D. Emerging pollutants in sewage, surface and drinking water in Galicia (NW Spain). Chemosphere Vol.: 86 Pag.: 1040-104,. 2012.

RODRIGUEZ-MOZAZ, S.; LOPEZ, A., M. J.; BARCELÓ, D. Advantages and limitations of online solid phase extraction coupled to liquid chromatography-mass spectrometry technologies versus biosensors for monitoring of emerging contaminants in water. Journal of Chromatography A, Amsterdam, v. 1152, n. 2, p. 97-115, 2007.

SÁ, J. C. Influencia das características da camada da filtrante e da taxa de filtração na influencia da remoção de Microcystis aeruginosa e microcistina na filtração lenta em areia. 2006. 186 f. Tese (Doutorado em Tecnologias Ambientais e Recursos Hídricos) - Departamento de Engenharia Civil e Ambiental, Universidade de Brasília, Brasília. 2006. 
SANTOS, L. O. Estudo comparativo entre as técnicas de voltametria em pulso diferencial, espectrofotometria no ultravioleta e visível e cromatografia líquida de alta eficiência como metodologias analíticas no doseamento da substância química paracetamol. Dissertação (Mestrado) - Instituto Nacional de Controle de Qualidade em Saúde, Fundação Oswaldo Cruz, Rio de Janeiro, 2003.

SCHLUMPF, M.; COTTON, B.; CONSCIENCE, M.; HALLER, V.; STEINMANN, B.; LICHTENSTEIGER, W. In Vitro and in Vivo Estrogenicity of UV Screens.Environmental Health Perspectives.Volume 109. Numero 3. Pag.: 239-244. 2001.

SIQUEIRA, N. M. 2008. Desenvolvimento tecnológico e avaliação da penetração cutânea de benzofenona-3 a partir de nanocápsulas revestidas de quitosana. Dissertação apresentada ao Programa de Pós-graduação em Ciências Farmacêuticas, em nível de mestrado da Faculdade de Farmácia da Universidade Federal do Rio Grande do Sul. Acesso em set. de 2011, disponível em: $\langle$ http://www.bibliotecadigital.ufrgs.br/da.php?nrb=000652542\&loc $=2008 \& \mathrm{l}=38 \mathrm{f} 82 \mathrm{a} 1 \mathrm{f} 422 \mathrm{fe} 02 \mathrm{~b}\rangle$. SKLIVANIOTIS, M.; ANGELAKIS, A. N. Water for Human Consumption through the History. In:1st IWA International Symposium on Water and Wastewater Technologies in Ancient Civilizations, Iraklion, Greece, p. 659-666, 2006.

SONI, M.G.; CARABIN, I.G.; BURDOCK, G.A. Safety assessment of esters of $p$-hydroxybenzoic acid (parabens). Food and Chemical Toxicology, v. 43, p. 985-1015, 2005.

STACKELBERG, P. E.; FURLONG, E. T; MEYER, M. T.; ZAUGG, S. D.; HENDERSON, A. K.; REISSMAN, D .B. Persistence of pharmaceutical compounds and other organic wastewater contaminants in a conventional drinking-water treatment plant. Science of the Total Environment, Amsterdam, v. 329, n. 2, p.99-113. 2004.

STUMPF, M.; TERNES, T. A.; WILKEN, R.; RODRIGUES, S. V.; BAUMANN, W. Polar drug residues in sewage and natural waters in the state of Rio de Janeiro, Brazil. Science Total Environmental, Amsterdam, v. 225, n. 1-3 p. 135-141. 1999.

SUI, Q.; CAO, X.; LU, S.; ZHAO, W.; QIU, Z.; YU, G. Occurrence, sources and fate of pharmaceuticals and personal care products in the groundwater: A review. Emerging Contaminants. v. 1, p. 14-24, 2015.

SUZUKI, T.; KITAMURA, S.; KHOTA, R.; SUGIHARA, K.; FUJIMOTO, N.; OHTA, S. Estrogenic and antiandrogenic activities of 17 benzophenone derivatives used as UV stabilizers and sunscreens. Toxicology and Applied Pharmacology. Vol.: 203 Pag.: 9-17. 2005.

TERNES, T. A. Occurrence of drugs in German sewage treatment plants and rivers. Water Research, Amsterdam, v. 32, n. 3, p. 3245-3260, 1998.

TERNES, T. A.; STUMPF, M.; MUELLER, J.; HABERER, K.; WILKEN, R. D.; SERVOS, M. Behavior and occurrence of strogens in municipal sewage treatment plants - I. investigations in Germany, Canada and Brazil. Science of the Total Environmental, Amsterdam, v. 225, n.1-2, p. 81-90. 1999. 
TERNESS, T.; BONERZ M; SCHMIDT T. Determination of neutral pharmaceuticals in wastewater and rivers by liquid chromatography-electrospray tandem mass spectrometry. Journal of Chromatography A, Amsterdam, v. 938, n. 12, p. 175-85. 2001.

TUNDISI, J. G. 2005. Água no século XXI: enfrentando a escassez. 2. ed. São Paulo: Rima, 248 p.

VELEGRAKI, T.; HAPESHI, E.; FATTA-KASSINOS, D.; POULIOS, I. Solar-induced heterogeneous photocatalytic degradation of methyl-paraben. Applied Catalysis B:

Environmental, v. 178, p.2-11, 2015.

WAKELIN, S. A.; PAGE, D.W.; PAVELIC, P.; GREGG, A. L.; DILLON, P. J. Rich microbial communities inhabit water treatment biofilters and are differentially affected by water type and sampling depth. Water Science and Technology: water supply. v. 10, p. 145-156, 2010.

WAKELIN, S., PAGE, D., DILLON, P., PAVELIC, P., ABELL, G.C.J., GREGG, A.L., BRODIE, E., DESANTIS, T.Z., GOLDFARB, K.C., ANDERSON, G. Microbial community structure of a slow sand filter Schmutzdecke: a phylogenetic snapshot based on rRNA sequence analysis. Water Science Technology. v. 11, p. 426-436, 2011.

WEIHONG LI, Y.; CHANGSHENG, G.; WEI HU, KEMING LIU, YUQIU WANG, TAN ZHU. Occurrence and behavior of four of the most used sunscreen UV filters in a wastewater reclamation plant. Water Research, v. 41, p. 3506-3512, 2007.

WHO. World Health Organization . Results of round I: of the WHO International Scheme to Evaluate Household Water Treatment Technologies. Geneva: World Health Organization, 20016. (http://www.who.int/household_water/scheme/household-water-treatment-report-round-1/en/, accessed 08/03/2016).

ZHANG, Y.; GEISSEN, S.U.; GAL, C. Carbamazepine and diclofenac: removal in wastewater treatment plants and occurrence in water bodies, Chemosphere, v. 73, p. 1151-1161, 2008.

ZUCCATO, E.; CALAMARI, D.; NATANGELO, M.; FANELLI, L.; Presence of therapeutic drugs in the environment. The lancet, v. 355, p. 1789-1790, 2000. 


\title{
Capítulo 1
}

\author{
Instalação piloto no tratamento de água por sistema de filtração ecológica.
}

\section{Resumo}

Muitas pessoas em todo o mundo ainda sofrem com a falta de saneamento básico, sendo que boa parte fica doente e até vem a óbito por consumo de água imprópria. Dentre as diversas tecnologias de tratamento de água, a filtração ecológica é bastante atraente, pois não necessita de aplicação de produtos químicos, não requer mão de obra especializada e apresenta eficiente remoção de organismos patogênicos. O objetivo deste estudo foi avaliar filtros ecológicos no tratamento de água, utilizando água do reservatório do Lobo, Itirapina, São Paulo. Foram confeccionados 22 filtros ecológicos identicamente, sendo estes operados por quatro meses consecutivos, continuamente. Variáveis de qualidade da água, tais como temperatura, $\mathrm{pH}$, turbidez, cor aparente, cor verdadeira, oxigênio dissolvido, sólidos totais dissolvidos, condutividade elétrica, foram medidos no afluente e efluente dos filtros. Houve remoção média de $64 \%$ de turbidez, $57 \%$ de cor aparente, $90 \%$ de cor verdadeira, mais de $70 \%$ de coliformes totais e mais de $80 \%$ de $E$. coli pelos filtros ecológicos. Foi observada a existência de quatro correlações significativas entre as variáveis de qualidade de água avaliadas. Em relação à aplicabilidade, apesar do sistema de filtração rápida ser dominante no Brasil, vê-se um crescente interesse em adotar o sistema de purificação ecológica da água, com implementação em diversos países. Devido ao insuficiente investimento em saneamento básico no Brasil e dentre as diversas vantagens da filtração ecológica, o baixo custo torna esta alternativa bastante atraente. Em relação a área ocupada por filtros ecológicos, levando em conta a área total ocupada por estações de tratamento que utilizam filtração rápida comparado com estações que usam filtração lenta, as estações praticamente se igualam, portanto, há aplicabilidade deste sistema de tratamento de água no Brasil.

Palavras-chave: Filtro ecológico, variáveis físico-químicas, remoção de coliformes. 


\begin{abstract}
Many people around the world still suffer from a lack of basic sanitation, and much get sick and even comes to death by consumption of unsafe water. Among the various water treatment technologies, ecological filtration is quite attractive because it does not require the application of chemicals, does not require skilled labor and has good removal of pathogenic organisms. The aim of this study was to evaluate ecological filters in water treatment, using water from the Lobo's reservoir, Itirapina, São Paulo. Twenty two ecological filters were made identically, which are operated for four consecutive months, continuously. Water quality variables, such as temperature, $\mathrm{pH}$, turbidity, apparent color, true color, dissolved oxygen, total dissolved solids, and electrical conductivity, were measured in the influent and effluent water from filters. There was a mean removal of $64 \%$ turbidity, $57 \%$ of apparent color, the true color $90 \%$, more than $70 \%$ of total coliforms and over $80 \%$ of E. coli, by the ecological filters. It was observed the existence of four significant correlations between the water quality parameters evaluated. Regarding the applicability, despite of the rapid filtration system is dominant in Brazil, we see a growing interest in adopting the ecological purification system, with implementation in several countries. Due to insufficient investment in basic sanitation in Brazil and among the several advantages of ecological filtration, low cost makes this alternative attractive enough. Regarding the area occupied by ecological filters, the total area occupied by treatment plants using rapid filtration compared stations using slow filtration stations are practically equal, so there is applicability of the water treatment system in Brazil.
\end{abstract}

Key-words: Ecological filter, físico-chemical variables, coliforms removal. 


\section{Introdução}

Ainda hoje, muitas pessoas em todo o mundo sofrem com a falta de saneamento básico. Globalmente, estima-se que 1,9 bilhões de pessoas ou usam uma fonte de água imprópria e urbanizada, ou de uma fonte não tratada e contaminada por resíduos fecais (WHO, 2016).

A Organização Mundial da Saúde (OMS) estima que melhorias em saneamento e higiene poderiam prevenir pelo menos 9,1\% da carga de doença global e 6,3\% das mortes, que são decorrentes de doenças de veiculação hídrica (PRUSS-ÜSTÜN, 2008). Doenças diarreicas representam uma fração significativa desta carga resultando em aproximadamente 4 bilhões de casos e 2 milhões de mortes (20\% das fatalidades ocorrem em países subdesenvolvidos) por ano em crianças com menos de 5 anos de idade (BOSCHI-PINTO, VELEBIT, e SHIBUYA, 2008).

Além disso, 502.000 mortes são causadas por diarreia em países de baixa e média renda e pode ser atribuída ao acesso insuficiente e inseguro a água potável (WHO, 2014). A maioria desta população encontra-se em países em desenvolvimento (GUNDRY, WRIGHT, e CONROY, 2004), ou em comunidades remotas e áreas rurais onde a pobreza é mais severa e o custo de abastecimento de água é mais alto. Mesmo onde existem poços protegidos muitas vezes a água abastecida é contaminada devido à falta de saneamento ambiental (RADWQ, 2008). Além disso, uma água potável do ponto de vista microbiológico muitas vezes está sujeita à re-contaminação durante a coleta, o transporte ou a reserva domiciliar (WRIGHT, GUNDRY, e CONROY, 2004).

O Brasil é um país em desenvolvimento e de acordo com dados do IBGE, 9,8 milhões de domicílios no Brasil ainda não possuem acesso à rede de distribuição de água e rede de esgoto, sendo que a Região Norte, que possui a maior proporção de crianças e adolescentes em sua população, apresenta o pior percentual de acesso à água de qualidade do país (45\%). (IBGE-CENSO, 2010).

Dentre as diversas tecnologias de tratamento de água, a filtração lenta é bastante atraente, pois não necessita de aplicação de produtos químicos, não requer mão de obra especializada e apresenta ótima remoção de organismos patogênicos incluindo os cistos de Giardia e oocistos de Cryptosporidium, além de compostos orgânicos complexos, como alguns fármacos (BELLAMY et al., 1985; HAARHOFF e CLEASBY, 1991; MELO, 2006; ERBA et al., 2014). 
O processo de filtração lenta em areia já foi, por mais de 100 anos, e continua sendo amplamente utilizado em tratamento da água, mas apesar de características importantes do processo já terem sido estudadas em detalhe, muitos aspectos do processo permanecem pouco compreendidos. Isto é em parte explicado pela maior atenção que se tem dado ao processo de filtração rápida, por ser mais amplamente aplicada, mas também devido à complexidade inerente ao processo de filtração lenta (GRAHAM e COLLINS, 2014).

$\mathrm{Na}$ década de 90, a filtração lenta foi objeto de uma série de conferências internacionais (GRAHAM, 1998; COLLINS e GRAHAM, 1994; GRAHAM e COLLINS, 1996; NAKAMOTO et al., 2014), manuais de orientação profissional (AWWA, 1991; ASCE, 1991) e revisões de literatura (LAMBERT e GRAHAM, 1995), que fornecem um extenso material de referência contendo detalhes dos estudos de investigação (GRAHAM e COLLINS, 2014).

Pode-se dizer que o processo de filtração lenta é uma combinação de processos físicos, químicos e biológicos. Os mecanismos responsáveis pela remoção das partículas no filtro lento podem ser divididos em três grupos, o que conduz a partícula em direção ao grão de areia (transporte), aqueles que operam para manter as partículas em contato com a superfície dos grãos de areia (aderência) e os processos microbiológicos, que são considerados de grande importância no processo (SÁ, 2006).

O filtro lento de areia opera com baixa taxa de filtração, e como consequência tem-se altos tempos de detenção. Esta baixa taxa e elevado tempo de detenção favorece o desenvolvimento de atividade biológica nas camadas mais superficiais do meio filtrante (também conhecido por biofilme ou schmutzdecke), sendo a base desta cadeia trófica formada por algas e cianobactérias.

Antes de ser colocado em operação, um filtro lento de areia precisa passar pelo processo de maturação. Um filtro é considerado "maturado" ou "maduro" quando a remoção de coliformes atinge seu melhor nível (> 90 \%) (BARRET et al., 1991). A maturação do filtro é uma importante e fundamental etapa, pois assegura a remoção de microrganismos patógenos e partículas, como turbidez da água.

Além da maturidade do leito de areia, o desenvolvimento do biofilme na superfície da areia é um importante processo de remoção de partículas e microrganismos (CAMPOS, 2002).

A importância do biofilme em filtros lentos já é sabida e documentada por diversos autores, que indicam que a eficiência do sistema depende do biofilme, e relatam que o desempenho dos filtros melhora com a maturidade dos mesmos (HUISMAN e WOOD 1974; 
CAMPOS et al., 2002; WAKELIN, 2011). As atividades predatórias associadas com a maturidade do leito filtrante são sugeridas como principais responsáveis pela remoção e inativação de patógenos microbianos (CAMPOS, 2002).

Apesar de sua eficácia na produção de água de qualidade, os filtros lentos de areia ainda são operados como "caixas pretas", sendo a purificação atribuída aos processos bioquímicos naturais, (por exemplo, predação e bio-oxidação), no entanto, estes processos nunca foram verificados com detalhes (HAIG et al., 2011).

É justamente pela presença deste biofilme no filtro lento que Nakamoto (2008), Nakamoto et al., (2014) sugerem que o nome ideal para o processo seja "filtração ecológica", dando ênfase ao processo microbiológico que ocorre no sistema, com a ação de diversos microrganismos essenciais à purificação da água.

Após um tempo de operação, a área superficial dos filtros pode passar por um processo de entupimento conhecido como "colmatação". O tempo para que a colmatação ocorra depende não só do numero de carreiras de filtração, mas também da qualidade da água que será filtrada. O processo de colmatação pode ser observado com o aumento da perda de carga dos filtros e atinge seu auge com o extravasamento de água pelos filtros, onde se faz necessária a interrupção da utilização para limpeza dos filtros.

De acordo com Sharpe et al. (1994), o uso da filtração lenta é indicada quando a turbidez da água é menor que 10 NTU. No caso de situações diferentes desta, recomenda-se um pré-tratamento da água antes da utilização dos filtros lentos. Um exemplo de prétratamento da água é a inclusão de Pré-Filtração Dinâmica (PFD) e a Pré-Filtração em Pedregulhos (PFP), que em conjunto com a filtração lenta em areia, é denominada de Filtração em Múltiplas Etapas (FiME) (DI BERNANRDO et al., 1999). Ainda assim, a qualidade da água bruta parece ser importante para o desempenho de uma FiME (TANGERINO e DI BERNARDO, 2005).

Em adicional, a mesma comunidade fitoplanctônica que compõe o biofilme de filtros ecológicos, pode colaborar para a colmatação do mesmo, no caso de florações de algas com células grandes e que podem formar colônias, incluindo as diatomáceas Melosira e Asterionella provenientes da água a ser tratada pelo filtro (HENDERSON et al., 2008), causando então uma obstrução dos vazios intergranulares das camadas superiores, e consequentemente gerando a diminuição da carreira de filtração pela formação de schmutzdecke mais impermeável (DI BERNARDO et al., 1999). Este também pode ser resolvido com a inclusão de um pré-tratamento no caso de constatada e recorrente presença de diatomáceas filamentosas. 
As cianobactérias também podem afetar a cor, sabor e odor da água de consumo, sendoque algumas de espécies também excretam toxinas que, se consumidos em quantidades suficientes, pode causar problemas de saúde (HUTSON et al. 1987; WHO, 1998 apud HENDERSON et al., 2008). Para tal, além de recomendações da inclusão de tratamentos como a pré-oxidação, carvão granular ativado, também há sugestões de métodos para o controle da eutrofização dos corpos de água utilizados como fonte de captação de água para abastecimento, como a limitação de nutrientes (HENDERSON et al., 2008).

Porém, Nakamoto (2014) diz que a "chave" do sistema de purificação ecológica da água está justamente na cadeia trófica que se forma no topo da areia dos filtros, com todos os microrganismos que a compõe, onde a própria comunidade ali estabelecida se encarrega de manter a estabilidade do sistema, com consórcio, predação, decomposição, simbiose, dentre outros.

A referida relevância da filtração lenta está consolidada no meio técnico, quer pela recente Portaria n 2.914 (BRASIL, 2011) quer pela Agência de Proteção Ambiental dos EUA (EPA - Environmental Protection Agency), pois ambas estabelecem, embora com distintos requisitos de qualidade, a necessidade dessa etapa na distribuição de água captada em mananciais superficiais (LIBÂNIO, 2005).

Apesar de varias tecnologias em tratamentos avançados de água estarem sendo desenvolvidas, deve-se levar em conta a aplicabilidade de tais tecnologias no Brasil, devido aos altos custos recorrentes. Em um país onde ainda há carência em saneamento básico, alternativas menos dispendiosas devem ser consideradas, como é o caso da filtração ecológica.

\section{Material e Métodos}

\subsection{Local de estudo}

O Reservatório do Lobo (também conhecido como represa do Broa) foi originalmente construído para a geração de energia elétrica em 1936 e tem sido investigado desde 1971, em vários aspectos ecológicos, a fim de se compreender o funcionamento hidrodinâmico e os processos biológicos deste raso lago artificial (RODRIGUEZ e MATSUMURA-TUNDISI, 2000). 
O reservatório foi classificado por Calijuri e Tundisi (1990) como oligomesotrófico. Os autores também identificaram algumas mudanças ambientais causadas por atividades humanas como o desmatamento, o despejo de esgotos domésticos e de fertilizantes utilizados em algumas áreas agrícolas.

A partir de uma observação do fitoplâncton no reservatório do Lobo em 1974, Nakamoto (2011) deu origem a uma discussão sobre o filtro lento de areia como um sistema ecológico de purificação da água.

A instalação piloto foi alocada à beira do reservatório do Lobo $\left(22^{\circ} 10^{\prime} 18.09 " \mathrm{~S}\right.$ 4754'5.00"W), nas dependências do CRHEA/EESC-USP. A água do reservatório do Lobo foi bombeada e utilizada para abastecer o sistema de tratamento de água (Figura 1).

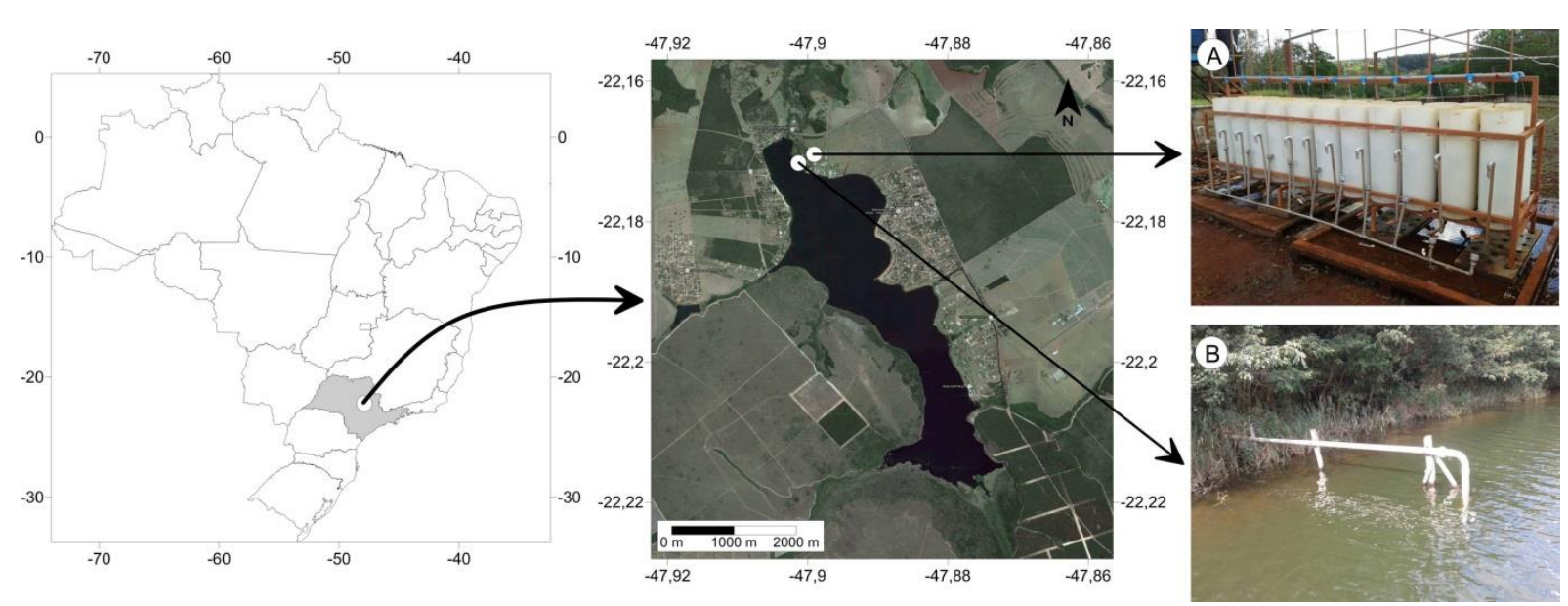

Figura 1: Mapa de localização de: A) sistema de filtração ecológica; B) local de captação de água na represa do Lobo.

\subsection{Confecção dos filtros ecológicos}

Foram confeccionados 22 filtros ecológicos idênticos, em tubo de PVC de $250 \mathrm{~mm}$ de diâmetro. Cada filtro possui $720 \mathrm{~mm}$ de altura. A camada suporte, ou base do filtro, é formada por três camadas de pedregulho, somando $15 \mathrm{~cm}$ de altura total, com granulometria de 12,5 $\mathrm{mm}$ a $1,41 \mathrm{~mm}$. O leito de areia possui $30 \mathrm{~cm}$ de altura em cada filtro, com granulometria entre 1,0 e $0,08 \mathrm{~mm}$, coeficiente de desuniformidade entre 2 e 3 e diâmetro efetivo de 0,25 mm (BELLAMY et al., 1985; DI BERNARDO, 1993). A lâmina d'água sobre a areia foi em media de $25 \mathrm{~cm}$. A Figura 3 mostra um esquema representativo de um filtro ecológico.

Os 22 filtros encontram-se alocados sob uma estrutura de ferro que contém 3,06 metros de comprimento total, 0,63 metros de largura e altura total de 1,65 metros. A caixa de 
nível constante da água que abasteceu os filtros possui 1,51 metros de altura do chão. A Figura 2 contém um esquema representativo do sistema composto por 22 filtros ecológicos.

A água utilizada neste estudo foi bombeada constantemente do Reservatório do Lobo e conduzida até uma caixa de nível constante, e posteriormente distribuída continuamente aos filtros ecológicos, conforme Figura 1. A taxa de aplicação média dos filtros foi de $3 \mathrm{~m}^{3} / \mathrm{m}^{2}$.d.
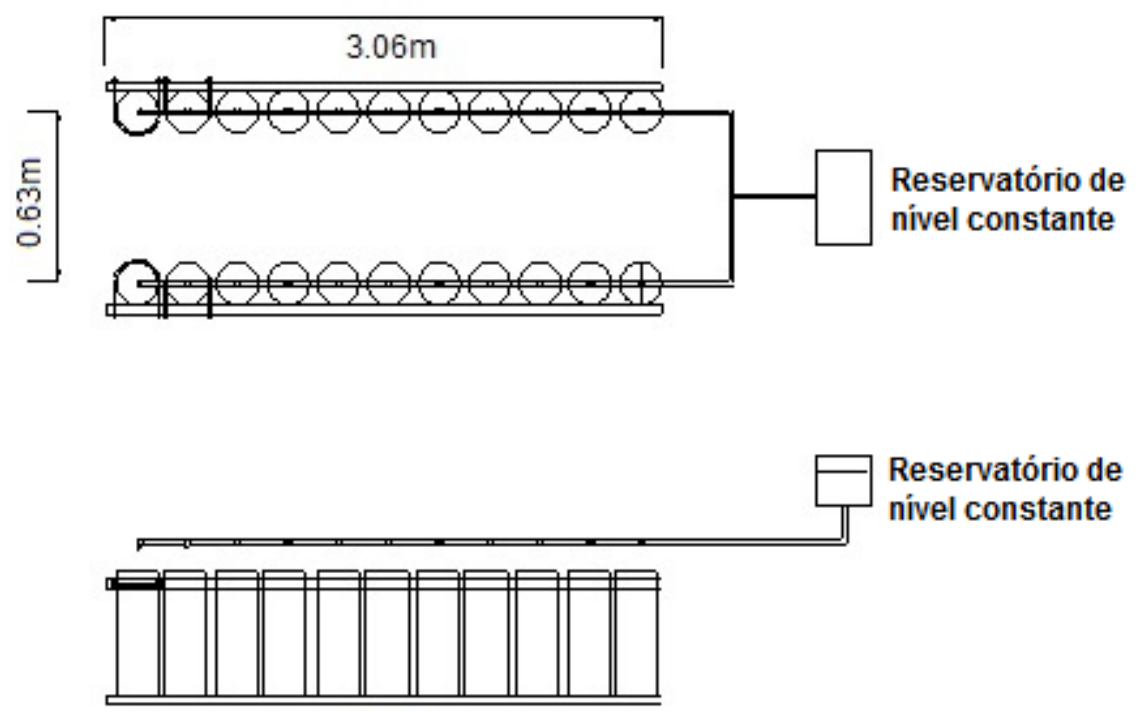

Figura 2: Esquema representativo do sistema de filtração ecológica.
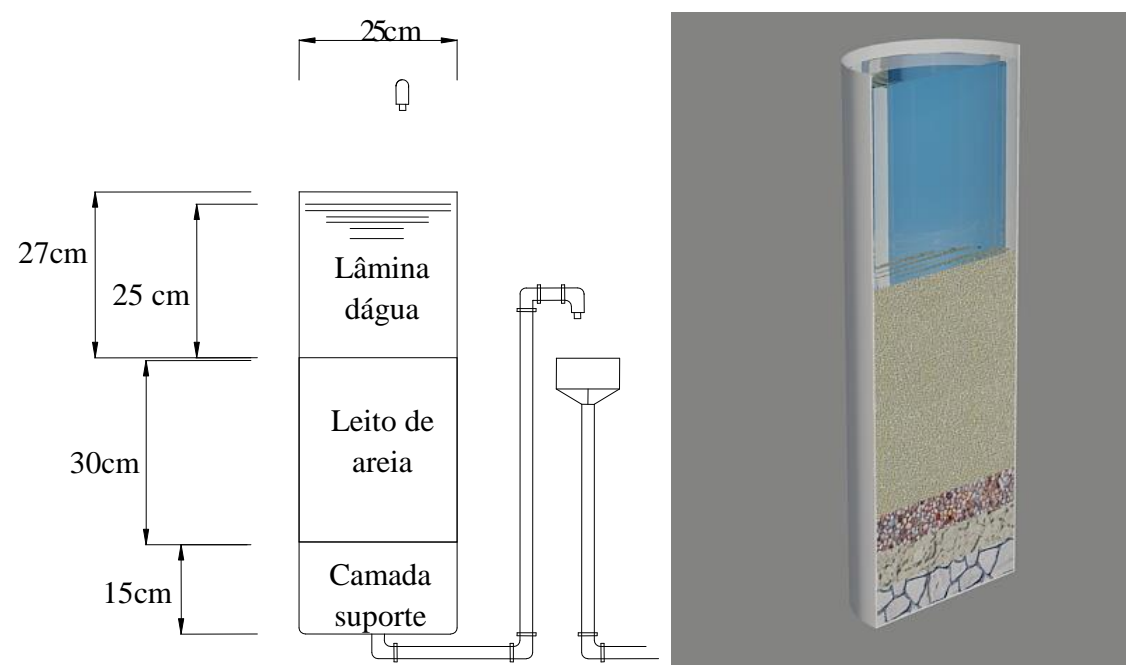

Figura 3: Esquema representativo de um filtro ecológico em corte. 


\subsection{Coleta de amostras e análises das variáveis de qualidade de água}

As amostras de água foram coletadas $(500 \mathrm{~mL})$ do afluente (água bruta do Reservatório do Lobo) e do efluente de cada filtro ecológico, três vezes por semana. As análises foram conduzidas durante os meses de setembro a dezembro de 2013, sendo que nos meses de novembro e dezembro ocorreu a contaminação dos filtros com produtos farmacêuticos e de cuidados pessoais, conforme Capítulo 2.

A turbidez da água (NTU) e a cor aparente (uC) foram medidas utilizando espectrofotômetro HACH DR 2000, selecionando as opções do equipamento em UV $455 \mathrm{~nm}$ para análises de cor e UV $750 \mathrm{~nm}$ para turbidez, conforme indicação do manual do usuário do equipamento. A cor verdadeira $(\mathrm{uC})$ foi medida com prévia filtração da água por meio de membrana 0,45 $\mu \mathrm{m}$ (Millipore, celulose, $90 \mathrm{~mm}$ de diâmetro), seguida de medição no mesmo espectrofotômetro citado anteriormente, selecionando UV $455 \mathrm{~nm}$.

$\mathrm{O}$ pH foi medido por meio de medição direta na água com o uso de pHmetro B374 Micronal. A Temperatura $\left({ }^{\circ} \mathrm{C}\right)$, os sólidos totais dissolvidos (STD) (mg L $\left.\mathrm{L}^{-1}\right)$, e a condutividade elétrica da água $\left(\mu \mathrm{S} \mathrm{cm}^{-1}\right)$ foram medidos por meio de sonda multiparâmetros Orion, modelo 145. O oxigênio dissolvido $\left(\mathrm{mg} \mathrm{L}^{-1}\right)$ foi medido utilizando-se oxímetro, YSIYellow Springs Incorporated (Ohio, USA), modelo 55-25 FT.

Exames de coliformes totais (NMP) e E. coli (NMP) foram realizadas uma vez por semana nos meses de setembro e outubro, a nos meses de novembro e dezembro quando ocorreram às contaminações nos filtros, os exames foram feitos antes e 24 horas após as contaminações. Utilizou-se o kit Colilert ${ }^{\circledR}$ para a realização dos exames, conforme instruções do fabricante.

\subsection{Análises dos dados}

Foi calculado o Desvio Padrão (DP) e o Coeficiente de Variação (CV) para avaliar como cada variável de qualidade da água variou em cada filtro ao longo do tempo e entre os filtros. As relações entre as variáveis de qualidade da água do afluente e do efluente dos filtros foram examinadas usando o teste estatístico teste-t, sendo considerado significativo o valor de $\mathrm{P}<0,05$. Estes cálculos foram feitos através do programa Microsoft Excel 2010. 


\section{Resultados e Discussões}

\subsection{Variáveis físicas, químicas e biológicas.}

Os valores médios de cada variável física e química avaliadas nos efluentes de cada Filtro Ecológico (FEco), e do afluente, durante o período que compreende os meses de setembro a dezembro de 2013 estão apresentados na Tabela 1. Foi efetuado um total de 30 medições durante o período.

Tabela 1: Valores médios de cada variável avaliada, desvios padrão (DP) e valores de P referente ao teste-t que considerou afluente e efluente, medidos nos filtros ecológicos $(n=30)$.

\begin{tabular}{|c|c|c|c|c|c|c|c|c|c|c|c|c|}
\hline \multirow[t]{2}{*}{$\begin{array}{l}\text { Ponto de } \\
\text { coleta }\end{array}$} & \multicolumn{3}{|c|}{$\begin{array}{l}\text { Temperatura } \\
\left({ }^{\circ} \mathrm{C}\right)\end{array}$} & \multicolumn{3}{|c|}{$\begin{array}{l}\text { Condutividade } \\
\text { elétrica }\left(\mu \mathrm{S} \mathrm{cm}^{1}\right)\end{array}$} & \multicolumn{3}{|c|}{$\begin{array}{c}\text { STD } \\
\left(\mathrm{mg} \mathrm{L}^{-1}\right)\end{array}$} & \multicolumn{3}{|c|}{$\mathrm{pH}$} \\
\hline & $\begin{array}{l}\text { Valor } \\
\text { médio }\end{array}$ & $\mathrm{DP}$ & $\mathrm{P}$ & $\begin{array}{l}\text { Valor } \\
\text { médio }\end{array}$ & $\mathrm{DP}$ & $\mathrm{P}$ & $\begin{array}{l}\text { Valor } \\
\text { médio }\end{array}$ & $\mathrm{DP}$ & $\mathrm{P}$ & $\begin{array}{l}\text { Valor } \\
\text { médio }\end{array}$ & DP & $\mathrm{P}$ \\
\hline Afluente & 23,18 & 1,90 & 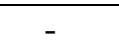 & 17,01 & 0,73 & 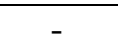 & 8,0 & 0,31 & 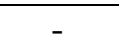 & 7,05 & 0,08 & 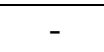 \\
\hline FEco 1 & 22,40 & 2,48 & 0,1 & 20,87 & 8,90 & $<0,0$ & 9,7 & 4,16 & $<0,05$ & 6,61 & 0,26 & 0,05 \\
\hline FEco 2 & 22,33 & 2,38 & 0,13 & 18,34 & 3,59 & 0,05 & 8,3 & 2,14 & 0,51 & 6,54 & 0,20 & $<0,05$ \\
\hline FEco 3 & 22,11 & 2,64 & 0,08 & 21,06 & 8,23 & $<0,05$ & 10,0 & 3,78 & $<0,05$ & 6,62 & 0,18 & $<0,05$ \\
\hline FEco 4 & 22,14 & 2,49 & 0,07 & 19,20 & 3,45 & $<0,05$ & 8,7 & 2,19 & 0,11 & 6,63 & 0,17 & $<0,05$ \\
\hline FEco 5 & 22,10 & 2,45 & 0,06 & 18,94 & 3,04 & $<0,05$ & 8,9 & 1,49 & $<0,05$ & 6,61 & 0,15 & $<0,05$ \\
\hline FEco 6 & 22,09 & 2,41 & 0,05 & 19,45 & 4,84 & $<0,05$ & 9,1 & 2,31 & $<0,05$ & 62 & 0,18 & $<0,05$ \\
\hline FEco 7 & 22,09 & 2,27 & 0,05 & 18,86 & 4,36 & $<0,05$ & 8,8 & 1,96 & $<0,05$ & 61 & 0,13 & $<0,05$ \\
\hline FEco 8 & 22,12 & 2,32 & 0,06 & 17,97 & 1,86 & $<0,05$ & 8,4 & 0,95 & 0,05 & 65 & 0,13 & $<0,05$ \\
\hline FEco 9 & 22,01 & 2,26 & $<0,05$ & 17,54 & 2,10 & 0,21 & 8,3 & 1,10 & 0,21 & 56 & 0,14 & $<0,05$ \\
\hline FEco 10 & 22,08 & 2,16 & $<0,05$ & 19,85 & 6,14 & $<0,05$ & 9,5 & 2,94 & $<0,05$ & 60 & 0,17 & $<0,05$ \\
\hline FECO 11 & 22,02 & 2,31 & $<0,05$ & 17,86 & 1,61 & $<0,05$ & 8,3 & 0,83 & $<0,05$ & ,57 & 0,14 & $<0,05$ \\
\hline FECO 12 & 21,83 & 2,20 & $<0,05$ & 20,10 & 4,18 & $<0,05$ & 9,5 & 2,09 & $<0,05$ & 69 & 0,20 & $<0,05$ \\
\hline FECO 13 & 21,79 & 2,24 & $<0,05$ & 19,64 & 4,20 & $<0,05$ & 9,2 & 1,98 & $<0,05$ &, 64 & 0,16 & $<0,05$ \\
\hline FEco 14 & 21,78 & 2,28 & $<0,05$ & 19,99 & 6,62 & $<0,05$ & 9,4 & 3,19 & $<0,05$ & 6,64 & 0,19 & $<0,05$ \\
\hline FEco 15 & 21,80 & 2,32 & $<0,05$ & 18,60 & 2,37 & $<0,05$ & 8,7 & 1,12 & $<0,05$ & 6,58 & 0,14 & $<0,05$ \\
\hline FEco 16 & 21,84 & 2,23 & $<0,05$ & 18,81 & 3,31 & $<0,05$ & 8,8 & 1,55 & $<0,05$ & 6,58 & 0,14 & $<0,05$ \\
\hline FEco 17 & 21,88 & 2,18 & $<0,05$ & 18,57 & 3,55 & $<0,05$ & 8,7 & 1,78 & $<0,05$ & 6,58 & 0,12 & $<0,05$ \\
\hline FEco 18 & 21,84 & 2,34 & $<0,05$ & 17,80 & 2,48 & 0,10 & 8,3 & 1,22 & 0,16 & 6,56 & 0,12 & $<0,05$ \\
\hline FEco 19 & 21,96 & 2,11 & $<0,05$ & 17,53 & 1,48 & 0,09 & 8,3 & 0,90 & 0,13 & 6,55 & 0,13 & $<0,05$ \\
\hline FEco 20 & 21,92 & 2,15 & $<0,05$ & 18,61 & 2,97 & $<0,05$ & 8,8 & 1,46 & $<0,05$ & 6,57 & 0,15 & $<0,05$ \\
\hline FEco 21 & 22,01 & 2,23 & $<0,05$ & 18,38 & 3,14 & $<0,05$ & 8,6 & 1,53 & $<0,05$ & 6,64 & 0,15 & $<0,05$ \\
\hline FEco 22 & 22,29 & 2,30 & 0,11 & 18,49 & 3,07 & $<0,05$ & 8,7 & 1,43 & $<0,05$ & 6,57 & 0,12 & $<0,05$ \\
\hline
\end{tabular}


Continuação da Tabela 1:

\begin{tabular}{|c|c|c|c|c|c|c|c|c|c|c|c|c|}
\hline \multirow[t]{2}{*}{$\begin{array}{l}\text { Ponto } \\
\text { de } \\
\text { coleta }\end{array}$} & \multicolumn{3}{|c|}{$\begin{array}{l}\text { Turbidez } \\
\text { (NTU) }\end{array}$} & \multicolumn{3}{|c|}{$\begin{array}{c}\text { Cor aparente } \\
\text { (uC) }\end{array}$} & \multicolumn{3}{|c|}{$\begin{array}{c}\text { Cor verdadeira } \\
\text { (uC) }\end{array}$} & \multicolumn{3}{|c|}{$\begin{array}{c}\mathrm{OD} \\
\left(\mathrm{mg} \mathrm{L}^{-1}\right)\end{array}$} \\
\hline & $\begin{array}{l}\text { Valor } \\
\text { médio }\end{array}$ & DP & $\mathrm{P}$ & $\begin{array}{l}\text { Valor } \\
\text { médio }\end{array}$ & DP & $\mathrm{P}$ & $\begin{array}{l}\text { Valor } \\
\text { médio }\end{array}$ & DP & $\mathrm{P}$ & $\begin{array}{l}\text { Valor } \\
\text { médio }\end{array}$ & $\mathrm{DP}$ & $\mathrm{P}$ \\
\hline Afluente & 7,4 & 1,76 & - & 38,86 & 6,60 & - & 7,60 & 7,23 & - & 7,19 & 0,43 & - \\
\hline FEco 1 & 3,4 & 1,72 & $<0,05$ & 20,13 & 8,43 & $<0,05$ & 1,36 & 2,54 & $<0,05$ & 6,84 & 0,64 & 0,12 \\
\hline FEco 2 & 1,7 & 1,00 & $<0,05$ & 10,30 & 6,97 & $<0,05$ & $<1$ & 2,06 & $<0,05$ & 6,55 & 0,68 & $<0,05$ \\
\hline FEco 3 & 3,9 & 2,14 & $<0,05$ & 16,20 & 12,79 & $<0,05$ & $<1$ & 1,80 & $<0,05$ & 6,52 & 0,62 & $<0,05$ \\
\hline FEco 4 & 3,4 & 2,57 & $<0,05$ & 26,63 & 14,03 & $<0,05$ & 1,80 & 4,25 & $<0,05$ & 6,67 & 0,65 & $<0,05$ \\
\hline FEco 5 & 3,6 & 3,47 & $<0,05$ & 19,96 & 19,52 & $<0,05$ & 1,96 & 5,02 & $<0,05$ & 6,51 & 0,62 & $<0,05$ \\
\hline FEco 6 & 3,2 & 2,35 & $<0,05$ & 19,90 & 14,14 & $<0,05$ & 1,60 & 3,33 & $<0,05$ & 6,59 & 0,52 & $<0,05$ \\
\hline FEco 7 & 3,4 & 2,10 & $<0,05$ & 19,30 & 15,78 & $<0,05$ & 1,00 & 2,52 & $<0,05$ & 6,60 & 0,65 & $<0,05$ \\
\hline FEco 8 & 3,8 & 3,55 & $<0,05$ & 22,56 & 23,47 & $<0,05$ & 2,40 & 4,82 & $<0,05$ & 6,53 & 0,62 & $<0,05$ \\
\hline FEco 9 & 2,7 & 2,12 & $<0,05$ & 18,33 & 16,42 & $<0,05$ & 1,72 & 3,07 & $<0,05$ & 6,67 & 0,55 & $<0,05$ \\
\hline FEco 10 & 3,4 & 3,20 & $<0,05$ & 19,93 & 19,86 & $<0,05$ & 1,28 & 2,63 & $<0,05$ & 6,58 & 0,67 & $<0,05$ \\
\hline FEco 11 & 2,7 & 2,22 & $<0,05$ & 15,26 & 12,44 & $<0,05$ & $<1$ & 1,97 & $<0,05$ & 6,60 & 0,54 & $<0,05$ \\
\hline FEco 12 & 3,4 & 3,17 & $<0,05$ & 19,76 & 18,20 & $<0,05$ & 1,64 & 3,12 & $<0,05$ & 6,99 & 0,55 & 0,12 \\
\hline FEco 13 & 4,8 & 3,07 & $<0,05$ & 26,13 & 18,48 & $<0,05$ & 2,08 & 5,07 & $<0,05$ & 6,76 & 0,70 & 0,07 \\
\hline FEco 14 & 4,0 & 3,83 & $<0,05$ & 20,00 & 20,83 & $<0,05$ & 2,20 & 4,33 & $<0,05$ & 6,72 & 0,61 & $<0,05$ \\
\hline FEco 15 & 3,5 & 3,12 & $<0,05$ & 19,30 & 18,69 & $<0,05$ & 1,72 & 3,42 & $<0,05$ & 6,39 & 0,66 & $<0,05$ \\
\hline FEco 16 & 3,9 & 3,49 & $<0,05$ & 20,60 & 20,52 & $<0,05$ & 1,92 & 4,62 & $<0,05$ & 6,54 & 0,54 & $<0,05$ \\
\hline FEco 17 & 3,5 & 3,27 & $<0,05$ & 19,16 & 18,23 & $<0,05$ & 2,04 & 3,78 & $<0,05$ & 6,47 & 0,61 & $<0,05$ \\
\hline FEco 18 & 2,7 & 2,13 & $<0,05$ & 14,76 & 12,30 & $<0,05$ & 1,48 & 3,15 & $<0,05$ & 6,59 & 0,57 & $<0,05$ \\
\hline FEco 19 & 2,8 & 2,42 & $<0,05$ & 17,30 & 17,36 & $<0,05$ & 1,64 & 3,36 & $<0,05$ & 6,47 & 0,54 & $<0,05$ \\
\hline FEco 20 & 3,0 & 2,60 & $<0,05$ & 16,43 & 12,78 & $<0,05$ & 1,60 & 3,37 & $<0,05$ & 6,76 & 0,60 & 0,05 \\
\hline FEco 21 & 3,4 & 2,49 & $<0,05$ & 18,40 & 16,66 & $<0,05$ & 1,40 & 2,74 & $<0,05$ & 6,82 & 0,61 & 0,10 \\
\hline FEco 22 & 3,1 & 2,20 & $<0,05$ & 16,80 & 11,88 & $<0,05$ & 1.36 & 3,01 & $<0,05$ & 6,67 & 0,58 & $<0,05$ \\
\hline
\end{tabular}

Para determinar a variabilidade entre os 22 filtros ecológicos calcularam-se o desvio padrão (DP) e o Coeficiente de Variação (CV) que está expresso em porcentagem, em cada coleta feita de setembro a dezembro de 2013, e encontram-se na Tabela 2. 
Tabela 2: Valores calculados de desvio padrão (DP), e coeficiente de variação (CV) - expresso em porcentagem, a partir dos valores médios dos 22 filtros ecológicos de cada variável física e química de qualidade da água medidos no efluente dos filtros.

\begin{tabular}{|c|c|c|c|c|c|c|c|c|c|c|c|c|c|c|c|c|}
\hline \multirow[b]{3}{*}{ Coletas } & \multicolumn{16}{|c|}{ Variáveis } \\
\hline & \multicolumn{2}{|c|}{ Temp. } & \multicolumn{2}{|c|}{ Cond. } & \multicolumn{2}{|c|}{ STD } & \multicolumn{2}{|c|}{$\mathrm{pH}$} & \multicolumn{2}{|c|}{ Turbidez } & \multicolumn{2}{|c|}{ Cor ap. } & \multicolumn{2}{|c|}{ Cor verd. } & \multicolumn{2}{|c|}{ OD } \\
\hline & DP & $\mathrm{CV}$ & DP & $\mathrm{CV}$ & DP & $\mathrm{CV}$ & DP & $\mathrm{CV}$ & DP & $\mathrm{CV}$ & DP & $\mathrm{CV}$ & DP & $\mathrm{CV}$ & DP & $\mathrm{CV}$ \\
\hline 1 & 0,54 & 0,03 & 1,24 & 7,61 & 0,78 & 0,10 & 0,07 & 0,01 & 2,60 & 0,29 & 16,55 & 0,34 & & - & & - \\
\hline 2 & 0,29 & 0,01 & 0,99 & 5,70 & 0,55 & 0,07 & 0,06 & 0,01 & 2,51 & 0,40 & 16,44 & 0,34 & - & 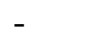 & - & - \\
\hline 3 & 0,52 & 0,02 & 3,08 & 18,12 & 1,49 & 0,19 & 0,08 & 0,01 & 3,20 & 0,30 & 21,93 & 0,33 & - & - & - & - \\
\hline 4 & 0,62 & 0,03 & 1,76 & 10,32 & 0,85 & 0,11 & 0,07 & 0,01 & 2,86 & 0,36 & 12,81 & 0,29 & - & 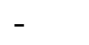 & - & - \\
\hline 5 & 0,40 & 0,02 & 3,74 & 19,30 & 1,73 & 0,19 & 0,09 & 0,01 & 1,37 & 0,40 & 8,00 & 0,38 & 4,15 & 0,42 & - & - \\
\hline 6 & 0,18 & 0,01 & 7,33 & 32,72 & 3,50 & 0,33 & 0,16 & 0,02 & 1,42 & 0,43 & 8,39 & 0,51 & - & - & - & - \\
\hline 7 & 0,48 & 0,02 & 1,52 & 8,61 & 0,72 & 0,09 & 0,08 & 0,01 & 1,64 & 0,34 & 9,68 & 0,67 & 4,38 & 0,89 & - & - \\
\hline 8 & 0,67 & 0,04 & 1,15 & 5,80 & 0,66 & 0,07 & 0,05 & 0,01 & 1,22 & 0,53 & 4,80 & 0,55 & 2,48 & 0,94 & - & - \\
\hline 9 & 0,42 & 0,02 & 1,05 & 5,08 & 0,57 & 0,06 & 0,07 & 0,01 & 0,67 & 0,17 & 4,22 & 0,59 & 2,83 & 1,33 & - & - \\
\hline 10 & 0,69 & 0,03 & 2,76 & 13,49 & 2,24 & 0,24 & 0,13 & 0,02 & 2,64 & 0,59 & 11,07 & 0,46 & 5,44 & 0,52 & - & - \\
\hline 11 & 0,37 & 0,02 & 5,71 & 29,82 & 2,68 & 0,30 & 0,12 & 0,02 & 1,10 & 0,35 & 5,28 & 0,23 & 2,54 & 0,53 & - & - \\
\hline 12 & 0,34 & 0,02 & 1,55 & 8,75 & 1,52 & 0,17 & 0,14 & 0,02 & 0,89 & 0,31 & 2,55 & 0,13 & 0,60 & 0,77 & - & - \\
\hline 13 & 0,80 & 0,03 & 6,59 & 26,73 & 3,11 & 0,27 & 0,16 & 0,02 & 1,02 & 0,52 & 5,37 & 0,61 & 2,34 & 0,63 & - & - \\
\hline 14 & 0,44 & 0,02 & 2,64 & 13,70 & 2,13 & 0,25 & 0,12 & 0,02 & 0,89 & 0,31 & 5,01 & 0,29 & 0,00 & 0,00 & - & - \\
\hline 15 & 0,40 & 0,02 & 3,45 & 18,42 & 1,62 & 0,18 & 0,11 & 0,02 & 0,47 & 0,16 & 3,71 & 0,22 & 0,49 & 2,69 & - & - \\
\hline 16 & 0,31 & 0,01 & 5,34 & 24,35 & 2,49 & 0,24 & 0,17 & 0,02 & 0,98 & 0,70 & 4,12 & 0,39 & 0,00 & 0,00 & - & - \\
\hline 17 & 0,23 & 0,01 & 2,53 & 13,64 & 1,33 & 0,15 & 0,13 & 0,02 & 0,81 & 0,94 & 4,52 & 0,46 & 0,00 & 0,00 & - & - \\
\hline 18 & 0,41 & 0,02 & 1,63 & 9,54 & 0,71 & 0,09 & 0,08 & 0,01 & 0,60 & 0,27 & 3,79 & 0,37 & 0,00 & 0,00 & 0,23 & 0,03 \\
\hline 19 & 0,14 & 0,01 & 10,88 & 47,83 & 5,05 & 0,47 & 0,17 & 0,02 & 1,73 & 0,78 & 5,95 & 0,59 & 0,21 & 4,58 & 0,04 & 0,01 \\
\hline 20 & 0,38 & 0,02 & 0,83 & 5,19 & 0,58 & 0,08 & 0,07 & 0,01 & 0,50 & 0,20 & 2,24 & 0,14 & 0,21 & 4,58 & 0,22 & 0,03 \\
\hline 21 & 0,72 & 0,04 & 0,74 & 4,51 & 0,49 & 0,06 & 0,06 & 0,01 & 1,10 & 0,84 & 3,07 & 0,54 & 0,00 & 0,00 & 0,26 & 0,04 \\
\hline 22 & 0,19 & 0,01 & 0,55 & 3,18 & 0,29 & 0,04 & 0,07 & 0,01 & 0,45 & 1,63 & 2,83 & 0,39 & 0,00 & 0,00 & 0,40 & 0,06 \\
\hline 23 & 0,25 & 0,01 & 8,67 & 38,34 & 4,18 & 0,39 & 0,27 & 0,04 & 2,87 & 0,94 & 14,62 & 0,84 & 0,00 & 0,00 & 0,43 & 0,07 \\
\hline 24 & 0,18 & 0,01 & 2,98 & 16,73 & 1,47 & 0,17 & 0,12 & 0,02 & 0,47 & 0,24 & 3,55 & 0,31 & 0,00 & 0,00 & 0,26 & 0,04 \\
\hline 25 & 0,31 & 0,01 & 2,82 & 13,19 & 1,41 & 0,14 & 0,14 & 0,02 & 0,97 & 0,34 & 1,95 & 0,20 & 0,00 & 0,00 & 0,29 & 0,04 \\
\hline 26 & 0,17 & 0,01 & 1,10 & 5,91 & 0,69 & 0,08 & 0,08 & 0,01 & 0,21 & 0,11 & 1,37 & 0,09 & 0,00 & 0,00 & 0,17 & 0,03 \\
\hline 27 & 0,09 & 0,00 & 0,68 & 3,97 & 0,29 & 0,04 & 0,07 & 0,01 & 0,49 & 0,27 & 2,52 & 0,24 & 0,00 & 0,00 & 0,21 & 0,03 \\
\hline 28 & 0,11 & 0,00 & 1,62 & 8,82 & 0,88 & 0,10 & 0,07 & 0,01 & 0,00 & 0,00 & 2,46 & 0,22 & 0,00 & 0,00 & 0,28 & 0,05 \\
\hline 29 & 1,05 & 0,04 & 1,67 & 9,93 & 0,83 & 0,11 & 0,14 & 0,02 & 0,52 & 0,29 & 2,45 & 0,34 & 0,00 & 0,00 & 0,30 & 0,05 \\
\hline 30 & 0,17 & 0,01 & 1,17 & 6,66 & 0,63 & 0,08 & 0,09 & 0,01 & 0,55 & 1,74 & 4,84 & 0,96 & 0,00 & 0,00 & 0,16 & 0,03 \\
\hline
\end{tabular}

A temperatura média da água aferida no afluente dos filtros $\left(23,18{ }^{\circ} \mathrm{C}\right)$ esteve superior à da água de efluente dos filtros ecológicos $\left(22,02{ }^{\circ} \mathrm{C}\right)$. As flutuações de temperatura da água observadas nos efluentes dos filtros acompanharam as observadas na água afluente aos filtros, ao longo do tempo (Figura 4).

Os filtros ecológicos FEco 1, 2, 3. 4, 5, 8 e 22 não apresentaram diferenças significativas entre afluente e efluente $(P \geq 0,05)$, enquanto os demais filtros apresentaram diferenças $(\mathrm{P} \leq 0,05)$ (Tabela 1$)$. Ao longo do tempo de análise, houve pouca variabilidade de temperatura da água no efluente dos filtros (Tabela 2), com coeficiente de variação (CV) $<0,1 \%$ em todas as coletas realizadas. 


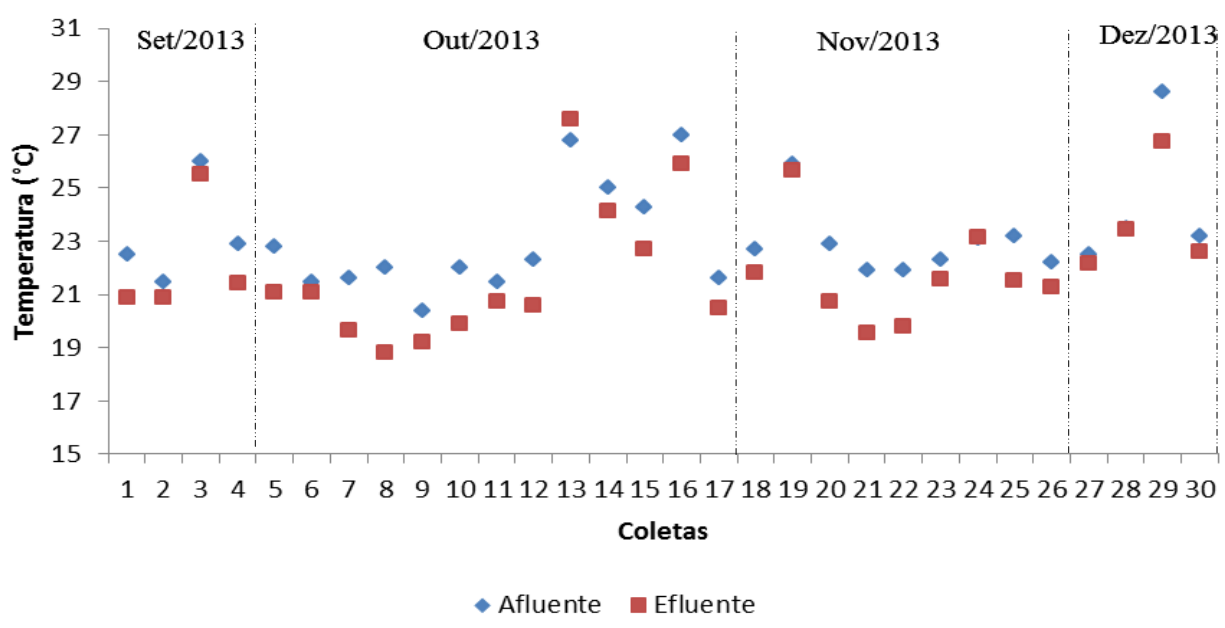

Figura 4: Temperatura média da água no afluente e efluente dos filtros ecológicos.

A condutividade elétrica da água média foi menor no afluente dos filtros $(17,01 \mu \mathrm{S}$ $\left.\mathrm{cm}^{1}\right)$ do que no efluente $\left(\mu \mathrm{S} \mathrm{cm}^{1}\right)$, com diferença significativa em quase todos os casos entre afluente e efluente dos filtros $(\mathrm{P} \leq 0,05)$ (Tabela 1), com exceção do filtro FEco $9(\mathrm{P}=0,21)$, FEcco $18(\mathrm{P}=0,10)$, FEco $19(\mathrm{P}=0,09)$.

Entre os parâmetros físico-químicos de qualidade da água, a condutividade elétrica teve as maiores variações entre os filtros ecológicos ao longo do tempo de coleta, confirmados pelos altos valores do coeficiente de variação (CV), que nas coletas $6 ; 11 ; 13 ; 16 ; 19$ e 23 foi acima de 20\% (Tabela 2). Isensee (1976), baseando-se em análises realizadas em mesocosmos, sugeriu que o limite superior considerado adequado fosse entre 20 e 30\%; considera-se este conceito para este caso, três coletas ainda permanecem acima do limite. Porém, o valor médio do coeficiente de variação da condutividade elétrica entre os filtros ecológicos foi de $14,53 \%$.

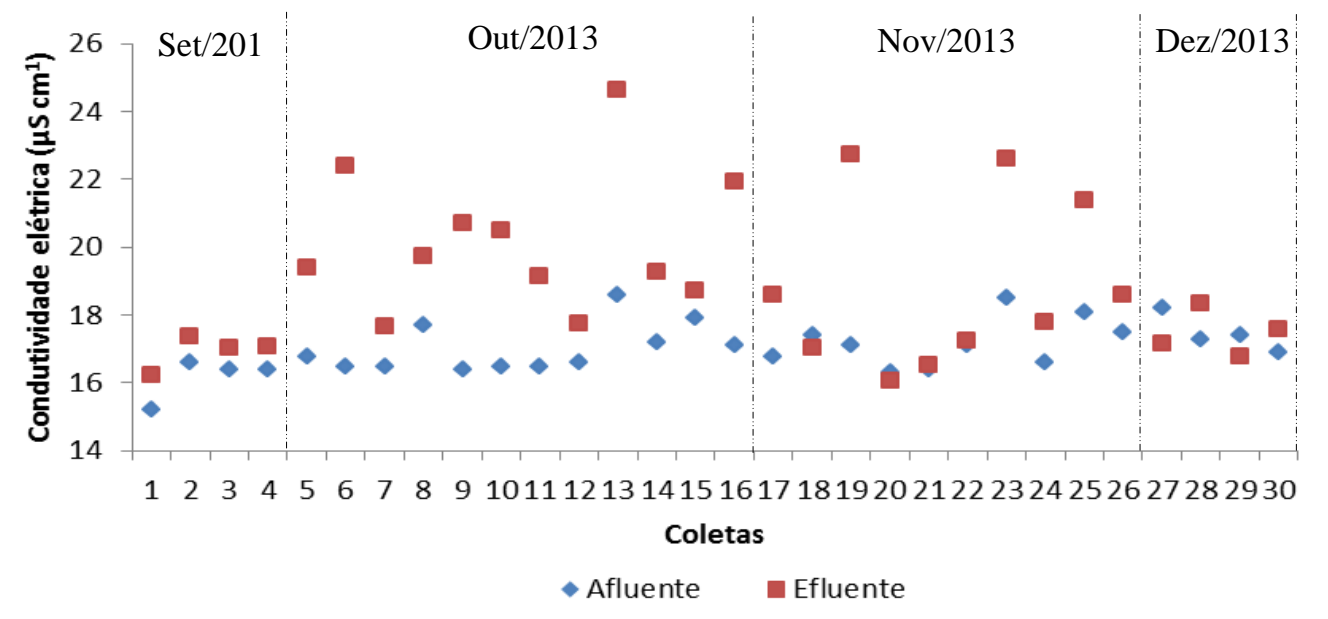

Figura 5: Condutividade elétrica média da água no afluente e efluente dos filtros ecológicos. 
A variável sólidos totais dissolvidos (STD) (Figura 6) teve maior concentração média no efluente dos filtros $\left(8,89 \mathrm{mg} \mathrm{L}^{-1}\right)$ do que no afluente $\left(8,03 \mathrm{mg} \mathrm{L}^{-1}\right)$, com diferença significativa entre a água de entrada e de saída dos filtros em quase todos os casos $(\mathrm{P} \leq 0,05)$ (Tabela 1). Entre os 22 filtros ecológicos durante o período de estudo, a variação média da variável foi pequena ( $\mathrm{DP}=1,91 ; \mathrm{CV}=0,16 \%)$. Na Figura 6 observa-se que houve variações nos valores de efluente dos filtros, se comparado com o afluente dos mesmos.

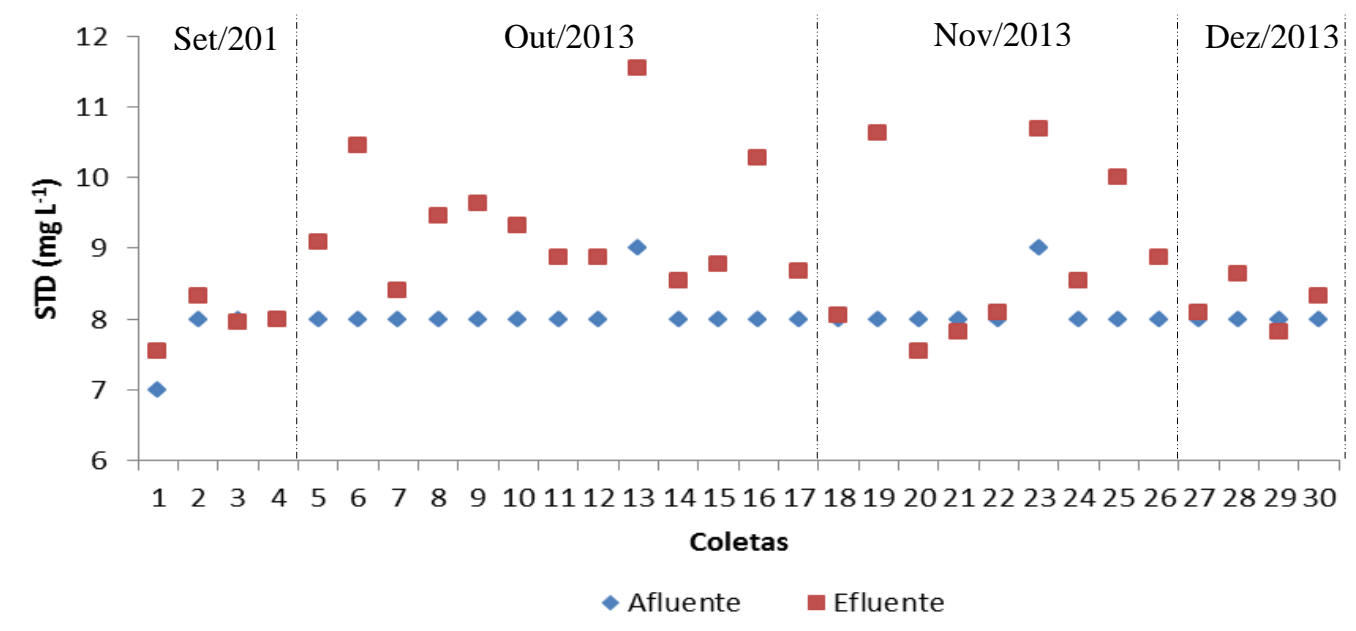

Figura 6: Sólidos totais dissolvidos (STD) médio da água no afluente e efluente dos filtros ecológicos.

Na Figura 7 observa-se o pH médio no afluente e efluente dos filtros ecológicos ao longo do tempo de operação dos filtros (coletas).

$\mathrm{O} \mathrm{pH}$ teve valores médios maiores no afluente dos filtros $(7,05)$ do que no efluente dos filtros $(6,60)$, com diferença significativa $(\mathrm{P} \leq 0,05)$ para todos os filtros ecológicos. De acordo com Nakamoto (2008), na presença da luz, que ativa o processo fotossintético, há aumento do pH da água e do oxigênio dissolvido, e com isso, várias matérias são transformadas em compostos de hidróxidos e se sedimentam, e pela ação dos microorganismos, a atividade de decomposição se acelera. No caso deste estudo, tal fenômeno pode ser observado com maior valor de $\mathrm{pH}$ no afluente dos filtros ecológicos, e após o processo de filtração, há queda de $\mathrm{pH}$.

Os valores aferidos se enquadram na faixa recomendada $\left(6,0\right.$ a 9,5) pela portaria $\mathrm{n}^{\circ}$ 2.914/2011, que estabelece os padrões de potabilidade da água vigentes no Brasil (BRASIL, 2011). De acordo com Oliveira e Pelegrini, (2008) a faixa de $\mathrm{pH}$ entre 6,5 e 9,5 é o considerado ótimo para o crescimento bacteriano, garantindo o crescimento e manutenção dos microrganismos que compõem o biofilme dos filtros ecológicos. 
A Tabela 2 mostra que houve pouca variação de $\mathrm{pH}$ entre os filtros ecológicos, com valores médios de $\mathrm{DP}=0,16$ e $\mathrm{CV}=0,02 \%$.

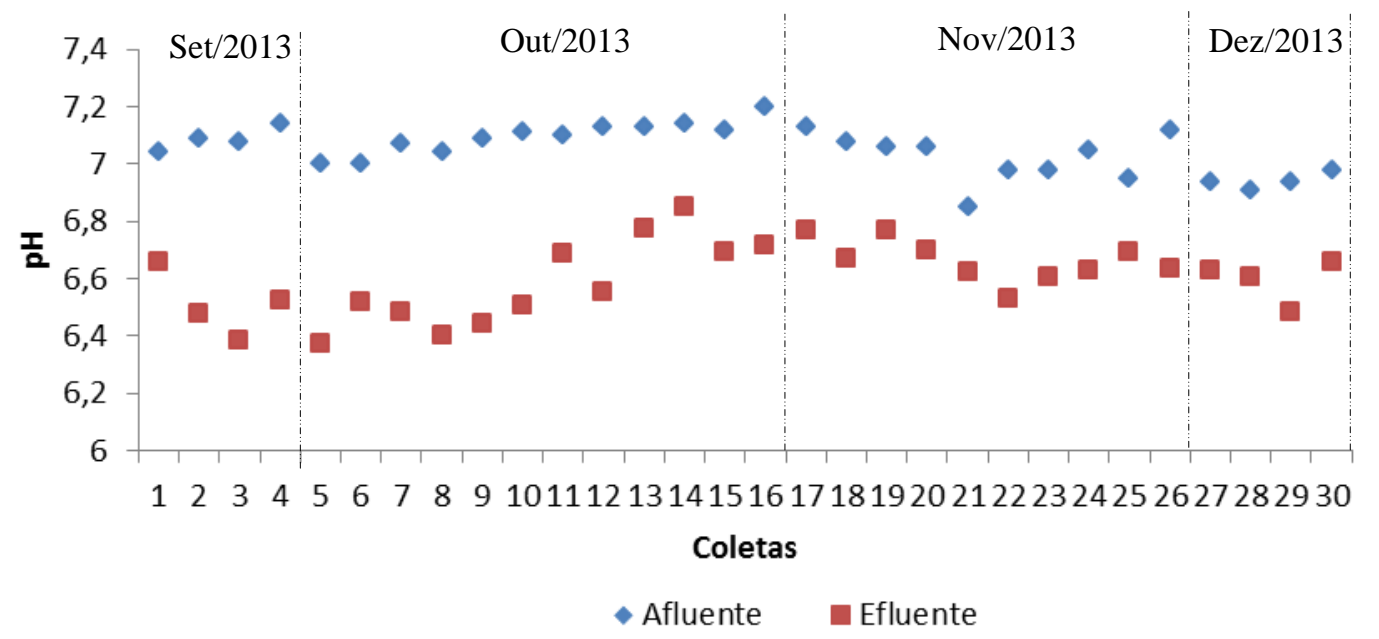

Figura 7: Valores médios de pH aferidos no afluente e efluente dos filtros ecológicos.

A turbidez da água é uma variável de fundamental importância para indicar a eficiência do filtro ecológico, juntamente com o monitoramento da remoção de coliformes.

Neste estudo, a turbidez média do afluente aos filtros foi de 7,40 NTU, dentro do limite sugerido por Sharpe et al., (1994) para o uso da filtração lenta de valor menor que 10 NTU. Na coleta 3 (Set/2013) o valor de turbidez no afluente esteve acima (12 NTU), e observa-se que a remoção pelo filtro não foi boa (16,66 \%), com valor médio final de 10 NTU (Tabela 1, Figura 8), confirmando que turbidez de 10 NTU ou mais, não é indicada, pois além disso, pode ocasionar a colmatação dos filtros rapidamente.

Observa-se na Figura 8 que até o dia 4 (Set/2013) de coleta a turbidez media no efluente dos filtros foi de 8,39, indicando que os filtros ainda não estavam maturados. Após esta data, houve melhora na remoção de turbidez pelos filtros, caracterizando o aumento da eficiência de remoção devido ao desenvolvimento da comunidade microbiológica no interior do meio filtrante (maturação dos filtros).

O valor médio afluente, considerando todos os dias de coleta, (7,4 NTU), foi maior que o valor efluente, em media considerando todos os filtros (3,21 NTU), sendo que houve diferença significativa $(\mathrm{P} \leq 0,05)$ em todos os filtros (Tabela 1$)$, com porcentagem media de remoção de 64,96 \% entre os filtros e em todo o período analisado. 
A linha verde na Figura 8 indica o valor máximo permitido de 1,0 NTU para água filtrada por filtração lenta, estabelecidos no Anexo II da portaria $n^{\circ}$ 2.914/2011, que estabelece os padrões de potabilidade da água vigentes no Brasil (BRASIL, 2011), em media, os filtros estiveram acima (3,21 NTU) do valor permitido, enquadrando-se apenas nas datas de coleta 17 (0,86 NTU), 22 (0,27 NTU) e 30 (0,31 NTU) (Figura 8).

De acordo com cálculos apresentados na Tabela 2, observa-se que a turbidez teve pouca variação entre os filtros, com valores médios de $\mathrm{DP}=2,62$ e $\mathrm{CV}=0,49 \%$.

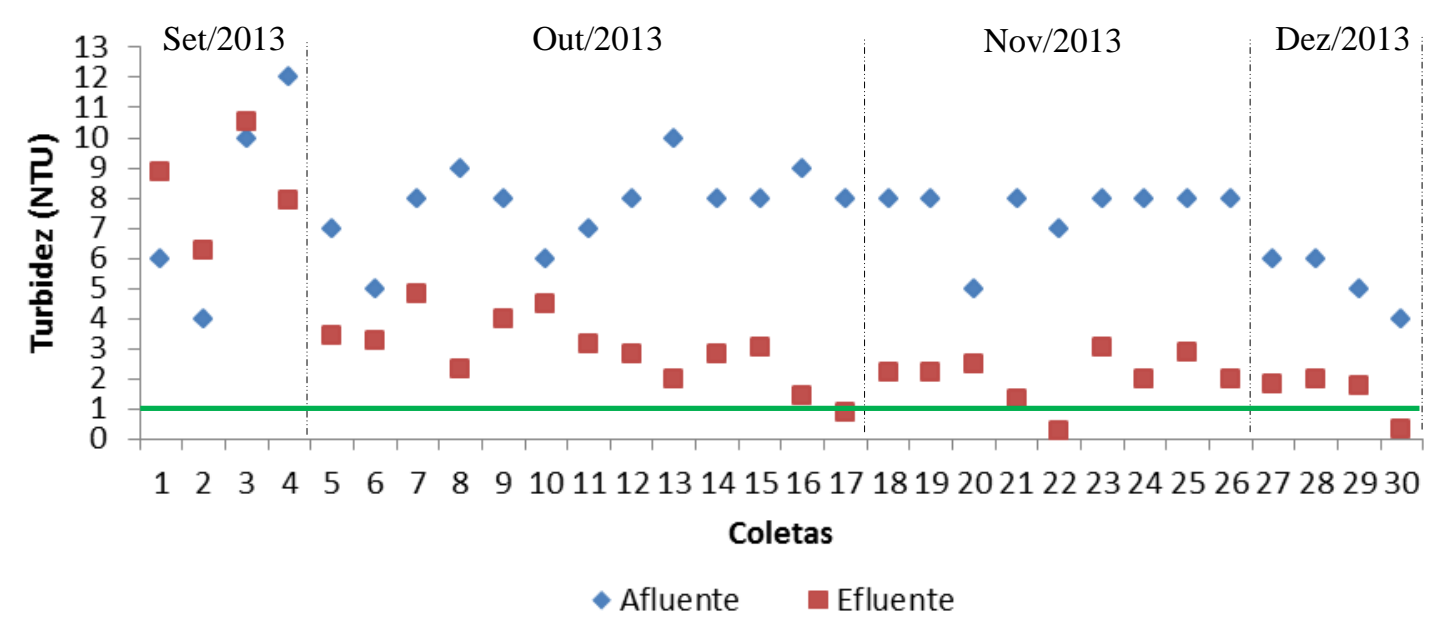

Figura 8: Valores médios de turbidez (NTU) aferidos no afluente e efluente dos filtros ecológicos.

A cor aparente (Figura 9) comportou-se similarmente à turbidez (Figura 8) ao longo do tempo nos filtros ecológicos. O valor médio no afluente $(38,86 \mathrm{uC})$ foi maior que o do efluente $(18,09 \mathrm{uC})$, com diferença significativa entre afluente e efluente $(\mathrm{P} \leq 0,05)$. A porcentagem media de remoção de cor aparente considerando todos os filtros e todo tempo de análise, foi de $57,78 \%$. Não houve remoção de cor aparente pelos filtros nas coletas feitas em setembro, confirmando os dados de remoção de turbidez e indicando que os filtros ainda não estavam maturados no período (Figura 9).

A linha verde na Figura 9 indica o valor máximo de cor aparente permitido de $15 \mathrm{uC}$ para o padrão organoléptico de potabilidade da água no Brasil, disponível no anexo $\mathrm{X}$ da portaria $\mathrm{n}^{\circ}$ 2.914/2011(BRASIL, 2011), indicando que os filtros estiveram fora do limite permitido em algumas datas de coleta.

A Tabela 2 mostra que houve pouca variação de cor aparente entre os filtros ecológicos, com valores médios de $\mathrm{DP}=15,90$ e $\mathrm{CV}=0,40 \%$. 


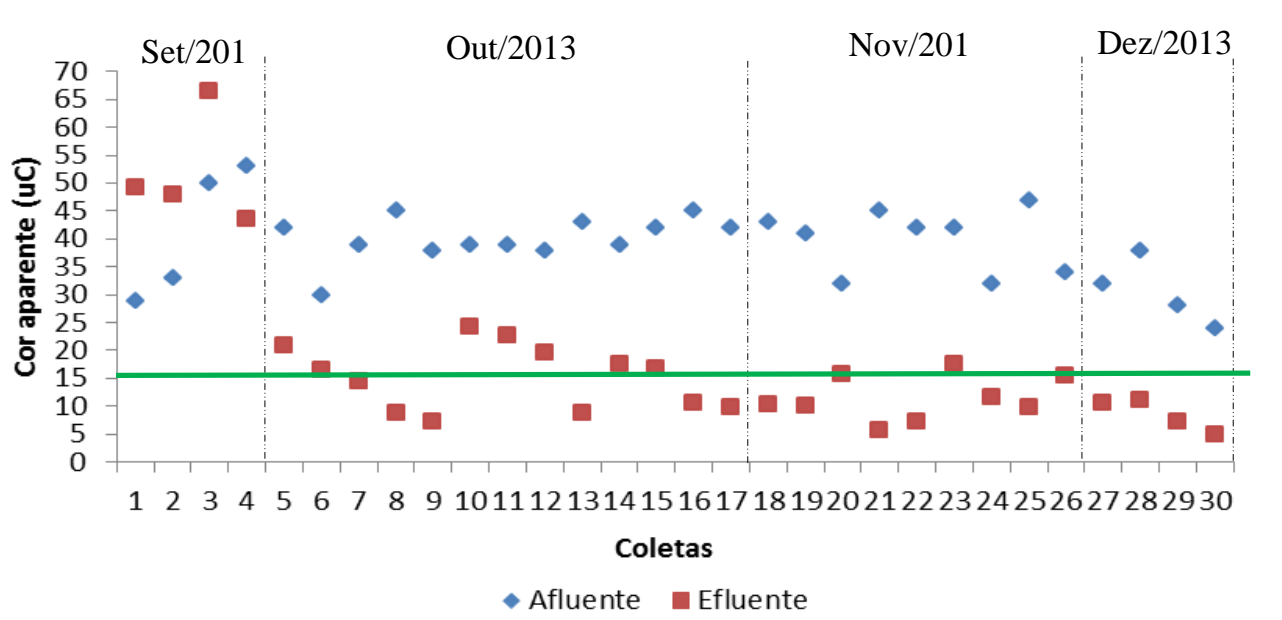

Figura 9: Valores médios de cor aparente (uC) aferidos no afluente e efluente dos filtros ecológicos.

A cor verdadeira começou a ser avaliada a partir de outubro/2013, 5 coleta (Figura 10). A partir da $14^{\mathrm{a}}$ coleta, a remoção foi de $100 \%$. O valor médio detectado no afluente dos filtros $(7,6 \mathrm{uC})$ esteve maior que no efluente $(1,58 \mathrm{uC})$, com diferença significativa $(\mathrm{P} \leq 0,05)$ em todos os filtros. A porcentagem média de remoção de cor aparente pelos filtros, considerando todos os filtros e todo tempo de analise foi de 90,47\%. A eficiência na remoção de cor aparente é compatível com as citações na literatura, dependendo da faixa de cor aparente afluente aos filtros ecológicos. Collins et al., (1992) descreveram eficiência na remoção de cor variando de 40 a $80 \%$ e Visscher (1990) considera uma faixa mais ampla, de 30 a $100 \%$.

A Tabela 2 mostra que houve pouca variação de cor aparente entre os filtros ecológicos, com valores médios de $\mathrm{DP}=3,48$ e $\mathrm{CV}=0,72 \%$.

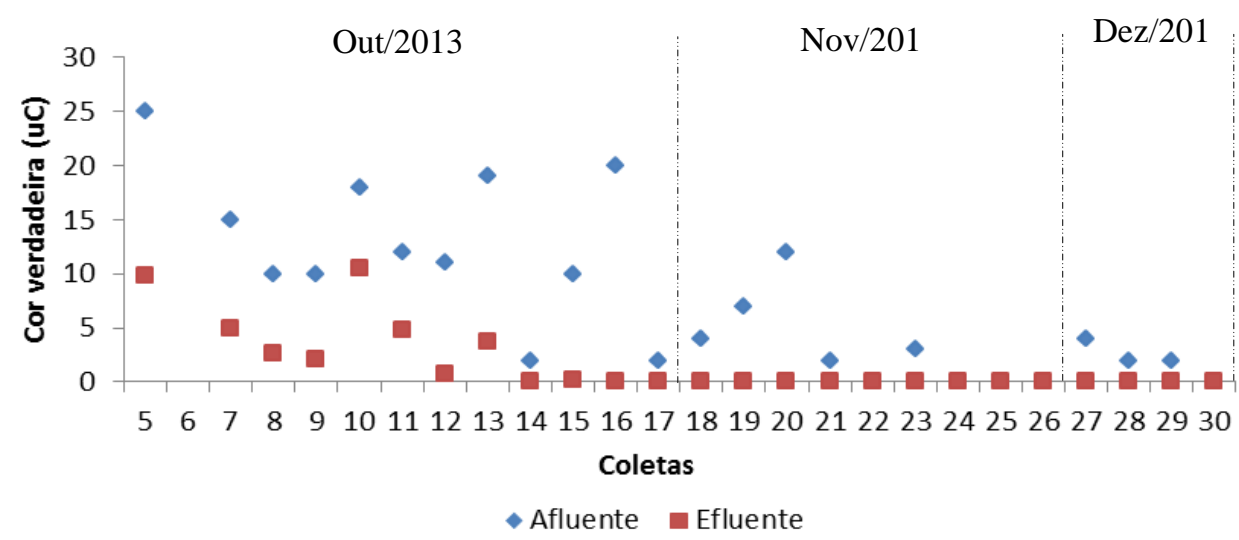

Figura 10: Valores médios de cor verdadeira (uC) aferidos no afluente e efluente dos filtros ecológicos. 
O valor médio de OD medido no afluente dos filtros $\left(7,19 \mathrm{mg} \mathrm{L}^{-1}\right)$ foi maior que o de efluente $\left(6,63 \mathrm{mg} \mathrm{L}^{-1}\right)$, com diferença significativa $(\mathrm{P} \leq 0,05)$ entre afluente e efluente para todos os filtros (Tabela 1, Figura 11). O que ocorreu com esta variável pode ser comparado com o ocorrido com o $\mathrm{pH}$.

De acordo com Nakamoto (2008), a presença de luz que ativa a fotossíntese faz com que o pH da água aumente e, várias matérias são transformadas em compostos de hidróxidos e se sedimentam. A água rica em oxigênio dissolvido propicia a oxidação de matérias, facilitando a sua precipitação e, pela ação dos microorganismos, a atividade de decomposição se acelera. A queda no oxigênio dissolvido observada no efluente dos filtros ecológicos indica consumo de oxigênio dissolvido por microrganismos

O indicado para uma adequada oxidação da matéria orgânica, é a concentração de oxigênio dissolvido superior a $3,0 \mathrm{mg} \mathrm{L}^{-1}$, ou as condições serão anaeróbias, formando produtos como metano, hidrogênio, sulfeto de hidrogênio, amônia e outras substâncias que podem causar gosto e odor à água (HESPANHOL, 1987; DI BERNARDO, 1993).

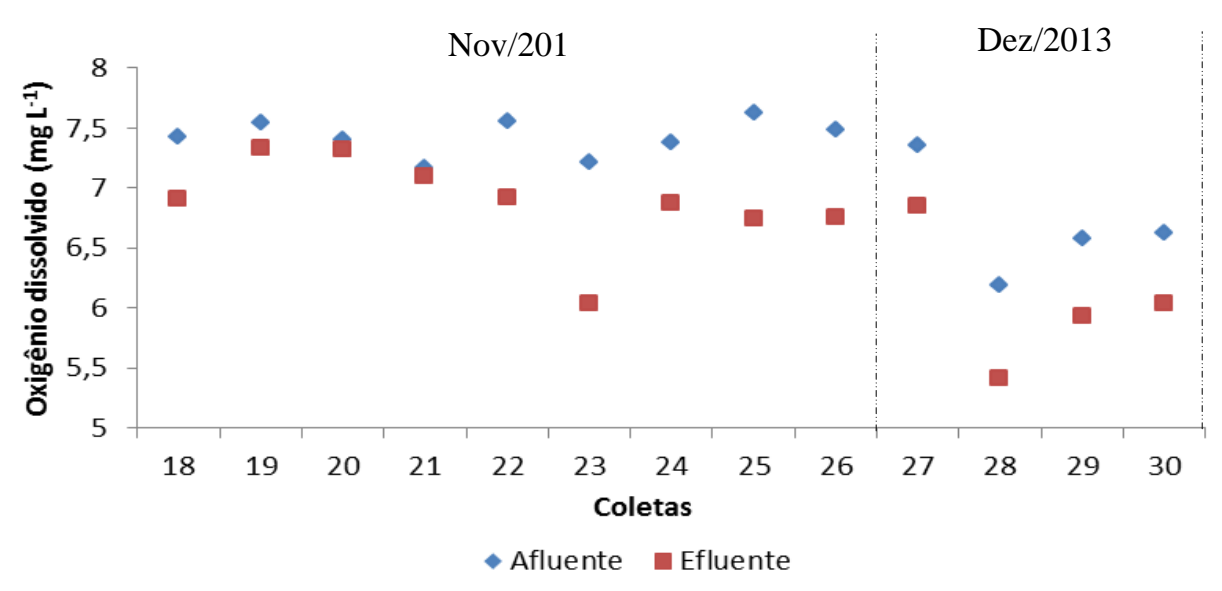

Figura 11: Valores médios de oxigênio dissolvido $\left(\mathrm{mg} \mathrm{L}^{-1}\right)$ aferidos no afluente e efluente dos filtros ecológicos.

\subsubsection{Remoção de coliformes totais e $E$. coli}

A Tabela 3 mostra os dados dos cálculos realizados a partir dos valores aferidos no afluente e efluente de cada filtro ecológico de coliformes totais e E. coli, no período de estudo. A água afluente aos filtros ecológicos (água do Reservatório do Lobo) foi diluída, com água Milli-Q, na concentração 1:500 para que fosse possível a contagem. Após passar pelos filtros, não foram necessárias diluições para realização da contagem. Inicialmente, os 
exames de coliformes totais e E. coli foram efetuados todos os dias, mas observando-se a maturação dos filtros, os exames foram efetuados semanalmente, o que totalizou 13 medições.

A Tabela 4 contém os valores do coeficiente de variação (CV) calculados a partir das medias e do desvio padrão, a fim de mostrar a pouca variação entre os valores aferidos nos efluentes dos filtros ecológicos durante o período de estudo.

De acordo com o padrão de potabilidade vigente no Brasil, disponível no anexo I da portaria $\mathrm{n}^{\mathrm{o}}$ 2.914/2011 (BRASIL, 2011), tanto para coliformes totais como para E. coli deve haver ausência em $100 \mathrm{~mL}$, e de acordo com a Tabela 3, observa-se que os filtros não se enquadraram no padrão de potabilidade, pois a água efluente aos filtros necessita ainda ser desinfetada para o abastecimento da população.

Tabela 3: Valores médios de coliformes totais e E. coli no afluente, afluente diluído e efluente dos filtros ecológicos, com seus respectivos valores de p para o teste-t realizado $(n=13)$ e desvio padrão (DP).

\begin{tabular}{lcccccr}
\hline & \multicolumn{3}{c}{ Coliformes totais (NMP) } & \multicolumn{3}{c}{ E. coli (NMP) } \\
\cline { 2 - 7 } & Média & $\mathrm{P}$ & $\mathrm{DP}$ & \multicolumn{1}{c}{ Média } & $\mathrm{P}$ & \multicolumn{1}{c}{ DP } \\
\hline Afluente & $2,4 \times 10^{3}$ & - & 0 & $2,5 \times 10^{1}$ & - & 23,7 \\
Afluente diluído & $1,4 \times 10^{1}$ & - & 7,2 & - & - & - \\
FEco 1 & $7,5 \times 10^{2}$ & $<0,05$ & 942,1 & $5,3 \times 10^{0}$ & $<0,05$ & 16,7 \\
FEco 2 & $5,1 \times 10^{2}$ & $<0,05$ & 703,5 & $2,7 \times 10^{0}$ & $<0,05$ & 5,6 \\
FEco 3 & $8,5 \times 10^{2}$ & $<0,05$ & 886,6 & $7,8 \times 10^{-1}$ & $<0,05$ & 1,5 \\
FEco 4 & $5,7,10^{2}$ & $<0,05$ & 753,8 & $1,7 \times 10^{0}$ & $<0,05$ & 2,6 \\
FEco 5 & $7,5 \times 10^{2}$ & $<0,05$ & 967,6 & $3,8 \times 10^{-1}$ & $<0,05$ & 0,8 \\
FEco 6 & $6,4 \times 10^{2}$ & $<0,05$ & 782,0 & $1,4 \times 10^{0}$ & $<0,05$ & 2,8 \\
FEco 7 & $5,2 \times 10^{2}$ & $<0,05$ & 770,1 & $7,7 \times 10^{-2}$ & $<0,05$ & 0,2 \\
FEco 8 & $5,1 \times 10^{2}$ & $<0,05$ & 655,5 & $1,5 \times 10^{-1}$ & $<0,05$ & 0,3 \\
FEco 9 & $6,3 \times 10^{2}$ & $<0,05$ & 840,6 & $5,4 \times 10^{-1}$ & $<0,05$ & 1,0 \\
FEco 10 & $6,0 \times 10^{2}$ & $<0,05$ & 846,0 & $1,1 \times 10^{0}$ & $<0,05$ & 2,8 \\
FEco 11 & $6,4 \times 10^{2}$ & $<0,05$ & 936,9 & $3,8 \times 10^{-1}$ & $<0,05$ & 0,8 \\
FEco 12 & $8,0 \times 10^{2}$ & $<0,05$ & 867,7 & $1,8 \times 10^{0}$ & $<0,05$ & 4,8 \\
FEco 13 & $6,5 \times 10^{2}$ & $<0,05$ & 802,0 & $2 \times 10^{1}$ & 0,79 & 63,6 \\
FEco 14 & $1,2 \times 10^{3}$ & $<0,05$ & 1057,7 & $1,0 \times 10^{0}$ & $<0,05$ & 1,6 \\
FEco 15 & $5,2 \times 10^{2}$ & $<0,05$ & 718,0 & $4,2 \times 10^{0}$ & $<0,05$ & 8,0 \\
FEco 16 & $4,1 \times 10^{2}$ & $<0,05$ & 713,9 & $4,5 \times 10^{1}$ & 0,65 & 154,2 \\
FEco 17 & $3,3 \times 10^{2}$ & $<0,05$ & 402,3 & $9,5 \times 10^{-1}$ & $<0,05$ & 1,5 \\
FEco 18 & $5,8 \times 10^{2}$ & $<0,05$ & 826,4 & $3,1 \times 10^{0}$ & $<0,05$ & 9,7 \\
FEco 19 & $6,2 \times 10^{2}$ & $<0,05$ & 832,3 & $2,3 \times 10^{0}$ & $<0,05$ & 6,7 \\
FEco 20 & $5,3 \times 10^{2}$ & $<0,05$ & 869,9 & $3,1 \times 10^{-1}$ & $<0,05$ & 0,8 \\
FEco 21 & $7,6 \times 10^{2}$ & $<0,05$ & 932,4 & $5,5 \times 10^{-1}$ & $<0,05$ & 1,1 \\
FEco 22 & $7,6 \times 10^{2}$ & $<0,05$ & 977,5 & $7,0 \times 10^{-1}$ & $<0,05$ & 1,2 \\
\hline Média dos filtros & $6,4 \times 10^{2}$ & - & 570,9 & $4,2 \times 10^{0}$ & - & 8,3 \\
\hline
\end{tabular}


Tabela 4: Valores de coeficiente de variação (CV) expressos em porcentagem, e desvio padrão (DP), calculados entre os 22 filtros ecológicos em cada coleta realizada.

\begin{tabular}{lrrrr}
\hline Coletas & \multicolumn{2}{c}{ Coliformes totais } & \multicolumn{2}{c}{ E. coli } \\
& CV $(\%)$ & DP & CV $(\%)$ & \multicolumn{1}{c}{ DP } \\
\hline 1 & 0,21 & 475,0 & 3,82 & 119,8 \\
2 & 0,71 & 812,1 & 2,20 & 3,8 \\
3 & 1,13 & 487,2 & 1,54 & 0,8 \\
6 & 0,80 & 872,1 & 3,87 & 13,0 \\
9 & 1,08 & 844,6 & 2,38 & 1,9 \\
14 & 1,23 & 883,3 & 2,27 & 2,2 \\
17 & 1,13 & 148,9 & 4,58 & 0,2 \\
19 & 1,20 & 326,3 & 3,01 & 5,2 \\
20 & 2,89 & 495,0 & 2,07 & 1,0 \\
23 & 1,45 & 822,0 & 3,51 & 3,9 \\
24 & 1,53 & 740,6 & 4,05 & 49,9 \\
27 & 2,17 & 362,5 & 2,43 & 2,3 \\
28 & 1,56 & 215,2 & 2,51 & 0,3 \\
\hline Média & 1,31 & 168,5 & 2,94 & 9,7 \\
\hline
\end{tabular}

(a)

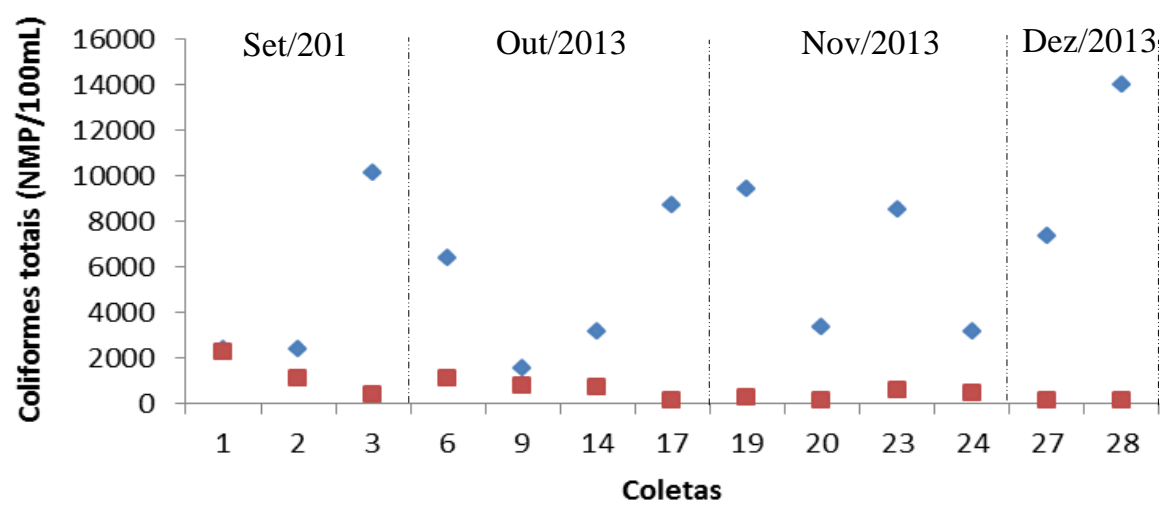

- Afluente $\quad$ Efluente

(b)

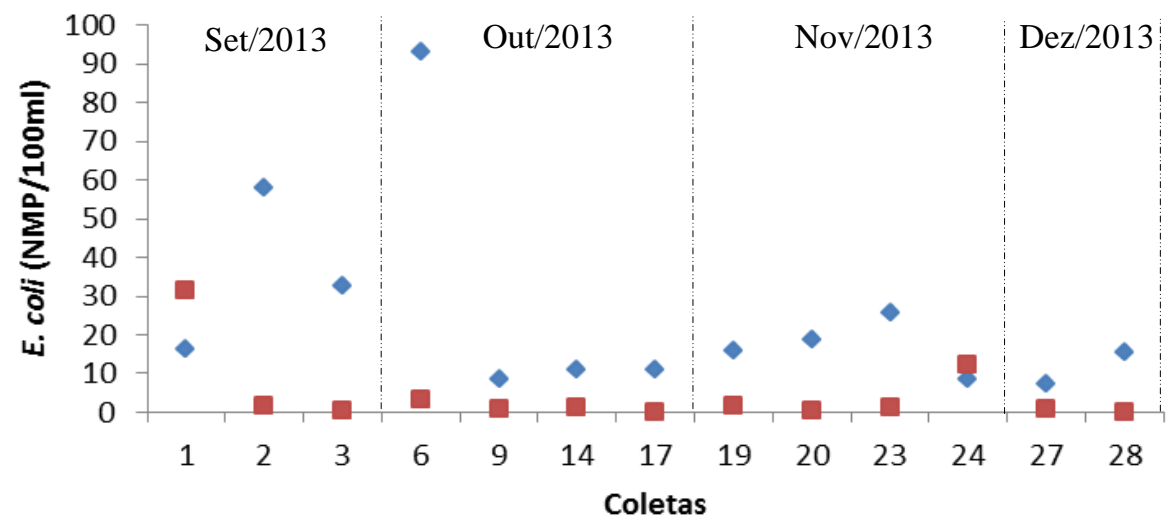

- Afluente Efluente

Figura 12: Valores médios de: a) coliformes totais e b) E. coli no afluente e no efluente dos filtros ecológicos, nas respectivas datas de coleta. 
Entre os valores médios de coliformes totais no afluente dos filtros e efluente, houve diferença significativa $(\mathrm{P} \leq 0,05)$ em todos os filtros. A Figura 12 mostra os valores médios de afluente e efluente aferidos em cada data de coleta, para coliformes totais e E. coli. Observase que na primeira coleta, os filtros não estavam maturados.

Para E. coli, na primeira coleta realizada, (Figura 12b) o valor médio do efluente dos filtros foi maior que o afluente, pois em um dos filtros (FEco 16) a concentração no efluente foi alta (579,4 NMP/100mL), o que acarretou em uma média elevada do dia 1 de coleta.

Houve remoção média de coliformes totais de $79,31 \%$, e $80,04 \%$ de E. coli pelos filtros ecológicos (Figura 13), mas ainda foram encontrados coliformes totais e E. coli na água efluente aos filtros (Tabela 3). Apesar de a filtração lenta ter uma excelente remoção microbiológica, é necessária a desinfecção do efluente do filtro, garantindo que haverá cloro residual na rede distribuidora (VISSCHER et al., 1990). De acordo com o estabelecido pela Portarian $^{\circ} 2.914$ do Ministério da Saúde (BRASIL, 2011), Art. 34, "É obrigatória a manutenção de, no mínimo, $0,2 \mathrm{mg} \mathrm{L}^{-1}$ de cloro residual livre ou $2 \mathrm{mg} \mathrm{L}^{-1}$ de cloro residual combinado ou de $0,2 \mathrm{mg} \mathrm{L} \mathrm{L}^{-1}$ de dióxido de cloro em toda a extensão do sistema de distribuição (reservatório e rede)".

Não houve remoção de coliformes totais nem de E. coli pelos filtros na coleta 1 , indicando que o filtros ainda não estavam maturados. Para coliformes totais, a remoção melhorou da $3^{\text {a }}$ coleta em diante (Figura 13). Estes dados estão de acordo com a remoção de turbidez pelos filtros (Figura 8).

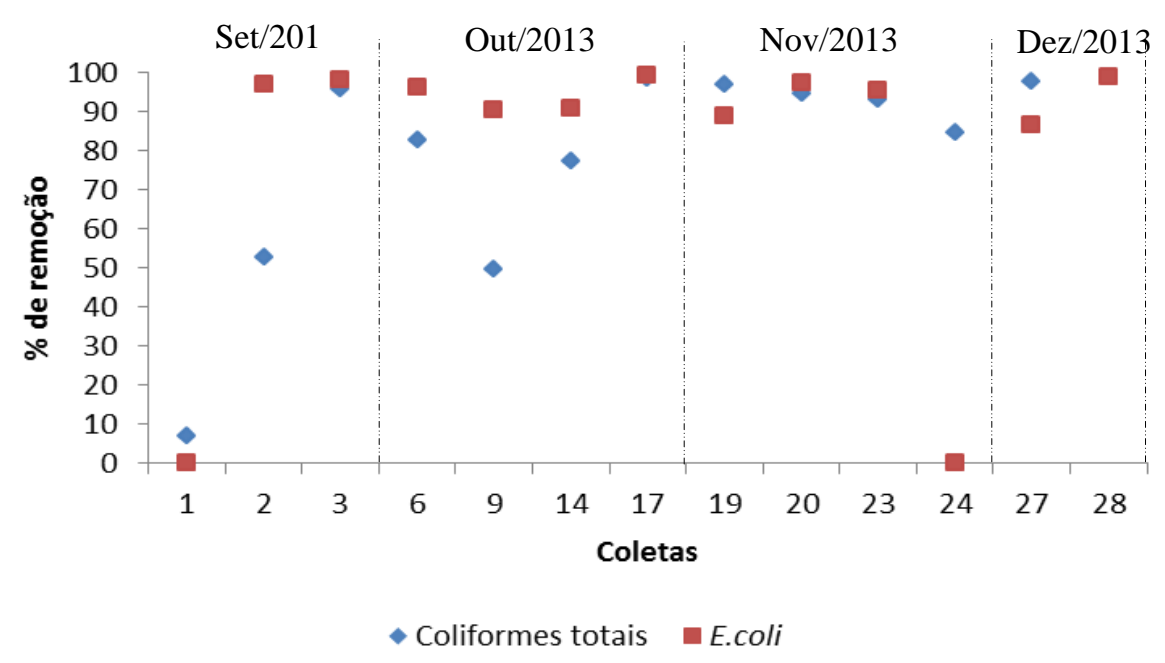

Figura 13: Porcentagem de remoção de coliformes totais e E. coli pelos filtros ecológicos. 


\subsection{Relações entre os parâmetros físicos e químicos de qualidade da água}

A existência de relação entre os parâmetros de qualidade de água foi avaliada por meio da determinação do coeficiente de correlação de Pearson (r), que foi obtido a partir dos valores médios aferidos no efluente de cada filtro ecológico $(n=22)$, avaliando a existência de relações lineares entre as variáveis aferidas, durante a operação dos mesmos de setembro a dezembro de 2013 ( $\mathrm{n}=30$ ), e também foi efetuada análise de regressão, onde $\mathrm{r}^{2}$ indica a qualidade da regressão, sendo que quanto mais próximo da unidade for o coeficiente de determinação (1), tanto maior será a validade da regressão.

A Tabela A.1. (anexos) apresenta os valores de correlação para todas as relações avaliadas, e os respectivos valores de $\mathrm{P}$, indicando a significância da regressão. Os valores de $\mathrm{r}^{2}$ estão sendo indicados em cada gráfico apresentado abaixo, onde houve correlação significativa entre os parâmetros; nos demais casos de correlações testadas e não apresentadas em gráficos, a correlação não foi significativa.

A correlação mais significativa observada foi entre a condutividade elétrica da água e os sólidos totais dissolvidos (STD) $(\mathrm{r}=0,98, \mathrm{P}<0,001)$ (Figura 14). A correlação existente entre estas duas variáveis não é novidade, sendo que se pode estimar o teor de sais pela medida de condutividade de uma água em uma dada temperatura, ou seja, o seu teor salino é aproximadamente dois terços do valor obtido para a condutividade (PEDROSA e CAETANO, 2002).

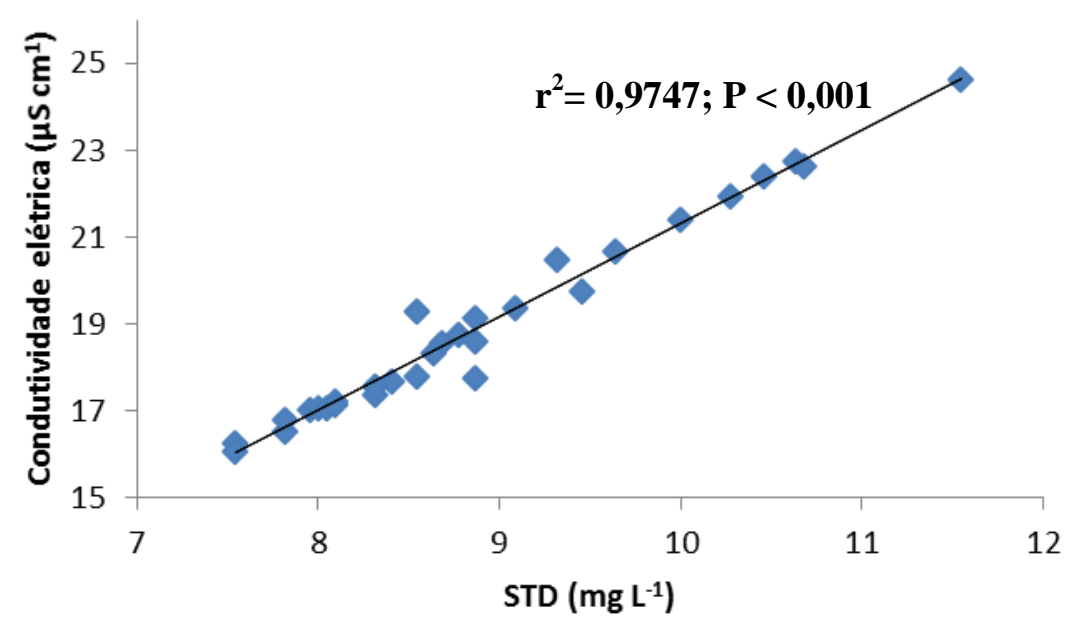

Figura 14: Correlação entre condutividade elétrica e STD no efluente dos filtros ecológicos. 
O coeficiente de correlação de pearson entre $\mathrm{pH}$ e temperatura da água aferidos no efluente dos filtros ecológicos foi de $\mathrm{r}=0,35$, sendo esta correlação considerada significativa $(\mathrm{P}=0,05)$ (Figura 15). Esta correlação observada também já era esperada, pois quando se aumenta a temperatura, as moléculas de água tendem a separarem-se em íons hidrogênio e oxigênio. Ao aumentar a proporção de moléculas decompostas, é produzido mais hidrogênio, diminuindo o pH. Tal correlação já foi descrita anteriormente na literatura (CARVALHO et al., 2000).

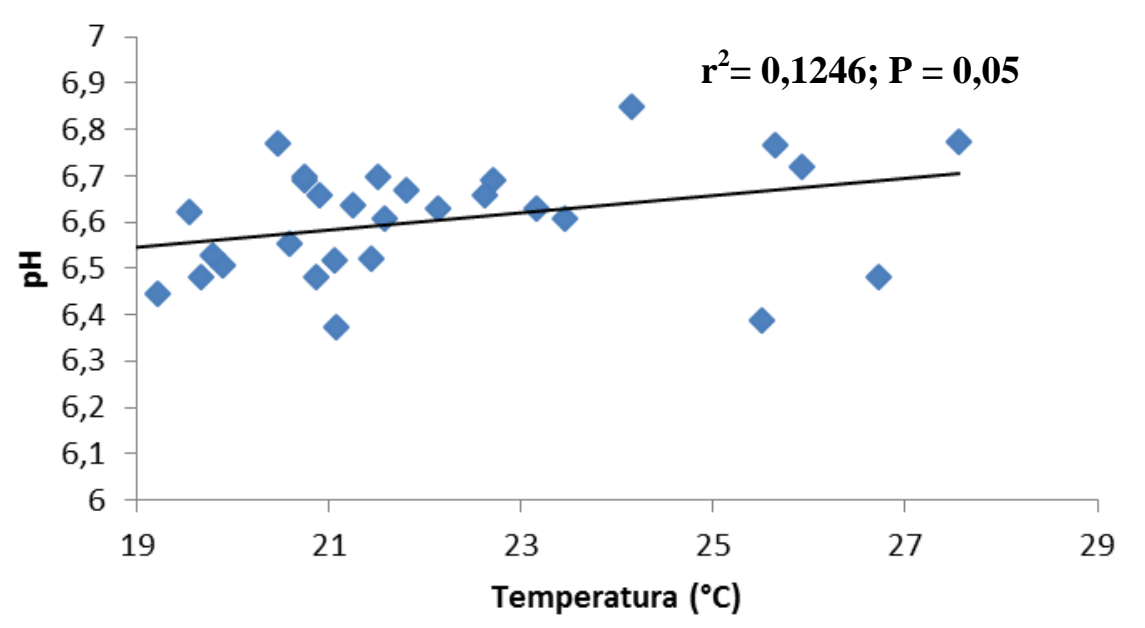

Figura 15: Correlação entre pH e temperatura da água no efluente dos filtros ecológicos.

A correlação entre cor aparente e turbidez da água efluente aos filtros ecológicos ( $\mathrm{r}=$ $0,93)$ foi significativa $(\mathrm{P}<0,001)$, e com boa explicabiliadade de regressão linear $\left(\mathrm{r}^{2}=0,87\right)$ (Figura 16). A cor aparente é em parte atribuível à turbidez, sendo esperada correlação entre essas variáveis. A turbidez pode estar relacionada ao aporte de efluentes, à erosão e a patógenos, que podem se adsorver e proliferar entre os sólidos em suspensão que a determinam (WHO, 1995). O termo cor aparente inclui não somente as substâncias dissolvidas, mas também aquela que envolve a matéria orgânica suspensa (MACÊDO, 2004).

Houve correlação negativa e significativa entre $\mathrm{pH}$ e cor verdadeira da água $(\mathrm{r}=-0,49)$ $(\mathrm{P}=0,01)$ aferidos no efluente dos filtros (Figura 17). Já foi relatada na literatura tal correlação, na avaliação da correlação entre parâmetros aferidos em águas superficiais na cidade de Goiás, GO (BONNET, FERREIRA e LOBO, 2008). 


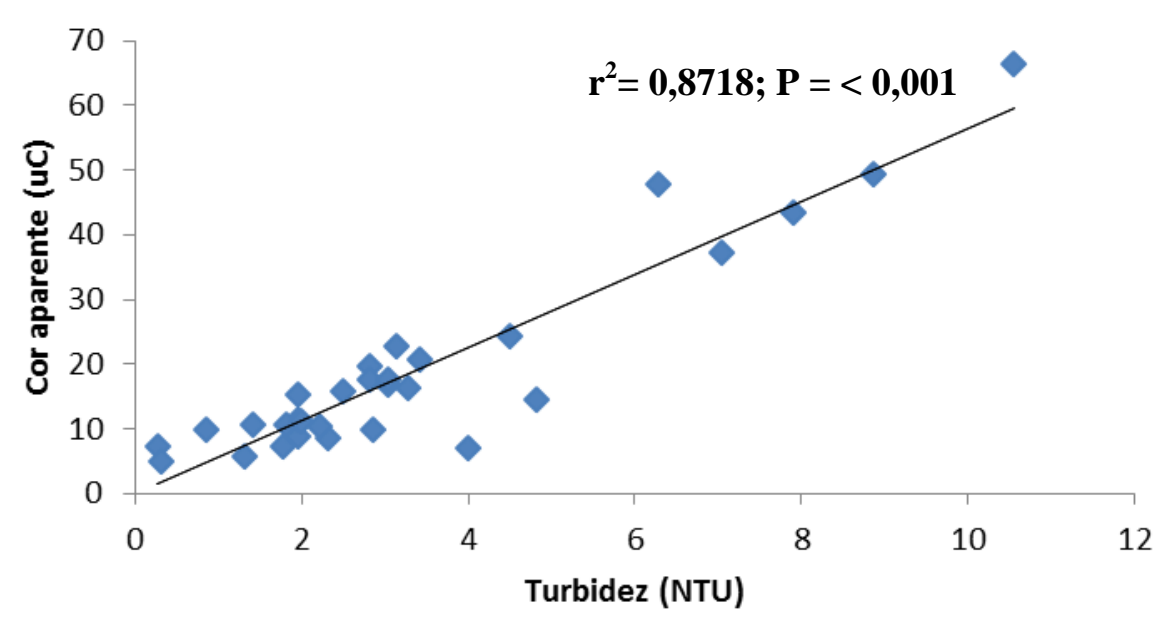

Figura 16: Correlação entre cor aparente e turbidez da água no efluente dos filtros ecológicos.

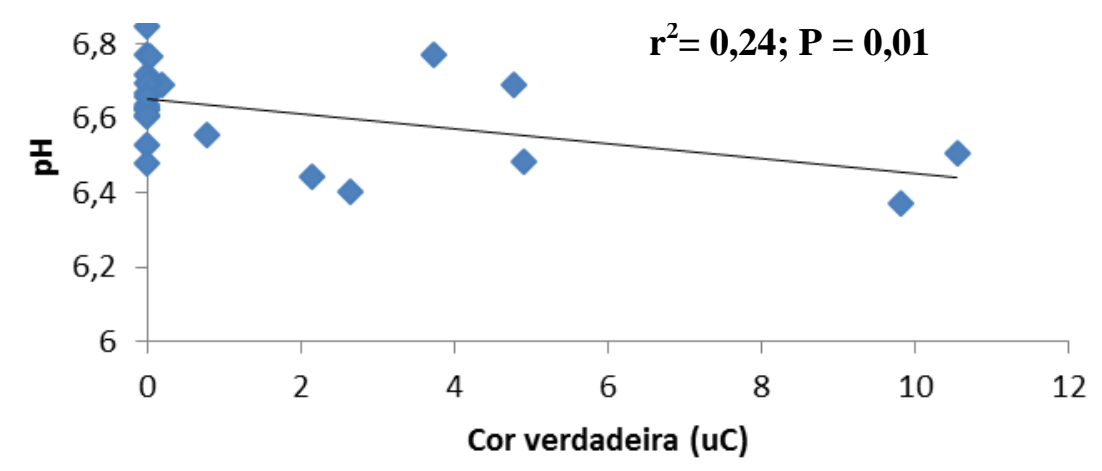

Figura 17: Correlação entre $\mathrm{pH}$ e cor verdadeira da água no efluente dos filtros ecológicos.

\subsection{Aplicabilidade do sistema de filtração ecológica}

Nakamoto, (2008) explica que a filtração lenta em areia vem recebendo concepção equivocada em vários países, inclusive no Japão, e para reverter essa situação, faz-se necessário alterar o nome para "Sistema de Purificação Ecológica". Este novo nome faz menção a fundamental importância do biofilme no sistema de filtração, e atribui valores de uma água tratada naturalmente.

Sabe-se que a filtração ecológica opera com baixa taxa de filtração, e, portanto, no caso de dimensionamento deste sistema de tratamento de água para abastecer uma cidade populosa, far-se-ia necessária grande área para implementação do sistema. Porém, o Brasil consta com grande área territorial, comparando-se com outros países do mundo, e é sabido que em diversos países que contam com áreas demográficas muito inferiores utilizam este sistema de tratamento de água para abastecer cidades. 
Um exemplo é a cidade de Londres, capital da Inglaterra, com população de aproximadamente 8,2 milhões de habitantes e área total de $1.579 \mathrm{~km}^{2}$, onde o sistema de filtração ecológica faz parte do sistema de tratamento de água utilizado na cidade. A Thames Water, de acordo com site oficial da companhia, é a maior empresa de tratamento de água e esgotos do Reino Unido, servindo 14 milhões de usuários em Londres e no Vale do Tâmisa.

Existem diversas estações de tratamento de água que utilizam filtros ecológicos na cidade de Londres (Ashford Common, Walton, Kempton Park, Hampton, e Coppermills), com capacidade total de tratamento de 2 milhões de litro por dia (CAMPOS, 2002). Dentre elas, pode-se citar a companhia Ashford Common works, a maior do rio Tamisa. Nela existem 32 tanques de filtração com 3,0 m de largura e 100 m de comprimento (NAKAMOTO, 2008).

Nakamoto (2008) relata construções de estações de tratamento de água utilizando filtração ecológica na Indonésia, em Bangladesh, e em diversas cidades do Japão.

Yamamura, (2014) realizou uma revisão sobre o uso e as condições da filtração ecológica no Japão. De acordo com o autor, há a necessidade do desenvolvimento técnico na área para a melhoria e renovação de ETAs (Estações de Tratamento de Água) para o futuro do país. A cidade de Nagoya, em 2014 colocou em operação 12 filtros ecológicos, com capacidade de tratar $140 \mathrm{~m}^{3} /$ dia de água (OKUYAMA, 2014), este autor ainda comenta que a técnica de tratamento de água é "amiga do meio ambiente", por não necessitar adicionar produtos químicos para o tratamento, e pouco uso de maquinário para operação, e consequente economia de energia.

No Brasil muitas estações de tratamento de água utilizam filtros rápidos. Apesar da filtração lenta em areia ter perdido sua popularidade por operar com baixa taxa de filtração, se comparada com a filtração rápida $-5 \mathrm{~m}^{3} / \mathrm{m}^{2}$.dia contra $120 \mathrm{~m}^{3} / \mathrm{m}^{2}$.dia da filtração rápida e por isso necessitar de espaço, Nakamoto, (2008) afirma que o sistema de filtração em areia tem bom rendimento em termos de área ocupada. O autor faz uma comparação entre duas cidades do Japão que utilizam cada uma um destes sistemas de tratamento e conclui que considerando-se a área total ocupada, as estações praticamente se igualam.

Para pessoas que não tem acesso a água potável, a filtração ecológica é uma alternativa viável por ser de fácil montagem, operação, manutenção e produzir água de qualidade para os consumidores. A não utilização de produtos químicos durante o tratamento torna a opção de tratamento muito vantajosa, por redução nos custos e gerar um produto final mais saudável, uma vez que pouco se conhece sobre o efeito que a adição de produtos químicos pode causar quando em contato com os demais compostos, como produtos farmacêuticos e de cuidados pessoais que estão presentes na água. 
Portanto, nota-se que se levando em consideração a área disponível, é aplicável o sistema de filtração ecológica no Brasil, não só para o uso em pequenas comunidades afastadas e/ou rurais, mas também para abastecer cidades com maior população.

\section{Conclusões}

As variáveis avaliadas no afluente e efluente dos 22 filtros ecológicos apresentaram baixo coeficiente de variação (menor que 10\%) no tempo de estudo (quatro meses de operação) e entre os 22 filtros ecológicos, com exceção da condutividade elétrica da água que apresentou coeficiente de variação médio de 14\%, mas em alguns filtros o coeficiente de variação foi acima de $30 \%$.

A temperatura da água e o pH estiveram dentro dos valores indicados no padrão de potabilidade, sendo que o efluente dos filtros tiveram menor valor médio que o afluente dos filtros, com diferença significativa $(\mathrm{P}<0,05)$ entre afluente e efluente.

Houve remoção de turbidez $(64,9 \%)$ pelos filtros ecológicos, com diferença significativa $(\mathrm{P}<0,05)$ entre afluente e efluente. A água efluente dos filtros não esteve dentro do padrão de potabilidade vigente no Brasil.

A cor aparente também foi removida pelos filtros $(57,7 \%)$, sendo que na maioria das datas de coleta, na media geral, os filtros se enquadraram na portaria $n^{\circ} 2.914 / 2011$. Houve remoção de cor verdadeira pelos filtros ecológicos (90,4 \%). Este estudo está de acordo com os resultados das pesquisas que avaliaram a filtração lenta em areia.

A água do reservatório do Lobo apresentou altos valores de coliformes totais, precisando ser diluída em 500 vezes $\left(2_{\mathrm{x}} 10^{-3}\right)$ para que fosse possível a contagem, e após passar pelos filtros ecológicos, a água não precisou ser diluída para a contagem, indicando boa remoção pelos filtros (>70\% de coliformes totais e $>80 \%$ de E. coli). A eficiência dos filtros ecológicos na remoção de coliformes totais e $E$. coli neste estudo está de acordo com a literatura.

Com a avaliação dos dados de remoção de turbidez, cor aparente, cor verdadeira, coliformes totais e E. coli, os filtros foram considerados maturados a partir do mês de outubro (20 dias de maturação).

Foi verificada a existência de correlações lineares entre os parâmetros aferidos no efluente dos filtros ecológicos, e foi efetuada análise de regressão. Quatro correlações foram significativas $(\mathrm{P}<0,05)$. Algumas correlações já eram esperadas pelo fato do parâmetro estar 
diretamente relacionado com o outro, como é o caso de: condutividade elétrica x sólidos totais dissolvidos (STD), $\mathrm{pH}$ x temperatura.

A correlação entre $\mathrm{pH}$ e cor verdadeira, apesar de sere significativa $(\mathrm{P}<0,05)$, apresentou baixa explicabilidade de regressão linear $\left(r^{2}\right)$.

A filtração ecológica tem sido implementada em diversos países e tem se mostrado uma alternativa viável e vantajosa em diversos aspectos, como o fato da produção de água por um método natural, e consequentemente, mais saudável.

De acordo com os resultados obtidos com esta pesquisa, no caso da utilização da água do reservatório do Lobo para aplicação do sistema de purificação ecológica, recomenda-se um pré-tratamento da água antes da filtração ecológica, como a inclusão de um pré-filtro de fluxo ascendente.

Há aplicabilidade do sistema de purificação ecológica para tratamento de água no Brasil, pois é uma alternativa com baixo custo, que fornece água tratada naturalmente, de fácil operação, não necessitando de mão de obra especializada e pode ser uma alternativa para fornecer água tratada para toda a população, com possibilidade de utilização de filtros domésticos (Capítulo 4). Além disso, foi descrito na literatura que levando em conta a área total ocupada por estações de tratamento que utilizam filtração rápida comparado com estações que usam filtração lenta, as estações praticamente se igualam.

\section{Referências}

ASCE - American Society of Civil Engineers. Slow Sand Filtration, G.S. Logsdon (Ed.), New York, USA, 1991.

AWWA - American Water Works Association. Manual of Design for Slow Sand Filtration, D. Hendricks (Ed.), American Water Assossiation Research Foundation, Denver, Co, USA, 1991.

BARRET, J. M., BRYCK, J., COLLINS, M. R., JANONIS, B. A., LOGSDON, G. S. Manual of Design for Slow Sand Filtration. Hendricks, D. (Ed.), AWWA Research Foundation, Denver, 1991.

BELLAMY,W.D., HENDRICKS,D.W. e LONGSDON,G.S."Slow and Filtration" Journal of the American Water Works Association. v. 77, p. 62-66, 1985.

BONNET, B. R. P., FERREIRA, L. G., LOBO, F. C. Relações entre qualidade da água e uso do solo em Goiás: uma análise à escala da bacia hidrográfica. Revista Árvore, v. 32(2), p. 311-322, 2008. 
BOSCHI-PINTO, C.; VELEBIT, L.; e SHIBUYA, K. Estimating child mortality due to diarrhoea in developing countries. Bulletin of the WHO, v. 86(9), p. 710-717, 2008.

CALIJURI, M.C., TUNDISI, J.G. Limnologia comparada das represas do Lobo (Broa) e Barra Bonita - Estado de São Paulo: mecanismos de funcionamento e bases para o gerenciamento. RJ. Revista Brasileira de Biologia. v. 50, p. 893-913, 1990.

CAMPOS, L.C. Modelling and Simulation of the Biological and Physical Processes of Slow Sand Filtration. PhD. Thesis, University of London, UK, 2002.

CAMPOS, L.C.; SU, M.F.J.; GRAHAM, N.J.D.; SMITH, S.R. Biomass development in slow sand filters. Water research 36, 4543-4551, 2002.

CARVALHO, A. R.; SCHLITTLER, F. H. M.; TORNISIELO, V. L. Influence of cattle ranching and agricultural activities on physical chemical parameters of water. Química Nova, v.23, n.5, p.618-622, 2000.

COLLINS, M.R. AND GRAHAM, N.J.D. (Eds.) Slow Sand Filtration: Na International Compilation of Recent Scientific ans Operation Developments, American Water Works Assossiation, Denver, USA, 1994.

COLLINS, R.M, et al. Removing natural organic matter by conventional slow sand filtration. Journal of the American Water Works Association - Research And Technology. New York. N. 5, p. 80-90. May 1992.

DI BERNARDO, L. Métodos e técnicas de tratamento de água. Rio de Janeiro: ABES, 1993.

DI BERNARDO; L.; BRANDÃO, C.C.S.; HELLER, L. Tratamento de águas de abastecimento por filtração em múltiplas etapas. PROSAB - Programa de Pesquisa em Saneamento Básico. Rio de Janeiro. ABES. 114p, 1999.

ERBA, C. M. ; TANGERINO, E.P. ; ISIQUE, W. D. ; CAMPOS, L. C. Removal of anti-inflammatory compounds by ecological filtration. In: Nobutada Nakamoto, Nigel Graham, M. Robin Collins and Rolf Gimbel. (2014) (Org.). Progress in slow sand and alternative biofiltration process. 1ed.: IWA publishing. v. 5, cap 19, p. 147-152, 2014.

GRAHAM, N.J.D. (Ed.) Slow Sand Filtration - recente Developments in Water Treatment Technology, Elis Horwood Ltd., Chichester, U.K, 1998.

GRAHAM, N.J.D. e COLLINS, M.R. (Eds.) Advances in Slow Sand and Alternative Biological Filtration, John Wiley \& Sons, Ltd. Chichester, U.K, 1996.

GRAHAM, N.J.D.; COLLINS, M.R. Slow sand filtration: recente research and application perspectives. In: Nobutada Nakamoto, Nigel Graham, M. Robin Collins and Rolf Gimbel. (Org.). 
Progress in slow sand and alternative biofiltration process. 1ed.: IWA publishing, 2014, v. 5, cap 1, p 3-16, 2014.

GUNDRY, S.; WRIGHT, J.; CONROY, R. A systematic review of the health outcomes related to household water quality in developing countries. Journal of Water and Health. v. 2, p. 1-13, 2004.

HAARHOFF, J.; CLEASBY, J.L. Biological and physical mechanisms in slow sand filtration. In Slow Sand Filtration, Logsdon, G.S.(Ed.), Task Committee on Slow Sand Filtration, ASCE, 19-68, 1991.

HAIG, S.J., COLLINS, G., DAVIES, R.L., DOREA, C.C., QUINCE, C. Biological aspects of slow sand filtration: past, present and future. Water Science and Technology. v. 11, p. 468-472, 2011.

HENDERSON, R.; CHIPS, M.; CORNWELL, N.; HITCHINS, P.; HOLDEN, B.; HURLEY, S.; PARSONS, S.A.; WETHERILL, A. \& JEDDERSON, B. Experiences of algae in UK waters: a treatment perspective. Water and Environment Journal. v.22, p. 184-192, 2008.

HUISMAN L, WOOD W. Slow sand filtration. World Health Organization, Geneva, Switzerland, 1974.

ISENSEE, A.R. Variability of aquatic model ecosystem derived data. International Journal of Environmental Studies. v. 10, p. 35-41, 1976.

KEMMER, F.N. The Nalco water handbook. 2a Ed. McGraw-Hill. Nova Iorque. EUA. 1120p, 1989.

LAMBERT, S.D.; GRAHAM, N.J.D. A comparative evaluation of the effectiveness of potable water filtration processes. Journal of Water SRT - Aqua. v. 44, p. 38-51, 1995.

LIBÂNIO, M. Fundamentos de qualidade e tratamento de água. Campinas: Átomo, 2005. 444 p, 2005.

MACÊDO, J.A.B. de. Águas \& águas. Belo Horizonte: CRQ-MG, 977p, 2004.

MELO, A. E. S. Avaliação da filtração lenta na remoção de células de Cylindrospermopsis raciborskii e saxitoxinas. Dissertação (Mestrado em Tecnologias Ambientais e Recursos Hídricos), Engenharia Civil e Ambiental, Universidade de Brasília, Brasília, 197 pag. 2006.

NAKAMOTO, N. Food chain is the key in ecological purification system: new concept and new name of slow sand filter. In: Nobutada Nakamoto, Nigel Graham, M. Robin Collins and Rolf Gimbel.

(Org.). Progress in slow sand and alternative biofiltration process. 1ed.: IWA publishing, v. 5, cap 9, p. 77-84, 2014. 
NAKAMOTO, N. Idea of ecological purification system for drinking water comes from Broa Resevoir. Oecologia Australis v.15, p. 709-713, 2011.

NAKAMOTO, N. Produza você mesmo uma água saborosa - sistema de purificação ecológica revendo a tecnologia de produção de água potável. São Paulo: Ferrari. 210p, 2008.

NAKAMOTO, N.; GRAHAM, N.; COLLINS, M.R. AND GIMBEL, R. (Eds.) Progress in slow sand and alternative biofiltration process - Further developments and Applications. 1ed.: IWA publishing, 2014.

OKUYAMA, A. The centenary slow sand filtration in Nagoya City - the reconstruction of the slow sand filters. In: Nobutada Nakamoto, Nigel Graham, M. Robin Collins and Rolf Gimbel. (2014) (Org.). Progress in slow sand and alternative biofiltration process. 1ed.: IWA publishing. v. 5, cap 5, p 45-49, 2014.

OLIVEIRA, V.M. e PELEGRINI, R.T. Avaliações Físicas, Químicas e Biológicas da Microbacia do Córrego Modeneis em Limeira- SP. Revista Engenharia Ambiental: Pesquisa e Tecnologia. v.5:(1),p. 86-96, 2008.

PEDROSA, C. A., CAETANO, F. A. Águas subterrâneas. Brasília: Agência Nacional de Águas, 2002.

PRUSS-ÜSTÜN, A.; BOS, R.; GORE, F.; BARTRAME, J. Safe Water, Better Health: Costs, Benefits and Sustainability of Interventions to Protect and Promote Health. Geneva: World Health Organization, 2008.

RADWQ - Rapid assessment of drinking-water quality in the Hashemite Kingdom of Jordan. Summary of Results of Rapid Drinking Water Quality Analysis. Geneva: World Health Organization, 2008.

RODRIGUES, M.P.; MATSUMURA-TUNDISI, T. Variation of denstity, species composition and dominance of rotifers at a shallow tropical resevoir (Broa resevoir, SP, Brazil) in a short scale time. Revista Brasileira de Biologia. v. 60, p. 1-9, 2000.

SÁ, J. C. Influencia das características da camada da filtrante e da taxa de filtração na influencia da remoção de Microcystis aeruginosa e microcistina na filtração lenta em areia. Tese (Doutorado em Tecnologias Ambientais e Recursos Hídricos) - Departamento de Engenharia Civil e Ambiental, Universidade de Brasília, Brasília. 186 p. 2006.

SHARPE, A.J., QUERN, P.A., AND CURRIER, R.A. A consultant's point of view. In Slow Sand Filtration, Collins, M.R. and N.D.J. Graham, (Eds.), AWWA, p. 37-45, 1994. 
TANGERINO, E.P. e DI BERNARDO L. Remoção de Substâncias Húmicas por meio da oxidação com Ozônio e Peróxido de Hidrogênio e FiME. Engenharia Sanitária e Ambiental. v. 10, p. 290298, 2005.

VISSCHER, J.T. Slow sand filtration: desing, operation, and maintenance. Journal of the American Water Works Association - Research And Technology . New York. V. N.6, p.67-71. June 1990.

WAKELIN, S., PAGE, D., DILLON, P., PAVELIC, P., ABELLM G.C.J., GREGG, A.L., BRODIE, E., DESANTIS, T.Z., GOLDFARB, K.C., ANDERSON, G. Microbial community structure of a slow sand filter Schmutzdecke: a phylogenetic snapshot based on rRNA sequence analysis. Water Science and Technology. v. 11, p. 426-436, 2011.

WHO - World Health Organization. Preventing diarrhoea through better water, sanitation and hygiene: Exposures and impacts in lowand middle-income countries. Geneva;

(http://www.who.int/water_sanitation_health/gbd_poor_water/en/, acessado em 08/03/2016), 2014.

WHO - World Health Organization. Results of round I: of the WHO International Scheme to Evaluate Household Water Treatment Technologies. Geneva: World Health Organization;

(http://www.who.int/household_water/scheme/household-water-treatment-report-round-1/en/, acessado em 08/03/2016), 2016.

WHO - World Health Organization. Physical Status: The Use and Interpretation of Anthropometry. WHO Technical Report Series 854. Geneva: WHO, 1995.

WRIGHT, J.; GUNDRY, S.; CONROY, R. Household drinking water in developing countries: a systematic review of microbiological contamination between source and point-of-use. Tropical Medicine \& International Health. v. 9, p. 106-117, 2004.

YAMAMURA, S. Overview on the current condition of slow sand filtration and its challenges in Japan. In: Nobutada Nakamoto, Nigel Graham, M. Robin Collins and Rolf Gimbel. (2014) (Org.). Progress in slow sand and alternative biofiltration process. 1ed.: IWA publishing. v. 5, cap 3, p. 25-33, 2014. 
Capítulo 2

\section{Identificação e quantificação de produtos farmacêuticos e de cuidados pessoais no Reservatório do Lobo, remoção por filtros ecológicos e produtos de degradação identificados.}

\section{Resumo}

Os produtos farmacêuticos e de cuidados pessoais (PFCPs) tem sido o foco de muitas pesquisas nos últimos anos acerca da detecção em águas superficiais, subterrâneas e até mesmo de consumo. Produtos de degradação (PDs) dos compostos originalmente descartados das mais diversas maneiras, também têm sido detectados no meio ambiente, onde podem ter sofrido vários processos de degradação naturais, ou em estações de tratamento de esgoto. Apesar das tecnologias avançadas em tratamento de água serem eficientes na remoção de diversos compostos recalcitrantes, os altos custos de implementação, operação e manutenção inviabilizam a utilização na maioria dos países em desenvolvimento onde uma porcentagem da população ainda sofre com a falta de saneamento básico. Os filtros ecológicos (modernização nomenclatural de filtros lentos de areia) são uma alternativa viável de sistema de purificação da água por ser um método natural, com baixos custos de implementação, operação e manutenção. No reservatório do Lobo foram detectados seis PFCPs em concentrações na ordem de $\mu \mathrm{g} \mathrm{L}^{-1}$ (paracetamol, diclofenaco, naproxeno, ibuprofeno, metilparabeno e benzofenona-3). Dois PDs foram identificados no reservatório do Lobo e foram propostas vias de degradação dos compostos, a saber: diclofenaco e benzofenona-3. Os dados obtidos refletem o resultado da contaminação detectada em decorrência de problemas ambientais relacionados às atividades antrópicas no entorno do reservatório. Foram constatadas remoções médias pelos filtros ecológicos de paracetamol em $81 \%, 91 \%$ de diclofenaco, 97\% de naproxeno, 99\% de ibuprofeno, $70 \%$ de metilparabeno e $71 \%$ de benzofenona-3. Pouco se sabe a respeito dos mecanismos responsáveis pela remoção destes compostos, mas atribui-se a ação microbiológica o sucesso do sistema ecológico de purificação da água.

Palavras-chave: produtos farmacêuticos e de cuidados pessoais, produtos de degradação, sistema de purificação ecológica. 


\begin{abstract}
Pharmaceuticals and personal care products (PPCPs) has been the focus of much research in recent years about the detection in surface water, groundwater and even tap water. Degradation products (DPs) of compounds originally disposed in various ways have also been detected in the environment, which may have undergone various processes of natural degradation, or are being degraded in sewage treatment plants. Despite the advanced technologies in water treatment are effective at removing many recalcitrant compounds, high implementation costs, operation and maintenance make it impossible to apply in most development countries where a percentage of the population still suffers from a lack of basic sanitation. The ecological filters (modern name of slow sand filters) are a viable alternative to water purification system for being a natural method, with low implementation costs, operation and maintenance. In Lobo's Reservoir six PPCPs were detected at concentrations on the order of $\mu \mathrm{g} \mathrm{L}^{-1}$ (paracetamol, diclofenac, naproxen, ibuprofen, methylparaben and benzophenone-3). Two DPs were identified in the Lobo's reservoir and has been proposed pathways of degradation of compounds of diclofenac and benzophenone-3. The data reflect the contamination detected as a result of environmental problems related to human activities around the reservoir. The ecological filters remove $81 \%$ of paracetamol, $91 \%$ of diclofenac, $97 \%$ of naproxen, $99 \%$ of ibuprofen, $70 \%$ of methylparaben and $71 \%$ of benzophenone-3. Little is known about the mechanisms responsible for the removal of these compounds, but is attributed to microbiological action the success of the ecological system of water purification.
\end{abstract}

Key words: pharmaceuticals and personal care products, degradation products, ecological purification system. 


\section{Introdução}

Os Produtos Farmacêuticos e de Cuidados Pessoais (PFCPs) são motivo de preocupação científica e pública, pois foram reconhecidos recentemente como uma classe de poluentes ambientais, descritos como grupo não esperado de contaminantes da água, com propriedades psicoativas potentes, desrregulação endócrina e efeitos desconhecidos para a biota aquática. (EVEGENIDOU et al., 2015).

O consumo mundial de fármacos é bastante significativo, um exemplo disso pode ser visto na União Europeia (UE) onde aproximadamente 3.000 diferentes substâncias são usadas em medicamento para consumo humano como analgésicos, anti-inflamatórios, conservantes, antibióticos, $\beta$-bloqueadores e muitos outros (PETROVIC et al., 2014).

Atualmente, o Brasil está entre os 10 países que mais comercializam medicamentos. Por ano, o Ministério da saúde investe $\mathrm{R} \$ 9$ bilhões na compra de medicamentos que são distribuídos pelo SUS (Sistema Único de Saúde) (BRASIL, 2012).

Além dos medicamentos, a procura da população pelo bem-estar e esforço ao cultivo da higiene pessoal e da melhor aparência, fez com que este mercado crescesse muito nos últimos tempos.

No mercado mundial de higiene pessoal, perfumaria e cosméticos, conforme dados do Euromonitor de 2011, o Brasil ocupa a terceira posição, sendo os Estados Unidos o primeiro e Japão o segundo. O Brasil é o primeiro mercado em perfumaria e desodorantes; segundo mercado em produtos para cabelos, produtos para higiene oral, masculinos, infantil, proteção solar; terceiro em produtos cosméticos; quarto em depilatórios; quinto em pele (ABIHPEC, 2012).

Da dosagem dos fármacos utilizados tanto na medicina humana como na medicina veterinária são excretados de 50 a $90 \%$ inalterada e persistente no ambiente (MULROY, 2001).

Em relação aos produtos de cuidados pessoais, outra maneira de entrarem no meio ambiente se dá por meio de atividades recreativas. Compostos que fazem parte da composição de produtos como cosméticos, loções e protetores solares entram em águas superficiais através do contato direto em atividades recreativas em rios e lagos (WEIHONG LI et al., 2007; BALMER et al., 2005).

A maioria das estações de tratamento de esgoto existentes atualmente não são projetadas para eliminar este tipo de substância e uma porção significativa dos compostos emergentes não são degradados e/ou removidos e o composto puro e seus produtos de 
degradação podem permanecer após o tratamento. Desta forma, podem adentrar no ambiente aquático por meio de efluentes de esgoto (DAUGHTON e TERNES, 1999; STUMPF et al., 1999; TERNES et al., 1999; HEBERER, 2002; PETROVIC et al 2003; JONES et al, 2005; FENT et al, 2006; CHRISTEN et al., 2010).

Os diversos estudos possibilitaram que, com o aumento da sensibilidade de equipamentos para a detecção dos PFCPs, mais estudos pudessem ser conduzidos acerca da ocorrência nos diversos meios (KOLPIN et al., 2002; TIXIER et al., 2003; ASHTON et al., 2004)

Os PFCPs têm sido encontrados em águas de superfície, solo e até mesmo na água potável na ordem de ng a $\mu \mathrm{g} \mathrm{L}^{-1}$ em todo o mundo (STUMPF et al., 1999; HEBERER, 2002; PETROVIC et al., 2003; ALMEIDA e WEBER, 2005; FENT et al., 2006; ELLIS, 2006; BECERRIL, 2009).

Dos anti-inflamatórios não-esteroidais mais consumidos, os encontrados com maior frequência nos ecossistemas aquáticos são aspirina, paracetamol, ibuprofeno, naproxeno e diclofenaco (FENT et al., 2006).

Em razão deste cenário, a presença de fármacos residuais e outros compostos xenobióticos na água potável configura uma questão de saúde pública, uma vez que pouco se conhece a respeito do seu potencial efeito na saúde associado com o consumo a longo prazo destes compostos na água potável (STACKELBERG et al., 2004).

\section{Filtros ecológicos na remoção de compostos}

Cerca de um bilhão de pessoas no mundo não tem acesso às fontes de água tratadas (WHO/UNICEF 2008), e globalmente, estima-se que 1,9 bilhão de pessoas ou usam uma fonte de água imprópria, ou de uma fonte de água não tratada e contaminada por resíduos fecais (WHO, 2016). Aproximadamente dois terços desta população vive em comunidades remotas e áreas rurais onde a pobreza é mais severa e o custo do abastecimento de água é mais alto. Mesmo onde existem poços protegidos ou chafarizes públicos, muitas vezes a água abastecida é contaminada devido à falta de saneamento ambiental (RADWQ, 2008).

A Organização Mundial da Saúde (OMS) estima que melhorias em saneamento e higiene poderiam prevenir pelo menos $9,1 \%$ da carga de doença global e 6,3\% das mortes (PRUSS-ÜSTÜN et al., 2008).

Apesar de diversas tecnologias estarem sendo desenvolvidas e modernizadas a fim de tratar a água de uma forma que o tratamento seja capaz de remover até mesmo os compostos 
considerados recalcitrantes, precisa-se levar em conta a questão da viabilidade de implementação e dos custos destas tecnologias.

O Brasil é um país em desenvolvimento e de acordo com dados do IBGE, 9,8 milhões de domicílios no Brasil ainda não possuem acesso à rede de distribuição de água e rede de esgoto, sendo que a Região Norte, que possui a maior proporção de crianças e adolescentes em sua população, apresenta o pior percentual de acesso à água de qualidade do país (45\%). (IBGE-CENSO, 2010).

De acordo com o relatório do Ministério das Cidades (BRASIL, 2016), a aplicação dos recursos nem sempre corresponde às reais necessidades apontadas pelos déficits, sendo que as regiões Norte e Nordeste do Brasil apresentam participação nos investimentos realizados inferior à participação no déficit de acesso. No Norte a situação é extrema, sendo esse déficit 4,8 vezes superior ao investimento.

O sistema convencional de tratamento de água apresentou resultados ineficientes na remoção de muitos fármacos, com porcentagens de remoções <5 a 40\% (VIENO et al., 2007; POJANA et al., 2011). Tecnologias avançadas de tratamento de água tem sido testadas com a finalidade de remoção dos PFCPs, tais como osmose reversa, ozonização, carvão ativado, UV (TERNES et al., 2002, CANONICA et al., 2008) mas na prática, o uso de tecnologias avançadas nas estações de tratamento de água ainda é bastante limitado, uma vez que o custo de tais tecnologias é alto, principalmente em países em desenvolvimento, como é o caso do Brasil.

Além disso, em geral, os processos oxidativos demonstram uma boa eficiência de transformação de contaminantes, mas a mineralização incompleta pode levar à formação de subprodutos com riscos desconhecidos para a saúde humana e do ambiente (ROSSNER, SNYDER e KNAPPE, 2009; ADAMS et al, 2002; YOON et al., 2002).

Em contrapartida, foi constatada por diversos autores a eficiência da filtração lenta na remoção de vários compostos, como toxinas de algas (SÁ, 2002 e 2006; ARANTES, 2004; MELO, 2006, dentre outros), remoção de patógenos, matérias orgânicas e substâncias húmicas (COLLINS et al., 1992), herbicidas (WOUDNEH et al., 1997). Kuhlmann et al., (2006) investigaram a eficiência dos filtros lentos na remoção de quatro diferentes fármacos. Hallé, (2009) avaliou a remoção de fármacos por biofiltros e relatou a biodegradação quase total de ibuprofeno e naproxeno. Rigobello et al., (2013) testaram a remoção de diclofenaco por sistema convencional de tratamento de água, que inclui filtros lentos de areia, utilizandose água preparada em laboratório. Erba et al., (2014) constataram eficiência do filtro ecológico na remoção de quatro fármacos, em até $95 \%$. 
Diante do exposto, a filtração ecológica pode ter eficiência significativa na remoção de diversos compostos orgânicos e inorgânicos, e por se tratar de uma tecnologia de baixo custo de implementação e operação, precisa ser mais explorada.

\section{Produtos de degradação dos PFCPs}

Alguns estudos indicam que a ausência dos compostos farmacêuticos em água tratada não necessariamente implica em sua total remoção. Na maioria dos casos, os fármacos de uso humano são metabolizados e se transformam em compostos mais polares, que são mais susceptíveis a passar pela estação de tratamento de esgoto (PÉREZ e BARCELÓ, 2007).

Outros autores nomeiam estes compostos como PT (Produtos de Transformação) tradução do inglês TPs (Transformation Products), como é o caso de um artigo recente escrito por PICÓ e BARCELÓ, (2015).

Os Produtos de Transformação (PTs), ou Produtos de Degradação (PDs), de contaminantes emergentes podem ser encontrados em amostras de água após o tratamento, ou em corpos d'água no meio ambiente, como resultado de uma multiplicidade de processos bióticos e abióticos (tal como hidrólise, fotólise, oxidação, e metabolismo microbiológico) atuando nos compostos originais ou em seus metabolitos (DEVIER et al., 2011; ANDRÉSCOSTA et al., 2014; VAN DOORSLAER et al., 2014; PORTIGO e RICHARDSON, 2014).

Segundo PÉREZ e BARCELÓ (2007), no corpo humano, os produtos farmacêuticos podem ser transformados em um ou mais metabólitos e excretados na forma de uma mistura do composto-mãe ou metabólitos, em que o composto progenitor é frequentemente o menor componente. No entanto, alguns medicamentos não são metabolizados e são excretados inalterados. O metabolismo depende de uma série de parâmetros, incluindo idade, sexo e etnia, a constituição do paciente e o período de administração. Já no ambiente, estes compostos podem ser carreados e se espalharem em rios, córregos, e, possivelmente, biodegradados. Para a maioria dos fármacos e seus produtos de biotransformação seus caminhos no ambiente aquático são desconhecidos, e as investigações das ocorrências dessas substâncias no meio ambiente ainda são escassas.

Os diversos estudos acerca dos produtos de degradação gerados a partir de cada molécula mãe foram realizados estudando-se mecanismos específicos que promovem tais degradações, como para o paracetamol. Estudos mencionam os produtos de degradações gerados a partir da cloração da água e observou-se a formação de dois produtos, o N-acetyl-pbenzoquinona imina (NAPQI), e o p-benzoquinona. A oxidação gerou o 1,4-benzoquinona (HUGUET et al., 2014). Ainda sobre o paracetamol, diversos trabalhos relatam os produtos de 
degradação formados a partir de diversos meios de degradação, como électro-fenton, degradação fotocatalítica, dentre outras (DE LUNA et al., 2012; JALLOULI et al., 2014; YANG et al., 2008).

A descrição de produtos de degradação do diclofenaco foram relatadas por Galmier et al., (2005), que mostram os três principais produtos de degradação gerados, a rota de formação e produtos derivados dos degradados. Pérez-Estrada et al., (2005) relatam 8 produtos de degradação deste composto; Noutsopoulos et al., (2015) relatam os produtos de degradação gerados após a cloração, e Marco-Urrea et al., (2010) relatam a degradação do diclofenaco por uma espécie de fungo.

No caso do naproxeno, Sidelmanm et al., (2001) apresentaram um perfil metabólico do composto com os produtos que podem ser gerados, e outros autores como Quintana et al., (2005) e Hsu et al., (2006) também apresentam informações sobre os produtos de degradação deste composto.

Três metabólitos do ibuprofeno foram identificados em experimentos de biodegradação com lodo ativado a partir de uma estação de tratamento de esgoto sanitário em condições óxida e anóxica (ZWIENER et al., 2002). Quintana et al., (2005) também investigaram a biodegradabilidade do ibuprofeno em lodos de esgoto, demonstrando que foi degradado somente os co-metabólitos. Dois isômeros de hidroxi-ibuprofeno foram identificados como os principais produtos de degradação. Loffler e Ternes, (2003) também registraram como produto de degradação do ibuprofeno o 2-hydroxy-ibuprofeno.

No caso dos produtos de cuidados pessoais, o primeiro trabalho que tratou sobre os produtos de degradação de parabenos, foi o de Canosa et al., (2006) que relataram os produtos gerados a partir de cloração da água. Tay et al., (2010) propõem estruturas para os produtos de degradação do metilparabeno gerados por ozonização, e Steter et al., (2013) mostram 10 produtos gerados a partir da oxidação eletroquímica. A pesquisa de Gong et al., (2015) mostra 4 produtos formados a partir de benzofenona-3.

Levando em conta o elevado consumo de produtos farmaceuticos e de cuidados pessoais, e a ocorrência em água com base em uma metodologia de referência, avaliações de saúde e riscos ecotoxicológicos devem ser desenvolvidas em paralelo com métodos analíticos que permitam a identificação e quantificação de subprodutos (DELPLA et al., 2009) para identificar onde e como os produtos de degradação estão sendo formados e então, direcionar o tratamento. 


\section{Materiais e Métodos}

\subsection{Padrões e reagentes utilizados}

A acetonitrila $\left(\mathrm{CH}_{3} \mathrm{CN}\right)$ e o metanol $\left(\mathrm{CH}_{3} \mathrm{OH}\right)$ utilizados foram de grau HPLC, adquiridos de J.T.Baker (Xalostoc, México). Os padrões do paracetamol (4-acetaminofenol), diclofenaco sódico, naproxeno, ibuprofeno, metilparabeno (metil 4-hidroxibenzoato) e benzofenona-3 (2-hidroxi-4-metoxibenzofenona) utilizados foram todos com pureza de $\geq 99 \%$ provenientesda Sigma-Aldrich. Informações adicionais de cada composto estão na Tabela 1. Os compostos deuterados que foram utilizados como padrões internos, a saber: paracetamol$d 4$, diclofenaco- $d 4$, naproxeno- $d 3$, ibuprofeno- $d 3$; todos obtidos da CDN Isotopes (Quebec, Canadá).

A solução estoque de cada composto foi preparada em metanol e armazenada a $4{ }^{\circ} \mathrm{C}$. A água utilizada foi previamente purificada utilizando o sistema Milli-Q da Millipore (Millipore, Bedford, MA, EUA). Para a secagem das amostras foi utilizado nitrogênio com $99 \%$ de pureza.

Tabela 1: Informações gerais e características dos compostos em estudo.

\begin{tabular}{lllll}
\hline Composto & CAS & Fórmula Molecular & logKow & pKa \\
\hline Paracetamol & $103-90-2$ & $\mathrm{C}_{8} \mathrm{H}_{9} \mathrm{NO}_{2}$ & 0.46 & 9.5 \\
Diclofenaco & $15307-79-6$ & $\mathrm{C}_{14} \mathrm{H}_{10} \mathrm{Cl}_{2} \mathrm{NNaO}_{2}$ & $4.51^{\mathrm{a}}$ & $4.14^{\mathrm{a}}$ \\
Naproxeno & $22204-53-1$ & $\mathrm{C}_{14} \mathrm{H}_{14} \mathrm{O}_{3}$ & $3.18^{\mathrm{a}}$ & $4.15^{\mathrm{a}}$ \\
Ibuprofeno & $15687-27-1$ & $\mathrm{C}_{13} \mathrm{H}_{18} \mathrm{O}_{7}$ & $3.91^{\mathrm{a}}$ & $4.59^{\mathrm{a}}$ \\
Metilparabeno & $39-73-3$ & $\mathrm{C}_{8} \mathrm{H}_{8} \mathrm{O}_{3}$ & 1.96 & 8.17 \\
Benzofenona-3 & $131-57-7$ & $\mathrm{C}_{14} \mathrm{H}_{12} \mathrm{O}_{3}$ & $3.79^{\mathrm{b}}$ & $7.56^{\mathrm{b}}$ \\
\hline \multicolumn{4}{r}{ a: Noutsopoulos et al., $(2015) ;$ b: Rodil e Moeder, $(2008) ;$}
\end{tabular}

\subsection{Aplicaçào dos PFCPs nos filtros ecológicos e coleta das amostras de água}

O sistema de operação dos filtros foi contínuo e foram realizados três eventos de contaminação dos filtros após a maturação dos mesmos, com intervalo de 15 dias entre cada uma das contaminações.

A concentração aplicada de cada composto em cada filtro foi de $2 \mu \mathrm{g} \mathrm{L} \mathrm{L}^{-1}$. Para tal, cada composto foi pesado em balança de precisão, e uma solução estoque de cada composto foi preparada, assim como uma solução estoque do mix dos seis compostos. Todas as soluções estoque foram preparadas em metanol. A partir da solução estoque, uma alíquota de 
cada uma das soluções foi diluída em um litro de água a fim de obter a concentração desejada. As misturas diluídas gotejaram juntamente com o afluente.

As amostras de água foram coletadas no efluente e afluente de cada filtro ecológico, em diferentes tempos após a contaminação para quantificação dos PFCPs: 3 horas, 6 horas e 24 horas após, sendo que o tempo de detenção médio dos filtros era de seis horas. A Figura 1 mostra como foi realizada a aplicação dos contaminantes nos filtros ecológicos.

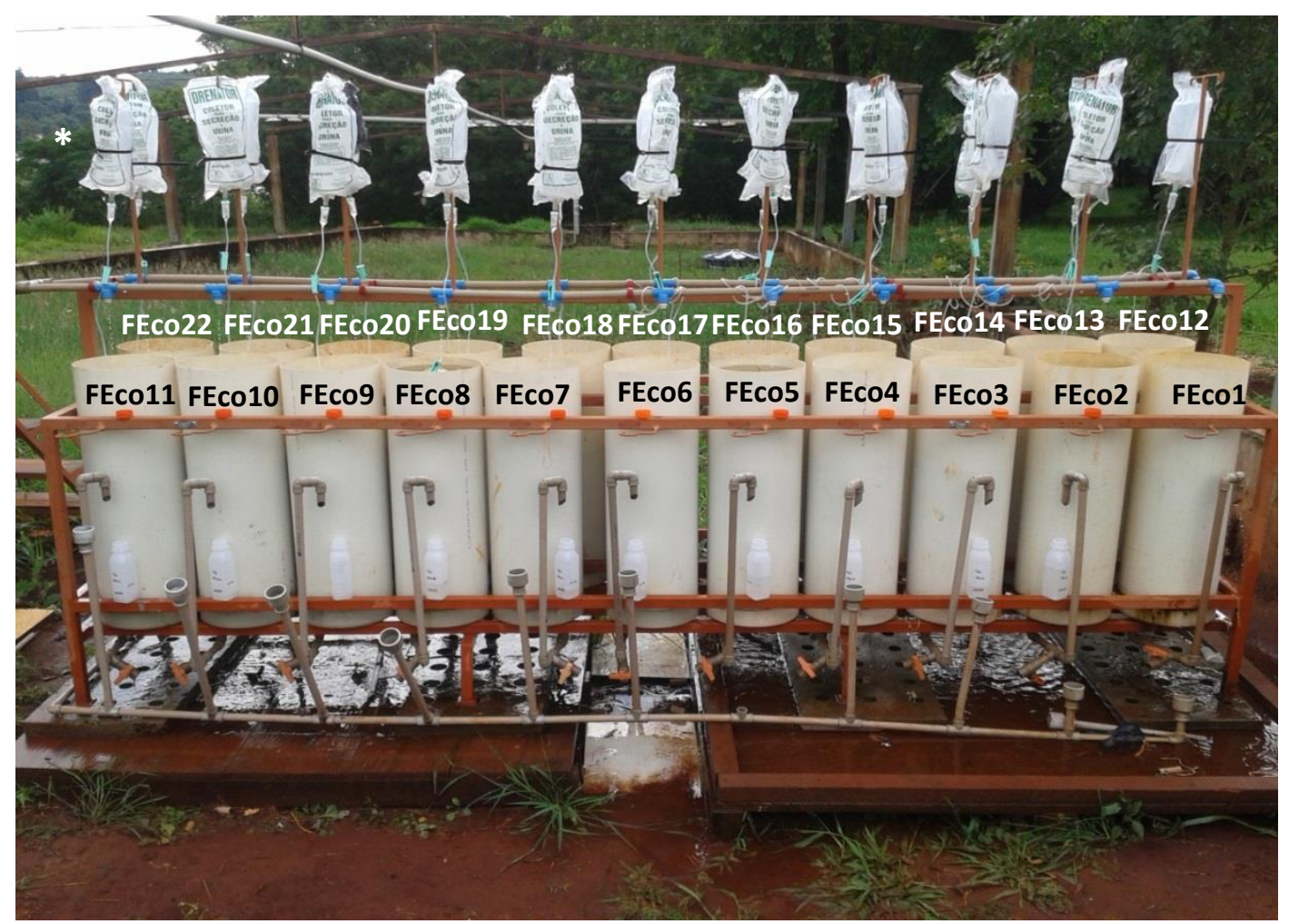

Figura 1: Filtros ecológicos e seus respectivos números. * = Equipos utilizados para a aplicação dos PFCPs.

\subsection{Método analítico utilizado para a identificação e a quantificação dos analitos}

Após coletadas, as amostras foram submetidas à extração em fase sólida (conhecida como SPE), utilizando o adsorvente C18; seguida de análise cromatográfica em cromatógrafo de alta eficiência da Agilent Technologies equipado com uma bomba quaternária Agilent 1200, amostrador automático de alta performance Agilent 1200, forno de coluna Agilent e detector de arranjo de diodos Agilent 1260. O cromatógrafo está acoplado ao espectrômetro de massas 3200 QTRAP (quadrupolo - ion trap linear) da AB SCiex Technologies equipado com a ionização TurboIon.

Utilizou-se a coluna Phenomenex kinetex PFP $(150$ x 4,6 mm, $5 \mu \mathrm{m})$ equipada com uma pré-coluna de mesma marca e do mesmo material. 
O método utilizado foi o modo gradiente de eluição, sendo água acidificada com ácido fórmico $(0,1 \%)$, acetonitrila e metanol $(50: 50, \mathrm{v} / \mathrm{v})$. A proporção de acetonitrila + metanol variou da seguinte maneira: 0 a 0,5 $\min (10 \%), 0,5$ a $5.0 \min (10-75 \%), 5,0$ a 10,0 $\min (75-$ 77,6\%), 10,0 a $11 \min (77,6-100 \%), 11$ a 14,0 $\min (100 \%), 14$ a 14,5 $\min (100-10 \%), 14,5$ a 17 min (10\%), totalizando 17 minutos de análise.

O desenvolvimento do método analítico, a identificação e quantificação dos compostos foi realizada na Unesp-Araraquara, no Instituto de Química, sob supervisão da Profa. Dra. Maria Valnice Boldrin Zanoni.

O método utilizado para a leitura das amostras no LC-MS-MS será apresentado mais detalhadamente em resultados já o método foi desenvolvido, otimizado e validado para este estudo em especifico, e se trata de um dos resultados obtidos.

Para analisar os dados e cromatogramas resultantes a fim de chegar à detecção e quantificação de cada analito, utilizou-se o software Analyst 1.5.2.

\subsubsection{Extração em fase sólida}

Os PFCPs foram extraídos das amostras de água usando extração em fase sólida (SPE). Os adsorventes utilizados foram da Estrata-X (Phenomenex) C18 $200 \mathrm{mg} / 6 \mathrm{~mL}$ (8BS100-FCH). Cada cartucho C18 foi pré-condicionado com $6 \mathrm{~mL}$ de metanol (2 vezes), $6 \mathrm{~mL}$ de água purificada (Milli-Q), e $6 \mathrm{~mL}$ de água purificada (Milli-Q) acidificada com $\mathrm{HCl}$ para pH 3 por gravidade, respectivamente. Em seguida, $300 \mathrm{~mL}$ de água (pH 3,0) foi passada através do sorvente $\mathrm{C} 18$, a uma taxa de fluxo de $5 \mathrm{~mL} \mathrm{~min}^{-1}$. Foi realizada a eluição dos analitos em $4 \mathrm{~mL}$ de metanol, duas vezes, sem vácuo, por gravidade. Os $8 \mathrm{~mL}$ resultantes foram secos sob atmosfera de nitrogênio a fluxo baixo para que não houvesse perda das amostras. Após a secagem foi feita a ressuspensão dos analitos em $300 \mu \mathrm{L}$ com $\mathrm{MeOH}+$ água Milli-Q (1:1 v/v).

\subsection{Identificação dos Produtos de Degradação}

No mesmo equipamento utilizado para conduzir as análises de identificação e quantificação dos PFCPs nas amostras, foram feitos os experimentos de varredura de íons nas amostras coletadas a fim de identificar possíveis Produtos de Degradação (PDs). 
Para tal, inicialmente foi feita uma busca na literatura sobre os trabalhos dedicados a degradação de cada um dos seis compostos e as informações obtidas foram utilizadas como banco de dados para a busca dos compostos nas amostras.

As mais variadas massas dos PDs descritas na literatura foram utilizadas para a realização de experimentos de íons fragmentos. Para tal, realizou-se a extração de cada uma das massas encontradas para todos os produtos de degradação de cada um dos compostos, e aquelas que foram detectadas nas amostras, foram selecionadas para as análises de fragmentação.

\subsection{Testes estatísticos}

Os resultados oriundos da quantificação dos PFCPs foram submetidos à análise estatística de perfis. Este tipo de análise tem como objetivo estudar o efeito dos tratamentos nos diferentes tempos de coleta, e utiliza técnicas de análise multivariadas ou univariadas (dependendo do resultado de análises prévias), e foi realizado com software SAS, por intermédio do PROC GLM (general linear model).

\section{Resultados e discussões}

\subsection{Desenvolvimento, otimização e validação do método analítico.}

Foi feito o desenvolvimento do método analítico para detecção dos seis analitos que foram estudados.

O ajuste dos parâmetros do espectrômetro de massas ocorreu através da injeção direta dos padrões dos analitos, preparados individualmente na concentração de $1 \mathrm{mg} \mathrm{L}^{-1}$, em metanol:água (50:50, v/v). A injeção direta ocorreu via seringa automática na vazão de $10 \mu \mathrm{L}$ $\min ^{-1}$. Os parâmetros de ionização otimizados em comum para todos os compostos foram IonSpray: $5500 \mathrm{~V}$ (modo positivo) e $-4500 \mathrm{~V}$ (modo negativo), Curtain Gas: 10 psi, Gas 1 e Gas 2: 50 psi, Interface heater: ON e Temperatura: $700{ }^{\circ} \mathrm{C}$.

Os parâmetros foram ajustados com as amostras individuais de todos os compostos a serem analisados, de acordo com a Directiva 2001/83/CE da União Europeia, para a quantificação de fármacos em amostras ambientais, e foram escolhidas três transições para cada composto, sendo uma de quantificação e duas de confirmação. 
Foram ainda empregados compostos deuterados para o desenvolvimento do método, sendo estes adicionados como surrogantes nas amostras analisadas, sendo assim aplicado o método de diluição isotópica dos analitos em interesse, o que torna o método ainda mais viável e já corrigido de erros experimentais (incluindo extração e equipamento). Os parâmetros ajustados para cada composto encontram-se listados na Tabela 2.

Os íons de transição, ou íons fragmentos selecionados neste estudo, estão de acordo com os íons fragmentos descritos na literatura para os mesmos compostos (MIAO et al., 2002; LOFFTER e TERNES, 2003; RODIL e MOEDER, 2008; MAGI et al., 2013).

Com os parâmetros do espectrômetro de massas definidos, partiu-se para o estudo da cromatografia líquida. Para tal, realizou-se o preparo de uma mistura de padrões, todos na mesma concentração (1 mg L L $\left.{ }^{-1}\right)$, em metanol:água (50:50, v/v). Utilizou-se a coluna Phenomenex kinetex PFP $(150$ x 4,6 mm, $5 \mu \mathrm{m})$ equipada com uma pré-coluna de mesma marca e do mesmo material.

O método utilizado foi o modo gradiente de eluição, sendo a água acidificada com ácido fórmico $(0,1 \%)$, acetonitrila e metanol $(50: 50, \mathrm{v} / \mathrm{v})$. A proporção de acetonitrila + metanol variou da seguinte maneira: 0 a $0,5 \min (10 \%), 0,5$ a $5.0 \min (10-75 \%), 5,0$ a 10,0 $\min (75-77,6 \%), 10.0$ a $11 \min (77,6$ a 100\%), 11 a 14,0 $\min (100 \%), 14$ a $14,5 \min (100$ a 10\%), 14,5 a 17 min (10\%), totalizando 17 minutos de análise.

Tabela 2: Parâmetros ajustados para cada um dos compostos estudados e os deuterados.

\begin{tabular}{|c|c|c|c|c|c|c|c|}
\hline \multicolumn{8}{|c|}{ Modo Negativo } \\
\hline Analitos & $\begin{array}{c}\text { Íon } \\
\text { precursor } \\
{[\mathrm{M}-\mathrm{H}]^{-}(m / z)}\end{array}$ & $\begin{array}{c}\text { Íon } \\
\text { fragmento } \\
{[\mathrm{M}-\mathrm{H}]^{-}(m / z)}\end{array}$ & $\begin{array}{c}\text { DP } \\
\text { (Volts) }\end{array}$ & $\begin{array}{c}\text { EP } \\
(\text { Volts })\end{array}$ & $\begin{array}{c}\text { CEP } \\
\text { (Volts) }\end{array}$ & $\begin{array}{c}\text { CE } \\
\text { (Volts) }\end{array}$ & $\begin{array}{c}\text { CXP } \\
\text { (Volts) }\end{array}$ \\
\hline \multirow{3}{*}{ Paracetamol } & \multirow{3}{*}{150} & 107,0 & -40 & $-8,5$ & -18 & -28 & 0 \\
\hline & & 107,4 & -40 & $-8,5$ & -18 & -18 & 0 \\
\hline & & 118,0 & -40 & $-8,5$ & -18 & -38 & 0 \\
\hline \multirow{3}{*}{ Diclofenaco } & \multirow{3}{*}{294} & 250,0 & -25 & $-3,0$ & -22 & -14 & -4 \\
\hline & & 214,0 & -25 & $-3,0$ & -22 & -22 & -4 \\
\hline & & 178,0 & -25 & $-3,0$ & -22 & -28 & -4 \\
\hline \multirow{3}{*}{ Ibuprofeno } & \multirow{3}{*}{205} & 158,9 & -20 & $-10,0$ & -18 & -10 & -2 \\
\hline & & 159,0 & -20 & $-10,0$ & -18 & -8 & -2 \\
\hline & & 161,0 & -20 & $-10,0$ & -18 & -6 & -4 \\
\hline \multirow{3}{*}{ Naproxeno } & \multirow{3}{*}{229} & 169,0 & -15 & $-9,0$ & -22 & -44 & -2 \\
\hline & & 170,0 & -15 & $-9,0$ & -22 & -18 & -4 \\
\hline & & 185,0 & -15 & $-9,0$ & -22 & -6 & -4 \\
\hline \multirow{3}{*}{ Diclofenaco-d4 } & \multirow{3}{*}{298} & 254,0 & -15 & $-3,0$ & -14 & -18 & -4 \\
\hline & & 217,0 & -15 & $-3,0$ & -14 & -22 & -8 \\
\hline & & 181,0 & -15 & $-3,0$ & -14 & -38 & -4 \\
\hline
\end{tabular}


Continuação da Tabela 2 ....

\begin{tabular}{|c|c|c|c|c|c|c|c|}
\hline \multirow{3}{*}{ Naproxeno-d3 } & \multirow{3}{*}{232} & 171,0 & -30 & $-2,5$ & -34 & -40 & -2 \\
\hline & & 173,0 & -30 & $-2,5$ & -34 & -16 & -4 \\
\hline & & 188,0 & -30 & $-2,5$ & -34 & -10 & -4 \\
\hline \multirow{3}{*}{ Ibuprofeno-d3 } & \multirow{3}{*}{208} & 161,0 & -15 & $-11,0$ & -26 & -6 & -2 \\
\hline & & 161,5 & -15 & $-11,0$ & -26 & -6 & -4 \\
\hline & & 164,0 & -15 & $-11,0$ & -26 & -8 & -2 \\
\hline \multirow{3}{*}{ Paracetamol-d4 } & \multirow{3}{*}{154} & 108,0 & -45 & $-9,5$ & -18 & -20 & -2 \\
\hline & & 107,5 & -45 & $-9,5$ & -18 & -22 & -2 \\
\hline & & 110,0 & -45 & $-9,5$ & -18 & -24 & -2 \\
\hline \multirow{3}{*}{ Paracetamol-d3 } & \multirow{3}{*}{153} & 107,0 & -50 & $-11,5$ & -10 & -5 & 0 \\
\hline & & 109,0 & -50 & $-11,5$ & -10 & -18 & 0 \\
\hline & & 134,0 & -50 & $-11,5$ & -10 & -30 & -2 \\
\hline \multicolumn{8}{|c|}{ Modo Positivo } \\
\hline Analitos & $\begin{array}{l}\text { Íon precursor } \\
{[\mathbf{M}+\mathbf{H}]^{+}(m / z)}\end{array}$ & $\begin{array}{c}\text { Íon } \\
\text { fragmento } \\
{[\mathbf{M}+\mathbf{H}]^{+}(m / z)} \\
\end{array}$ & $\begin{array}{c}\text { DP } \\
\text { (Volts) }\end{array}$ & $\begin{array}{c}\text { EP } \\
\text { (Volts) }\end{array}$ & $\begin{array}{c}\text { CEP } \\
\text { (Volts) }\end{array}$ & $\begin{array}{c}\text { CE } \\
\text { (Volts) }\end{array}$ & $\begin{array}{c}\text { CXP } \\
\text { (Volts) }\end{array}$ \\
\hline \multirow{3}{*}{ Benzofenona-3 } & \multirow{3}{*}{229} & 151,0 & 41 & 4,5 & 12 & 27 & 4 \\
\hline & & 105,0 & 41 & 4,5 & 12 & 27 & 4 \\
\hline & & 77,0 & 41 & 4,5 & 12 & 49 & 4 \\
\hline \multirow{3}{*}{ Metilparabeno } & \multirow{3}{*}{153} & 121,0 & 31 & 8,0 & 10 & 17 & 4 \\
\hline & & 109,0 & 31 & 8,0 & 10 & 13 & 4 \\
\hline & & 93,0 & 31 & 8,0 & 10 & 29 & 4 \\
\hline
\end{tabular}

Sendo: DP (Declustering Potential), EP (Entrance Potential), CEP (Cell Entrance Potential), CE (Collision Energy) e CXP (Cell Exit Potential).

Na Figura 2 tem-se o cromatograma de íons totais de todos os analitos separados obtidos após a otimização das condições cromatográficas. A divisão nesta figura trata-se de segmentos adicionados para a possível realização de análises em modo positivo e negativo simultaneamente na mesma injeção. A Figura 3 possui os cromatogramas de íons extraídos para cada um dos compostos, incluindo as três transições definidas para cada composto, sendo que o pico em azul representa a transição de quantificação e as transições vermelhas e verdes, as de confirmação.

Os tempos de retenção de cada um dos seis analitos estudados foram: paracetamol (3,83 min.), diclofenaco sódico (7,65 min.), naproxeno (7,29 min.), ibuprofeno (7,59 min.), metilparabeno (5,99 min.) e benzofenona-3 (8,31 min.).

Para assegurar que um novo método analítico seja capaz de gerar informações confiáveis e interpretáveis sobre a amostra, ele deve ser submetido a uma série de estudos experimentais denominados validação. A validação de um método é um processo contínuo que começa no planejamento da estratégia analítica e continua ao longo de todo o seu desenvolvimento e transferência (RIBANI et al., 2004). 
- TIC: from Sample 16 (Mix_mix) of Carol_metodo.wiff (Turbo Spray)

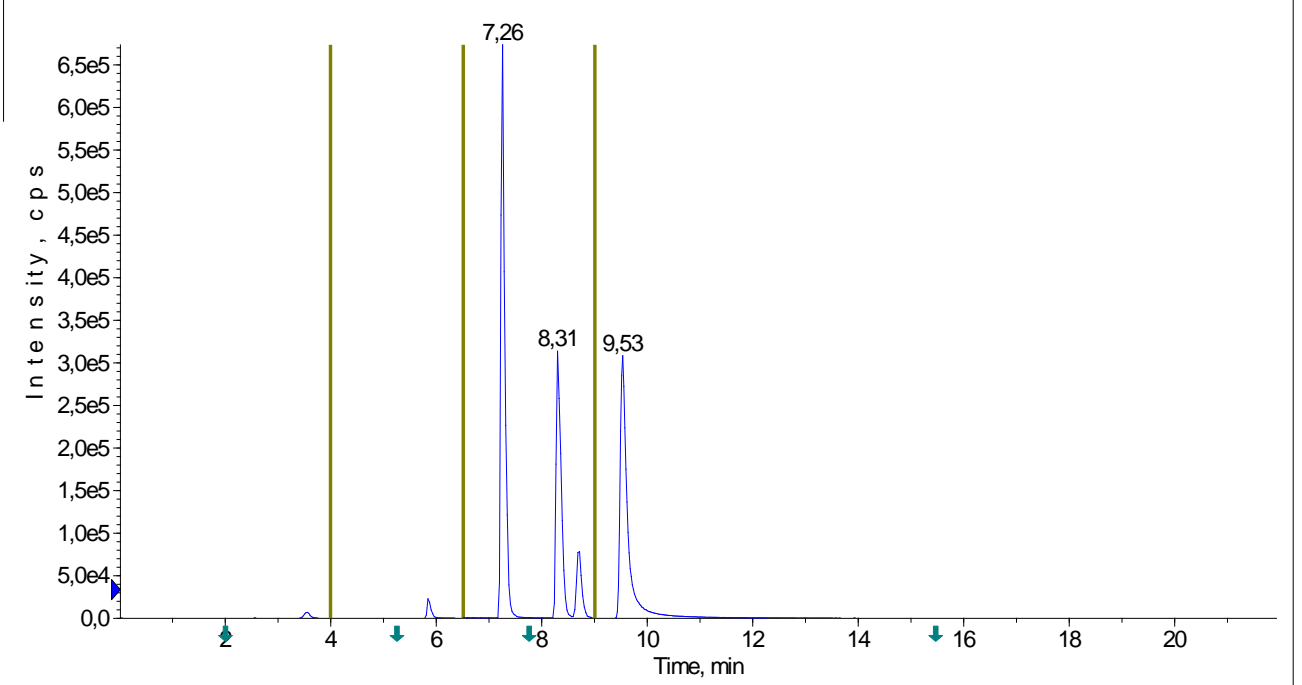

Figura 2: Cromatograma de íons totais obtido para a mistura dos analitos estudados.

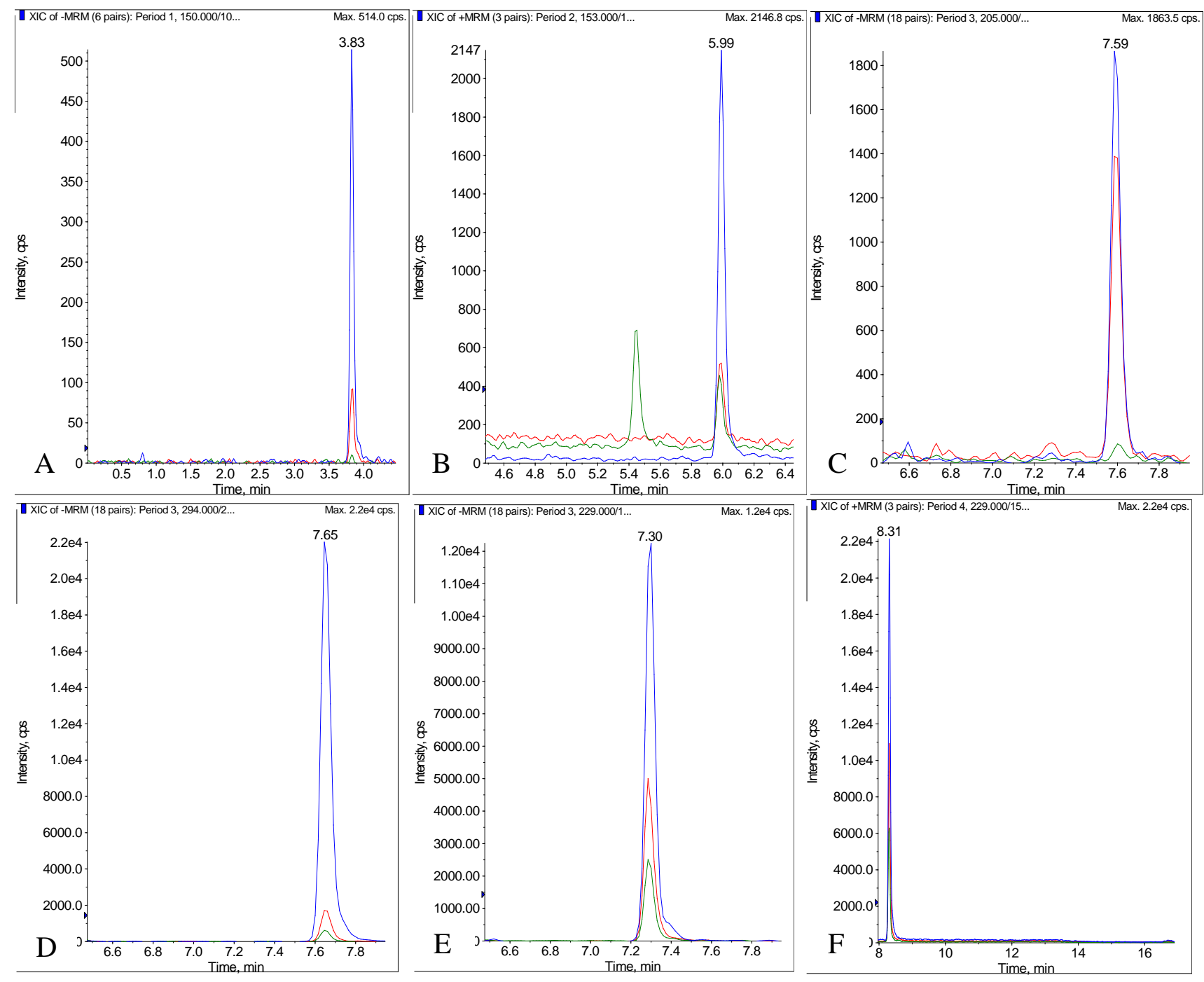

Figura 3: Cromatogramas individuais para cada composto, ilustrando as três transições, sendo que: A) Paracetamol; B) Metilparabeno; C) Ibuprofeno; D) Diclofenaco; E) Naproxeno; F) Benzofenona-3. 
Existem algumas agências regulamentadoras deste processo de validação, destacandose nacionalmente: Instituto Nacional de Meteorologia, Qualidade e Tecnologia (INMETRO) e a Agência Nacional de Vigilância Sanitária (ANVISA); e internacionalmente: União Internacional de Química Pura e Aplicada (IUPAC), Organização Internacional para Padronização (ISO), Environmental Protection Agency (EPA), Comitê Europeu para Análise Química (EURACHEM) e International Conference on Harmonisation (ICH).

Segundo alguns autores, como: Brasil, (2003) e Cassiano et al., (2009), devido ao fato de os guias fazerem vagas recomendações em alguns casos, o analista procede de acordo com suas possibilidades experimentais e de interesse, sem deixar de se pautar pelos princípios gerais contidos nas recomendações existentes; além disso em alguns casos não há uma legislação, norma ou recomendação indicando o protocolo de validação a ser seguido.

Como parâmetros para a validação deste método, foram utilizados: curva analítica e linearidade, LOD e LOQ, precisão, exatidão (recuperação). O método utilizado foi validado de acordo com a resolução número 899 da Agência Nacional de Vigilância Sanitária (ANVISA, 2003), e os resultados para alguns parâmetros encontram-se na Tabela 3.

Tabela 3: Alguns parâmetros avaliados para a validação do método analítico por LC/MS-MS.

\begin{tabular}{lccrrr}
\hline \multicolumn{1}{c}{ Analito } & $\mathbf{Y}=\mathbf{a x}+\mathbf{c}$ & $\mathbf{R}^{2}$ & $\begin{array}{c}\mathbf{L O D} \\
\left(\boldsymbol{\mu g ~ \mathbf { L } ^ { - 1 } )}\right.\end{array}$ & $\begin{array}{c}\mathbf{L O Q} \\
\left(\boldsymbol{\mu g} \mathbf{L}^{-1}\right)\end{array}$ & $\begin{array}{r}\text { Recuperação } \\
(\mathbf{\%})\end{array}$ \\
\hline Paracetamol & $5,472 \mathrm{x}+0,322$ & 0,9994 & 0,50 & 1,0 & 80,50 \\
Diclofenaco sódico & $0,491 \mathrm{x}+0,065$ & 0,9996 & 0,10 & 0,5 & 97,00 \\
Naproxeno & $1,062 \mathrm{x}+0,010$ & 0,9994 & 0,10 & 0,5 & 104,70 \\
Ibuprofeno & $0,918 \mathrm{x}+0,102$ & 0,9997 & 0,10 & 0,5 & 99,90 \\
Metilparabeno & $0,115 \mathrm{x}+0,005$ & 0,9990 & 0,10 & 0,5 & 94,05 \\
Benzofenona-3 & $0,794 \mathrm{x}+0,071$ & 0,9994 & 0,05 & 0,1 & 87,60 \\
\hline
\end{tabular}

Analisando as equações das curvas obtidas por LC-MS/MS, pode-se perceber que quanto maiores foram os coeficientes angulares "a" das equações, mais sensível foi o método para o composto (LANÇAS, 2004). Outro parâmetro avaliado que se mostrou adequado foi o modelo linear, representado pelo coeficiente de determinação $\left(\mathrm{r}^{2}\right)$, maior do que 0,99 , que é recomendado tanto pela ANVISA (2003), quanto pela Diretiva Europeia (2002/657/EC). Para o INMETRO (2003), acima de 0,90 já é considerado um valor adequado.

Para a determinação do LOD e do LOQ do método, um fator de pré-concentração de 1000 vezes foi considerado na sua determinação. Por se tratar de um método com diluição isotópica para a maioria dos compostos (cada composto analisado foi comparado com seu 
respectivo padrão deuterado), as curvas analíticas e os limites foram calculados utilizando soluções em metanol.

A exatidão do método foi feita por meio do estudo de recuperação dos compostos na matriz. Como se trata de uma amostra ambiental (água de represa) específica da região e a inexistência de um material de referência permitiu-se o cálculo da exatidão pelo estudo de recuperação, onde uma concentração conhecida do analito é adicionada a amostra e submetida à extração. A comparação da área do composto na amostra dopada antes da extração e após extração fornece a recuperação expressa em \% do método utilizado. A recomendação do processo de validação de métodos cromatográficos para o estudo de recuperação é de 70 $120 \%$.

Além da recuperação dos analitos, estudou-se ainda a recuperação dos deuterados utilizados no método para a maior confiabilidade dos dados. Os resultados de recuperação absoluta dos deuterados foram: paracetamol-d4 (93,2\%), diclofenaco-d4 (30,5\%), naproxenod3 $(97,8 \%)$ e ibuprofeno-d3 $(78,8 \%)$.

Com o uso de padrões deuterados antes da extração por SPE das amostras, pode-se observar a confiabilidade que os dados passam a apresentar, pois o mesmo comportamento dos padrões é obtido para seus respectivos deuterados.

Dessa forma, pode-se utilizá-los para corrigir todo o processo de extração e análise, além de proporcionar uma boa recuperação relativa, ou seja, a recuperação do composto em relação ao deuterado. Essa informação é importante em casos onde se obtêm uma recuperação muito baixa como no caso do diclofenaco. No entanto, o seu respectivo deuterado também apresenta baixa recuperação e uma vez que esteja acontecendo com o deuterado vai acontecer com o analito e vice e versa.

Como a recuperação relativa entre eles é de $97 \%$, o mesmo se enquadra na faixa de validação. Assim, o método com emprego de diluição isotópica trata-se hoje de um estado na arte em termos de quantificação de analitos em diversas amostras, uma vez que qualquer alteração que ocorra na amostra, às interferências ao analito serão as mesmas nos deuterados e, portanto constantemente corrigidos.

A precisão do instrumento em termos de repetibilidade foi obtida da análise de três soluções com diferentes níveis de concentração selecionados na elaboração das curvas analíticas. Para matrizes ambientais, a precisão é dependente da matriz da amostra, da concentração do analito e da técnica de análise, podendo variar até 20\% (RIBANI et al., 2004), portanto os dados apresentados estão dentro dos limites sugeridos. Os resultados de repetibilidade encontram-se na Tabela 4. 
Tabela 4: Resultados de repetibilidade das amostras dopadas em 3 níveis de concentração.

\begin{tabular}{ccr}
\hline Compostos & $\begin{array}{c}\text { Concentração do } \\
\text { padrão }\left(\boldsymbol{\mu g} \mathbf{L}^{\mathbf{- 1}}\right)\end{array}$ & $\begin{array}{r}\text { Repetibilidade } \\
(\mathbf{\%})\end{array}$ \\
\hline \multirow{3}{*}{ Paracetamol } & 1 & 3,07 \\
& 10 & 6,43 \\
Diclofenaco & 50 & 3,72 \\
& 1 & 11,90 \\
& 10 & 0,62 \\
Naproxeno & 50 & 6,21 \\
\hline \multirow{3}{*}{ Ibuprofeno } & 1 & 2,51 \\
& 50 & 3,13 \\
& 1 & 3,78 \\
\hline \multirow{3}{*}{ Metilparabeno } & 10 & 4,37 \\
& 50 & 5,67 \\
& 1 & 0,75 \\
\hline \multirow{3}{*}{ Benzofenona-3 } & 10 & 1,02 \\
& 10 & 2,05 \\
$\mathrm{~N}=9$ (três amostras dopadas em triplicata) de cada concentração. & 0,86 \\
\hline
\end{tabular}

\subsection{Identificação e quantificação dos produtos farmacêuticos e de cuidados pessoais na água do Reservatório do Lobo}

Foram identificados e quantificados os seis PFCPs foco deste estudo na água do Reservatório do Lobo, que abasteceu os 22 filtros ecológicos, durante todo o período das contaminações $\left(22^{\circ} 10^{\prime} 18.09^{\prime \prime S} 47^{\circ} 54^{\prime} 5.00^{\prime \prime W}\right)$.

Calijuri e Tundisi (1990) identificaram no reservatório do Lobo mudanças ambientais causadas por atividades humanas o desmatamento, o despejo de esgoto sanitário e de fertilizantes utilizados em algumas áreas agrícolas. Porém, até o presente momento não haviam sido divulgadas informações de contaminações do reservatório do Lobo por PFCPs.

A concentração de cada um dos compostos detectados na água afluente aos filtros ecológicos encontram-se na Tabela 5. O ponto de coleta das amostras na represa foi sempre o mesmo, sendo este o local onde está localizada a bomba hidráulica que bombeou água para abastecer o sistema de tratamento de água (Figura 1 do Capítulo 1).

Na primeira coleta realizada (S1) a concentração do metilparabeno e da benzofenona-3 foram as mais altas detectadas em todo o período de análise $\left(1.192,3900 \mu \mathrm{g} \mathrm{L}^{-1}\right.$ e 1,4810 $\mu \mathrm{g} \mathrm{L}$ ${ }^{1}$, respectivamente). Em um trabalho feito no interior do estado de São Paulo, Brasil, por 
Galinaro et al., (2015) o metilparabeno foi detectado em diversos pontos de coleta de água do rio Mogi Guaçu em concentração média de $8 \mu \mathrm{g} \mathrm{L}^{-1}$, sendo $27,5 \mu \mathrm{g} \mathrm{L}^{-1}$ a concentração mais alta. Neste estudo, a média da concentração do metilparabeno foi de $170,87 \mu \mathrm{g} \mathrm{L}^{-1}$.

Tabela 5: Concentrações dos compostos detectados nas amostras de água do reservatório do Lobo, expressos em $\mu \mathrm{g} \mathrm{L}{ }^{-1}$, por SPE-LC-MS/MS.

\begin{tabular}{lcccccc}
\hline Amostras & Paracetamol & Diclofenaco & Naproxeno & Ibuprofeno & Metilparabeno & Benzofenona-3 \\
\hline S1 & 0,0250 & 0,0560 & 0,1050 & 0,1380 & $1.192,3900$ & 1,4810 \\
S2 & 0,1321 & 0,0200 & 0,0092 & 0,0005 & 1,3127 & 2,1041 \\
S3 & LOQ & $<$ LOQ & n.d. & $<$ LOQ & 0,4575 & 1,1811 \\
S4 & 0,0269 & 0,0509 & $<$ LOQ & n.d. & 0,7657 & 0,7793 \\
S5 & 0,0084 & 0,0202 & 0,0051 & n.d. & 0,6486 & 1,5071 \\
S6 & 0,0198 & n.d. & LLOQ & n.d. & 0,4708 & 0,6663 \\
S7 & n.d. & n.d. & <LOQ & n.d. & 0,1049 & 0,3268 \\
\hline
\end{tabular}

n.d.: Não detectado.<LOQ: menor que o limite de quantificação.

De acordo com dados meteorológicos coletados na estação climatológica do CRHEA (Centro de Recursos Hídricos e Estudos Ambientais) que segue as normas da Organização Mundial de Meteorologia, no dia da coleta S1, choveu uma média de 55,40 mm.

A coleta S1 ocorreu no dia 04/11/2013 (segunda-feira), sendo que no final de semana que antecedeu a coleta foi feriado nacional. O provável aumento do uso do reservatório e do seu entorno para atividades recreativas, e maior possibilidade de uso para banhos e despejo de esgoto pelos ranchos que beiram o reservatório, podem estar relacionados ao aumento na concentração dos compostos, como diclofenaco $\left(0,056 \mu \mathrm{g} \mathrm{L}^{-1}\right)$, naproxeno $\left(0,1050 \mu \mathrm{g} \mathrm{L}^{-1}\right)$, ibuprofeno $\left(0,138 \mu \mathrm{g} \mathrm{L}^{-1}\right)$, e principalmente de metilparabeno $\left(1.192,39 \mu \mathrm{g} \mathrm{L}^{-1}\right)$.

Se for desconsiderado o dia atípico, a concentração média do metilparabeno encontrada foi de $0,6267 \mu \mathrm{g} \mathrm{L}^{-1}$. Este composto também foi encontrado em diversos corpos d'água no mundo, como Índia, Estados Unidos, Reino Unido, China e diversos países da Europa (BENIJITS et al., 2004; LORAINE e PETTIGROVE, 2006; PENG et al., 2008; BLANCO et al, 2009; PEDROUZO et al, 2009; JONKERS et al, 2010; RAMASWAMY et al., 2011; RENZ et al., 2013; HAMAN et al., 2015) em concentração variando de 0,005 a 79,6 $\mu \mathrm{g} \mathrm{L}^{-1}$. Considera-se geralmente que os parabenos são predominantemente presentes na fase aquosa do afluente (> 97\%), provavelmente devido à sua moderada solubilidade em água (BRATKOWSKA et al., 2011).

A concentração média de benzofenona-3 foi de 1,1493 $\mu \mathrm{g} \mathrm{L}^{-1}$. Em lagos da Suíça a concentração da benzofenona-3 encontradas foram de $<2$ a $125 \mathrm{ng} \mathrm{L}^{-1}$ (POIGER et al., 2004). No Brasil Silva et al (2013) registraram $<2 \mathrm{ng} \mathrm{L}^{-1}$ em Araraquara, São Paulo. Também foi 
encontrado em diversos países, como Japão, Espanha, Coréa do Sul, Reino Unido, dentre outros $\left(<0,3-103 \mathrm{ng} \mathrm{L}^{-1}\right)$ (KIM e CHOI, 2014).

O paracetamol foi encontrado na concentração que variou de $0,0198 \mu \mathrm{g} \mathrm{L}^{-1}$ a 0,1321 $\mu \mathrm{g} \mathrm{L}^{-1}$ ao longo do período estudado, com média de $0,042 \mu \mathrm{g} \mathrm{L}^{-1}$. Em demais trabalhos realizados no Brasil, Almeida e Weber, (2005) descrevem que a concentração de paracetamol na represa Billings esteve entre 0,3 e 10,3 ng L ${ }^{-1}$, Montagner e Jardim (2011) encontraram 13,440 ng L $\mathrm{L}^{-1}$ em amostras de água da bacia hidrográfica do Atibaia, e Oliveira (2014) reportou a concentração de 11 a $531 \mathrm{ng} \mathrm{L}^{-1}$ na represa do Guarapiranga. Em demais países, o composto foi encontrado com concentração media de $0,055 \mu \mathrm{g} \mathrm{L}^{-1}$ (BOUND e VOULVOLIS, 2006; GROS et al., 2006).

O paracetamol é amplamente utilizado e na maioria dos países, não é necessário receita medica para a sua compra, além disso, faz parte da composição de vários medicamentos. Devido a grande produção e extensivo uso, esta substância é relatada como um dos medicamentos mais frequentemente encontrados em amostras de aguas de superfície, águas residuárias e até mesmo agua potável (PAROLINI et al., 2010). Henschel et al., (1997) classificaram este medicamento como nocivo para os organismos aquáticos, com base em alguns ensaios ecotoxicológicos com diferentes modelos biológicos, como bactérias, algas, cladóceros e peixes.

O diclofenaco está dentre os 10 compostos mais frequentemente encontrados nos ecossistemas aquáticos (SOTELO et al., 2014). Neste trabalho sua média de detecção foi de $0,036 \mu \mathrm{g} \mathrm{L}^{-1}$, sendo que o composto não foi detectado ou esteve abaixo do limite de detecção em três das sete coletas realizadas. No Brasil o composto foi encontrado na represa Billings em concentração entre 8,1 a 394,5 ng L ${ }^{-1}$ (ALMEIDA e WEBER, 2005), na represa do Guarapiranga a concentração esteve entre 6 e 36 ng L ${ }^{-1}$ (OLIVEIRA, 2014), e no Rio de Janeiro foi encontrado na concentração de até $60 \mathrm{ng} \mathrm{L}^{-1}$ (STUMPF et al, 1999). Na Alemanha, a concentração chegou a $600 \mathrm{ng} \mathrm{L}^{-1}$ (HEBERER, 2002).

O naproxeno e o ibuprofeno também estão entre os fármacos mais encontrados em corpos de água, com concentração média entre $0,039 \mu \mathrm{g} \mathrm{L}^{-1}$ e $0,069 \mu \mathrm{g} \mathrm{L} \mathrm{L}^{-1}$, respectivamente, similarmente a outros trabalhos que encontraram estes compostos no Brasil, como a concentração encontrada na represa Billings (10 a 78,2 ng L ${ }^{-1}$ ) (ALMEIDA e WEBER, 2005), e no Rio de Janeiro $\left(<0,01 \mu \mathrm{g} \mathrm{L}^{-1}\right.$ ) (STUMPF et al., 1999). O naproxeno, também foi encontrado no Rio de Janeiro (STUMPF et al., 1999) com concentração media de $0,03 \mu \mathrm{g} \mathrm{L} \mathrm{L}^{-1}$. 
Neste estudo, o naproxeno não foi encontrado em um dos dias de coleta e esteve abaixo do limite de quantificação em três dias. O ibuprofeno não foi encontrado em quatro dias de coleta e esteve abaixo do limite de quantificação em um deles.

É importante ressaltar que a poluição da água está diretamente ligada às atividades humanas, urbana, industrial ou agrícola. Delpla et al., (2009) descrevem que as mudanças climáticas podem levar à degradação nas águas superficiais e a qualidade como uma consequência indireta desta fonte pontual de atividades.

\subsection{Identificação de produtos de degradação nas águas do reservatório do Lobo}

Inicialmente foi feita uma busca na literatura sobre os trabalhos que trataramda degradação de cada um dos seis dos compostos foco deste estudo (WIESENBERGBOETHER et al, 1991; KEPP et al., 1997; SIDELMANN et al 2001; WINKLER et al., 2001; LOFFLER e TERNES, 2003; GALMIER et al., 2005; PÉREZ-ESTRADA et at., 2005; AGUERA et al., 2005; QUINTANA et al., 2005; HSU et al., 2006; CANOSA et al., 2006; YANG et al., 2008; MARCO-URREA et al., 2010; TAY et al., 2010; DE LUNA et al., 2012; STETER et al., 2013; HUGUET et al., 2014; JALLOULI et al., 2014; NOETSOPOULOS et al., 2015; GONG et al., 2015).

As informações foram utilizadas como banco de dados para a busca dos compostos nas amostras. As mais variadas massas dos produtos de degradação descritas na literatura foram utilizadas para o monitoramento dos experimentos de íons fragmentos.

Primeiramente, realizou-se a extração de cada uma das massas encontradas para todos os produtos de degradação de cada um dos compostos, e aquelas que foram detectadas nas amostras, foram selecionadas para as análises de fragmentação. As massas selecionadas foram: m/z 292 (PD do diclofenaco), m/z 278 (PD de diclofenaco), m/z 201 (PD do metilparabeno), 282 (PD do diclofenaco), m/z 185 (PD metilparabeno), m/z 245 (PD da benzofenona-3), m/z 215 (PD da Benzofenona-3), m/z 231(PD da benzofenona-3), sendo PD Produto de Degradação.

Foram feitos os experimentos de varredura de íons para as amostras estudadas, e ao analisar os espectros obtidos, observou-se que os mesmos compostos detectados nas amostras da água de entrada nos filtros, em todos os tempos e dias de coletas, eram os mesmos encontrados nas amostras da saída do filtro. Ou seja, os mesmos compostos que se esperava identificar como produtos de degradação gerados pelo tratamento da água por filtros ecológicos já se encontravam presentes na água de entrada (Reservatório do Lobo), o que 
condiz com as análises de quantificação já que todos os compostos em estudos foram encontrados na água afluente aos filtros.

Das massas selecionadas, os PDs que podem ser correlacionados aos compostos descritos na literatura tratam-se dos de m/z 292 e 245, PDs dos compostos diclofenaco e Benzofenona-3, respectivamente.

O PD $291(\mathrm{~m} / \mathrm{z} 292)$ apresentou os íons fragmentos $274\left(\mathrm{C}_{14} \mathrm{H}_{9} \mathrm{NO}_{3} \mathrm{Cl}\right), 218$ $\left(\mathrm{C}_{12} \mathrm{H}_{9} \mathrm{NOCl}\right)$ e $150\left(\mathrm{C}_{11} \mathrm{H}_{4} \mathrm{~N}\right)$ (Figura 4). O PD $244(\mathrm{~m} / \mathrm{z} 245)$ apresentou como principais fragmentos $217\left(\mathrm{C}_{13} \mathrm{H}_{13} \mathrm{O} 3\right), 199\left(\mathrm{C}_{13} \mathrm{H}_{11} \mathrm{O}_{2}\right), 189\left(\mathrm{C}_{12} \mathrm{H}_{13} \mathrm{O}_{2}\right)$ e $157\left(\mathrm{C}_{11} \mathrm{H}_{9} \mathrm{O}\right)$ (Figura 5). Ambos os compostos estão condizentes com a literatura já citada e já foram detectados em corpos d'água.

Em adicional, propõe-se uma via de degradação de cada composto identificado, diclofenaco e benzofenona-3, que podem ser observadas nas Figuras 4 e 5, respectivamente.

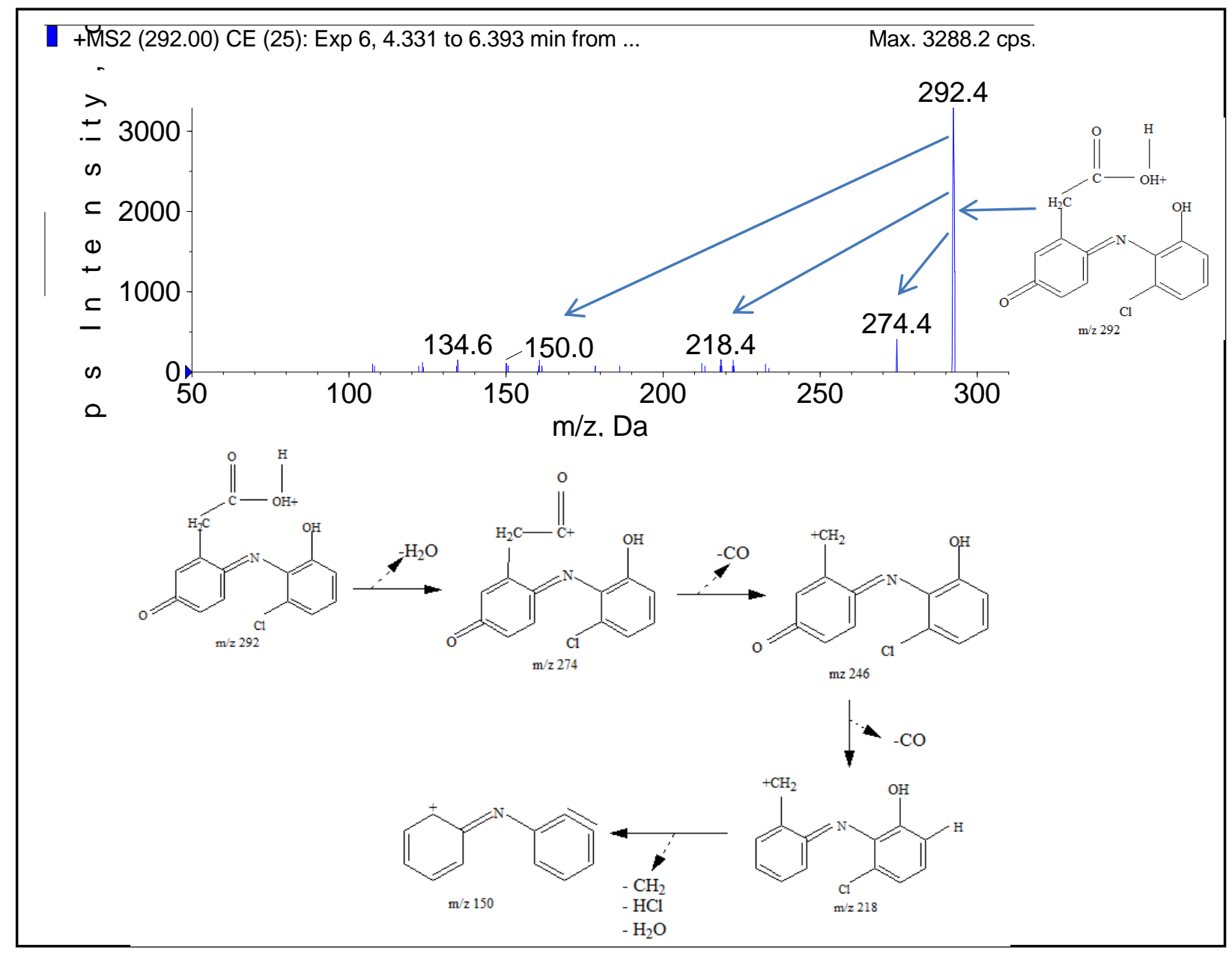

Figura 4: Espectro de íons fragmentos do PD do diclofenaco nas amostras, e estrutura proposta (pelo autor) da via de degradação.

Como sugestões para futuros trabalhos a respeito, devem ser realizados estudos mais aprofundados para a confirmação de quais produtos são ou não formados pelo processo de 
filtração estudado, em experimentos de bancada com água sintética, ou água proveniente de nascente, que ainda não foram contaminadas.

Foram feitas as análises para as amostras do efluente dos filtros ecológicos, porém, observou-se o mesmo perfil cromatográfico em todas as amostras. Induz-se então que, provavelmente, não houve a total remoção dos PDs detectados na água da represa pelos filtros ecológicos.

$+\mathrm{MS} 2$ (245.00) CE (25): Exp 12, 4.640 to 5.550 min fro...

Max. 3742.4 cps.
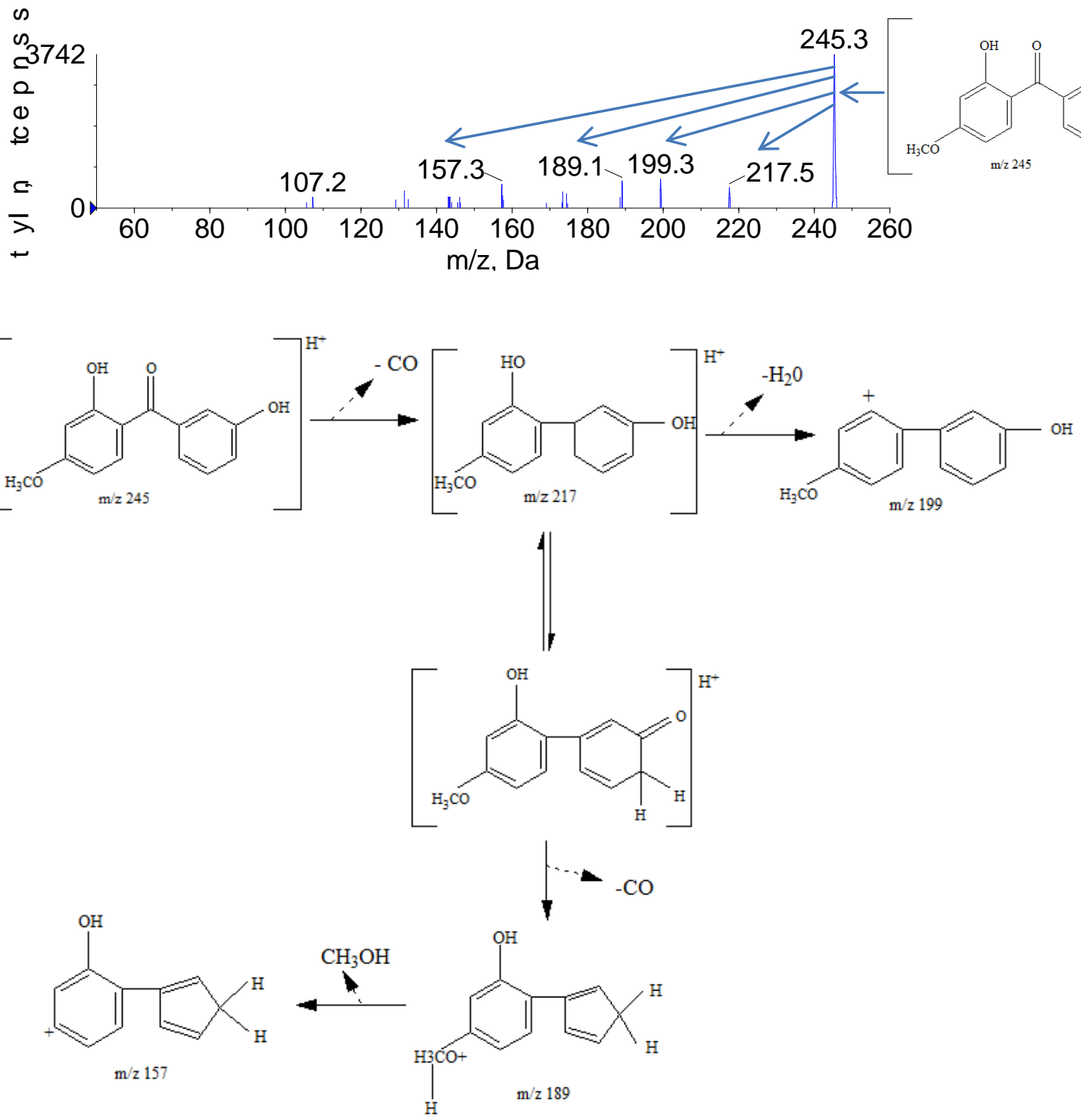

Figura 5: Espectro de íons fragmentos do PD de benzofenona-3 nas amostras, e estrutura proposta (pelo autor) da via de degradação. 


\subsection{Remoção dos produtos farmacêuticos e de cuidados pessoais por filtros ecológicos}

A fim de avaliar a remoção dos seis PFCPs, foram efetuados três eventos de contaminações dos filtros, com intervalo de 15 dias entre elas, sendo que as amostras no efluente de cada filtro foram coletadas em três instantes distintos: 3; 6 e 24 horas após o início do processo de filtragem com a adição dos contaminantes.

Dado que o intervalo de 15 dias entre as medições é um período longo, foram consideradas como sendo independentes.

Tabela 6: Descrição de cada tratamento e respectivas unidades amostrais.

\begin{tabular}{llcc}
\hline & \multicolumn{1}{c}{ Tratamentos } & Filtros & Tempos de coleta \\
\hline Controle & (nenhuma contaminação aplicada) & 1 & 3h, 6h e 24h \\
Filtro FEco & (contaminado com uma substância específica) & 2 a 19 & 3h, 6h e 24h \\
Filtro Mix & (contaminado com uma mistura de todas as substâncias) & 20 a 22 & 3h, 6h e 24h \\
\hline
\end{tabular}

Conforme mostra a Tabela 6, os filtros FEco foram contaminados com uma substância pré-definida, sendo considerados 3 filtros para cada substância, sendo assim considerados:

- Filtro 1: filtro controle, sem receber contaminação;

- Filtros FEco 2 a 4: filtros contaminados com paracetamol;

- Filtros FEco 5 a 7: filtros contaminados com diclofenaco;

- Filtros FEco 8 a 10: filtros contaminados com naproxeno;

- Filtros FEco 11 a 13: filtros contaminados com ibuprofeno;

- Filtros FEco 14 a 16: filtros contaminados com metilparabeno;

- Filtros FEco 17 a 19: filtros contaminados com benzofenona-3;

- Filtros Mix 20 a 22: filtros contaminados com um mix de todas essas substâncias.

Os filtros foram dispostos de forma independente, ou seja, a água que abasteceu o sistema foi a mesma para todos os filtros, mas a filtragem em cada um, após a respectiva contaminação, foi independente dos demais. Foram adicionados os contaminantes específicos, na concentração de $2 \mu \mathrm{g} \mathrm{L}^{-1}$, em cada filtro, como descrito anteriormente em materiais e métodos. Desta forma, a água a ser filtrada nos filtros específicos para uma determinada 
substância, recebeu uma contaminação proposital de $2 \mu \mathrm{g} \mathrm{L}^{-1}$ da substância, além da concentração já presente na água da represa.

Para os tratamentos FEco e Mix foram coletadas um total de nove coletas para cada contaminação enquanto que, para o Controle, foram três coletas já que este era comum aos demais. Desta forma, teve-se um experimento longitudinal para cada composto utilizado na contaminação, comparando o seu processo de filtragem com as filtragens nos filtros Controle e Mix, ou seja, têm-se seis análises, uma para cada substância.

Numa análise exploratória inicial, foram calculadas as médias do percentual na concentração de cada substância e nos instantes de coleta. Para os filtros FEco e Mix, como foram coletadas nove amostras, foi possível construir intervalos assintóticos normais para as médias com 95\% de confiança. Para os filtros Controle não foi possível construir os intervalos de confiança pelo fato de terem três observações cada. Os resultados obtidos são apresentados nas Tabelas 7 a 9.

Tabela 7: Redução percentual média na concentração de cada substância pelos filtros controle.

\begin{tabular}{|c|c|c|c|c|c|}
\hline Compostos & $\begin{array}{c}\text { Coleta } \\
(\text { tempo) }\end{array}$ & $\mathbf{N}$ & $\begin{array}{c}\text { Abaixo } \\
\text { do limite }\end{array}$ & Médias & Desvio Padrão ${ }^{1}$ \\
\hline \multirow{3}{*}{ Paracetamol } & 3 & 3 & 0 & 46,03 & 48,50 \\
\hline & 6 & 2 & 1 & 14,78 & 9,08 \\
\hline & 24 & 2 & 1 & 73,80 & 37,05 \\
\hline \multirow{3}{*}{ Diclofenaco } & 3 & 3 & 0 & 45,99 & 42,56 \\
\hline & 6 & 1 & 2 & 95,00 & . \\
\hline & 24 & 2 & 1 & 93,47 & 9,23 \\
\hline \multirow{3}{*}{ Naproxeno } & 3 & 3 & 0 & 84,83 & 24,64 \\
\hline & 6 & 1 & 2 & 99,43 & . \\
\hline & 24 & 1 & 2 & 96,19 & . \\
\hline \multirow{3}{*}{ Ibuprofeno } & 3 & 2 & 1 & 99,28 & 1,02 \\
\hline & 6 & 1 & 2 & 98,77 & $\cdot$ \\
\hline & 24 & 1 & 2 & 100,00 & . \\
\hline \multirow{3}{*}{ Metilparabeno } & 3 & 3 & 0 & 49,75 & 43,10 \\
\hline & 6 & 3 & 0 & 51,34 & 47,24 \\
\hline & 24 & 3 & 0 & 54,17 & 50,02 \\
\hline \multirow{3}{*}{ Benzofenona-3 } & 3 & 3 & 0 & 44,66 & 29,58 \\
\hline & 6 & 3 & 0 & 39,87 & 57,68 \\
\hline & 24 & 3 & 0 & 66,16 & 28,79 \\
\hline
\end{tabular}

(1) medidas que não puderam ser calculadas devido às observações abaixo do limite (composto não detectado, ou abaixo dos limites de quantificação e/ou detecção). 
Tabela 8: Percentual de redução média na concentração de cada substância pelos filtros FEco.

\begin{tabular}{|c|c|c|c|c|c|c|c|}
\hline Compostos & \begin{tabular}{|c|} 
Coleta \\
(Tempo)
\end{tabular} & $\mathbf{N}$ & $\begin{array}{l}\text { Abaixo do } \\
\text { limite }\end{array}$ & Média & $\begin{array}{l}\text { Desvio } \\
\text { Padrão }\end{array}$ & \multicolumn{2}{|c|}{$\begin{array}{c}\text { Intervalo }^{2} \text { de } \\
\text { Confiança } 95 \%\end{array}$} \\
\hline \multirow{3}{*}{ Paracetamol } & 3 & 9 & 0 & 99,43 & 1,43 & 98,33 & 100,53 \\
\hline & 6 & 9 & 0 & 99,33 & 0,68 & 98,80 & 99,85 \\
\hline & 24 & 9 & 0 & 99,56 & 0,44 & 99,22 & 99,89 \\
\hline \multirow{3}{*}{ Diclofenaco } & 3 & 9 & 0 & 97,15 & 2,61 & 95,15 & 99,16 \\
\hline & 6 & 9 & 0 & 94,85 & 9,13 & 87,83 & 101,87 \\
\hline & 24 & 9 & 0 & 97,83 & 5,40 & 93,68 & 101,99 \\
\hline \multirow{3}{*}{ Naproxeno } & 3 & 9 & 0 & 98,26 & 1,92 & 96,79 & 99,74 \\
\hline & 6 & 9 & 0 & 99,37 & 0,45 & 99,03 & 99,72 \\
\hline & 24 & 9 & 0 & 99,93 & 0,09 & 99,86 & 99,99 \\
\hline \multirow{3}{*}{ Ibuprofeno } & 3 & 9 & 0 & 98,50 & 4,26 & 95,22 & 101,78 \\
\hline & 6 & 9 & 0 & 99,89 & 0,25 & 99,70 & 100,08 \\
\hline & 24 & 9 & 0 & 99,98 & 0,04 & 99,95 & 100,01 \\
\hline \multirow{3}{*}{ Metilparabeno } & 3 & 9 & 0 & 78,12 & 14,19 & 67,21 & 89,02 \\
\hline & 6 & 9 & 0 & 90,55 & 9,42 & 83,31 & 97,80 \\
\hline & 24 & 9 & 0 & 85,22 & 16,12 & 72,83 & 97,61 \\
\hline \multirow{3}{*}{ Benzofenona-3 } & 3 & 9 & 0 & 79,32 & 22,04 & 62,38 & 96,27 \\
\hline & 6 & 9 & 0 & 74,34 & 23,89 & 55,97 & 92,70 \\
\hline & 24 & 9 & 0 & 85,19 & 19,27 & 70,38 & 100,00 \\
\hline
\end{tabular}

(2) Devido ao caráter normal assintótico dos intervalos de confiança, alguns valores no limite superior são maiores de $100 \%$.

Tabela 9: Percentual de redução média na concentração de cada substância pelos Filtros Mix.

\begin{tabular}{|c|c|c|c|c|c|c|c|}
\hline Composto & $\begin{array}{c}\text { Coleta } \\
\text { (tempo) }\end{array}$ & $\mathbf{N}$ & $\begin{array}{c}\text { Abaixo do } \\
\text { limite }\end{array}$ & Média & $\begin{array}{l}\text { Desvio } \\
\text { Padrão }\end{array}$ & $\begin{array}{l}\text { Inte } \\
\text { Confi }\end{array}$ & $\begin{array}{l}2 \text { de } \\
95 \%\end{array}$ \\
\hline \multirow{3}{*}{ Paracetamol } & 3 & 9 & 0 & 99,41 & 0,68 & 98,89 & 99,93 \\
\hline & 6 & 9 & 0 & 98,64 & 1,69 & 97,34 & 99,94 \\
\hline & 24 & 9 & 0 & 98,91 & 2,17 & 97,24 & 100,58 \\
\hline \multirow{3}{*}{ Diclofenaco } & 3 & 9 & 0 & 97,70 & 1,94 & 96,21 & 99,19 \\
\hline & 6 & 9 & 0 & 98,13 & 3,71 & 95,28 & 100,98 \\
\hline & 24 & 9 & 0 & 99,53 & 0,46 & 99,18 & 99,89 \\
\hline \multirow{3}{*}{ Naproxeno } & 3 & 9 & 0 & 98,86 & 0,85 & 98,21 & 99,51 \\
\hline & 6 & 9 & 0 & 99,23 & 1,05 & 98,42 & 100,04 \\
\hline & 24 & 9 & 0 & 99,90 & 0,09 & 99,83 & 99,97 \\
\hline \multirow{3}{*}{ Ibuprofeno } & 3 & 9 & 0 & 99,91 & 0,15 & 99,80 & 100,03 \\
\hline & 6 & 9 & 0 & 99,94 & 0,16 & 99,82 & 100,06 \\
\hline & 24 & 9 & 0 & 99,95 & 0,11 & 99,86 & 100,04 \\
\hline \multirow{3}{*}{ Metilparabeno } & 3 & 9 & 0 & 62,88 & 47,01 & 26,74 & 99,02 \\
\hline & 6 & 9 & 0 & 89,52 & 7,83 & 83,50 & 95,53 \\
\hline & 24 & 9 & 0 & 75,81 & 33,76 & 49,86 & 101,76 \\
\hline \multirow{3}{*}{ Benzofenona-3 } & 3 & 9 & 0 & 76,58 & 16,38 & 63,99 & 89,16 \\
\hline & 6 & 9 & 0 & 90,27 & 3,66 & 87,46 & 93,09 \\
\hline & 24 & 9 & 0 & 88,81 & 11,59 & 79,90 & 97,71 \\
\hline
\end{tabular}

(2) Devido ao caráter normal assintótico dos intervalos de confiança, alguns valores no limite superior são maiores de $100 \%$. 
Após as análises exploratórias iniciais, a análise considerada foi a de variância (ANOVA) a um fator com medidas repetidas. A análise de experimentos com medidas repetidas apresenta um caráter multivariado, porém, uma condição suficiente e necessária para que os testes de hipóteses possam ser aplicados é que a matriz de covariâncias satisfaça a condição de esfericidade. Para verificar essa condição foi usado o teste de esfericidade de Mauchly.

A partir dos resultados de tais testes realizados, e percebido que a condição de esfericidade não foi satisfeita para nenhum dos compostos, analisou-se os dados através de uma análise de variância multivariada (MANOVA).

Os resultados estão apresentados a seguir, divididos por contaminante, sendo comparados os filtros em que o composto foi aplicado individualmente em triplicata (FEco), com o filtro controle (Controle) e com os três filtros em que foi aplicado o mix (Mix) dos compostos.

\section{Remoção do Paracetamol}

No caso da contaminação dos filtros com paracetamol, foram considerados os filtros FEco de números 2 a 4, os quais foram comparados com os filtros Controle e Mix, nos tempos de coleta de 3; 6 e 24 horas após o início da contaminação (Tabela 10).

Na Figura 6 são apresentados os perfis individuais das concentrações encontradas nas amostras coletadas em cada filtro no gráfico da esquerda, e os perfis amostrais médios por tratamento no gráfico da direita, onde se observa a médiaentre tratamentos (FEco, Mix e Controle) e possíveis tendências nos tratamentos.

Na Figura 7 tem-se um gráfico com as porcentagens médias de remoção do composto. Observa-se que o filtro controle apresentou menor porcentagem média de remoção no tempo de coleta de 6 horas, e que as porcentagens de remoção se igualaram nos filtros FEco e FMix, indicando que não houve diferenças na eficiência de remoção quando há mistura de compostos na água afluente.

Na Tabela 11 tem-se o resultado do teste de Mauchly. Os valores p's dos testes, iguais a 0,0123 , são menores do que 0,05 indicando que a condição de esfericidade não está sendo satisfeita, indicando que as análises devem ser feitas pela técnica multivariada, ou MANOVA. 
Tabela 10: Valores médios de concentração de paracetamol por tratamento e média geral, expressas

\begin{tabular}{c|c|c|c}
\hline \multicolumn{4}{c}{ em $\mu \mathrm{g} \mathrm{L}^{-1}$. } \\
\cline { 2 - 4 } Tratamento & 3h & Th & $24 \mathrm{~h}$ \\
\hline FEco & 0,01141 & 0,01361 & 0,00896 \\
Mix & 0,01201 & 0,02742 & 0,02211 \\
\hline Controle & 0,04702 & 0,01263 & 0,00437 \\
\hline Geral & 0,01675 & 0,01939 & 0,01394 \\
\hline
\end{tabular}

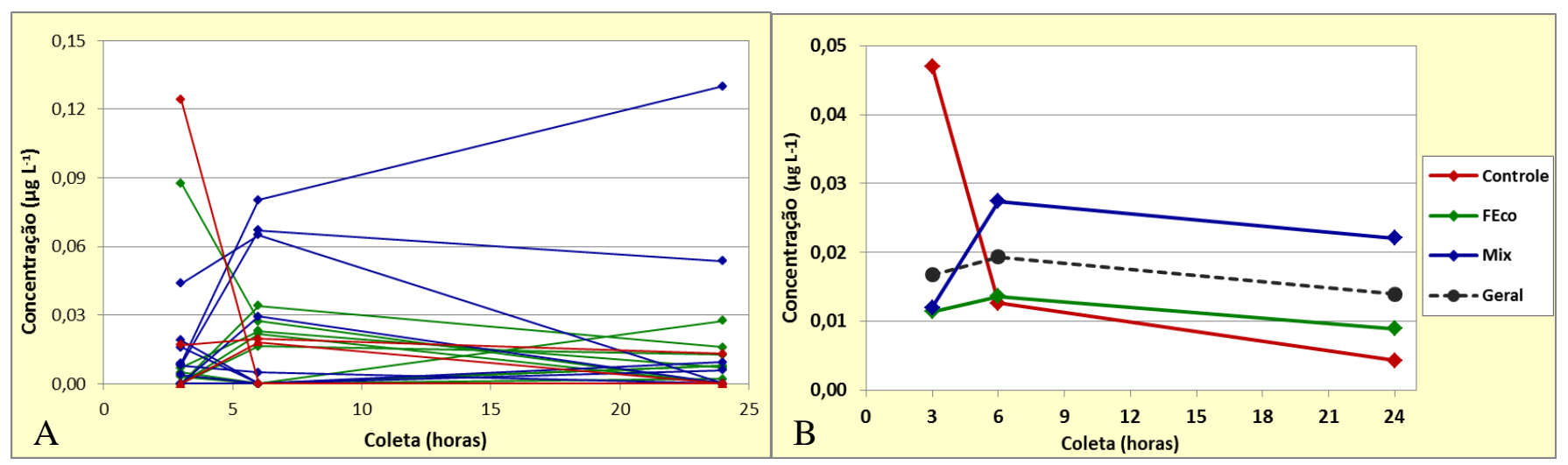

Figura6: Perfis individuais (A) e perfis amostrais médios (B) para as contaminações com paracetamol.

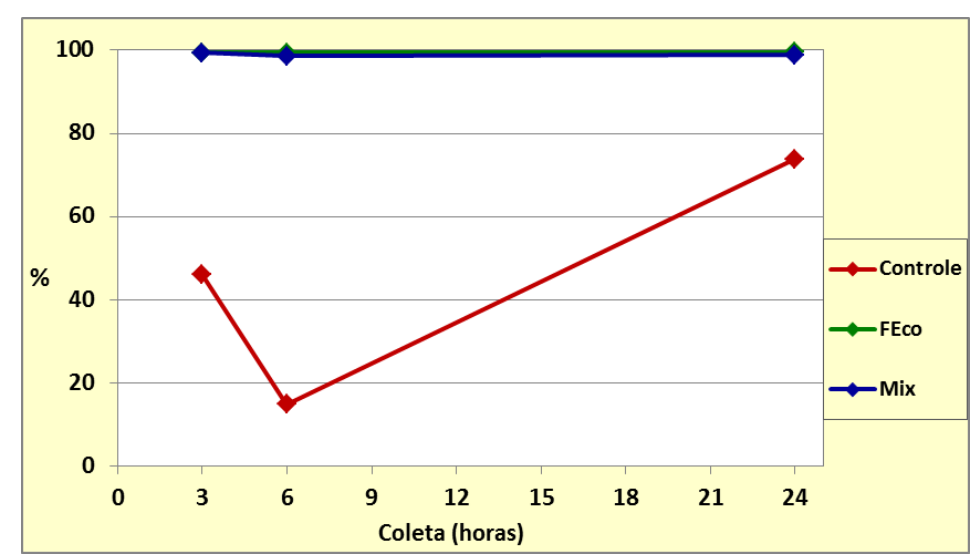

Figura 7: Médias das porcentagens de remoção do paracetamol pelos filtros Controle, FEco e Mix, durante todas contaminações e diferentes tempos de coleta.

Tabela 11: Teste de esfericidade de Mauchly na contaminação com paracetamol.

\begin{tabular}{lccc}
\hline Variáveis & GL & $\chi^{\mathbf{2}}$ & Valor $\mathbf{p}$ \\
\hline Transformed Variates & 2 & 8,7899 & 0,0123 \\
\hline Orthogonal Components & 2 & 8,7899 & 0,0123 \\
\hline
\end{tabular}


Na Tabela 12 são apresentados os testes multivariados para a hipótese de que não existe efeito da interação tempo de coleta $\times$ tratamento, ou seja, para testar se há paralelismo entre os perfis médios.

Como os valores $\mathrm{p}$ dos testes são maiores do que 0,05 , logo, não se rejeita a hipótese de paralelismo entre os perfis médios de concentração de paracetamol.

Tabela 12: MANOVA para testar a hipótese da ausência do efeito da interação coleta $x$ tratamento, nas contaminações com paracetamol.

\begin{tabular}{lccccc}
\hline Estatística & $\begin{array}{c}\text { Valor } \\
\text { observado }\end{array}$ & Razão F & $\begin{array}{c}\text { GL do } \\
\text { numerador }\end{array}$ & $\begin{array}{c}\text { GL do } \\
\text { denominador }\end{array}$ & Valor $\boldsymbol{p}$ \\
\hline Wilks' Lambda & 0,82342 & 0,870 & 4 & 34,000 & 0,4936 \\
Pillai's Trace & 0,17676 & 0,870 & 4 & 36,000 & 0,4899 \\
Hotelling-Lawley Trace & 0,21423 & 0,900 & 4 & 19,407 & 0,4854 \\
Roy's Greatest Root & 0,21319 & 1,920 & 2 & 18,000 & 0,1756 \\
\hline
\end{tabular}

Na Tabela 13 têm-se os testes para a hipótese de que não existe efeito de tratamento, ou seja, de que os perfis médios efluente dos filtros possuem retas coincidentes no gráfico. Pelos valores de $\mathrm{p}$ apresentados, todos maiores do que 0,05 , não se descarta a hipótese de perfis coincidentes. Isso indica as concentrações médias do paracetamol não apresentaram diferenças significativas com relação aos filtros Controle, Mix e FEco.

Tabela 13: MANOVA para testar a hipótese da ausência do efeito de tratamento, nas contaminações com paracetamol.

\begin{tabular}{lccccc}
\hline Estatística & $\begin{array}{c}\text { Valor } \\
\text { observado }\end{array}$ & Razão F & $\begin{array}{c}\text { GL do } \\
\text { numerador }\end{array}$ & $\begin{array}{c}\text { GL do } \\
\text { denominador }\end{array}$ & Valor $\boldsymbol{p}$ \\
Wilks' Lambda & 0,76572 & 0,760 & 6 & 32,000 & 0,6054 \\
Pillai's Trace & 0,24619 & 0,800 & 6 & 34,000 & 0,5800 \\
Hotelling-Lawley Trace & 0,29041 & 0,750 & 6 & 19,652 & 0,6136 \\
Roy's Greatest Root & 0,21959 & 1,24 & 3 & 17,000 & 0,3247 \\
\hline
\end{tabular}

Na Tabela 14, por sua vez, estão os testes que verificaram se há evidência do efeito do tempo de coleta na concentração de saída dos filtros. Com valor de p iguais a 0,5369 para os testes aplicados, maior do que o nível de significância de 0,05 , não se rejeitou a hipótese de igualdade entre as medias dos tempos de coleta.

Tabela 14: MANOVA para testar a hipótese da ausência do efeito do tempo de coleta.

\begin{tabular}{lccccc}
\hline Estatística & $\begin{array}{c}\text { Valor } \\
\text { observado }\end{array}$ & Razão F & $\begin{array}{c}\text { GL do } \\
\text { numerador }\end{array}$ & $\begin{array}{c}\text { GL do } \\
\text { denominador }\end{array}$ & Valor $\boldsymbol{p}$ \\
Wilks' Lambda & 0,92944 & 0,650 & 2 & 17 & 0,5369 \\
Pillai's Trace & 0,07056 & 0,650 & 2 & 17 & 0,5369 \\
Hotelling-Lawley Trace & 0,07592 & 0,650 & 2 & 17 & 0,5369 \\
Roy's Greatest Root & 0,07592 & 0,650 & 2 & 17 & 0,5369 \\
\hline
\end{tabular}


Apesar dos testes estatísticos iniciais e das porcentagens de remoção (Figura 6) mostrarem que a porcentagem de remoção do paracetamol nos filtros controle tenha sido menor de que nos tratamentos FEco e Mix, com os resultados dos testes estatísticos MANOVA apresentados nas Tabelas 12 a 14, verifica-se que os perfis médios de concentração de paracetamol são paralelos, coincidentes e horizontais, ou seja, não houve diferença significativa entre os tempos de coleta ( $3 ; 6$ ou 24 horas), nem de tratamento (FEco, Controle ou Mix), nem da interação. A porcentagem média global de remoção do paracetamol pelos filtros ecológicos foi de $81 \%$. Erba et al., (2012) relataram a remoção de $80 \%$ por filtro ecológico, o que se assimila muito com este estudo em questão.

Muitos trabalhos avaliaram a remoção do paracetamol por diversos sistemas de tratamento de esgoto ou sistemas de tratamento avançado de água, com remoções de até 90\% mas são técnicas dispendiosas. São escassos os trabalhos que avaliem a remoção por filtros ecológicos. Alguns estudos relatam a biodegradação do composto, e podem ser vistos na revisão bibliográfica realizada por Onesios, Yu e Bouwer, (2009).

Westerhoff, (2003) relata que os biofiltros avaliados foram capazes de remover paracetamol, mas não há informações sobre a concentração ou porcentagem de remoção pelo filtro. $\mathrm{O}$ autor diz ainda que testes mostraram que há acumulação no biofilme, mas os testes em escalas laboratoriais realizados não foram conclusivos.

\section{Remoção de Diclofenaco}

No caso da contaminação dos filtros com diclofenaco, foram considerados os filtros FEco de números 5 a 7, os quais foram comparados com os filtros Controle e Mix, nos tempos de coleta 3; 6 e 24 horas após o início da contaminação (Tabela 15).

Tabela 15: Valores médios da concentração de diclofenaco por tratamento e concentração média geral, expressas em $\mu \mathrm{g} \mathrm{L}{ }^{-1}$.

\begin{tabular}{c|c|c|c}
\hline \multirow{2}{*}{ Tratamento } & \multicolumn{3}{c}{ Tempos de coleta } \\
\cline { 2 - 4 } & $3 \mathrm{~h}$ & $6 \mathrm{~h}$ & $24 \mathrm{~h}$ \\
\hline FEco & 0,05784 & 0,10354 & 0,04444 \\
Mix & 0,04662 & 0,03750 & 0,00953 \\
\hline Controle & 0,01152 & 0,00093 & 0,00222 \\
\hline Geral & 0,04641 & 0,06058 & 0,02345 \\
\hline
\end{tabular}

Na Figura 8 são apresentados os perfis individuais de cada filtro no gráfico da esquerda e os perfis amostrais médios por tratamento no gráfico da direita, nos quais se pode 
observar a variabilidade presente entre os filtros e entre tratamentos e, também, possíveis tendências nos tratamentos.

$\mathrm{Na}$ Figura 9 tem-se um gráfico com as porcentagens médias de remoção do diclofenaco. Observa-se que o filtro controle apresentou menor porcentagem média de remoção no tempo de coleta de 3 horas, e que as porcentagens de remoção se igualaram nos filtros FEco e FMix, indicando que não houve diferenças na eficiência de remoção quando há mistura de compostos na água a ser tratada.
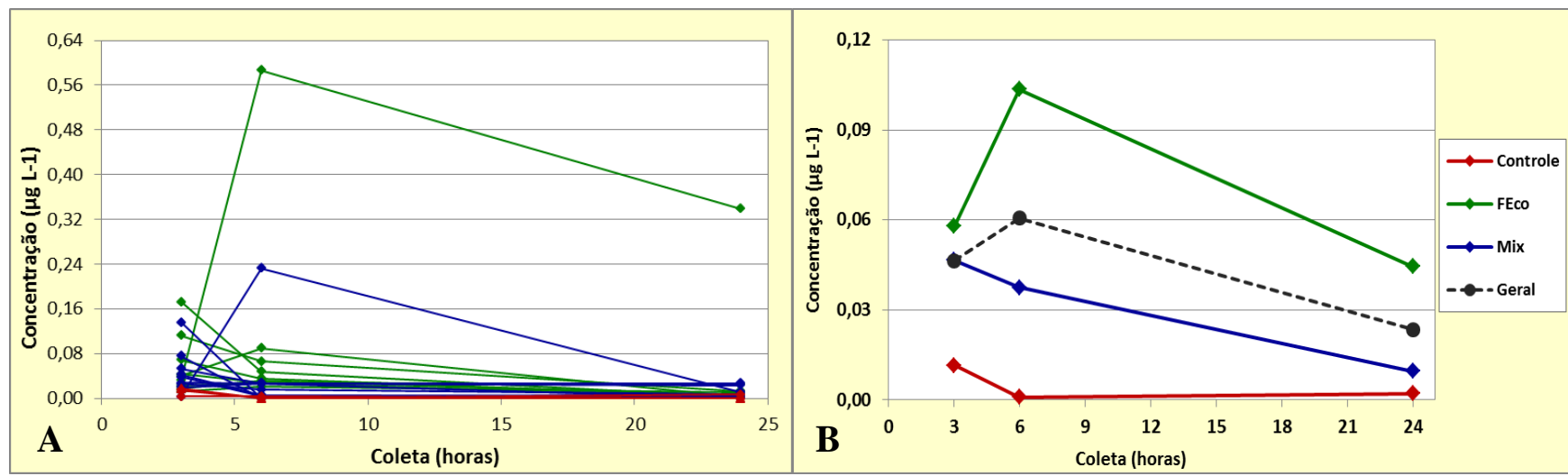

Figura 8: Perfis individuais (A) e perfis amostrais médios (B) para as contaminações com diclofenaco.

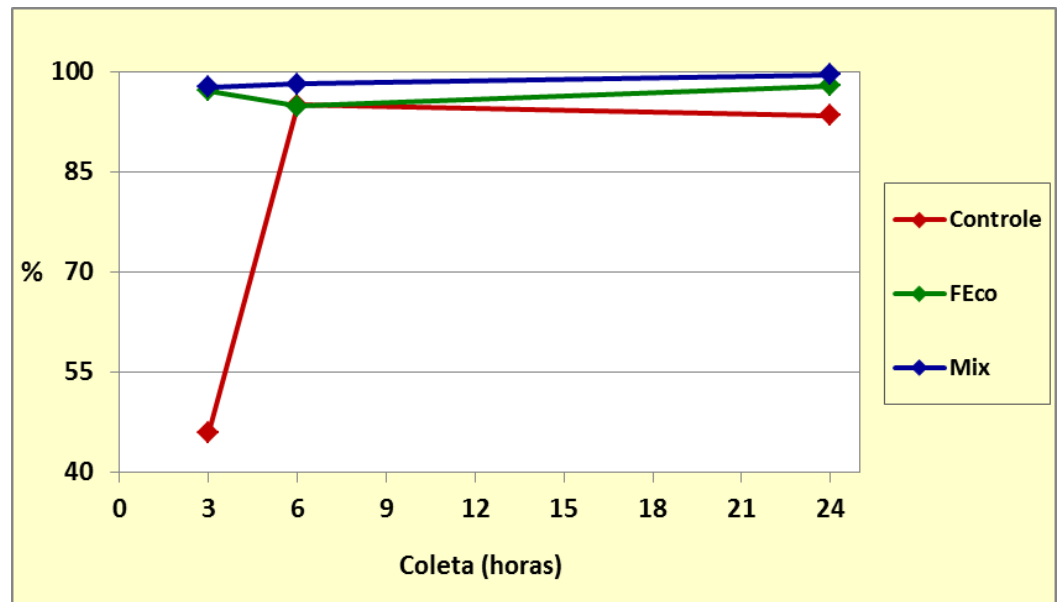

Figura 9: Médias das porcentagens de remoção do diclofenaco pelos filtros Controle, FEco e Mix, durante todas contaminações e diferentes tempos de coleta.

Em avaliação da remoção do diclofenaco por sistema convencional de tratamento de água, Rigobello et al., (2013) constataram que não houve remoção pelo filtro lento de areia, porem, o experimento foi conduzido com água preparada em laboratório, e acredita-se que não houve formação ideal do biofilme, como acontece quando utiliza-se água provenientes de 
lagos e/ou represas onde já existe uma biota aquática que irá colonizar o topo da areia dos filtros. Erba et al., (2012) relataram a remoção de 94\% do composto por filtro ecológico.

Uma extensa revisão bibliográfica realizada por Onesios, Yu e Bouwerm, (2009) mostra as diversas tecnologias de tratamento de águas residuárias que apresentaram remoção do diclofenaco, e citam a biodegradação do composto. Em trabalhos realizados com tratamento de águas residuárias, a remoção de diclofenaco mostrou grandes diferenças nas porcentagens de remoção, 17\% (HEBERER et al., 2002), 69\% (TERNES et al.,1998), e 100\% (THOMAS e FOSTER, 2004), que para estes casos, de acordo com Delpla et al., (2009), ocorreu por diferenças de temperatura e clima.

Na Tabela 16 estão os resultados do teste de Mauchly para os dados da contaminação por diclofenaco. Como o valor $p$ do teste é pequeno $(<0,0001)$, a condição de esfericidade não está sendo satisfeita, indicando que as análises devem ser feitas pela técnica multivariada, ou MANOVA.

Na Tabela 17 são apresentados os testes multivariados para testar a hipótese de que não existe efeito da interação tempo de coletaxtratamento, ou seja, para testar se há paralelismo entre os perfis médios.

Tabela 16: Teste de esfericidade de Mauchly na contaminação com diclofenaco.

\begin{tabular}{lccc}
\hline Variáveis & GL & $\chi^{\mathbf{2}}$ & Valor $\boldsymbol{p}$ \\
\hline Transformed Variates & 2 & 37.2503 & $<0,0001$ \\
\hline Orthogonal Components & 2 & 23.6714 & $<0,0001$ \\
\hline
\end{tabular}

Tabela 17: MANOVA para testar a hipótese da ausência do efeito da interação tempo de coletaxtratamento, na contaminação com diclofenaco.

\begin{tabular}{lccccc}
\hline Estatística & $\begin{array}{c}\text { Valor } \\
\text { observado }\end{array}$ & Razão F & $\begin{array}{c}\text { GL do } \\
\text { numerador }\end{array}$ & $\begin{array}{c}\text { GL do } \\
\text { denominador }\end{array}$ & Valor $\boldsymbol{p}$ \\
\hline Wilks' Lambda & 0,84080 & 0,770 & 4 & 34 & 0,5524 \\
Pillai's Trace & 0,16206 & 0,790 & 4 & 36 & 0,5372 \\
Hotelling-Lawley Trace & 0,18595 & 0,780 & 4 & 19,407 & 0,5532 \\
Roy's Greatest Root & 0,16542 & 1,490 & 2 & 18 & 0,2521 \\
\hline
\end{tabular}

Como os quatro testes considerados apresentam valores de $\mathrm{p}$ são maiores do que 0,05 , não se rejeita a hipótese de paralelismo entre os perfis médios de concentração de diclofenaco.

Para a verificação de um possível efeito de tratamento na concentração de diclofenaco no efluente dos filtros, testamos a hipótese de que não existiu efeito de tratamento, ou seja, de que os perfis médios são iguais. 
Conforme Tabela 18, os quatro testes apresentam valores de p maiores do que 0,05 , indicando que não há diferença. Isso indica que além de comportamentos semelhantes em relação aos seus perfis, as concentrações médias das filtragens de diclofenaco não apresentaram diferenças significativas com relação aos filtros Controle, Mix e FEco.

Tabela 18: MANOVA para teste da hipótese de ausência do efeito de tratamento, nas contaminações com diclofenaco.

\begin{tabular}{lccccc}
\hline Estatística & $\begin{array}{c}\text { Valor } \\
\text { observado }\end{array}$ & Razão F & $\begin{array}{c}\text { GL do } \\
\text { numerador }\end{array}$ & $\begin{array}{c}\text { GL do } \\
\text { denominador }\end{array}$ & Valor $\boldsymbol{p}$ \\
\hline Wilks' Lambda & 0,75113 & 0,820 & 6 & 32 & 0,5624 \\
Pillai's Trace & 0,25395 & 0,820 & 6 & 34 & 0,5593 \\
Hotelling-Lawley Trace & 0,32456 & 0,840 & 6 & 19,652 & 0,552 \\
Roy's Greatest Root & 0,30218 & 1,710 & 3 & 17 & 0,2023 \\
\hline
\end{tabular}

Na Tabela 19, por sua vez, estão os resultados dos testes efetuados para verificar evidências do efeito do tempo de coleta na concentração do diclofenaco no efluente dos filtros. Como os valores $\mathrm{p}$ dos testes $(0,0358)$ são menores do que o nível de significância de 0,05 rejeitou-se a hipótese de perfis horizontais. Logo, tem-se evidência de que pelo menos uma concentração em relação as demais na saída dos filtros, nos tempos 3; 6 e 24 horas é diferente.

Aplicou-se então, a partir de combinações dos resultados anteriores, análise por meio de contrastes, específicos para identificar em qual tempo (ou quais tempos) a diferença se verifica (Tabela 20).

Tabela 19: MANOVA para testar a hipótese da ausência do efeito do tempo de coleta, nas contaminações com diclofenaco.

\begin{tabular}{lccccc}
\hline Estatística & $\begin{array}{c}\text { Valor } \\
\text { observado }\end{array}$ & Razão F & $\begin{array}{c}\text { GL do } \\
\text { numerador }\end{array}$ & $\begin{array}{c}\text { GL do } \\
\text { denominador }\end{array}$ & Valor $\boldsymbol{p}$ \\
\hline Wilks' Lambda & 0,67580 & 4,080 & 2 & 17 & 0,0358 \\
Pillai's Trace & 0,32420 & 4,080 & 2 & 17 & 0,0358 \\
Hotelling-Lawley Trace & 0,47973 & 4,080 & 2 & 17 & 0,0358 \\
Roy's Greatest Root & 0,47973 & 4,080 & 2 & 17 & 0,0358 \\
\hline
\end{tabular}

Tabela 20: Testes para comparações da concentração média de diclofenaco nos Tempo de Coleta.

\begin{tabular}{ccl}
\hline Teste & Valor p & Conclusão \\
\hline$\mu_{3}=\mu_{6}$ & 0,8152 & $\begin{array}{l}\text { Não se rejeita a hipótese de igualdade entre as concentrações } \\
\text { médias nos tempos 3 e 6 horas. }\end{array}$ \\
$\mu_{3}=\mu_{24}$ & 0,3985 & $\begin{array}{l}\text { Não se rejeita a hipótese de igualdade entre as concentrações } \\
\text { médias nos tempos 3 e 24 horas. }\end{array}$ \\
\hline
\end{tabular}

Verifica-se que os valores de $\mathrm{p}$ dos testes são altos indicando que não foi detectada nenhuma diferença significativa entre os tempos de coleta. Esse resultado conflita com o 
anterior (Tabela 19), quando foi identificada pelo menos uma diferença significativa entre a concentração média nos efluentes de cada filtro. Os testes individuais não apresentaram a diferença indicada pelo teste geral. Nessa situação, considera-se a diferença entre as concentrações médias nos tempos 6 e 24 horas, já que são, respectivamente, a maior e a menor média amostral (3 horas: 0,04641; 6 horas: 0,06058; 24 horas: 0,02345).

\section{Remoção do Naproxeno}

No caso da contaminação com naproxeno, foram considerados os filtros FEco de números 8 a 10, os quais foram comparados com os filtros Controle e Mix, nos tempos de coleta: 3, 6 e 24 horas após o início da contaminação. A concentração média encontrada em cada tipo de tratamento está apresentada na Tabela 21.

Tabela 21: Concentração média de naproxeno por tratamento e média geral, expressas em $\mu \mathrm{g} \mathrm{L}^{-1}$, em cada tempo de coleta.

\begin{tabular}{c|c|c|c}
\hline \multirow{2}{*}{ Tratamento } & \multicolumn{3}{|c}{ Coletas } \\
\cline { 2 - 4 } & $3 \mathrm{~h}$ & $6 \mathrm{~h}$ & $24 \mathrm{~h}$ \\
\hline FEco & 0,03491 & 0,01259 & 0,00148 \\
\hline Mix & 0,02293 & 0,01544 & 0,00204 \\
\hline Controle & 0,00200 & 0,00020 & 0,00217 \\
\hline Geral & 0,02508 & 0,01204 & 0,00182 \\
\hline
\end{tabular}

Na Figura 10 são apresentados os perfis individuais de cada filtro no gráfico da esquerda e os perfis amostrais médios por tratamento no gráfico da direita, onde se observa a variabilidade presente entre indivíduos, entre tratamentos (FEco, Mix e controle) e possíveis tendências nos tratamentos.

Na Figura 11 tem-se um gráfico com as porcentagens médias de remoção de naproxeno. Observa-se que o filtro controle apresentou menor porcentagem média de remoção no tempo de coleta de 3 e 24 horas. As porcentagens de remoção se igualaram nos filtros FEco e FMix, indicando que não houve diferenças na eficiência de remoção quando os compostos são aplicados em mistura na água a ser tratada. 

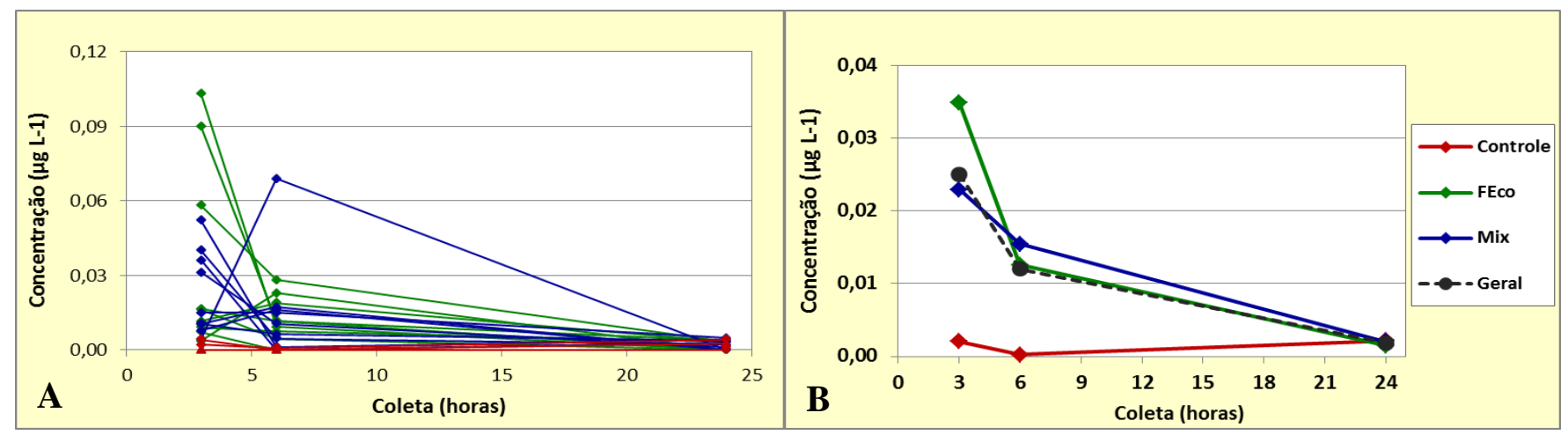

Figura 10: Perfis individuais (A) e perfis amostrais médios (B) para as contaminações com naproxeno.

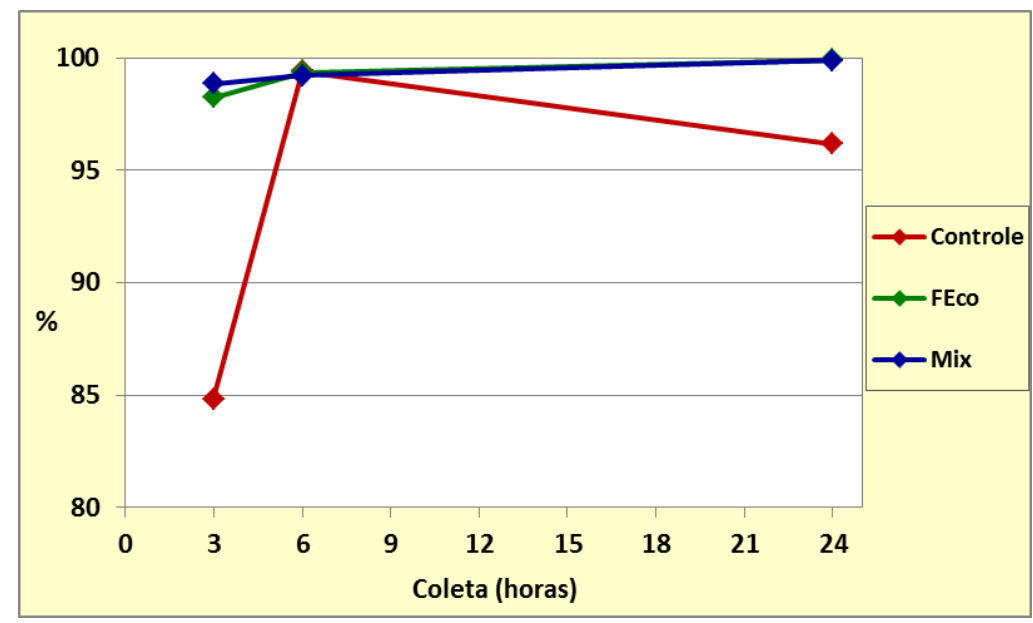

Figura 11: Médias das porcentagens de remoção de naproxeno pelos filtros Controle, FEco e Mix, durante todas contaminações e diferentes tempos de coleta.

Na Tabela 22 está o resultado do teste de Mauchly para os dados da contaminação por naproxeno. Como os valores de p dos testes são pequenos a condição de esfericidade não está sendo satisfeita, indicando que as análises devem ser feitas pela técnica multivariada, ou MANOVA.

Tabela 22: Teste de esfericidade de Mauchly, nas contaminações com naproxeno.

\begin{tabular}{lccc}
\hline Variáveis & GL & $\chi \mathbf{2}$ & Valor $\boldsymbol{p}$ \\
\hline Transformed Variates & 2 & 17,5234 & 0,0002 \\
\hline Orthogonal Components & 2 & 13,4026 & 0,0012 \\
\hline
\end{tabular}

Na Tabela 23 são apresentados os testes multivariados para a hipótese de que não existe efeito da interação coleta×tratamento, ou seja, para testar se há paralelismo entre os perfis médios. 
Como os valores de $\mathrm{p}$ dos testes são maiores do que 0,05 , então não se rejeita a hipótese de paralelismo entre os perfis médios de concentração de naproxeno, indicando que não existe o efeito da interação coleta $\times$ tratamento.

Tabela 23: MANOVA para testar a hipótese da ausência do efeito da interação coleta x tratamento, nas contaminações com naproxeno.

\begin{tabular}{lccccc}
\hline Estatística & $\begin{array}{c}\text { Valor } \\
\text { observado }\end{array}$ & Razão F & $\begin{array}{c}\text { GL do } \\
\text { numerador }\end{array}$ & $\begin{array}{c}\text { GL do } \\
\text { denominador }\end{array}$ & Valor $\boldsymbol{p}$ \\
\hline Wilks' Lambda & 0,72487 & 1,480 & 4 & 34,000 & 0,2288 \\
Pillai's Trace & 0,28329 & 1,490 & 4 & 36,000 & 0,2271 \\
Hotelling-Lawley Trace & 0,36830 & 1,540 & 4 & 19,407 & 0,2301 \\
Roy's Greatest Root & 0,33467 & 3,010 & 2 & 18,000 & 0,0744 \\
\hline
\end{tabular}

Na Tabela 24 estão os resultados dos testes para a hipótese de que não existe efeito de tratamento, ou seja, de que os perfis médios de saída dos filtros são iguais.

Os quatro testes apresentaram valores $p$ maiores do que 0,05 , ou seja, indicando que não se descartou a hipótese de perfis coincidentes. Isso indica que a concentração média de naproxeno não apresentou diferenças significativas com relação aos filtros Controle, Mix e FEco.

Tabela 24: MANOVA para testar a hipótese da ausência do efeito de tratamento, na contaminação com naproxeno.

\begin{tabular}{lccccc}
\hline Estatística & $\begin{array}{c}\text { Valor } \\
\text { observado }\end{array}$ & Razão F & $\begin{array}{c}\text { GL do } \\
\text { numerador }\end{array}$ & $\begin{array}{c}\text { GL do } \\
\text { denominador }\end{array}$ & Valor $\boldsymbol{p}$ \\
\hline Wilks' Lambda & 0,69465 & 1,070 & 6 & 32,000 & 0,4032 \\
Pillai's Trace & 0,32284 & 1,090 & 6 & 34,000 & 0,3877 \\
Hotelling-Lawley Trace & 0,41440 & 1,080 & 6 & 19,652 & 0,4097 \\
Roy's Greatest Root & 0,34045 & 1,930 & 3 & 17,000 & 0,1632 \\
\hline
\end{tabular}

Na Tabela 25, por sua vez, estão os resultados dos testes para verificar se há evidência do efeito do tempo de coleta na concentração de naproxeno no efluente dos filtros. Como os valores de $\mathrm{p}$ dos testes são menores do que o nível de significância de 0,05 rejeita-se a hipótese de perfis horizontais. Logo, tem-se evidência de que uma concentração do naproxeno no efluente dos filtros nos tempos de coleta 3; 6 e 24 horas é diferente das demais.

Uma vez tendo observado um efeito do tempo de coleta na concentração de naproxeno no efluente dos filtros, aplicou-se contrastes específicos para identificar em qual tempo (ou quais tempos) a diferença se verifica. A análise por meio de contrastes foi, então, realizada a partir de combinações dos resultados anteriores e os resultados podem ser observados na Tabela 26. 
Foi comparada a concentração média do naproxeno nos afluentes dos filtros ecológicos nos tempos 3 e 24 horas com a concentração média no tempo de 6 horas. Os resultados são apresentados pelos respectivos valores $\mathrm{p}$ dos testes.

Tabela 25: MANOVA para testar a hipótese da ausência do efeito do tempo de coleta nas contaminações com naproxeno.

\begin{tabular}{lccccc}
\hline Estatística & $\begin{array}{c}\text { Valor } \\
\text { observado }\end{array}$ & Razão F & $\begin{array}{c}\text { GL do } \\
\text { numerador }\end{array}$ & $\begin{array}{c}\text { GL do } \\
\text { denominador }\end{array}$ & Valor $\boldsymbol{p}$ \\
\hline Wilks' Lambda & 0,58092 & 6,13 & 2 & 17 & 0,0099 \\
Pillai's Trace & 0,41908 & 6,13 & 2 & 17 & 0,0099 \\
Hotelling-Lawley Trace & 0,72140 & 6,13 & 2 & 17 & 0,0099 \\
Roy's Greatest Root & 0,72140 & 6,13 & 2 & 17 & 0,0099 \\
\hline
\end{tabular}

Tabela 26: Testes para comparações da concentração média de naproxeno nos tempo de coleta.

\begin{tabular}{|c|c|c|}
\hline Teste & Valor $\mathbf{p}$ & Conclusão \\
\hline$\mu_{3}=\mu_{6}$ & 0,2344 & $\begin{array}{l}\text { Não se rejeita a hipótese de igualdade entre as concentrações } \\
\text { médias nos tempos } 3 \text { e } 6 \text { horas. }\end{array}$ \\
\hline$\mu_{6}=\mu_{24}$ & 0,0716 & $\begin{array}{l}\text { Rejeita-se a hipótese de igualdade entre as concentrações } \\
\text { médias nos tempos } 3 \text { e } 24 \text { horas. }\end{array}$ \\
\hline
\end{tabular}

Nas comparações entre a concentração média de naproxeno nos três tempos de coleta, não se rejeita a igualdade entre os tempos de coleta 3 e 6 horas para a concentração de saída do naproxeno. No tempo de coleta 24 horas a concentração de saída de naproxeno foi significativamente menor do que nos dois tempos de coleta anteriores, sendo os valores das medias amostrais de $0,02508 \mu \mathrm{g} \mathrm{L}^{-1}$ no tempo de 3 horas; 0,01204 $\mu \mathrm{g} \mathrm{L}^{-1}$ no tempo de 6 horas; e $0,00182 \mu \mathrm{g} \mathrm{L}^{-1}$ no tempo de coleta de 24 horas após a contaminação dos filtros com o composto.

Diversos estudos foram realizados para avaliar a remoção de naproxeno para tratamento de águas residuárias e podem ser vistos na revisão bibliográfica realizada por Onesios, Yu e Bouwer, (2009), assim como os relatos de biodegradação do composto (QUINTANA, et al., 2005).

Vieno, Tuhkane e Kronberg, (2005) relatam a remoção do naproxeno em tratamento de água de abastecimento humano, utilizando coagulação (cloreto férrico), seguido de filtração em carvão ativado granular e cloração. Westerhoff, (2003) relata que biofiltros avaliados foram capazes de remover naproxeno, mas não há informações sobre a concentração ou porcentagem de remoção pelo filtro. $\mathrm{O}$ autor diz ainda que testes mostraram que há acumulação no biofilme, mas os testes em escalas laboratoriais realizados não foram conclusivos. 
Hallé, (2009) mostra que o naproxeno foi removido em quase a totalidade por biofiltros após processo de maturação. A autora menciona ainda a biodegradação do composto e que as bactérias presentes continham as enzimas necessárias para biodegradar os compostos. Em concordância com este trabalho, Erba et al., (2012) relataram a remoção de 94,11\% do naproxeno aplicado, sendo o filtro ecológico responsável por $87,25 \%$, e o restante, removido por coluna de carvão ativado granular.

\section{Remoção do Ibuprofeno}

Para a contaminação dos filtros ecológicos com ibuprofeno, foram considerados os filtros FEco de números 11 a 13, os quais foram comparados com os filtros Controle e Mix, nos tempos de coleta 3; 6 e 24 horas após o início da contaminação. A concentração do ibuprofeno nos diferentes tratamentos é apresentada na Tabela 27.

Tabela 27: Concentração média de ibuprofeno por tratamento e média geral, expressas em $\mu \mathrm{g} \mathrm{L}{ }^{-1}$, em cada tempo de coleta.

\begin{tabular}{c|c|c|c}
\hline \multirow{2}{*}{ Tratamento } & \multicolumn{3}{|c}{ Coletas } \\
\cline { 2 - 4 } & $3 \mathrm{~h}$ & $6 \mathrm{~h}$ & $24 \mathrm{~h}$ \\
\hline FEco & 0,03211 & 0,00232 & 0,00044 \\
Mix & 0,00189 & 0,00116 & 0,00111 \\
\hline Controle & 0,00067 & 0,00057 & 0,00000 \\
\hline Geral & 0,01467 & 0,00157 & 0,00067 \\
\hline
\end{tabular}

Na Figura 12 são apresentados os perfis individuais de cada filtro no gráfico da esquerda e os perfis amostrais médios por tratamento no gráfico da direita, onde se observa a variabilidade presente entre indivíduos, entre tratamentos (FEco, Mix e controle) e possíveis tendências nos tratamentos.

Na Figura 13 tem-se um gráfico com as porcentagens médias de remoção de ibuprofeno. Observa-se que assim como ocorreu nos demais casos, o filtro controle apresentou menor porcentagem média de remoção no tempo de coleta de 3 horas, se comparar com os demais tratamentos. Ocorreu também menor porcentagem de remoção no tempo de coleta de 3 horas para o FEco. Ressalta-se que a escala vai de 98 a $100 \%$ de remoção e as diferenças nos tempos de coleta foram baixas, se comparar com os demais contaminantes. Erba et al., (2012) relataram a remoção de $76 \%$ do ibuprofeno por filtro ecológico. 


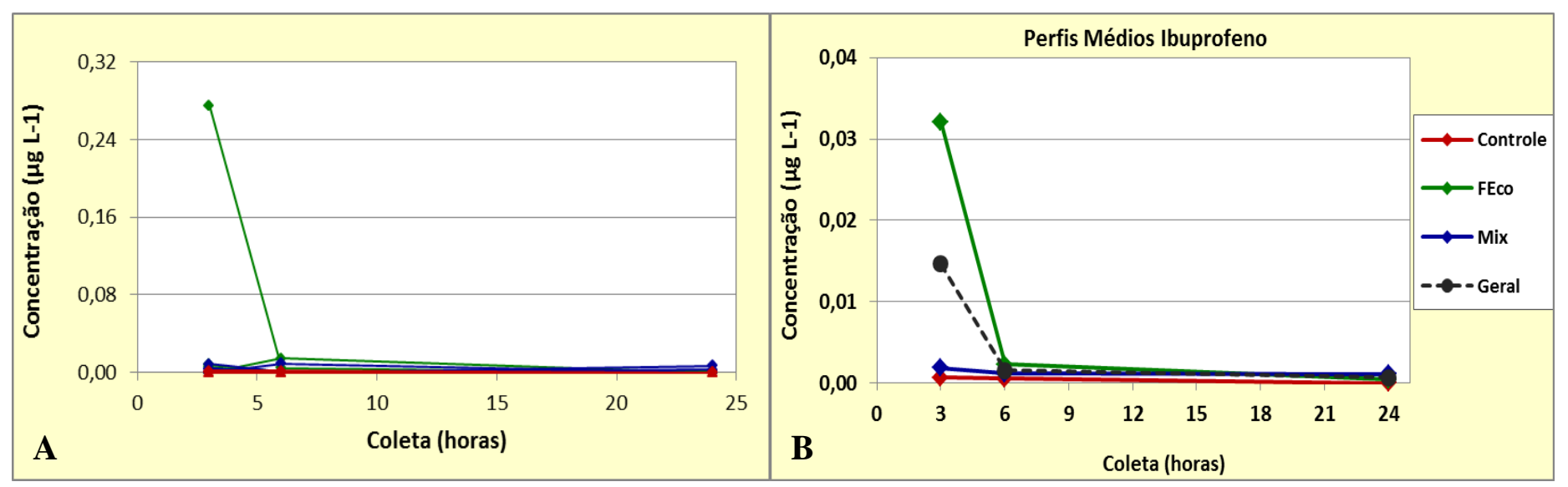

Figura 12: Perfis individuais (A) e perfis amostrais médios (B) para as contaminações com ibuprofeno.

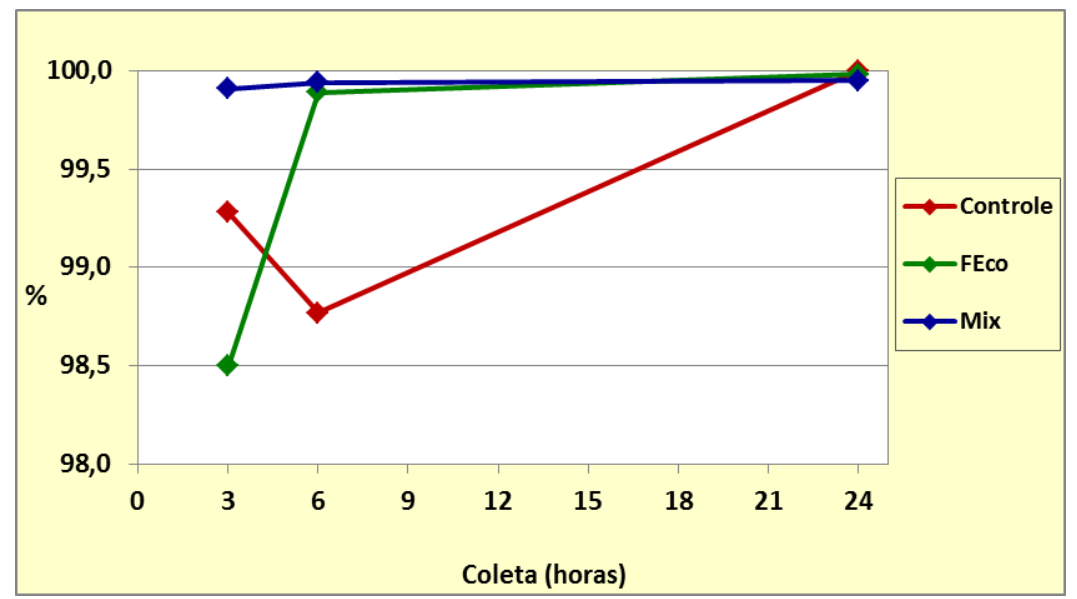

Figura 13: Médias das porcentagens de remoção de ibuprofeno pelos filtros Controle, FEco e Mix, durante todas contaminações e diferentes tempos de coleta.

Na Tabela 28 está o resultado do teste de Mauchly para os dados das contaminações com ibuprofeno, o que evidencia que com os valores de $p$ sendo pequenos, a condição de esfericidade não está sendo satisfeita, indicando que as análises devem ser feitas pela técnica multivariada, ou MANOVA.

Tabela 28: Teste de esfericidade de Mauchly nas contaminações com ibuprofeno.

\begin{tabular}{lccc}
\hline Variáveis & GL & $\boldsymbol{\chi 2}$ & Valor $\boldsymbol{p}$ \\
\hline Transformed Variates & 2 & 69,9453 & $<0,0001$ \\
\hline Orthogonal Components & 2 & 69,9453 & $<0,0001$ \\
\hline
\end{tabular}

Na Tabela 29 são apresentados os testes multivariados para a hipótese de que não existe efeito da interação tempo de coleta×tratamento, ou seja, para testar se há paralelismo entre os perfis médios. Como os valores de p dos testes são maiores do que 0,05 , então não se 
rejeita a hipótese de paralelismo entre os perfis médios de concentração de ibuprofeno, indicando que não existe o efeito da interação tempo de coleta× tratamento.

Tabela 29: MANOVA para testar a hipótese da ausência do efeito da interação tempo de coleta $x$ tratamento, nas contaminações com ibuprofeno.

\begin{tabular}{lccccc}
\hline Estatística & $\begin{array}{c}\text { Valor } \\
\text { observado }\end{array}$ & Razão F & $\begin{array}{c}\text { GL do } \\
\text { numerador }\end{array}$ & $\begin{array}{c}\text { GL do } \\
\text { denominador }\end{array}$ & Valor $\boldsymbol{p}$ \\
\hline Wilks' Lambda & 0,90949 & 0,410 & 4 & 34 & 0,7981 \\
Pillai's Trace & 0,09062 & 0,430 & 4 & 36 & 0,7880 \\
Hotelling-Lawley Trace & 0,09939 & 0,420 & 4 & 19,407 & 0,7954 \\
Roy's Greatest Root & 0,09811 & 0,880 & 2 & 18 & 0,4307 \\
\hline
\end{tabular}

Na Tabela 30 estão os resultados dos testes para a hipótese de que não existe efeito de tratamento, ou seja, de que os perfis médios de saída dos filtros são coincidentes. Pelos valores $\mathrm{p}$ apresentados, todos maiores do que 0,05 , não se descarta a hipótese de perfis coincidentes. Isso indica que as médias da concentração do ibuprofeno não apresentaram diferenças significativas com relação aos resultados dos filtros Controle, Mix e FEco.

Tabela 30: MANOVA para testar a hipótese da ausência do efeito de tratamento, nas contaminações com ibuprofeno.

\begin{tabular}{lccccc}
\hline Estatística & $\begin{array}{c}\text { Valor } \\
\text { observado }\end{array}$ & Razão F & $\begin{array}{c}\text { GL do } \\
\text { numerador }\end{array}$ & $\begin{array}{c}\text { GL do } \\
\text { denominador }\end{array}$ & Valor $\boldsymbol{p}$ \\
\hline Wilks' Lambda & 0,85863 & 0,420 & 6 & 32 & 0,8586 \\
Pillai's Trace & 0,14634 & 0,450 & 6 & 34 & 0,8417 \\
Hotelling-Lawley Trace & 0,15886 & 0,410 & 6 & 19,652 & 0,8617 \\
Roy's Greatest Root & 0,10225 & 0,580 & 3 & 17 & 0,6365 \\
\hline
\end{tabular}

Na Tabela 31, por sua vez, estão os testes para verificar se houve evidência do efeito do tempo de coleta na concentração de saída dos filtros. Com um valor p único de 0,6553 , maior do que o nível de significância de 0,05 , não se rejeita a hipótese de igualdade entre as medias dos tempos de coleta.

Tabela 31: MANOVA para testar a hipótese da ausência do efeito do tempo de coleta, nas contaminações com ibuprofeno.

\begin{tabular}{lccccc}
\hline Estatística & $\begin{array}{c}\text { Valor } \\
\text { observado }\end{array}$ & Razão F & $\begin{array}{c}\text { GL do } \\
\text { numerador }\end{array}$ & $\begin{array}{c}\text { GL do } \\
\text { denominador }\end{array}$ & Valor $\boldsymbol{p}$ \\
\hline Wilks' Lambda & 0,95149 & 0,430 & 2 & 17 & 0,6553 \\
Pillai's Trace & 0,04851 & 0,430 & 2 & 17 & 0,6553 \\
Hotelling-Lawley Trace & 0,05098 & 0,430 & 2 & 17 & 0,6553 \\
Roy's Greatest Root & 0,05098 & 0,430 & 2 & 17 & 0,6553 \\
\hline
\end{tabular}


Com os resultados das Tabelas 28 a 31, verifica-se que os perfis médios de concentração do ibuprofeno são paralelos, coincidentes e horizontais, ou seja, não houve diferença entre os tempos de coleta (3; 6 ou 24 horas), nem de tratamento (FEco, Controle ou Mix), nem da interação, o que condiz com a Figura 12, pois as diferenças observadas nas porcentagens médias de remoção calculadas são pequenas.

Kuhlmann et al., (2006) avaliaram a remoção de alguns fármacos por filtração lenta em areia, a fim de investigar a degradação dos compostos por bactérias, e concluíram que houve remoção do ibuprofeno pelos filtros após duas semanas de testes, porem os resultados sobre degradação bacteriana foram inconclusivos. Porém, Onensios, Yu e Bouwer, (2009) apresentam uma extensa listagem de trabalhos realizados na remoção de ibuprofeno para tratar águas residuárias por diferentes tecnologias de tratamento com atribuições da biodegradação do composto.

Winkler et al., (2001) avaliou a biodegradação do ibuprofeno por biofilme proveniente de águas superficiais e observaram degradação rápida até $90 \%$ do ibuprofeno na fase aquosa. Também observaram que a adsorção do ibuprofeno e dos seus dois metabolitos principais (hidroxilo-ibuprofeno e carboxyibuprofeno) no biofilme não foram significativos.

O trabalho feito por Hallé (2009) mostrou que os biofiltros precisaram passar por um período de aclimatação (maturação) para começarem a remover os compostos testados, dentre eles, o ibuprofeno, que foi removido quase na totalidade. Segundo a autora, isso comprova que o que ocorre é a biodegradação dos compostos, e que as bactérias presentes continham as enzimas necessárias para biodegradar os compostos.

Em relação à remoção dos produtos farmacêuticos, algumas investigações foram realizadas a respeito do processo de biodegradação dos PFCPs, e podem ser encontradas em detalhes na revisão bibliográfica feita por Onesios, Yu e Bouwer, (2009), onde o paracetamol, o diclofenaco, ibuprofeno, naproxeno tiveram <80 a 99\% de biodegradação por diversos tipos de processos.

\section{Remoção do Metilparabeno}

Para as contaminações realizadas com metilparabeno, foram considerados os filtros FEco de números 14 a 16, os quais foram comparados com os filtros Controle e Mix, nos tempos de coleta: 3; 6 e 24 horas após o início da contaminação. A concentração do metilparabeno nos diferentes tempos de coleta estão apresentadas na Tabela 32. 
Tabela 32: Concentração média do metilparabeno por tratamento e média geral, expressas em $\mu \mathrm{g} \mathrm{L}^{-1}$, em cada tempo de coleta.

\begin{tabular}{c|c|c|c}
\hline \multirow{2}{*}{ Tratamento } & $3 \mathrm{3}$ & $6 \mathrm{~h}$ & $24 \mathrm{~h}$ \\
\cline { 2 - 4 } & 101,415 & 0,232 & 3,130 \\
\hline FEco & 62,754 & 27,488 & 91,028 \\
\hline Mix & 28,925 & 0,242 & 0,311 \\
\hline Controle & 74,490 & 11,914 & 40,398 \\
\hline Geral & \multicolumn{3}{|c}{}
\end{tabular}

Na Figura 14 são apresentados os perfis individuais da concentração do metilparabeno nos efluentes de cada filtro no gráfico da esquerda, e os perfis amostrais médios por tratamento no gráfico da direita, onde se observa a concentraçãodo composto no efluente de cada filtro, entre tratamentos (FEco, Mix e controle) e possíveis tendências nos tratamentos.
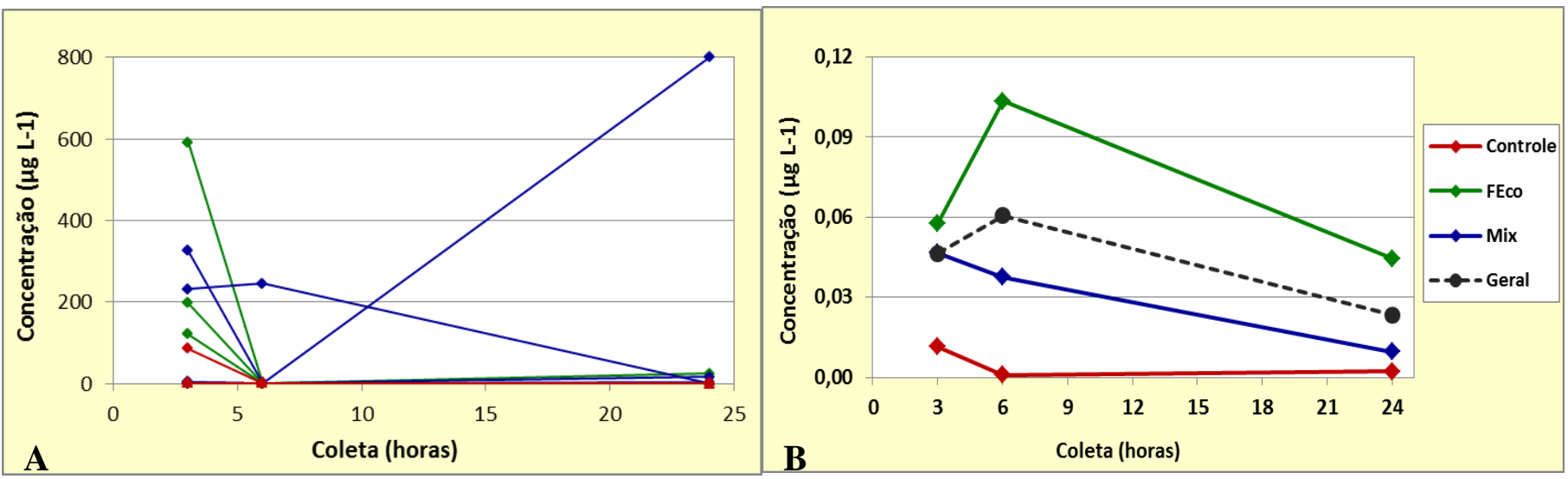

Figura 14: Perfis individuais (A) e perfis amostrais médios (B) para as contaminações com metilparabeno.

Na Figura 15 verifica-seo gráfico com as porcentagens médias de remoção do metilparabeno. Observa-se que o filtro controle apresentou remoção média abaixo de $55 \%$ em todos os tempos de coleta. Nos tratamentos FEco e FMix a melhor porcentagem de remoção para o período foi no tempo de 6 horas $(<85 \%)$.

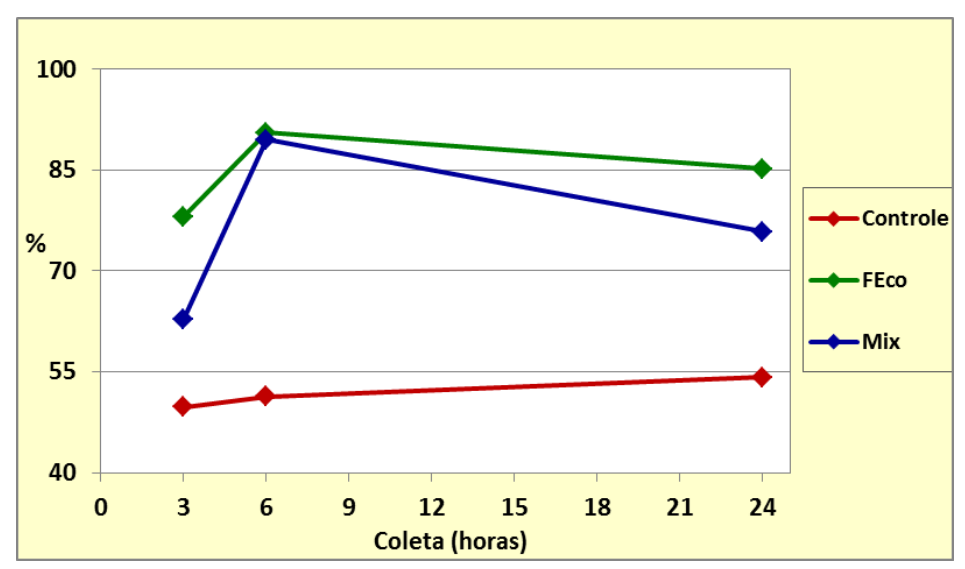

Figura 15: Médias das porcentagens de remoção de metilparabeno pelos filtros Controle, FEco e Mix, durante todas contaminações e diferentes tempos de coleta. 
Na Tabela 33 está o resultado do teste de Mauchly para os dados da concentração do metilparabeno em cada uma das contaminações. Os valores p dos testes, iguais a 0,0442, são menores do que 0,05 indicando que a condição de esfericidade não está sendo satisfeita mostrando que as análises devem ser feitas pela técnica multivariada, ou MANOVA.

Tabela 33: Teste de esfericidade de Mauchly, nas contaminações com metilparabeno.

\begin{tabular}{lccc}
\hline Variáveis & GL & $\chi \mathbf{2}$ & Valor $\boldsymbol{p}$ \\
\hline Transformed Variates & 2 & 6,2364 & 0,0442 \\
\hline Orthogonal Components & 2 & 6,2364 & 0,0442 \\
\hline
\end{tabular}

Na Tabela 34 são apresentados os testes multivariados para a hipótese de que não existe efeito da interação tempo de coletaxtratamento, ou seja, para testar se há paralelismo entre os perfis médios. Como os valores p's dos testes são maiores do que 0,05 , logo, não se rejeita a hipótese de paralelismo entre os perfis médios de concentração do metilparabeno.

Tabela 34: MANOVA para testar a hipótese da ausência do efeito da interação tempo de coleta $\mathrm{x}$ tratamento, nas contaminações com metilparabeno.

\begin{tabular}{lccccc}
\hline Estatística & $\begin{array}{c}\text { Valor } \\
\text { observado }\end{array}$ & Razão F & $\begin{array}{c}\text { GL do } \\
\text { numerador }\end{array}$ & $\begin{array}{c}\text { GL do } \\
\text { denominador }\end{array}$ & Valor $\boldsymbol{p}$ \\
\hline Wilks' Lambda & 0,92055 & 0,360 & 4 & 34 & 0,8358 \\
Pillai's Trace & 0,08027 & 0,380 & 4 & 36 & 0,8240 \\
Hotelling-Lawley Trace & 0,08541 & 0,360 & 4 & 19,407 & 0,8360 \\
Roy's Greatest Root & 0,07323 & 0,660 & 2 & 18 & 0,5294 \\
\hline
\end{tabular}

Na Tabela 35 estão os resultados dos testes para a hipótese de que não existe efeito detratamento, ou seja, de que os perfis médios de saída dos filtros são coincidentes. Pelos valores p apresentados, todos maiores do que 0,05, aceita-se a hipótese de perfis coincidentes. Isso indica que as médias da concentração do metilparabeno não apresentaram diferenças significativas com relação aos filtros Controle, Mix e FEco.

Tabela 35: MANOVA para testar a hipótese da ausência do efeito do tratamento, nas contaminações com metilparabeno.

\begin{tabular}{lccccc}
\hline Estatística & $\begin{array}{c}\text { Valor } \\
\text { observado }\end{array}$ & Razão F & $\begin{array}{c}\text { GL do } \\
\text { numerador }\end{array}$ & $\begin{array}{c}\text { GL do } \\
\text { denominador }\end{array}$ & Valor $\boldsymbol{p}$ \\
\hline Wilks' Lambda & 0,82304 & 0,550 & 6 & 32 & 0,7697 \\
Pillai's Trace & 0,18097 & 0,560 & 6 & 34 & 0,7560 \\
Hotelling-Lawley Trace & 0,21012 & 0,550 & 6 & 19,652 & 0,7672 \\
Roy's Greatest Root & 0,18355 & 1,040 & 3 & 17 & 0,4000 \\
\hline
\end{tabular}

Na Tabela 36, por sua vez, estão os testes realizados para verificar se houve evidência do efeito do tempo de coleta nas concentrações do metilparabeno na saída dos filtros. Com 
um valor $p$ único de 0,3452 , maior do que o nível de significância de 0,05 , não se rejeita a hipótese de igualdade entre as medias dos tempos de coleta.

Tabela 36: MANOVA para testar a hipótese da ausência do efeito do tempo de coleta.

\begin{tabular}{lccccc}
\hline Estatística & $\begin{array}{c}\text { Valor } \\
\text { observado }\end{array}$ & Razão F & $\begin{array}{c}\text { GL do } \\
\text { numerador }\end{array}$ & $\begin{array}{c}\text { GL do } \\
\text { denominador }\end{array}$ & Valor $\boldsymbol{p}$ \\
\hline Wilks' Lambda & 0,88237 & 1,130 & 2 & 17 & 0,3452 \\
Pillai's Trace & 0,11763 & 1,130 & 2 & 17 & 0,3452 \\
Hotelling-Lawley Trace & 0,13331 & 1,130 & 2 & 17 & 0,3452 \\
Roy's Greatest Root & 0,13331 & 1,130 & 2 & 17 & 0,3452 \\
\hline
\end{tabular}

Portanto, com os resultados estatísticos das Tabelas 31 a 33, verifica-se que apesar das grandes diferenças em porcentagens de remoção do metilparabeno no filtro controle em relação aos demais tratamentos, os perfis médios de concentração de metilparabeno são paralelos, coincidentes e horizontais, ou seja, não houve diferença entre os tempos de coleta (3; 6 ou 24 horas), nem de tratamento (FEco, Controle ou Mix), nem da interação.

Ainda não houveram trabalhos realizados que testaram a remoção do metilparabeno por filtração ecológica, mas Verlicchi, Zambello e Aukidy, (2014) realizaram uma revisão bibliográfica sobre a remoção de produtos de cuidados pessoais por wetlands, com trabalhos realizados na Europa, América no norte e Ásia, que mostram que a remoção foi influenciada principalmente pelo potencial redox, temperatura, tempo de retenção hidráulica e concentração afluente do composto.

\section{Remoção de Benzofenona-3}

Os filtros FEco identificados pelos números 17 a 19 foram contaminados com $2 \mu \mathrm{g} \mathrm{L}^{-1} \mathrm{de}$ benzofenona-3 e foram comparados com os filtros Controle e Mix, nos tempos de coleta: 3; 6 e 24 horas após o início de cada contaminação.

A Tabela 37 contém os valores médios de cada concentração de benzofenona-3 em cada tratamento durante todo o período de coleta e a média geral.

Tabela 37: Concentração média da benzofenona-3 por tratamento e média geral, expressas em $\mu \mathrm{g} \mathrm{L}^{-1}$, em cada tempo de coleta.

\begin{tabular}{c|c|c|c}
\hline \multirow{2}{*}{ Tratamento } & $3 \mathrm{~h}$ & Coletas & \multicolumn{3}{|c}{$24 \mathrm{~h}$} \\
\cline { 2 - 4 } & 0,95025 & 0,76306 & 0,41820 \\
\hline FEco & 1,03346 & 0,28507 & 0,31367 \\
Mix & 1,00485 & 0,64123 & 0,25820 \\
\hline Controle & 0,99371 & 0,54080 & 0,35055 \\
\hline Geral &
\end{tabular}


$\mathrm{Na}$ Figura 16, são apresentados os perfis individuais de cada filtro no gráfico da esquerda e os perfis amostrais médios por tratamento no gráfico da direita, nos quais se pode observar os valores aferidosem cada tratamento e, também, possíveis tendências nos tratamentos.

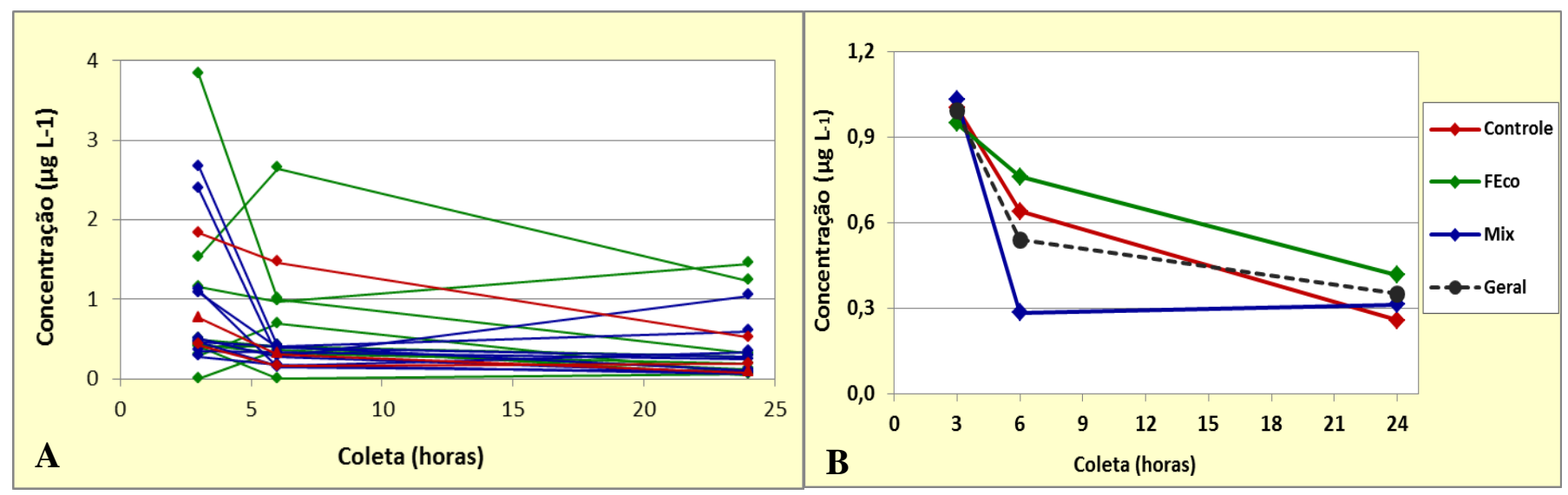

Figura 16: Perfis individuais (A) e perfis amostrais médios (B) para as contaminações com benzofenona-3.

$\mathrm{Na}$ Figura 17 tem-se o gráfico com as porcentagens médias de remoção de benzofenona-3 pelos filtros ecológicos. Observa-se que o filtro controle apresentou remoção média abaixo de 58\% nos tempos de coleta de 3 e 6 horas. A melhor porcentagem de remoção ocorreu no FMix, nos tempos de coleta 6 e 24 horas (<86\%). Observa-se que as porcentagens de remoção deste composto foram similares ao ocorrido para o contaminante metilparabeno, e ambos são produtos de cuidados pessoais.

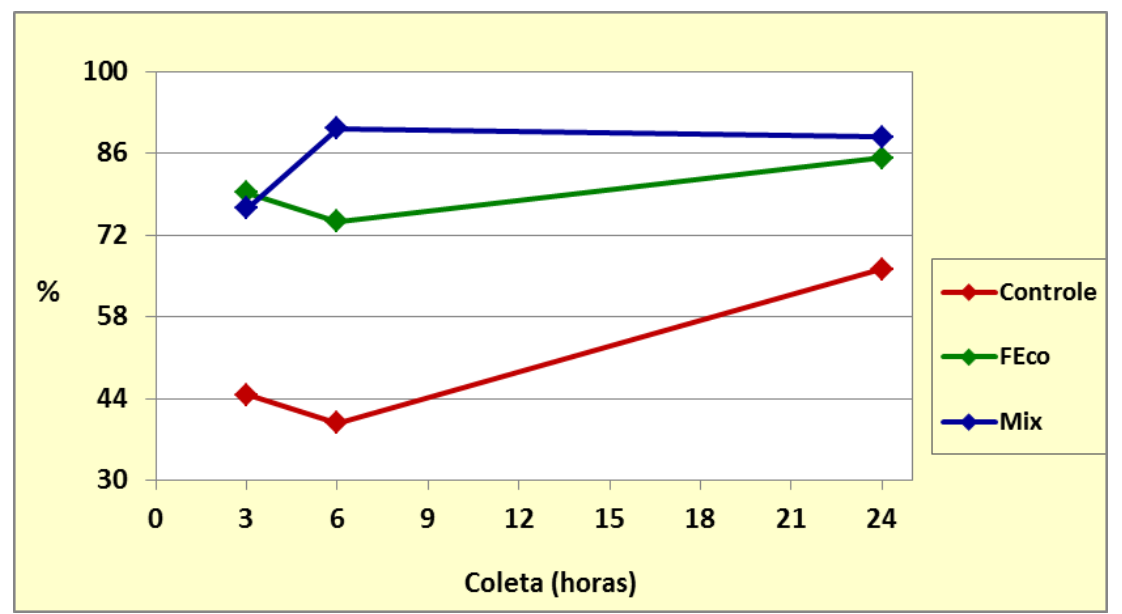

Figura 17: Médias das porcentagens de remoção da benzofenona-3 pelos filtros Controle, FEco e Mix, durante todas contaminações e diferentes tempos de coleta. 
Na Tabela 38 está o resultado do teste de Mauchly para os dados da contaminação por benzofenona-3. Como o valor p do teste é pequeno (menor do que 0,05 ), então, a condição de esfericidade não está sendo satisfeita, indicando que as análises devem ser feitas pela técnica multivariada, ou MANOVA.

Tabela 38: Teste de esfericidade de Mauchly nas contaminações com benzofenona-3.

\begin{tabular}{lccc} 
Variáveis & GL & $\boldsymbol{\chi 2}$ & Valor $\boldsymbol{p}$ \\
\hline Transformed Variates & 2 & 10,1556 & 0,0062 \\
\hline Orthogonal Components & 2 & 10,7401 & 0,0047 \\
\hline
\end{tabular}

Na Tabela 39 são apresentados os testes multivariados para testar a hipótese de que não existe efeito da interação coleta×tratamento, ou seja, para testar se há paralelismo entre os perfis médios. Os resultados dos testes com suas respectivas probabilidades de significância, ou valores p, são apresentados na Tabela 40.

Tomando um nível de significância de 0,05 (5\%) como referência, caso o valor p seja menor do que 0,05 , então, há evidência suficiente na amostra para concluir que o efeito da interação é significativo, rejeitando, assim, a hipótese de paralelismo. Por outro lado, se o valor $\mathrm{p}$ do teste for maior do que 0,05 , então, observa-se que o efeito da interação não é significativo, não rejeitando a hipótese de paralelismo.

Como os quatro testes considerados apresentam valores $\mathrm{p}$ maiores do que 0,05 (última coluna da Tabela 39), então não se descarta a hipótese de paralelismo entre os perfis médios da concentração de benzofenona-3. Neste caso, foram aplicados testes para avaliar a presença, ou não, dos efeitos individuais do tratamento e do tempo de coleta.

Tabela 39: MANOVA para testar a hipótese da ausência do efeito da interação tempo de coleta $x$ tratamento, nas contaminações com benzofenona-3.

\begin{tabular}{lccccc}
\hline Estatística & $\begin{array}{c}\text { Valor } \\
\text { observado }\end{array}$ & Razão F & $\begin{array}{c}\text { GL do } \\
\text { numerador }\end{array}$ & $\begin{array}{c}\text { GL do } \\
\text { denominador }\end{array}$ & Valor $\boldsymbol{p}$ \\
\hline Wilks' Lambda & 0,80013 & 1,00 & 4 & 34 & 0,4198 \\
Pillai's Trace & 0,20123 & 1,01 & 4 & 36 & 0,4166 \\
Hotelling-Lawley Trace & 0,24802 & 1,04 & 4 & 19,407 & 0,4135 \\
Roy's Greatest Root & 0,24061 & 2,17 & 2 & 18 & 0,1436 \\
\hline
\end{tabular}

NOTA: A estatística F para a Roy's Greatest Root é um limite superior.

NOTA: A estatística F para o Wilks' Lambda é exata. 
Para a verificação de um possível efeito de tratamento na concentração de saída dos filtros, a hipótese a ser testada foi de que não existe efeito de tratamento, ou seja, de que os perfis médios são iguais.

Os testes são os mesmos do caso anterior, pois se tratam de um desdobramento da técnica MANOVA, sendo os respectivos valores p's, apresentados na última coluna da Tabela 40. Conforme Tabela 40 ( $\mathrm{P}>0,05)$, não se descartou a hipótese de perfis coincidentes. Isso indica que além de comportamentos semelhantes em relação aos seus perfis, os valores médios da benzofenna-3 no efluente dos filtros não apresentaram diferenças significativas com relação aos filtros Controle, Mix e FEco.

Tabela 40: MANOVA para testar a hipótese da ausência do efeito de tratamento, nas contaminações com benzofenona-3.

\begin{tabular}{lccccc}
\hline Estatística & $\begin{array}{c}\text { Valor } \\
\text { observado }\end{array}$ & Razão F & $\begin{array}{c}\text { GL do } \\
\text { numerador }\end{array}$ & $\begin{array}{c}\text { GL do } \\
\text { denominador }\end{array}$ & Valor $\boldsymbol{p}$ \\
\hline Wilks' Lambda & 0,7691 & 0,75 & 6 & 32 & 0,6155 \\
Pillai's Trace & 0,2360 & 0,76 & 6 & 34 & 0,6076 \\
Hotelling-Lawley Trace & 0,2935 & 0,76 & 6 & 19,652 & 0,6079 \\
Roy's Greatest Root & 0,2687 & 1,52 & 3 & 17 & 0,2447 \\
\hline
\end{tabular}

Na Tabela 41, por sua vez, estão os resultados dos testes feitos para verificar se havia evidência do efeito do tempo de coleta na concentração de saída dos filtros. Como os valores $\mathrm{p}$ dos testes $(0,0149)$ são menores do que o nível de significância de 0,05 os perfis não são horizontais. Logo, há evidência de que em pelo menos um dos tempos de coleta houve diferença entre os efluentes dos filtros.

Tabela 41: MANOVA para testar a hipótese da ausência do efeito do tempo de coleta, na contaminação com benzofenona-3.

\begin{tabular}{lccccc}
\hline Estatística & $\begin{array}{c}\text { Valor } \\
\text { observado }\end{array}$ & Razão F & $\begin{array}{c}\text { GL do } \\
\text { numerador }\end{array}$ & $\begin{array}{c}\text { GL do } \\
\text { denominador }\end{array}$ & Valor $\boldsymbol{p}$ \\
\hline Wilks' Lambda & 0,6095 & 5,45 & 2 & 17 & 0,0149 \\
Pillai's Trace & 0,3905 & 5,45 & 2 & 17 & 0,0149 \\
Hotelling-Lawley Trace & 0,6407 & 5,45 & 2 & 17 & 0,0149 \\
Roy's Greatest Root & 0,6407 & 5,45 & 2 & 17 & 0,0149 \\
\hline
\end{tabular}

A análise por meio de contrastes foi, então, realizada a partir de combinações dos resultados anteriores. Na Tabela 42 estão os resultados de tais testes, com os quais se comparou as médias da benzofenona-3 nos tempos 3 e 24 horas com a concentração média no tempo 6 horas. Os resultados são apresentados pelos respectivos valores p dos testes. 
Tabela 42: Testes para comparações da concentração média de benzofenona-3 nos tempo de coleta.

\begin{tabular}{ccl}
\hline Teste & Valor $\mathbf{p}$ & Conclusão \\
\hline$\mu_{3}=\mu_{6}$ & 0,0760 & $\begin{array}{l}\text { Não se rejeitou a hipótese de igualdade entre as concentrações } \\
\text { médias nos tempos } 3 \text { e } 6 \text { horas. }\end{array}$ \\
$\mu_{6}=\mu_{24}$ & 0,0485 & $\begin{array}{l}\text { Descarta-se a hipótese de igualdade entre as concentrações } \\
\text { médias nos tempos 6 e 24 horas. }\end{array}$ \\
\hline
\end{tabular}

Apesar de os resultados dos cálculos de porcentagens de remoções da benzofenona-3, de acordo com os testes estatísticos realizados com as médias da concentração de benzofenona-3 nos três tempos de coleta, e com as médias amostrais, não se descarta a igualdade entre os tempos de coleta de 3 e 6 horas $\left(0,99371 \mu \mathrm{g} \mathrm{L} \mathrm{L}^{-1}\right.$ e $0,54080 \mu \mathrm{g} \mathrm{L}^{-1}$, respectivamente). Já o tempo de coleta de 24 horas, com concentração media de $0,35055 \mu$ g $\mathrm{L}^{-1}$ indica concentração significativamente menor do que nos outros dois tempos de coleta.

Ainda não há trabalhos realizados que testaram a remoção de benzofenona-3 por filtração ecológica, mas Onensios, Yu e Bouwer, (2009) apresentam uma extensa listagem de trabalhos realizados na remoção de protetores solares para tratar águas residuárias por diferentes tecnologias de tratamento com atribuições de biodegradação do composto. Verlicchi, Zambello e Aukidy, (2014) realizaram uma revisão bibliográfica sobre a remoção de produtos de cuidados pessoais por wetlands, com trabalhos realizados na Europa, América do norte e Ásia, que mostram que a remoção foi influenciada principalmente pelo potencial redox, temperatura, tempo de retenção hidráulica e concentração afluente do composto.

\section{Conclusões}

Foram identificados e quantificados os seis PFCPs, a saber: paracetamol, diclofenaco, naproxeno, ibuprofeno, metilparabeno e benzofenona-3 na água do Reservatório do Lobo, durante o período de estudo (novembro a dezembro de 2013).

As concentrações médias de cada composto encontrado no Reservatório do Lobo foram de $0,030 \mu \mathrm{g} \mathrm{L}^{-1}$ de paracetamol sendo que em uma medição o composto não foi encontrado e em uma o composto esteve abaixo do limite de quantificação; $0,021 \mu \mathrm{g} \mathrm{L}^{-1}$ de diclofenaco sendo não detectado em duas coletas e esteve abaixo do limite de quantificação em uma coleta; $0,017 \mu \mathrm{g} \mathrm{L}{ }^{-1}$ de naproxeno, estando abaixo do limite de quantificação em uma coleta e não foi encontrado em três coletas; $0,019 \mu \mathrm{g} \mathrm{L}^{-1}$ de ibuprofeno, sendo não encontrado em quatro coletas e esteve abaixo do limite de quantificação em uma coleta; $170,87 \mu \mathrm{g} \mathrm{L}^{-1}$ de 
metilparabeno, sendo que a alta concentração no primeiro dia de coleta foi a mais elevada de todas $\left(1.192,39 \mu \mathrm{g} \mathrm{L}^{-1}\right) ; 1,149 \mu \mathrm{g} \mathrm{L}^{-1}$ de benzofenona-3.

Os produtos de cuidados pessoais (metilparabeno e benzofenona-3) estiveram presentes em $100 \%$ das amostras de água coletadas e foram os compostos detectados em maior concentração no reservatório do Lobo.

Dois produtos de degradação (PDs) foram identificados na água do Reservatório do Lobo, referente aos compostos diclofenaco e benzofenona-3. O PD do diclofenaco foi o 291 (m/z 292), com três íons fragmentos. O PD da benzofenona-3 identificado foi o PD 244 (m/z 245), com quatro principais fragmentos. Ambos os compostos estão condizentes com a literatura. Identificados os íons fragmentos de cada PD, foi possível propor uma rota de degradação para cada composto em questão.

Os filtros ecológicos apresentaram bons resultados na remoção dos PFCPs adicionados. Apesar de serem observadas diferenças de porcentagens de remoção do filtro controle com os filtros FEco e FMix, os testes estatísticos aplicados mostraram que para os compostos paracetamol, ibuprofeno e metilparabeno os filtros não apresentaram diferenças significativas de remoção dos compostos nem referente aos diferentes tempos de coleta, nem ao tipo de tratamento - composto aplicado individualmente (FEco) ou aplicação do mix dos seis PFCPs (FMix) e nem da interação.

Para diclofenaco, naproxeno e benzofenona-3, os testes estatísticos aplicados mostraram que não houve diferença entre os tratamentos, mas houve diferença em relação ao tempo de coleta.

No caso do diclofenaco, os testes individuais não detectaram a diferença indicada pelo teste geral, porém, consideramos haver diferença entre as concentrações médias nos tempos 6 horas e 24horas, já que são, respectivamente, a maior e a menor média amostral (3 horas: 0,046 $\mu \mathrm{g} \mathrm{L}{ }^{-1} ; 6$ horas: 0,060 $\mu \mathrm{g} \mathrm{L}^{-1} ; 24$ horas: 0,023 $\mu \mathrm{g} \mathrm{L}^{-1}$ ).

Na remoção de naproxeno pelos filtros, não houve diferença entre os tempos de coleta 3 e 6 horas ( $\mathrm{p}=0,2344)$, mas não rejeitamos a hipótese entre os tempos de coleta 3 e 24 horas $(\mathrm{p}=0,0716)$. No tempo de coleta 24 horas a concentração de saída de naproxeno foi significativamente menor $\left(0,00182 \mu \mathrm{g} \mathrm{L}^{-1}\right)$ do que nos dois tempos de coleta anteriores. Já para a remoção de benzofenona-3 pelos filtros ecológicos, os testes estatísticos indicaram diferença entre os tempos de coleta 6 e 24 horas $(\mathrm{p}=0,0485)$, com concentração média de $0,35055 \mu \mathrm{g} \mathrm{L}^{-1}$, significativamente menor do que nos outros dois tempos de coleta.

A porcentagem média global de remoção pelos filtros ecológicos, levando em conta todas as contaminações realizadas, todos os filtros e todos os tempos de coleta, foi de $81,09 \%$ 
de paracetamol, 91,07\% de diclofenaco, 97,33\% de naproxeno, 99,57\% de ibuprofeno, $70,81 \%$ de metilparabeno e $71,69 \%$ de benzofenona-3.

Os compostos farmacêuticos tiveram melhor remoção pelos filtros ecológicos do que os produtos de cuidados pessoais.

No Brasil ainda não foram estabelecidos os limites permitidos da concentração destes compostos em corpos d'água e água de consumo. Levando-se em conta que pouco se conhece a respeito do efeito na saúde da biota aquática e humana em longo prazo, o cenário torna-se preocupante.

Ainda não há conhecimento acerca do que exatamente leva os filtros ecológicos a removerem os produtos farmacêuticos (mais de 80\%) e os produtos de cuidados pessoais (mais de 70\%), mas com indicativos de que a qualidade da água tratada melhora nas remoções de parâmetros básicos de qualidade da água como turbidez e cor, e E. coli após a maturação do filtro, não restam duvidas de que a ação biológica que ocorre principalmente no biofilme dos filtros é a chave para o sucesso do sistema de purificação ecológica. Diversos trabalhos encontrados na literatura citam a biodegradação de compostos farmacêuticos.

Apesar de tecnologias avançadas em tratamento de água serem capazes de remover em quase $100 \%$ contaminantes orgânicos, devem ser levar em consideração que tais tecnologias são dispendiosas e no Brasil, um pais ainda em desenvolvimento onde grande parte da população ainda sofre com a falta de saneamento básico, e ainda não são feitos grandes investimentos em tecnologias avançadas de tratamento de água, o sistema de purificação ecológica pode vir a ser uma alternativa viável e aplicável.

\section{Referências}

ABIHPEC. Associação Brasileira da Indústria de Higiene Pessoal, Perfumaria e Cosméticos. 2012. Panorama do setor 2011. Disponível em: <http://www.abihpec.org.br/2012/04/panorama-do-setor2011/> Acesso em: 17 de out. 2012.

ADAMS, C.; WANG, Y.; LOFTIN, K.; MEYER, M. Removal of antibiotics from surface and distilled water in conventional water treatment processes. Journal of Environmental. Engeneerging. ASCE. v. 128, p. $253-260,2002$.

AGUERA, A.; PÉREZ-ESTRADA, L.A.; FERRER, I.; THURMAN, E.M.; MALATO, S.; FERNANDEZ-ALBA, A.R. Application of time-of-flight mass spectrometry to the analysis of phototransformation products of diclofenac in water under natural sunlight. Journal of mass spectrometry. v. 40, p. 908-915, 2005. 
ALMEIDA, G.A.; WEBER, R.R. Fármacos na Represa Billings. Revista Saúde e Ambiente. v.6, p.7$13,2005$.

ANDRÉZ-COSTA, MJ, RUBIO-LÓPEZ, N., MORALES SUÁREZ-VARELA M, PICÓ, Y. Occurrence and removal of drugs of abuse in wastewater treatment plants of Valencia (Spain). Environmental Pollution. v. 194, p.152-162, 2014.

ANVISA - Agência Nacional de Vigilância Sanitária; Resolução RE nº 899, de 29/05/2003.

ARANTES, C. Uso da filtração lenta para remoção da Cylindrospermopsis raciborskii e saxitoxinas. Dissertação (Mestrado em Biologia Animal) Departamento de Ciências Fisiológicas, Universidade de Brasília, Brasília-DF, 109 p., 2004.

ASHTON, D.; HILTON, M.; THOMAS, K.V. (2004) Investigating the environmental transport of human pharmaceuticals to streams in the United Kingdom. Science Total Environment. v. 333, p. 167-184, 2004.

BALMER, M.E.; BUSER, H-R.; MULLER, M.D.; POIGER, T. Occurrence of Some Organic UV Filters in Wastewater, in Surface Waters, and in Fish from Swiss Lakes. Environmental Science \& Technology. v. 39, p. 953-962, 2005.

BECERRIL, J.E.B. Contaminantes emergentes en el agua. Revista digital universitária. v. 10, n. 8, 2009.

BENIJTS, T.; LAMBERT, W.; DE LEENHEER, A.; Analysis of Multiple Endocrine Disruptors in Environmental Waters via Wide-Spectrum Solid-Phase Extraction and Dual-Polarity Ionization LCIon Trap-MS/MS. Analytical Chemistry. v. 76, p. 704-711, 2004.

BLANCO, E.; CASAIS, M. D. C.; MEJUTO, M. D. C.; CELA, R. Combination of off-line solidphase extraction and on-column sample stacking for sensitive determination of parabens and $p$ hydroxybenzoic acid in waters by non-aqueous capillary electrophoresis. Analytica Chimica Acta. v. 647, p. 104-111, 2009.

BOUND, J.P.; VOULVOLIS, N. Predicted and measured concentrations for selected pharmaceuticals in UK rivers: implication for risk assessment. Water research. v. 40, p. 2885-2892, 2006.

BRASIL. Agencia Nacional de Vigilancia Sanitaria (ANVISA). Guia para validacao de metodos analiticos e bioanaliticos. Resolucao - RE no 899, de 29 de maio de 2003. Diario Oficial da Uniao, Brasilia, DF. Seção 1, p. 56-59, 2003. 
BRASIL. Governo Federal. Pesquisa vai avaliar consumo e acesso a medicamentos por brasileiros. Disponível em: <http://www.brasil.gov.br/noticias/arquivos/2012/10/09/pesquisa-vai-avaliarconsumo-e-acesso-a-medicamentos-por-brasileiros> Acesso em: 11 de out. 2012.

BRASIL. Ministério das Cidades. Secretaria Nacional de Saneamento Ambiental - SNSA. Sistema Nacional de Informações sobre Saneamento: Diagnóstico dos Serviços de Água e Esgotos - 2014. Brasília: SNSA/MCIDADES, 212, 2016.

BRATKOWSKA, D., MARC_E, R.M., CORMACK, P.A.G., BORRULL, F., FONTANALS, N. Development and application of a polar coating for stir bar sorptive extraction of emerging pollutants from environmental water samples. Analytica Chimica Acta. v. 706, p.135-142, 2011.

CALIJURI, M.C., TUNDISI, J.G. Limnologia comparada das represas do Lobo (Broa) e Barra Bonita - Estado de São Paulo: mecanismos de funcionamento e bases para o gerenciamento. RJ. Revista Brasileira de Biologia. v. 50, p. 893-913, 1990.

CANONICA, L.; MEUNIER, U.GUNTEN, V. Phototransformation of selected pharmaceuticals during UV treatment of drinking water. Water Research. v. 42, p. 121-128, 2008.

CANOSA, P.; RODRIGUEZ, I.; RUBI, E.; NEGREIRA, N.; CELA, R. Formation of halogenated byproducts of parabens in chlorinated water. Analytica Chimica Acta. v. 575, p. 106-113, 2006.

CASSIANO, N. M.; BARREIRO, J. C.; MARTINS, L. R. R.; OLIVEIRA, R.V.; CASS, Q. B. Validação em métodos cromatográficos para análises de pequenas moléculas em matrizes biológicas. Quimica Nova. v. 32, n. 4, p. 1021-1030, 2009.

CHRISTEN,V.; HICKMANN, S.; RECHEMBERG, B.; FENT, K. Highly active human pharmaceuticals in aquatic systems: A concept for their identification based on their mode of action. Aquatic Toxicology. v. 96, p. 167-181, 2010.

COLLINS, M.R.; EIGHMY, T.T.; FENSTERMACHER, J.M.; SPANOS, S.K. Removing Natural Organic Matter by Conventional Slow Sand Filtration. Journal (American Water Works Association). v. 84, No. 5, p. 80-90, 1992.

DAUGHTON, C.G.; TERNES, T.A. Pharmaceuticals and personal care products in the environment: agents of subtle change? Environ Health Perspect. v. 107, p. 907-938, 1999.

DE LUNA, M.D.G.; VECIANA, M.L.; SU, C-C.; LU, M-C. Acetaminophen degradation by electroFenton and photoelectro-Fenton using a double cathode electrochemical cell. Journal of Hazardous Materials. v. 217-218, p. 200-27, 2012.

DELPLA, I.; JUNG, A.-V.; BAURES, E.; CLEMENT, M.; THOMAS, O. Impacts of climate change on surface water quality in relation to drinking water production. Environment International. v. 35, p. 1225-1233, 2009. 
DEVIER, MH, MAZELLIER, P., AIT-AISSA, S., BUDZINSKI, H. New challenges in environmental analytical chemistry: identification of toxic compounds in complex mixtures. C R Chim v. 14, p. 766779, 2011.

ELLIS, J.B. Pharmaceutical and personal care products (PPCPs) in urban receiving waters.

Environmental Pollution. v. 144, p. 184-189, 2006.

ERBA, C.M.; TANGERINO, E.P.; CARVALHO, S.L.; ISIQUE, W.D. Remoção de diclofenaco, ibuprofeno, naproxeno e paracetamol em filtro ecológico seguido por filtro de carvão granular biologicamente ativado. Engenharia Sanitária e Ambiental. v.17, n.2, p. 136-142, 2012.

ERBA, C. M.; TANGERINO, E.P.; ISIQUE, W. D.; CAMPOS, L. C. Removal of anti-inflammatory compounds by ecological filtration. In: Nobutada Nakamoto, Nigel Graham, M. Robin Collins and Rolf Gimbel (Org.). Progress in slow sand and alternative biofiltration process. 1ed.: IWA publishing. v. 5, cap 19, p. 147-152, 2014.

EVGENIDOU, E.N., KONSTANTINOU, I.K., DIMITRA, A.L. Occurrence and removal of transformation products of PPCPs and illicit drugs in wastewaters: A review. Science of the Total Environment. v. 505, p. 905-926, 2015.

FENT, K; WESTON, A. A.; CAMINADA, D. Ecotoxicology of human pharmaceuticals. Aquatic Toxicology, v. 76, p.122-159, 2006.

GALINARO, C.A.; PEREIRA, F.M.; VIEIRA, E.M. Determination of Parabens in Surface Water from Mogi Guaçu River (São Paulo, Brazil) Using Dispersive Liquid-Liquid Microextraction Based on Low Density Solvent and LC-DAD. Journal of the Brazilian Chemical Society. v. 0, p.1-9, 2015.

GALMIER, M.J.; BOUCHON, B., MADELMONT, J.C.; MERCIER, F., PILATAZ, F., LARTIGUE, C. Identification of degradation products of diclofenac by electrospray ion trap mass spectrometry. $\mathrm{J}$ Pharm Biomed Anal. v. 38, p. 790-796, 2005.

GONG, H.; KINGER, J.; DAMAZYN, K.; LI, X.; HUANG, S. A novel procedure for statistical inference and verification of gene regulatory subnetwork. BMC Bioinformatics. v. 16, suplemente 7, 2015.

GROS, M.; PETROVIC, M.; BARCELÓ, D. Development of multi-residue analytical methodology based on liquid chromatography-tandem mass spectrometry (LC-MS/MS) for screening and trace level determination of pharmaceuticals in surface and wastewaters. Talanta. v. 70, p. 678-690, 2006.

HALLÉ, C. Biofiltration in Drinking Water Treatment: Reduction of Membrane Fouling and Biodegradation of Organic Trace Contaminants. Tese (Doutorado). University of Waterloo, Waterloo, Ontario, Canada, 2009.

HAMAN, C; XAVIER, D.; CHRISTOPHE, R.; JEAN-FRANÇOIS, M. Occurrence, fate and behavior of parabens in aquatic environments: A review. Water research. v.68, p. 1-11, 2015. 
HEBERER, T. Occurrence, fate and removal of pharmaceuticals residues in the aquatic environment: a review of recent research data. Toxicology Letters, Amsterdam. v. 131, p. 5-17, 2002.

HENSCHEL, K.P.; WENZEL, A.; DIEDRICH, M.; FLIEDNER, A. Environmental hazard assessment of pharmaceuticals. Regulatory Toxicology and Pharmacology. v. 25, p. 220-225, 1997.

HSU, Y-H.; LIOU, Y-B.; LEE, J-A.; CHEN, C-Y.; WU, A-B. Assay of naproxen by highperformance liquid chromatography and identification of its photoproducts by LC-ESI MS. Biomeical Chromatography. v. 20, p. 787-793, 2006.

HUGUET, KAPLAN, M.S.; McFARLAND, B.H. The Effects of Misclassification Biases on Veteran Suicide Rate Estimates. American Journal of Public Health. v. 104, No. 1, p. 151-155, 2014.

INMETRO - Instituto Nacional de Metrologia, Normalização e Qualidade Industrial; Orientações sobre Validação de Métodos de Ensaios Químicos, DOQ-CGCRE-008, 2003.

IBGE. Censo 2010. Disponível em: <http://www.censo2010.ibge.gov.br/>. Consultado em: 08/08/2012.

JALLOULI, N.; ELGHNIJI, K.; TRABELSI, H.; KSIBI, M. Photocatalytic degradation of paracetamol on $\mathrm{TiO}_{2}$ nanoparticles and $\mathrm{TiO}_{2}$ /cellulosic fiber under $\mathrm{UV}$ and sunlight irradiation. Arabian Journal of Chemistry. In Press, Corrected Proof, 2014.

JONES, O.A.; LESTER, J.N.; VOULVOULIS, N. Pharmaceuticals: a threat to drinking water? Trends in Biotechnology. v. 23, p. 163-167, 2005.

JONKERS, N.; SOUSA, A.; GALANTE-OLIVEIRA, S.; BARROSO, C. M.; KOHLER, H. P. E.; GIGER, W. Occurrence and sources of selected phenolic endocrine disruptors in Ria de Aveiro, Portugal. Environmental Science and Pollution Research. v. 17, p. 834-843, 2010.

KEEP, D.R.; SIDELMANN, U.G.; TJORNELUND, J.; HANSEN, S.H. Simultaneous Metabolites liquid quantitative determination of the major phase I and II of ibuprofen in biological fluids by highperformance chromatography on dynamically modified sílica. Journal of Chromatography B. v. 696, p. 235-241, 1997.

KIM, S.; CHOI, K.. Occurrences, toxicities, and ecological risks of benzophenone-3, a common component of organic sunscreen products: A mini-review. Environment International. v. 70, p. 143$157,2014$.

KOLPIN, D.W.; FURLONG, E.T.; MEYER, M.T.; THURMAN, E.M.; ZAUGG, S.D.; BARBER, L.B.; BUXTON, H.T. Pharmaceuticals, hormones, and other organic wastewater contaminants in U.S. streams, 1999-2000: a national reconnaissance. Environmental Science and Technology. v. 36, p. 1202-1211, 2002. 
KUHLMANN, B.; ZULLEI-SEIBERT, N;, NOLTE, J.; GROTE, M. Behaviour select drug during slow sand filtration. In: GIMBLE, R., GRAHAM, N. J .D.; COLLINS, M. R. (Ed.) Recept progress in slow sand and anternative biofiltration process.Londres: IWA Publishing. p. 188-193. 2006.

LANÇAS, F. M. Validação de métodos cromatográficos de análise. São Carlos: RiMa, 2004. 62p.

LOFFLER, D.; TERNES, T.A. Determination of acidic pharmaceuticals, antibiotics and ivermectin in river sediment using liquid chromatography-tandem mass spectrometry. Journal of

Chromatography A. v. 1021, p. 133-144, 2003.

LORAINE, G. A.; PETTIGTOVE, M. E. Seasonal Variations in Concentrations of Pharmaceuticals and Personal Care Products in Drinking Water and Reclaimed Wastewater in Southern California. Environmental Science \& Technology. v. 40, p. 687- 695, 2006.

MAGI, E.; SCAPOLLA, C.; CARRO, M. D.; RIVARO, P.; NGUYEN, K.T.N. Emerging pollutants in aquatic environments:monitoring of UV filters in urban wastewater treatment plants. Analitycal Methods. v. 5, p. 428-433, 2013.

MARCO-URREA, E.; PÉREZ-TRUJILLO, M.; BLÁNQUEZ,P.; VICENT, T.; CAMINAL, G. Biodegradation of the analgesic naproxen by Trametes versicolor and identification of intermediates using HPLC-DAD-MS and NMR. Bioresource Technology. v. 101, p. 2159-2166, 2010.

MELO, A. E. S. Avaliação da filtração lenta na remoção de células de Cylindrospermopsis raciborskii e saxitoxinas. Dissertação (Mestrado em Tecnologias Ambientais e Recursos Hídricos), Engenharia Civil e Ambiental, Universidade de Brasília, Brasília, 197 pag. 2006.

MIAO, X-C.; KOENIG, B.G.; METCALFE, C.G. Analysis of acidic drugs in the effluents of sewage treatment plants using liquid chromatography-electrospray ionization tandem mass spectrometry. Journal of Chromatography A. v. 952, p. 139-147, 2002.

MONTAGNER, C.C.; JARDIM, W.F. Spatial and seasonal variations of pharmaceuticals and endocrine disruptors in the Atibaia River, São Paulo State (Brazil). Journal of the Brazilian Chemical Society. v. 22, p. 1452-1462, 2011.

MULROY, A. Monitoring and analysis of water and wastes. Water Environment Technology, Alexandria, v.13, n. 2 p. 32-36, 2001.

NOUTSOPOULOS, C.; KOUMAKI, E.; MAMAIS, D.; NIKA, M-C.; BLETSOU, A.A.; THOMAIDIS, N.S Removal of endocrine disruptors and non-steroidal anti-inflammatory drugs through wastewater chlorination: The effect of $\mathrm{pH}$, total suspended solids and humic acids and identification of degradation by-products. Chemosphere. v. 119, p. 109-114, 2015.

OLIVEIRA, L. L.D. Biomarcadores enzimáticos e testes ecotoxicológicos na avaliação da toxicidade de fármacos em invertebrados aquáticos. Tese (Doutorado em Ciências da Engenharia Ambiental) Universidade de São Paulo, Escola de Engenharia de São Carlos. 2014. 
ONESIOS, K.M.; YU, J.T.; BOUWER, E.J. Biodegradation and removal of pharmaceuticals and personal care products in treatment systems: a review. Biodegradation. v. 20, p. 441-466, 2009.

PAROLINI, M.; BINILLI, A.; COGNI, D.; RIVA, C.; PROVINI, A. In vitro biomarker approach for the evaluation of the ecotoxicity of non-steroidal anti-inflamatory drugs (NSAIDs). Toxicology in Vitro. v. 23, p. 935-942, 2010.

PEDROUZO M, BORRULL F, MARCE R.M., POCURULL E. Ultra-high-performance liquid chromatography-tandem mass spectrometry for determining the presence of eleven personal care products in surface and wastewaters. Journal of Chromatography A. v. 1216(42), p.6994-7000, 2009.

PENG, X.; YU, Y.; TANG, C.; TAN, J.; HUANG, Q.; WANG, Z. Occurrence of steroid estrogens, endocrine-disrupting phenols, and acid pharmaceutical residues in urban riverine water of the Pearl River Delta, South China. Science Total Environmental. v.397, p. 158-166, 2008.

PEREZ., S; BARCELO, D. (Application of advanced MS techniques to analysis and identification of human and microbial metabolites of pharmaceuticals in the aquatic environment. TrAC-Trends. Analitycal Chemistry. v. 26, p.494-514, 2007.

PÉREZ-ESTRADA, A.L.; MALATO, S.; GERNJAK, W.; AGUERA, A.; THURMAN, E.M.; FERRER, I.; FERNÁNDEZ-ALBA, A.R. Photo-Fenton Degradation of Diclofenac: Identification of Main Intermediates and Degradation Pathway. Environmental Science and Technology. v. 39, p. 8300-8306, 2005.

PETROVIC, M., GONZALES, S., BARCELÓ, D. Analysis and removal of emerging contaminants in wastewater and drinking water. Trends in Analytical Chemistry. v 22, n 10, p685-696, 2003.

PETROVIć, M.; ŠKRBIć, B.; ŽIVANčEV, J.; FERRANDO-CLIMENT, L.; BARCELÓ, D. Determination of 81 pharmaceutical drugs by high performance liquid chromatography coupled to mass spectrometry with hybrid triple quadrupole-linear ion trap in different types of water in Serbia. Science of the total Environment, v. 468-469, p. 415-428, 2014.

PICÓ, Y.; BARCELÓ, D. Transformation products of emerging contaminants in the environment and high-resolution mass spectrometry: a new horizon.Anal. Bioanal. Chem. v. 407, p. 6257-73, 2015.

POIGER, T.; BUSER, H.R.; BALMER, M.E.; BERGQVIST, P-A.; MULLER, M.D. Occurrence of UV filter compounds from sunscreens in surface waters: regional mass balance in two Swiss lakes. Chemosphere. v. 55(7), p. 951-963, 2004.

POJANA, G.; FANTINATI, A.; MARCOMINI, A. Occurrence of environmentally relevant pharmaceuticals in Italian drinking water treatment plants. International Journal of Environmental Analytical Chemistry. v. 91, p. 537-552, 2011. 
POSTIGO, C.; RICHARDSON, S.D. Transformation of pharmaceuticals during oxidation/disinfection processes in drinking water treatment. Journal of Hazard Materials. v. 279, p. 461-475, 2014.

PRUSS-ÜSTÜN, A.; BOS, R.; GORE, F.; BARTRAME, J. Safe Water, Better Health: Costs, Benefits and Sustainability of Interventions to Protect and Promote Health. Geneva: World Health Organization, 2008.

QUINTANA, J.B.; WEISS, S.; REEMTSMA, T. Pathways and metabolites of microbial degradation of selected acidic pharmaceutical and their occurrence in municipal wastewater treated by a membrane bioreactor. Water Research. v. 39, p. 2654-2664, 2005.

RADWQ - Rapid assessment of drinking-water quality in the Hashemite Kingdom of Jordan. Summary of Results of Rapid Drinking Water Quality Analysis. Geneva: World Health Organization, 2008.

RAMASWAMY, B. R.; SHANMUGAM, G.; VELU, G.; RENGARAJAN, B.; LARSSON, D. G. J. GC-MS analysis and ecotoxicological risk assessment of triclosan, carbamazepine and parabens in Indian rivers. Journal of Hazardous Materials. v. 186, p. 1586-1593, 2011.

RENZ, L.; VOLZ, C.; MICHANOWICZ, D.; FERRAR, K.; CHRISTIAN, C.; LENZNER, D.; ELHEFNAWY, T. A study of parabens and bisphenol A in surface water and fish brain tissue from the Greater Pittsburgh Area. Ecotoxicology. v. 22, p. 632-641, 2013.

RIBANI, M.; BOTTOLI, C. B. G.; COLLINS, C. H.; JARDIM, I. C. S. F.; MELO, L. F. C. Validação em métodos cromatográficos e eletroforéticos. Quimica Nova. v. 27, p.771-780. 2004.

RIGOBELLO, E.S.; DANTAS, A. DI-B.; DI BERNARDO, L.; VIEIRA, E.M. Removal of diclofenac by conventional drinking water treatment processes and granular activated carbon filtration.

Chemosphere. v. 92, p. 184-191, 2013.

RODIL, R. and MOENDER, M. Development of a method for the determination of UV filters in water samples using stir bar sorptive extraction and thermal desorption-gas chromatography-mass spectrometry. Journal of Chromatography A. v. 1179, p. 81-88, 2008.

ROSSNER, A., SNYDER, S.A.; KNAPPE, D.R.U. Removal of emerging contaminants of concern by alternative adsorbents. Water Research. v. 43, p. 3787-3796, 2009.

SÁ, J. C. Influencia das características da camada da filtrante e da taxa de filtração na influencia da remoção de Microcystis aeruginosa e microcistina na filtração lenta em areia. Tese (Doutorado em Tecnologias Ambientais e Recursos Hídricos) - Departamento de Engenharia Civil e Ambiental, Universidade de Brasília, Brasília. 186 p. 2006.

SÁ, J. C. Remoção de Microcystis aeruginosa e microcistina pelo processo de filtração lenta. 2002. 115 f. Dissertação (Mestrado em Tecnologias Ambientais e Recursos Hídricos) - Departamento de Engenharia Civil e Ambiental, Universidade de Brasília, Brasília. 2002. 
SIDELMANN, U.G.; BJORNSDOTTIR, I.; SHOCKCOR, J.P.; HANSEN, S.H.; LONDON, J.C.; NICHOLSON, J.K. Directly coupled HPLC-NMR and HPLC-MS approaches for the rapid characterisation of drug metabolites in urine: application to the human metabolism of naproxen. Journal of Pharmaceutical and Biomedical Analysis. v. 24, p. 569-579, 2001.

SILVA, C.P.; EMÍDIO, E.S.; MARCHI, M.R.R. UV Filters in Water Samples: Experimental Design on the SPE Optimization followed by GC-MS/MS Analysis. Journal of the Brazilian Chemical Society. v. 24, p.1433-1441, 2013.

SOTELO, J.L.; OVEJERO, G.; RODRIGUEZ, A.; ÁLVAREZ, S.; GALÁN, J.; GARCIA, J. Competitive adsorption studies of caffeine and diclofenac aqueous solutions by activated carbon. Chemical Engeneering Journal. v. 240, p. 443-453, 2014.

STACKELBERG, P. E.; FURLONG, E. T; MEYER, M. T.; ZAUGG, S. D.; HENDERSON, A. K.; REISSMAN, D .B. Persistence of pharmaceutical compounds and other organic wastewater contaminants in a conventional drinking-water treatment plant. Science of the Total Environment, Amsterdam, v. 329, n. 2, p.99-113. 2004.

STETER, J.R.; ROCHA, R.S.; DIONÍSIO, D.; LANZA, M.R.V.; MOTHEO, A.J. Electrochemical oxidation route of methyl paraben on a boron-dopeddiamond anode. Electrochimica Acta. v. 117, p. $127-133,2013$.

STUMPF, M.; TERNES, T. A.; WILKEN, R.; RODRIGUES, S. V.; BAUMANN, W. Polar drug residues in sewage and natural waters in the state of Rio de Janeiro, Brazil. Science Total Environmental, Amsterdam, v. 225, n. 1-3 p. 135-141. 1999.

TAY, K.S.; RAHMAN, N.A.; ABAS, M.R.B. Ozonation of parabens in aqueous solution: Kinetics and mechanism of degradation. Chemosphere. v. 81, p. 1446-1453, 2010.

TERNES, T. A.; STUMPF, M.; MUELLER, J.; HABERER, K.; WILKEN, R. D.; SERVOS, M. Behavior and occurrence of strogens in municipal sewage treatment plants - I. investigations in Germany, Canada and Brazil. Science of the Total Environmental, Amsterdam, v. 225, n.1-2, p. 8190. 1999.

TERNES, T.; HIRSCH, R.; MUELLER, J.; HABERER, K. Methods for the determination of neutral drugs as well as betablockers and alpha2-sympathomimetics in aqueous matrices using GC/MS and LC/MS/MS. Fresen Journalof Analytical Chemistry. v. 362, p. 329-40, 1998.

TERNES, T.A.; MEISENHEIMER, M; MCDOWELL, D.; SACHER, F.; BRAUCH, H-J.; HAISTGULDE, B.; PREUSS, G.; WILME, U.; ZULEI-SEIBERT, N. Removal of Pharmaceuticals during Drinking Water Treatment.Environmental Science \& Technology. v. 36, p. 3855-3863, 2002. 
THOMAS, P.M.; FOSTER, G.D. Determination of nonsteroidal anti-inflammatory drugs, caffeine, and triclosan in wastewater by gas chromatography-mass spectrometry. Journal of Environmental and Science Health A. v. 39, p. 1969-78, 2004.

TIXIER, C.; SINGER, H.P.; OELLERS, S.; MULLER, S.R. Occurrence and fate of carbamazepine, clofibric acid, diclofenac, ibuprofen, ketoprofen, and naproxen in surface waters. Environmental Science and Technology. v. 37, p. 1061-1068, 2003.

VAN DOORSLAER, X., DEWULF, J., VAN LANGENHOVE, H., DEMEESTERE, K. Fluoroquinolone antibiotics: an emerging class of environmental micropollutants. Science and Total Environment. v. 500, p.250-269, 2014.

VERLICCHI, P.; ZAMBELLO, E.; AUKIDY, M.AL. Removal of Personal Care Products in Constructed Wetlands. Chapter. Personal Care Products in the Aquatic Environment. v. 36 of the series The Handbook of Environmental Chemistry. p. 319-353, 2014.

VIENO, N.M., TUHKANEN, T.; KRONBERG, L. Seasonal variation in the occurrence or pharmaceuticals in effluents from a sewage treatment plant and in the recipient water. Environmental Science and Technology. v. 39, p. 8220-8226, 2005.

VIENO, A., SANTINELLO, M., PASTORE, M., PERKINS, D. D. Social support, sense of community in school, and self-efficacy as resources during early adolescence: An integrative, developmentally oriented model. American Journal of Community Psychology. v. 39, p. 177-190, 2007.

WEIHONG LI, Y.; CHANGSHENG, G.; WEI HU, KEMING LIU, YUQIU WANG, TAN ZHU. Occurrence and behavior of four of the most used sunscreen UV filters in a wastewater reclamation plant. Water Research, v. 41, p. 3506-3512, 2007.

WESTERHOFF, P. Removal of endocrine disruptors, pharmaceuticals, and personal care products during water treatment. Southwest Hydrology. v. 2.6, p. 18-19, 2003.

WHO. Results of round I: of the WHO International Scheme to Evaluate Household Water Treatment Technologies. Geneva: World Health Organization, 2016;

(http://www.who.int/household_water/scheme/household-water-treatment-report-round-1/en/, accessado em 08/03/2016).

WHO/UNICEF. Progress in Drinking-Water and Sanitation: Special Focus on Sanitation. Geneva: World Health Organization and United Nations Children's Fund, 2008.

WIESENBERG-BOETTCHER, I.; PFEILSCHIFTER, J.; SCHWEIZER, A.; SALLMANN, A.; WENK, P. Pharmacological properties of five diclofenac metabolites identified in human plasma. Agents and Actions, v. 34, 1/2, 1991.

WINKLER, M.; LAWRENCE, J.R.; NEU, T.R. Selective degradation of ibuprofeno and clofibic acid in two model river biofilm system. Water Research. v. 35, p. 3197-3205, 2001. 
WOUDNEH, M.B.; LLOYD, B. ; STEVENSON, D. The behaviour of 2,4-D as it filters through slow sand filters. Aqua. v. 46, no3, p. 144-14, 1997.

YANG, L.; YU, L.E.; RAY, M.B. Degradation of paracetamol in aqueous solutions by $\mathrm{TiO}_{2}$ photocatalysis. Water Research. v. 42, p. 3480-3488, 2008.

YOON, Y., WESTERHOFF, P., SNYDER, S., SONG, R. and LEVINE, B. A review on removal of endocrine-disrupting compounds and pharmaceuticals by drinking water treatment processes, WQTC - water quality technology conference, American Water Works Association, Seattle, WA, US, 2002.

ZWIENER, C.; SEEGER, S.; GLAUNER, T.; FRIMMEL, F.H. Metabolites from the biodegradation of pharmaceutical residues of ibuprofen in biofilm reactors and batch experiments. Analytical and Bioanalytical Chemistry. v. 372, p. 569-575, 2002. 
Capítulo 3

Comunidade de algas e cianobactérias em filtros ecológicos utilizados para o tratamento

de água contaminada com produtos farmacêuticos e de cuidados pessoais.

\section{Resumo}

O biofilme desenvolvido no topo da areia dos filtros ecológicos é tido como a chave do sucesso no sistema de purificação ecológica da água. Neste complexo mecanismo de filtração, ainda pouco conhecido, que é o biológico, a comunidade de algas e cianobactérias compõe a base da cadeia trófica. Diante da conhecida contaminação de corpos d'água, água de consumo e até mesmo água subterrânea por produtos farmaceuticos e de cuidados pessoais (PFCPs), estudos devem ser conduzidos para avaliar o efeito que a presença destes e de outros contaminantes exercem no biofilme, importante compartimento dos filtros ecológicos. Assim, este estudo teve por objetivo avaliar a comunidade de algas e cianobactérias do biofilme de filtros ecológicos que receberam água contaminada por seis PFCPs, aplicados isoladamente em cada filtro e em conjunto, comparados com um filtro controle, que não recebeu contaminação. Foram identificados 156 táxons. A flora de algas e cianobactérias identificada nos filtros foi bem diversificada, com elevado número de táxons e densidade de Chlorophyceae e Cyanobacteria. Registrou-se efeito na comunidade de algas e cianobactérias diante da presença dos produtos farmacêuticos e de cuidados pessoais na água a ser tratada pelos filtros ecológicos, porém, não foram evidenciadas as diferenças com a aplicação dos PFCPs isoladamente ou em mistura. O efeito tempo (número de carreiras de filtração) também influenciou nos resultados do biovolume; riqueza, espécies descritoras, e composição de um modo geral. O efeito tempo de coleta, se antes ou 96 horas após a contaminação também foi observado por PCoAs, indicando diferença entre os biovolumes estimados, e consequentemente, efeito da contaminação sobre a comunidade. A análise de Análise de correspondência canônica (ACC) realizada detectou que houve correlação dos fatores abióticos (nitrogênio total, fósforo total, e clorofila-a) com os biovolumes das espécies significativas presentes nos filtros em todas as contaminações.

Palavras-chave: Biofilme de algas, contaminação por PFCPs, Lepocinclis sp. 


\begin{abstract}
The biofilm developed on the top of the sand of the ecological filters is regarded as the key of the success in the ecological purification system. In this complex filtration mechanism, still little known, which is the biological, community of algae and cyanobacteria forms the basis of the food chain. Given the known contamination of water bodies, water consumption and even underground water with pharmaceuticals and personal care products (PPCPs), studies should be conducted to assess the effect that the presence of these and other contaminants have on the biofilm, important compartment on ecological filters. This study aimed to evaluate the community of algae and cyanobacteria from the biofilm of the ecological filters that received water contaminated with six PPCPs applied separately on each filter and together, compared with a control filter, which received no contamination. 156 taxa were identified. The flora of algae and cyanobacteria identified on the filters was diverse, with high number of taxa and density of Chlorophyceae and Cyanobacteria. Was registered an effect on the community of algae and cyanobacteria in the presence of pharmaceuticals and personal care compounds in water to be treated by ecological filters, however, were not evident differences in the application of PPCPs alone or mixed. The effect of time (number of filtration runs) also influenced the biovolume results; richness of species, descriptor speciesand composition generally. The effect of collection time, before or 96 hours after the contamination was also observed by Principal Coordinate Analysis (PCoAs), indicating the difference between the estimated biovolumes, and therefore, the effect of contamination on the community. Canonical correspondence analysis (CCA) analysis conducted found that correlation of abiotic factors (total nitrogen, total phosphorus, and chlorophyll-a) with biovolumes of significant species present in the filters in all contaminations.
\end{abstract}

Key-words: Biofilm of algae; contamination with PPCPs; Lepocinclis sp. 


\section{Introdução}

Antigamente, a presença de microorganismos e fitoplâncton em filtros de tratamento de água era vista como prejudicial, associando-os a doenças, ou no caso do fitoplâncton, como causadores de obstruções nos filtros, o que tornava a visão do público em relação ao filtro lento de areia um pouco preconceituosa.

Já é sabido que a eficiência da filtração lenta está diretamente ligada à presença do biofilme formado no topo do leito de areia dos filtros, tanto que, quando se inicia a utilização de um filtro para o tratamento de água, este deve ser submetido, primeiramente, ao processo de maturação, que nada mais é do que a colonização da parte superficial da areia do filtro por diversos microrganismos que já estavam presentes na água a ser filtrada.

Segundo Nakamoto (2014), idealizador da ideia de um novo nome e conceito para a filtração lenta em areia, como sendo: "sistema de purificação ecológica", a cadeia trófica formada no filtro é a chave para a eficiência do sistema e também para a modificação da nomenclatura, uma vez que a maior contribuição deste sistema para purificar e tratar a água seja biológica.

As algas e cianobactérias exercem importância fundamental na atividade biológica de um filtro ecológico. Compõem a base para a cadeia trófica e, além disso, durante seu processo fotossintético as algas absorvem o gás carbônico, nitratos, fosfatos e produzem oxigênio, proporcionando condições ideais para o desenvolvimento da vida de microrganismos que dependem de oxigênio para sua sobrevivência e permite a realização da decomposição (NAKAMOTO, 2008).

Ainda de acordo com Nakamoto (2008) a comunidade de algas e cianobactérias também forma uma "malha" sobre a areia do filtro, o que auxilia na retenção de impurezas.

Segundo Nakamoto e Kato (2006), a pequena flutuação nos parâmetros ambientais é "gentil" para os pequenos organismos na camada de areia, o que não ocorre no caso da filtração rápida, por exemplo. Em paralelo a esse processo, os compostos nitrogenados são oxidados formando nitratos que são facilmente assimilados pelas algas (HESPANHOL, 1987).

De acordo com Haig et al., (2015), a composição da comunidade microbiana de filtros lentos de areia depende de vários fatores como: mês de coleta das amostras, as profundidades a que as amostras foram coletadas, sendo a idade do filtro o parâmetro mais importante para explicar as mudanças na comunidade microbiana. 
O sistema de crescimento contínuo de algas é importante para a manutenção da condição aeróbia do filtro (NAKAMOTO, 2014). Em contrapartida, a elevada concentração de algas na água afluente aos filtros pode causar obstruções do meio filtrante, resultando no aumento acelerado da perda de carga (DI BERNARDO, 1993).

Em estudo realizado com filtros lentos abastecidos pelas águas do rio Tâmisa, em Londres, no período de 1994 a 1996, a alga verde filamentosa Clarophora dominou durante o período de verão, sendo que diatomáceas filamentosas do gênero Melosira foram as dominantes no inverno (NAKAMOTO et al., 1996, HENDERSON et al., 2008). De acordo com Henderson et al., (2008) as diatomáceas Melosira sp., Asterionella formosa e Fragillaria crotonensis são formadoras de colônias, e foram as responsáveis pelo bloom que promoveu considerável perda de carga e quedas acentuadas nos tempos de execução registrados em uma estação de tratamento de água que utilizou filtros lentos em areia em Londres, Inglaterra.

Neste tipo de sistema de tratamento de água não se pode fugir do processo de limpeza dos filtros quando estes colmatam. Porém, o próprio biofilme formado no topo da areia do filtro, caracterizado como uma cadeia trófica se encarrega de manter a operação dos filtros por maior tempo.

Em casos extremos e da indisponibilidade de parar o filtro para limpeza, ou casos como "bloom" na água que abastece o sistema, os autores Bernhardt e Clasen, (1991) afirmam que a remoção de algas ocorre quando se usa uma dose baixa de metais coagulantes.

Muitos trabalhos têm sido desenvolvidos com o foco no biofilme de filtros lentos de areia, ou filtros ecológicos ou "Household Biosand filters", porém ainda não há relatos de trabalhos realizados em relação à composição, densidade e biovolume de algas e cianobactérias de biofilmes de filtros ecológicos que sofreram contaminação de PFCPs. A maioria dos trabalhos aborda o estudo das bactérias que fazem parte da composição do biofilme (CALVO-BADO et al., 2003; WAKELIN et al., 2010; WAKELIN et al., 2011; HWANG et al., 2014; HAIG et al., 2015). Além disso, a maioria dos estudos foram realizados em escala laboratorial e com parâmetros cuidadosamente controlados, que não podem representar plenamente as complexas e diversificadas comunidades microbianas que formam o biofilme dos filtros lentos de areia em grande escala (HAIG et al., 2011).

Ante a sabida contaminação das águas por PFCPs, e a possibilidade da aplicação do sistema ecológico de purificação da água como tratamento, fazem-se necessários conhecimentos sobre o possível efeito da contaminação da água no ponto mais importante e essencial para o sucesso da filtração ecológica, o biofilme, e mais especificamente a comunidade de algas e cianobactérias que compõe a base da cadeia trófica. 
Um indício do que pode ocorrer com algumas espécies do fitoplâncton pode ser observado no estudo realizado por Pomati et al., (2004) com cultura de espécies isoladas, que mostrou que o ibuprofeno na concentração de 1-1.000 $\mu \mathrm{g} \mathrm{L}^{-1}$ estimula o crescimento da cianobactéria Synechocystis sp. ao longo de cinco dias de exposição, sendo o maior crescimento (em densidade) observado na concentração de $10 \mu \mathrm{g} \mathrm{L}^{-1}$. Já em uma concentração de $1000 \mu \mathrm{g} \mathrm{L}^{-1}$ do fármaco ocorre inibição do crescimento da macrófita Lemna gibba, após sete dias de exposição.

\section{Material e Métodos}

\subsection{Análises dos fatores abióticos}

As seguintes análises da água foram efetuadas: fósforo total $\left(\mu \mathrm{g} \mathrm{L}^{-1}\right)$ de acordo com Golterman et al. (1978); nitrogênio Kjeldahl total $\left(\mu \mathrm{g} \mathrm{L}^{-1}\right)$ de acordo com método descrito por Mackereth et al.(1978); clorofila-a $\left(\mu \mathrm{g} \mathrm{L}^{-1}\right)$ de acordo com método descrito por Nusch, (1980). Foram realizadas as medições de: pH utilizando pHmetro Micronal B374; oxigênio dissolvido $\left(\mathrm{mg} \mathrm{L}^{-1}\right)$ com Oxímetro YSI e temperatura da água $\left({ }^{\circ} \mathrm{C}\right)$ utilizando-se sonda multiparâmetros Orion, modelo 145.

As amostras foram coletadas na parte interna dos filtros ecológicos (coluna d'água sobre a areia). As coletas foram realizadas antes da contaminação e 96 horas após a contaminação. A coleta final de 96 horas após a contaminação foi definida por ser o tempo de duração de um teste de toxicidade para algas, quando o intuito é avaliar o efeito de alguma substância sob o crescimento e desenvolvimento de algas, ABNT- NBR 12648 (ABNT, 2011).

\subsection{Análises qualitativas e quantitativas da comunidade de algas e cianobactérias}

A identificação e contagem das algas e cianobactérias que se desenvolveram nos filtros ecológicos foram realizadas em São Paulo, no Instituto de Botânica, Núcleo de Pesquisa em Ficologia, sob a orientação da Profa. Dra. Andrea Tucci.

As amostras de fitoplâncton foram coletadas e analisadas de duas maneiras distintas, de acordo com a finalidade da amostra, sendo 2.2.1 e 2.2.2. 


\subsubsection{Análise qualitativa da comunidade de algas e cianobactérias}

Para a análise taxonômica da comunidade as amostras da sub-superfície d'água de cada filtro foram filtradas por meio de rede de plâncton com abertura de malha de $20 \mu \mathrm{m}$ e fixadas com formalina na concentração final de 4 a 5\%. A análise taxonômica foi realizada com base no exame morfológico e morfométrico dos organismos fazendo uso de microscópio fotônico, Zeiss Axioplan 2, com sistema de captura de imagem acoplado. Quando necessário, foi utilizada luz de epifluorescência para diferenciar bacterioplâncton de cianobactérias; contraste de fase e nanquim para evidenciar bainha mucilaginosa.

As amostras foram examinadas em aumentos de 400 e 1000 vezes, e para a identificação foram utilizadas bibliografias especializadas incluindo floras, revisões e monografias. Os sistemas de classificação adotados foram: Round, (1971) para as classes de Chlorophyta, Round et al., (1990) para as Bacillariophyceae, Fragilariophyceae e Coscinodiscophyceae; Komárek e Anagnostidis (1989, 1998 e 2005) e Hoffmam et al., (2005) para Cyanobacteria e van den Hoek et al., (1995) para as demais classes.

Dentre os trabalhos especializados utilizados para identificação de gêneros e espécies destacam-se: Komárek e Fott, (1983); Sant'Anna, (1984); Comas, (1996); Godinho et al., (2010); Rodrigues et at., (2010); Rosini et al., (2012 e 2013a); Ramos et al., (2012) para algas verdes; Tell e Conforti, (1986) para Euglenophyceae; Castro et al., (1991) para Cryptophyceae; Komárková-Legnerová e Cronberg, (1994); Azevedo et al., (1996); Azevedo e Sant'Anna, (1999, 2003); Komárek e Azevedo, (2000); Rosini et al., (2013b) e Sant'Anna et al., (2004) para Cyanobacteria.

Após a análise taxonômica, as amostras foram depositadas na coleção líquida de algas do Herbário "Maria Eneida P.K. Fidalgo" do Instituto de Botânica, São Paulo. As amostras dos filtros triplicatas para cada tratamento deram origem a uma amostra composta, sendo que as amostras foram incluídas com os vouchers de 469.577 a 469.608.

\subsubsection{Análise quantitativa da comunidade de algas e cianobactérias}

Para coleta do material, foi feito sorteio de um dos quadrantes de cada filtro; um frasco de vidro foi submerso no quadrante sorteado. Foi coletado $100 \mathrm{~mL}$ de amostra e fixada com lugol acético $1 \%$ na proporção de 1:100.

A contagem do fitoplâncton foi realizada conforme o método descrito por Utermöhl (1958) em microscópio invertido Zeiss Axiovert 25 em aumento de 400 vezes. O tempo de 
sedimentação das amostras foi de três horas para cada centímetro de altura da câmara (LUND et al., 1958). A câmara de sedimentação utilizada foi de 2 e $10 \mathrm{~mL}$, dependendo da concentração do fitoplâncton de cada amostra.

A contagem dos indivíduos foi realizada em transectos e o limite da contagem, ou seja, o número mínimo de campos contados por câmara de sedimentação foi determinado por meio de dois critérios: a) gráfico de estabilização do número de espécies, obtido a partir de espécies novas adicionadas com o número de campos contados e b) o de espécies mais abundantes, obtido pela contagem de até 100 indivíduos da espécie mais comum. No caso de ocorrência de florações de cianobactérias ou outras microalgas, foi realizada a contagem de 100 indivíduos da segunda espécie mais abundante (TUCCI, 2002). Cada célula, colônia, cenóbio e filamento foram considerados como um indivíduo. Os resultados foram expressos em densidade (org $\mathrm{mL}^{-1}$ ) e calculados de acordo com a fórmula descrita em Weber (1973):

Organismos $\mathbf{m L}^{-1}=(\mathbf{n} / \mathbf{s c}) .(\mathbf{1} / \mathbf{h}) .(\mathbf{F})$; onde:

$\mathrm{n}=$ número de indivíduos efetivamente contados;

$\mathrm{s}=$ área do campo em $\mathrm{mm}^{2}$ no aumento de 40x;

$\mathrm{c}=$ número de campos contados;

$\mathrm{h}=$ altura da câmara de sedimentação em mm;

$\mathrm{F}=$ fator de correção para mililitro $\left(10^{3} \mathrm{~mm}^{3} / 1 \mathrm{~mL}\right)$.

A Riqueza $(\mathrm{R})$ foi considerada como o número total de táxons encontrados na amostra do quantitativo. A partir dos resultados de densidade (org $\mathrm{mL}^{-1}$ ) foi calculado o Índice de Diversidade (H') de Shannon e Weaver, (1963), (bits ind $\mathbf{~}^{-1} / \mathbf{b i t s} \boldsymbol{\mu \mathbf { m } ^ { 3 }}$ ), estimado pelo índice de Shannon e Weaver (1963). Calculado a partir da fórmula:

$$
\mathbf{H}^{\prime}=-\underset{\mathbf{i}-\mathbf{l}}{\stackrel{\mathbf{n}}{\log } \mathbf{p i}, \text { onde: }}
$$

$\mathrm{pi}=\mathrm{ni} / \mathrm{n}$;

ni = número total de indivíduos de cada táxons na amostra;

$\mathrm{n}=$ número total de indivíduos na amostra.

\section{Biovolume da Comunidade Fitoplanctônica $\left(\mathrm{mm}^{3} \mathrm{~L}^{-1}\right)$}

$\mathrm{O}$ biovolume é calculado a partir da densidade (org $\mathrm{mL}^{-1}$ ) calculada anteriormente. $\mathrm{O}$ método do cálculo do biovolume é importante, pois atribui aos indivíduos de maior tamanho sua devida importância ambiental como contribuidores da biomassa fitoplanctônica (DIAS JR., 1998).

O biovolume de cada espécie do fitoplâncton pode ser estimado através da associação da forma das algas com modelos geométricos aproximados, onde se considera a dimensão 
média dos indivíduos para fins de cálculo de volume celular (HILLEBRAND et. al., 1999; SUN e LIU, 2003).

Para tanto, mede-se as dimensões lineares $(\mu \mathrm{m})$ de cada espécie (diâmetro, altura, largura) e efetuam-se as referidas medições em pelo menos 20 células de cada espécie. Utiliza-se a forma geométrica que melhor representa a forma da célula e utiliza-se a respectiva equação para calcular o volume celular para a espécie $\left(\mu \mathrm{m}^{3}\right)$. Determina-se então o volume celular da espécie utilizando a mediana da série de volumes individuais. A mediana da série de valores individuais calculados é considerada como o valor mais robusto e representativo do volume específico para um determinado táxon. Calcular o biovolume $\left(\mathrm{mm}^{3}\right.$ $\left.\mathrm{L}^{-1}\right)$ da espécie multiplicando o volume celular médio $\left(\mu \mathrm{m}^{3}\right)$ da espécie pelo número de células contadas (cel $\mathrm{mL}^{-1}$ ), e o biovolume total da amostra é obtido pelo somatório do biovolume de cada táxon (INAG, 2009).

Para este estudo em questão, o volume celular para cada espécie foi calculado com base em modelos geométricos, cujas formas se aproximassem mais, isolados ou combinados, da forma dos indivíduos de acordo com Hillebrand et al., (1999), Wetzel e Likens, (2000), Sun e Liu, (2003) e Fonseca et al., (2014).

O Biovolume $\left(\mathrm{mm}^{3} \mathrm{~L}^{-1}\right)$ foi estimado multiplicando-se as densidades de cada espécie pelo volume médio de suas células e, sempre que possível, foram consideradas as dimensões médias de 20 indivíduos. O biovolume de algumas espécies foram obtidos de Tucci, (2002), Fonseca et al., (2014), Osti, (2013), Rossini, (2015). O valor obtido em $\mu \mathrm{m}^{3} \mathrm{~mL}^{-1}$ foi transformado para $\mathrm{mm}^{3} \mathrm{~L}^{-1}$ dividindo-se esse valor por $10^{6}$.

A partir dos resultados de densidade (org $\left.\mathrm{mL}^{-1}\right)$ e de biovolume $\left(\mu \mathrm{m}^{3} \mathrm{~mL}^{-1}\right)$ da comunidade de algas e cianobactérias foram calculadas as espécies descritoras.

\section{Espécies Descritoras}

Como espécies descritoras da comunidade de algas e cianobactérias considerou-se o seguinte critério sobre os resultados de biovolume: foram consideradas espécies descritoras, aquelas que contribuíram com $1 \%$ (ou mais) do biovolume total obtido e que juntas somaram $80 \%$ do biovolume total.

\subsection{Análises estatísticas}

Foi realizada a análise de agrupamento com as espécies registradas em todo o período estudado, gerando um dendrograma de similaridade de espécies, por índice de Jaccared. 
A análise de coordenadas principais (ACoP) (GOODALL, 1954 apud VALENTIN, 2000) foi utilizada para determinar a variabilidade dos dados abióticos em relação às contaminações (temporal) e aos filtros (espacial). Utilizou-se a matriz de covariância, sendo os dados transformados pela amplitude de variação "ranging" ([x-xmin)/(xmax-xmin)]).

Para avaliação conjunta das variáveis abióticas e bióticas foi utilizada a análise de correspondência canônica (ACC). A ACC foi realizada a partir de matrizes de covariância, com transformação dos dados abióticos pela amplitude de variação "ranging" $([\mathrm{xxmin}) /(\mathrm{xmax}-\mathrm{xmin})])$ e dos dados bióticos pelo $[\log (\mathrm{x}+1)]$.

Primeiramente, realizou-se uma ACoP com todas as espécies registradas para selecionar as que foram estatisticamente significativas $(\mathrm{p} \leq 0,05)$. Posteriormente, foi realizada a ACC para explicar as possíveis relações entre as espécies de algas e cianobactérias com as variáveis abióticas. Para testar o nível de significância dos dois primeiros eixos canônicos utilizou-se o teste de Monte Carlo (999 permutações; $p \leq 0,05$ ), que determina se há probabilidade dos autovalores terem distribuição ao acaso.

Os dados foram analisados mediante análises estatísticas multivariadas utilizando o Programa PC-ORD versão 6.0 para Windows (MCCUNE e MEFFORD, 2011). Consideramos as variáveis com correlação significativa aquelas que apresentaram $r>0,5$ com os eixos 1 e 2 da ordenação.

\section{Resultados e Discussões}

\subsection{Parâmetros abióticos}

Os valores médios da temperatura da água estiveram próximos entre os filtros controle e mix $\left( \pm 22{ }^{\circ} \mathrm{C}\right)$, enquanto os filtros contaminados com uma única substância estiveram mais próximos entre si $\left( \pm 21^{\circ} \mathrm{C}\right)$. O oxigênio dissolvido $(\mathrm{OD})$ manteve-se entre 6,5 e $6,7 \mathrm{mg} \mathrm{L}^{-1} \mathrm{em}$ todos os filtros durante o período, assim como o $\mathrm{pH}$ (Tabela 1).

Os valores médios de NT (nitrogênio total) estiveram próximos, entre 0,4 e $0,5 \mathrm{mg} \mathrm{L}^{-1}$ em todos os filtros durante o período, com desvio padrão $\pm 0,5$, enquanto as variações de PT (fósforo total) foram maiores, com valores de desvios padrões variando entre 27 e 80 . Os filtros que apresentaram maiores valores de PT foram os contaminados com metilparabeno $\left(82,7 \mathrm{mg} \mathrm{L}^{-1}\right)$ e ibuprofeno $\left(80,1 \mathrm{mg} \mathrm{L}^{-1}\right)$, enquanto o filtro controle teve valor médio de 58 $\mathrm{mg} \mathrm{L}^{-1}$. Os filtros que receberam contaminação extra pelos compostos apresentaram maiores 
valores de fósforo total, se comparado com o filtro controle, exceto para o composto paracetamol $\left(45 \mathrm{mg} \mathrm{L}^{-1}\right)$.

Tabela 1: Valor médio total e desvio padrão para os valores de: Temperatura (Temp) $\left({ }^{\circ} \mathrm{C}\right)$, Oxigênio Dissolvido (OD) $\left(\mathrm{mg} \mathrm{L}^{-1}\right), \mathrm{pH}$, Nitrogênio Total (NT) $\left(\mu \mathrm{g} \mathrm{L}^{-1}\right)$, Fósforo Total (PT) $\left(\mu \mathrm{g} \mathrm{L}^{-1}\right), \mathrm{e}$ Clorofila-a (Cloro a) $\left(\mathrm{mg} \mathrm{L}^{-1}\right)$, aferidos durante as três contaminações.

\begin{tabular}{lrrrrrrrr}
\hline & \multicolumn{1}{c}{ C } & \multicolumn{1}{c}{ P } & \multicolumn{1}{c}{ D } & \multicolumn{1}{c}{ N } & \multicolumn{1}{c}{ I } & \multicolumn{1}{c}{ M } & \multicolumn{1}{c}{ B } & \multicolumn{1}{c}{ Mix } \\
\hline Temp & $22,06 / 1,09$ & $21,75 / 1,10$ & $21,71 / 1,14$ & $21,79 / 1,19$ & $21,78 / 1,16$ & $21,80 / 1,19$ & $21,82 / 1,22$ & $22,02 / 1,21$ \\
OD & $6,79 / 0,62$ & $6,59 / 0,61$ & $6,64 / 0,44$ & $6,61 / 0,53$ & $6,77 / 0,44$ & $6,57 / 0,44$ & $6,52 / 0,44$ & $6,79 / 0,48$ \\
pH & $6,59 / 0,21$ & $6,64 / 0,12$ & $6,68 / 0,11$ & $6,62 / 0,06$ & $6,70 / 0,07$ & $6,64 / 0,06$ & $6,56 / 0,06$ & $6,62 / 0,06$ \\
NT & $0,54 / 0,21$ & $0,50 / 0,25$ & $0,43 / 0,18$ & $0,55 / 0,36$ & $0,54 / 0,24$ & $0,59 / 0,37$ & $0,41 / 0,23$ & $0,50 / 0,32$ \\
PT & $58,01 / 43,69$ & $45,66 / 27,75$ & $63,59 / 29,97$ & $55,49 / 42,45$ & $80,09 / 30,20$ & $82,68 / 80,43$ & $60,85 / 39,08$ & $72,02 / 58,57$ \\
Cloro a & $10,00 / 3,41$ & $21,53 / 28,22$ & $11,74 / 5,40$ & $13,41 / 6,74$ & $16,93 / 9,36$ & $14,06 / 8,46$ & $12,17 / 7,23$ & $10,45 / 4,86$ \\
\hline
\end{tabular}

Assim como PT, a clorofila- $a$ também apresentou variabilidade entre as coletas e entre os filtros. O filtro contaminado com paracetamol apresentou maior concentração de clorofila$a\left(21,5 \mathrm{mg} \mathrm{L}^{-1}\right)$, e o filtro controle apresentou a menor concentração detectada, seguido pelo filtro contaminação com o mix dos compostos $\left(10,00 \mathrm{mg} \mathrm{L}^{-1}\right.$ e $\left.10,45 \mathrm{mg} \mathrm{L}^{-1}\right)$.

A variabilidade nos dados de PT aferidos no filtro controle (desvio padrão $=43,69$ ) reflete a variabilidade deste parâmetro na água de entrada nos filtros (água do Reservatório do Lobo) e pode estar relacionada com as atividades antrópicas do entorno já reportada anteriormente por Calijuri e Tundisi, (1990), onde os autores citam despejo de esgotos domésticos e de fertilizantes utilizados em algumas áreas agrícolas.

A avaliação da disponibilidade de nutrientes na água está diretamente relacionada com a comunidade fitoplanctônica, podendo esta apresentar crescimento acelerado, caracterizando as florações de cianobactérias e algas. No entanto, outras condições e fatores são necessários para que a floração se estabeleça, como as condições de temperatura da água, luminosidade, tempo de residência do sistema, fotoperíodo, atividade do vento, bem como a presença de zooplâncton que se alimentam das algas, dentre outros (REYNOLDS, 1980; PADISÁK, 1997; BENSON-EVANS et al. 1999; BOUVY et al., 2000; FERNANDES et al., 2009).

A adição dos produtos farmacêuticos e de cuidados pessoais nos filtros, não ocasionou aumentos significativos nos valores médios dos nutrientes avaliados (PT e NT). A clorofila-a também não apresentou valores discrepantes na comparação entre os filtros em que foram aplicadas as contaminações quando comparados com o filtro controle, fato este que pode ser observado também na comparação dos valores de desvio padrão calculado (Tabela 1). 


\subsection{Comunidade de algas e cianobactérias no biofilme dos filtros ecológicos}

Nos 22 filtros ecológicos, durante o período de 04/11/2013 a 02/12/2013 (da primeira a terceira contaminações) foram identificados 156 táxons, distribuídos em 9 grupos taxonômicos (Tabela 2).

Chlorophyceae e Cyanobacteria foram os grupos que apresentaram maior número de táxons, 58 e 37, respectivamente. Chlorophyceae e Cyanobacteria são mencionadas como as classes mais representativas quanto à riqueza de táxons em ambientes rasos e classificados como eutróficos (SANT'ANNA et al., 2006; TUCCI et al., 2006; MERCANTE et al., 2011). A Tabela 3 contém a lista completa de táxons registrados nos filtros para o período em questão.

Tabela 2: Grupos taxonômicos registrados nos filtros ecológicos durante o período.

\begin{tabular}{lcc}
\hline Grupos Taxonômicos & $\mathbf{N}^{\mathbf{0}}$ de táxons & \% \\
\hline Chlorophyceae & 58 & $37,17 \%$ \\
Cyanobacteria & 37 & $23,71 \%$ \\
Zygnemaphyceae & 18 & $11,53 \%$ \\
Bacillariophyceae & 17 & $10,89 \%$ \\
Cryptophyceae & 7 & $4,44 \%$ \\
Chrysophyceae & 6 & $3,84 \%$ \\
Euglenophyceae & 6 & $3,84 \%$ \\
Xanthophyceae & 5 & $3,20 \%$ \\
Dinophyceae & 2 & $1,28 \%$ \\
\hline
\end{tabular}

Tabela 3: Táxons registrados nos filtros ecológicos durante o período.

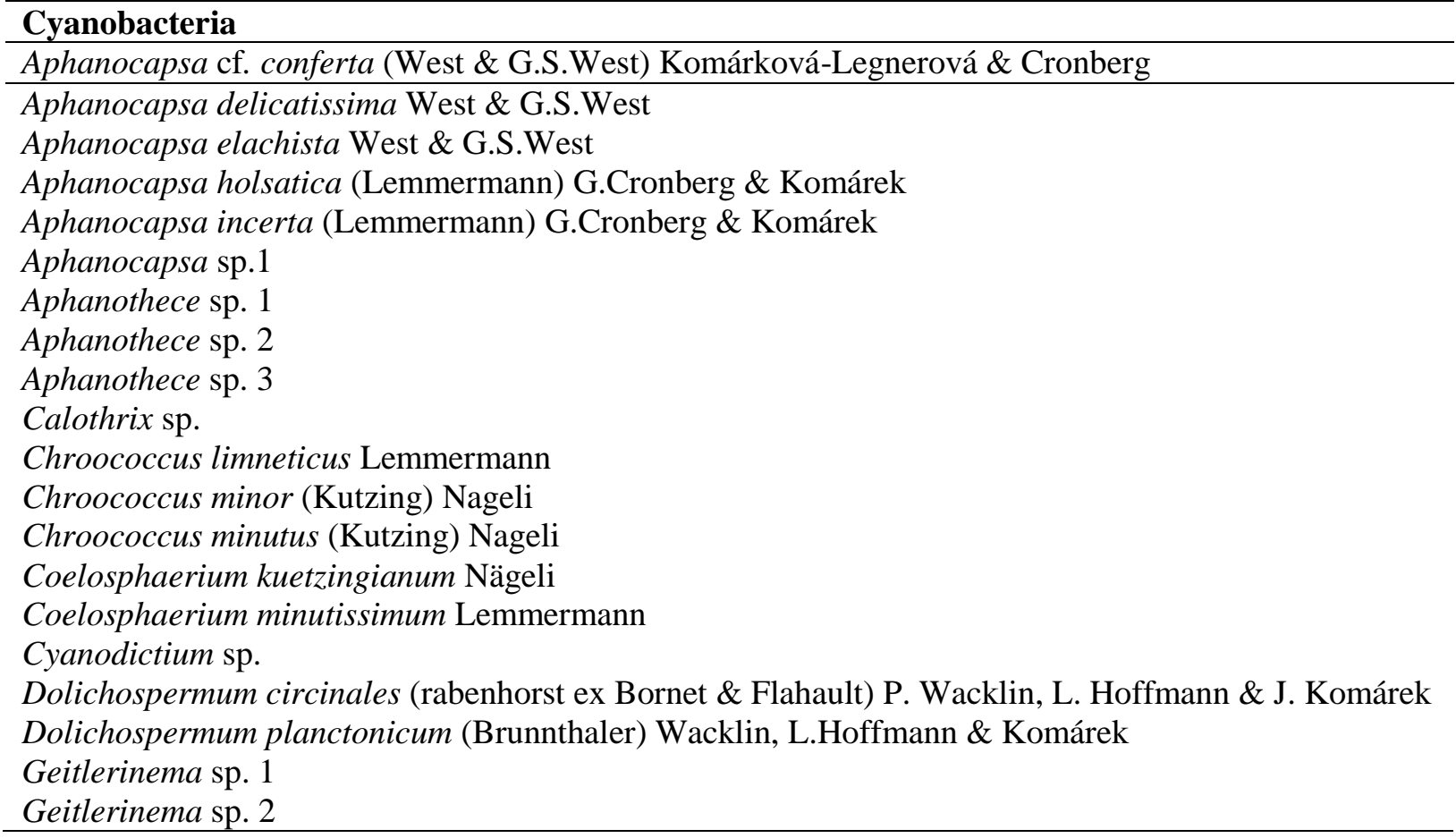




\section{Continuação da Tabela 3.....}

Gloeotrichia sp.

Merismopedia sp. 1

Merismopedia sp. 2

Merismopedia sp. 3

Microcystis aeruginosa (Kützing) Kützing

Microcystis protocystis W.B.Crow

Phormidium sp.1

Planktolyngbya limnetica (Lemmermann) Komárková-Legnerová \& Cronberg

Planktolyngbya sp. 1

Planktolyngbya sp. 2

Planktothrix sp. 1

Pseudanabaena limnetica (Lemmermann) Komárek

Pseudanabaena mucicola (Naumann \& Huber-Pestalozzi) Schwabe

Pseudanabaena sp. 1

Pseudanabaena sp. 2

Radiocystisfernandoi Komárek \& Komárková-Legnerová

Synechocystis aquatilis Sauvageau

\section{Bacillariophyceae}

Achnanthidium minutissimum (Kützing) Czarnecki

Aulacoseira granulata (Ehrenberg) Ralfs

Aulacoseira sp. 1

Aulacoseira sp. 2

Aulacoseira sp. 3

Cyclotella meneghiniana Kützin

Discostella stelligera (Cleve \& Grunow) Houk \& Klee

Encyonema cf. minutum (Hilse ex Rabenh.) D.G.Mann

Eunotia camelus Ehrenberg

Fragilaria sp.

Gomphonema gracile Ehremberg

Gomphonema sp. 1

Gomphonema sp. 2

Melosira sp.

Navicula sp.

Pennales sp.

Surirella sp.

\section{Chlorophyceae}

\section{Actinastrum sp.}

Ankistrodesmus fusiformis Corda

Ankistrodesmus gracilis (Reinsch) Korshikov

Ankyra sp.

Botryococcus sp.

Bulbochaete sp.

Carteria sp. 1

Carteria sp. 2

Chlamydomonas sp. 2

Chlamydomonas sp. 3

Chlamydomonas sp. 4

Chlamydomonas gloeopara Rodhe \& Skuja

Chlamydomonas planctogloea Skuja

Chlamydomonas sp. 1

Chlorella minutíssima Fott \& Nováková

Chlorella vulgaris Beverinck (Beijerinck)

Coelastrum microporum Nägeli

Coenocystis planktonica Korshikov

Coenocystisquadriguloides Fott 


\section{Continuação da Tabela 3.....}

Desmodesmus abundans (Kirchner) E.Hegewald

Desmodesmus brasiliensis (Bohlin) E.Hegewald

Desmodesmus communis (E.Hegewald) E.Hegewald

Desmodesmus intermedius (Chodat) E.Hegewald

Dictyosphaerium ehrembergianum Nageli

Dictyosphaerium pulchellum H.C.Wood

Elakatothrix gelatinosa Wille

Eutetramorus fotti (Hindák) Komárek

Eutetramorus planctonicus (Korshikov) Bourrelly

Eutetramorus tetrasporus Komárek

Golenkinia sp.

Kirchneriella lunaris (Kirchner) Mobius

Kirchneriella rosellata Hindák

Monoraphidium arcuatum (Korshikov) Hindák

Monoraphidium caribeum Hindák

Monoraphidium contortum (Thuret) Komárková-Legnerová

Monoraphidium irregulare (G.M.Smith) Komárková-Legnerová

Monoraphidium komarkovae Nygaard

Monoraphidium minutum (Nägeli) Komárková-Legnerová

Monoraphidium tortile (West \& G.S.West) Komárková-Legnerová

Oedogonium sp.

Oocystis lacustris Chodat

Oocystis marssoni Lemmermann

Oocystis sp.1

Pseudodidymocystis fina (Komárek) E.Hegewald \& Deason

Pseudodidymocystis planctonica (Korshikov) E. Hegewald \& Deason

Radiococcus hindakii (J.Komárek) I.Kostikov, T.Darienko, A.Lukesová, \& L.Hoffmann

Radiococcus planktonicus J.W.G.Lund

Scenedesmus bijugus (Turpin) Lagerheim

Scenedesmus caudato-aculeolatus Chodat

Scenedesmus cf. quadriculata (Turpin) Brébisson

Scenedesmus opoliensis P.G.Richter

Scenedesmus sp. 1

Scenedesmus sp. 2

Sphaerocystis sp.

Stauridium tetras (Ehrenberg) E.Hegewald

Tetradesmus lunatus Korshikov

Tetrastrum heteracanthum (Nordstedt) Chodat

Tetrastrum komarekii Hindák

\section{Chrysophyceae}

Chromulina elegans Doflein

Chromulina sp. 1

Mallomonas sp. 1

Mallomonas sp. 2

Mallomonas sp. 3

Ochromonas ovalis Doflein

\section{Cryptophyceae}

Cryptomonas brasiliensis A.Castro, C. Bicudo \& D.Bicudo

Cryptomonas curvata Ehremberg

Cryptomonas erosa Ehremberg

Cryptomonas marssonii Skuja

Cryptomonasobovata Skuja

Cryptomonas tetrapyrenoidosa Skuja

Rhodomonas lacustris Pascher \& Ruttner

Dinophyceae 
Continuação da Tabela 3.....

Gymnodinium sp.

Peridinium sp.

Euglenophyceae

Lepocinclis sp. 1

Phacus curvicauda Svirenko

Phacus tortus (Lemmermann) Skvortzov

Trachelomonas sp. 1

Trachelomonas volvocina (Ehrenberg) Ehrenberg

Trachelomonas volvocinopsis Svirenko

Xanthophyceae

Characiopsis sp. 1

Characiopsis sp. 2

Isthmochlorom lobulatum (Nägeli) Skuja

Tetraediella spinigera Skuja

Tetraplektron torsum (W.B.Turner) Dedusenko-Shchegoleva

Zygnemaphyceae

Actinathaenium sp.

Arthrodesmus sp.

Closterium sp.1

Cosmariumhumile Nordstedt ex De Toni

Cosmarium sp.1

Cosmarium sp. 2

Cosmarium sp. 3

Cosmarium sp. 4

Cosmarium sp.5

Mougeotia sp.

Pleurotaenium sp. 1

Spirogyra sp.

Staurastrum rotula Nordstedt

Staurastrum sp. 1

Staurastrum vista apical sp. 1

Staurastrum vista apical sp. 2

Staurodesmus sp.

Staurodesmus triangularis (Lagerheim) Teiling

As várias descrições disponíveis para schmutzdecke desenvolvidos em filtros descobertos indicam que suas características variam significativamente de um local para outro e de sazonalidade (CAMPOS, 2002).

No trabalho realizado por Bowles et al., (1983) as diatomáceas Melosira sp., Navicula sp. e Nitzschia acecularis foram as espécies predominantes durante o inverno. No entanto, um tapete verde e espesso da alga filamentosa Zygnema sp. desenvolveu-se em uma espessura de aproximadamente $2 \mathrm{~mm}$ com o aumento da temperatura e da energia solar radiação na primavera.

De acordo com Haig et al., (2015) que realizaram análises de sequenciamento genético para bactérias do biofilme, as composições de comunidades microbianas de filtros lentos de areia são significativamente diferentes, dependendo do estado (operacional ou drenado), idade 
do filtro, a localização da amostra, mês de coleta das amostras, e as distâncias do afluente e efluente dos tubos e as profundidades a que as amostras foram tomadas.

Neste estudo, observou-se que ao longo do tempo de operação dos filtros, houve o desenvolvimento de uma espessa camada formada por Spyrogira sp. (Figura 1), tanto sobre a areia dos filtros, como nas bordas.
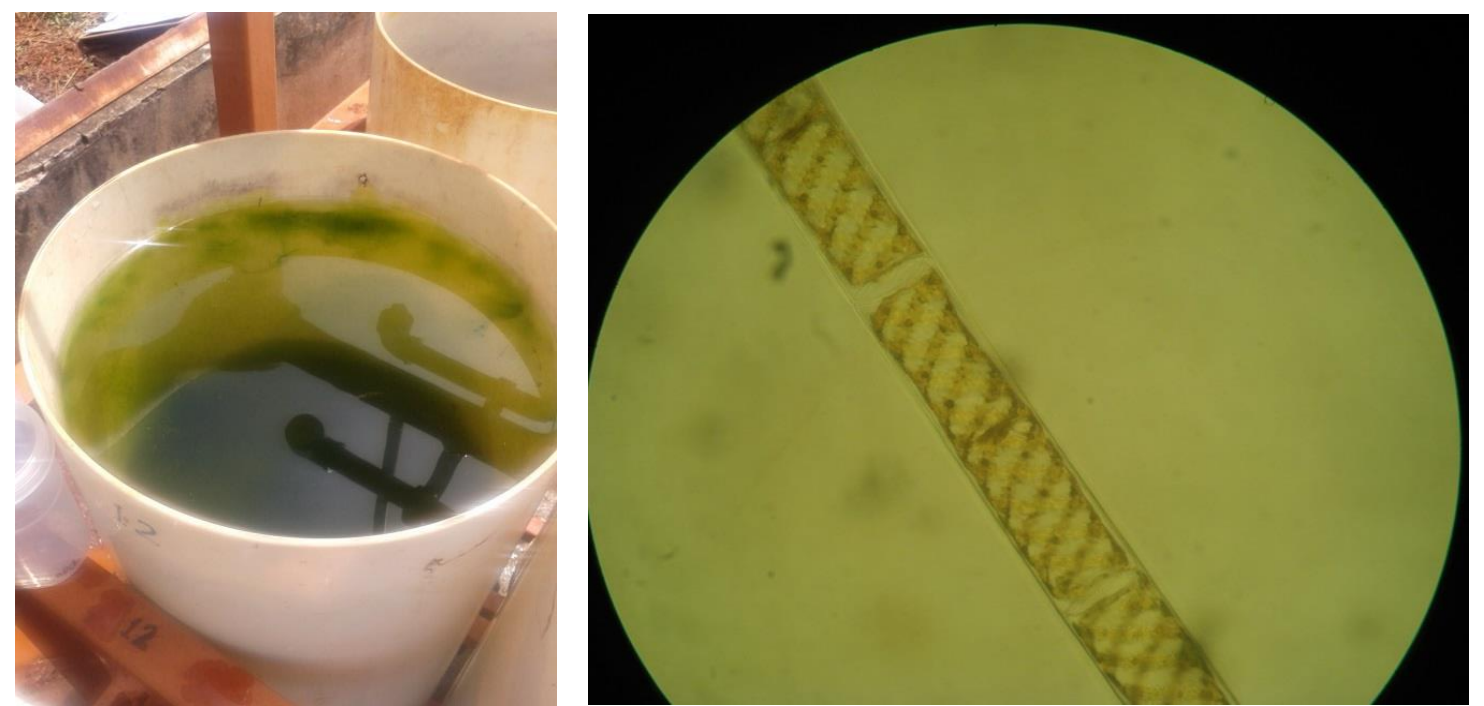

Figura 1: Desenvolvimento da alga Spyrogira sp. nos filtros ecológicos.

Com base nas análises estatísticas feitas no Capítulo 2, que mostrou não haver diferença significativa entre os filtros considerados triplicatas dos compostos aplicados, para o cálculo da densidade e biovolume das algas e cianobactérias em cada filtro, foi feita a média entre os filtros triplicata para a aplicação dos compostos. Uma síntese das abreviações usadas encontra-se na Tabela 4. As contaminações foram chamadas de 1, 2 e 3, sendo que "a" significa antes da contaminação e "b" significa 96 horas após a contaminação.

Tabela 4: Abreviações definidas para os filtros e seus respectivos PFCPs aplicados.

\begin{tabular}{lll}
\hline Filtros & Contaminante & Abreviação \\
\hline F1 & Nenhum - Controle & C \\
F2, 3 e 4 & Paracetamol & P \\
F5, 6 e 7 & Diclofenaco & D \\
F8, 9 e 10 & Naproxeno & N \\
F11,12 e 13 & Ibuprofeno & I \\
F14, 15 e 16 & Metilparabeno & M \\
F17, 18 e 19 & Benzofenona-3 & B \\
F 20, 21 e 22 & Mix & Mix \\
\hline
\end{tabular}

Considerando-se a média geral de riqueza de espécies (todas as contaminações e tempos de coleta), a riqueza aumentou com o aumento do tempo de operação dos filtros, 
sendo o menor número observado na $1^{\text {a }}$ contaminação e o maior na $3^{\mathrm{a}}(40$, 46 e 49, respectivamente).

Os resultados de riqueza antes da contaminação indicam que a $2^{\mathrm{a}}$ contaminação teve o maior valor médio de riqueza de espécies (52), enquanto 38 e 44 da $1^{\text {a }}$ e $3^{\text {a }}$ contaminações, respectivamente. Após a contaminação dos filtros, observou-se riqueza média de 43 táxons na $1^{\mathrm{a}}$ contaminação e 41 na $2^{\mathrm{a}}$, sendo na $3^{\mathrm{a}}$ observado maior riqueza (54 espécies).

O filtro controle apresentou menor riqueza de espécies comparada com os filtros contaminados, durante todo o período de estudo. Pode-se concluir com base nestes resultados que a presença dos contaminantes nos filtros parece favorecer a riqueza de espécies nos filtros ecológicos. Apesar de o fator tempo (idade dos filtros e número de carreira de filtração) estar sendo considerado, quando se compara o filtro controle, que também sofreu a influência do tempo, observa-se que a riqueza de espécies continua maior nos filtros contaminados na $3^{\text {a }}$ contaminação realizada (Figura 2).

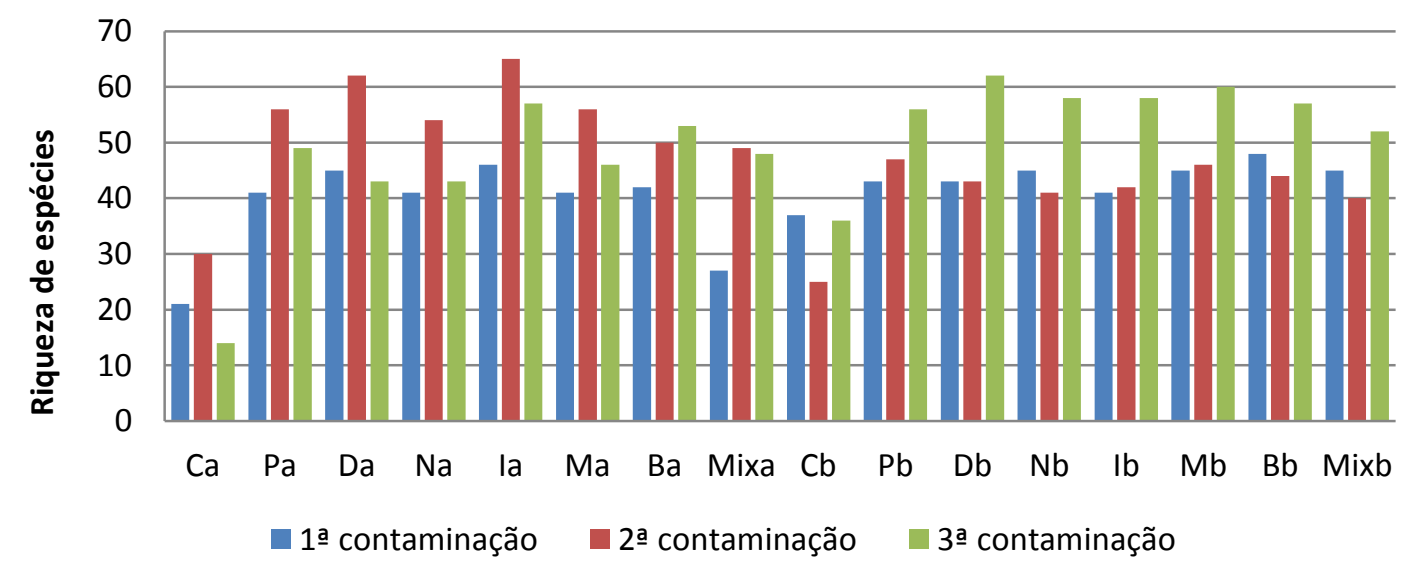

Figura 2: Variação de riqueza de espécies em cada contaminação e filtros (de acordo com contaminante aplicado - Tabela 4 e tempo de coleta, onde "a"= antes da contaminação e "b" $=96$ horas após a contaminação).

A análise de agrupamento (Figura 3) mostrou a formação de três grupos (divididos nas três contaminações). Os filtros "controle" das diferentes contaminações e tempos de coleta realizados não se agruparam. O coeficiente cofenético calculado foi de 0,846 .

Em nível de $40 \%$ de similaridade houve a formação de dois grandes grupos, sendo um referente à $1^{\mathrm{a}}$ contaminação e o outro contendo a $2^{\mathrm{a}}$ e $3^{\mathrm{a}}$ contaminações. Em $50 \%$ de similaridade formaram-se dois grupos distintos ( $2^{\mathrm{a}}$ e $3^{\mathrm{a}}$ contaminações).

Após, os agrupamentos que podem ser observados dentro dos grandes grupos, referem-se aos diferentes tempos de coleta de cada contaminação (antes e após a contaminação). 


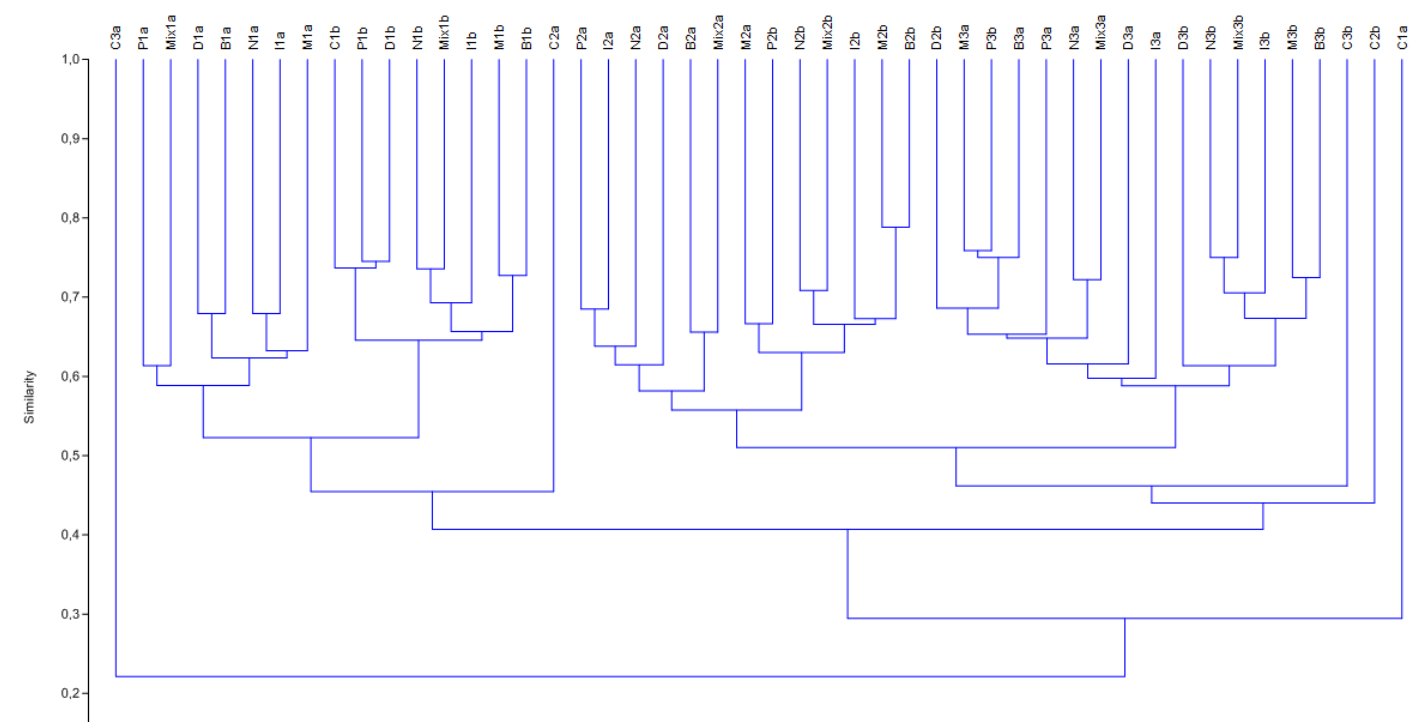

Figura 3: Dendrograma de similaridade de espécies identificadas nos filtros ecológicos em todas as contaminações e diferentes tempos de coleta.

\subsection{Análises quantitativas da comunidade de algas e cianobactérias}

Foi registrada variação do biovolume de algas e cianobactérias ao longo do tempo de operação dos filtros ( $1^{\mathrm{a}}, 2^{\mathrm{a}}$ e $3^{\mathrm{a}}$ contaminações), e entre os tempos de coleta $(\mathrm{a}=$ antes da contaminação; $b=96$ horas após a contaminação) (Figura 4).

$\mathrm{Na}$ primeira contaminação, as classes com os maiores valores de biovolume, e consequentemente, maior contribuição foram: Euglenophyceae, Cyanobacteria, Bacillariophyceae, e Cryptophyceae, respectivamente. Na segunda e terceira contaminações, as mesmas classes foram as com maiores valores de biovolume nos filtros ecológicos, sendo estas: Bacillariophyceae, Cyanobacteria, Euglenophyceae, e Zygnemaphyceae (Figura 4).

Na segunda contaminação, ocorreu diminuição do biovolume de Euglenophyceae em todos os filtros, até mesmo no filtro controle, o que indica não ter sido o fator da presença do contaminante o determinante para a ocorrência do fato. Mas pode-se observar uma diminuição do biovolume total nos filtros 96 horas após a segunda contaminação.

$\mathrm{Na}$ terceira contaminação, houve elevado biovolume de Zygnemaphyceae no filtro que recebeu contaminação por ibuprofeno após 96 horas da contaminação. A Zygnemaphyceae filamentosa Spyrogira sp., por apresentar grande biovolume, foi a responsável pelo pico registrado. Nas segunda e terceira contaminações, nos filtros em que foi aplicado ibuprofeno, houve maior contribuição de biovolume da classe Zygnemaphyceae pela presença da espécie Spyrogira sp. (Figura 4). 
Primeira contaminação

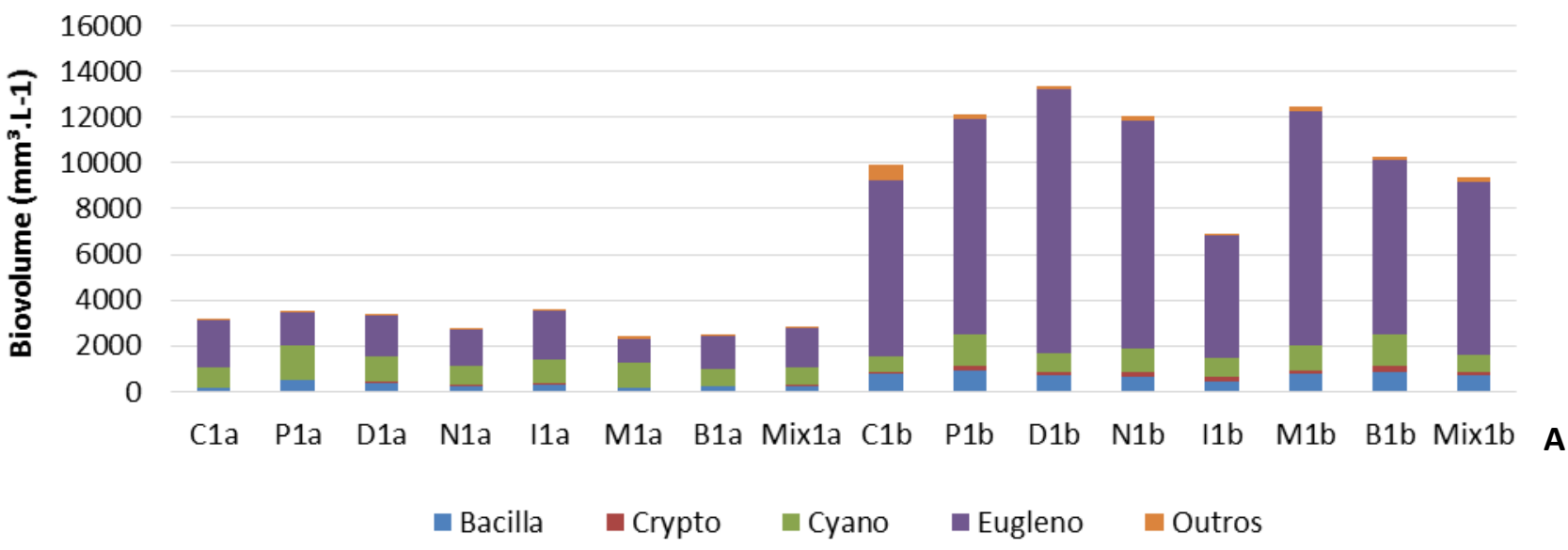

Segunda contaminação

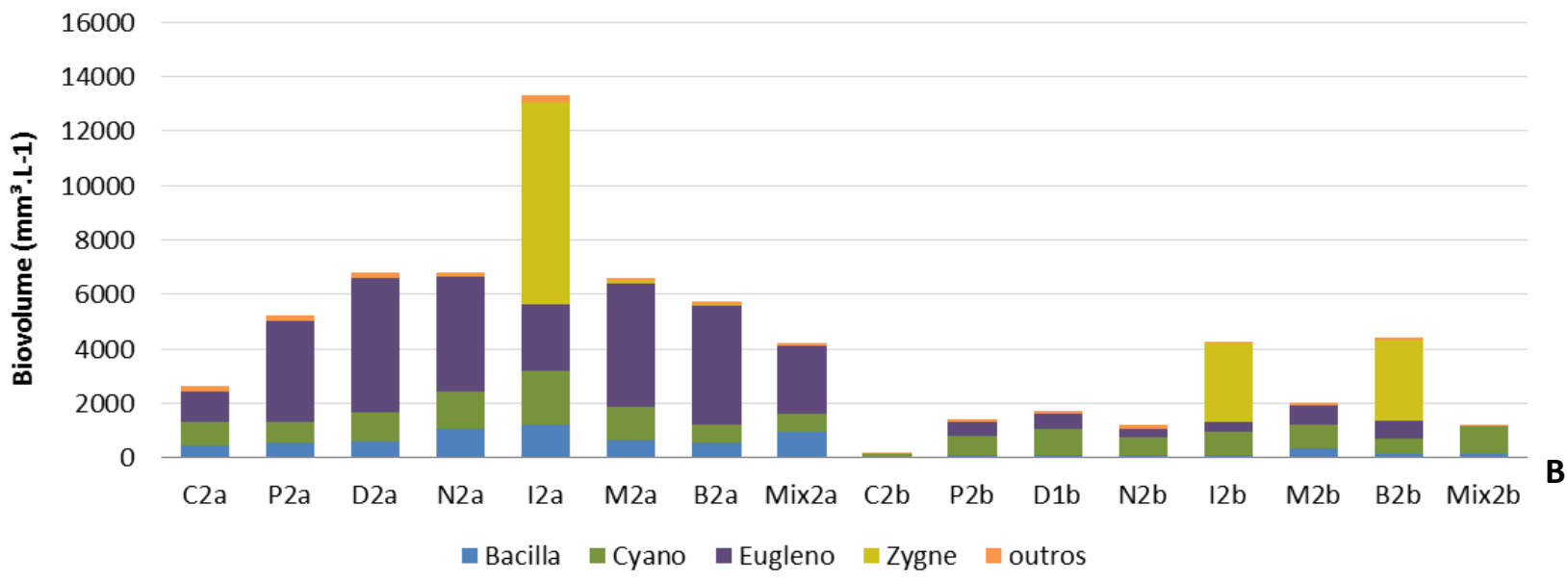

Terceira contaminação

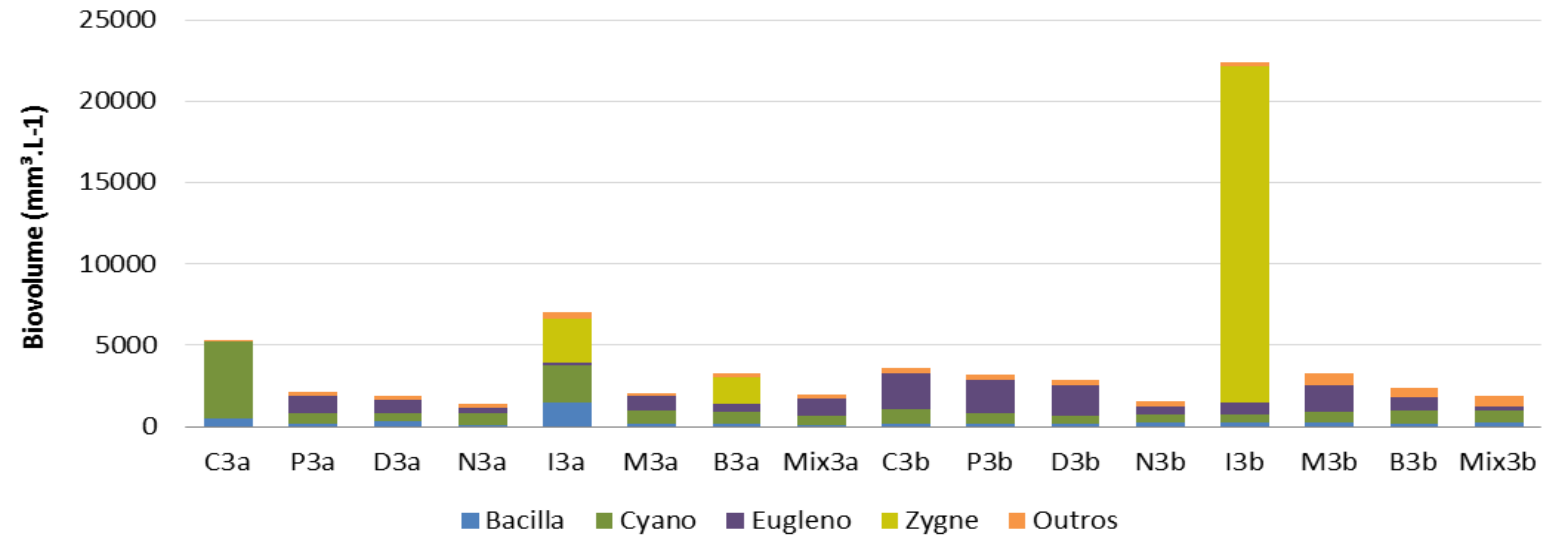

Figura 4: Variação do biovolume $\left(\mathrm{mm}^{3} \mathrm{~L}^{-1}\right)$ em cada filtro ecológico (siglas de acordo com Tabela 4), e no tempo de coleta na: A) primeira contaminação; B) segunda contaminação e C) terceira contaminação. Bacilla $=$ Bacillariophyceae Crypto $=$ Cryptophyceae Cyano $=$ Cyanobacteria; Eugleno $=$ Euglenophyceae; Zygne $=$ Zugnemaphyceae e Outros = soma do biovolume das classes Chlorophyceae, Chrysophyceae, Dinophyceae, Xanthophyceae, Zygnemaphyceae - para A. Em B e C, Outros = soma do biovolume das classes Chlorophyceae, Chrysophyceae, Cryptophyceae, Dinophyceae, Xanthophyceae. 
Bacillariophyceae (Figura 4) teve reduzida contribuição na comunidade ao longo das contaminações, indicando uma possível sensibilidade da classe ante a presença dos contaminantes, ou em decorrência das modificações na composição da comunidade de algas e cianobactérias com o efeito tempo (carreiras de filtração).

Com base nos valores de biovolume, nove táxons foram classificados como descritores antes da contaminação e 8 táxons 96 horas após, tanto na primeira como na segunda contaminação (Tabela 5, Tabela 6), que juntos representaram $>90 \%$ do biovolume total da comunidade na primeira contaminação e $>50 \%$ na segunda contaminação. A espécie que mais contribuiu nas duas contaminações foi Lepocincles sp.1 (Euglenophyceae).

$\mathrm{Na}$ terceira contaminação 14 táxons foram classificados como descritores antes da contaminação e nove táxons no tempo de coleta de 96 horas após a contaminação (Tabela 7), que juntos representaram $>90 \%$ do biovolume total da comunidade. Assim como nas demais contaminações, a espécie que mais contribuiu foi Lepocincles sp. (Euglenophyceae).

A diatomácea Aulacoseira granulata foi classificada como espécie descritora em todas as contaminações, com porcentagens de contribuição que variaram de 0,5 a $6,2 \%$. Dentre os táxons de Cyanobacteria, destaca-se Chroococcus minutus (0,8 a 21\%), Dolichospermum planctonicum (0,6 a 43,1\%) e Microcystis aeruginosa (0,7 a 22,3\%), que foram classificadas como descritoras em todas as contaminações.

Tabela 5: Espécies descritoras da comunidade de algas e cianobactérias com base na porcentagem de contribuição em biovolume, nos filtros ecológicos (siglas conforme Tabela 4), na primeira contaminação.

\begin{tabular}{lrrrrrrrr}
\hline & \multicolumn{10}{c}{ \% } \\
\cline { 2 - 9 } Espécies descritoras (antes) & C1a & P1a & D1a & N1a & I1a & M1a & B1a & Mix1a \\
\hline Aulacoseira granulata & 0,0 & 3,6 & 0,9 & 1,2 & 0,9 & 0,5 & 2,2 & 0,5 \\
Aulacoseira sp2 & 2,8 & 3,3 & 1,8 & 1,1 & 1,1 & 1,5 & 0,9 & 1,4 \\
Aulacoseira sp3 & 0,0 & 2,1 & 1,3 & 1,1 & 0,0 & 1,6 & 2,8 & 0,5 \\
Chroococcus minutus & 0,8 & 2,2 & 2,8 & 2,3 & 2,3 & 3,1 & 2,3 & 3,1 \\
Cyclotela meneghiniana & 0,9 & 4,3 & 5,0 & 4,9 & 3,1 & 2,4 & 1,5 & 5,6 \\
Dolichospermum planctonicum & 13,7 & 14,6 & 17,6 & 20,2 & 15,1 & 29,6 & 20,2 & 23,5 \\
Lepocincles sp.1 & 66,0 & 42,4 & 51,9 & 58,4 & 57,8 & 45,0 & 58,3 & 61,5 \\
Microcystis aeruginosa & 11,6 & 21,6 & 11,7 & 6,0 & 8,7 & 6,2 & 4,5 & 0,0 \\
Microcystis protocystis & 0,9 & 1,0 & 0,3 & 0,2 & 1,4 & 2,4 & 2,0 & 0,2 \\
Espécies descritoras (96 horas após) & $\mathbf{C 1 b}$ & $\mathbf{P 1 b}$ & $\mathbf{D 1 b}$ & $\mathbf{N 1 b}$ & $\mathbf{I 1 b}$ & $\mathbf{M 1 b}$ & $\mathbf{B 1 b}$ & Mix1b \\
\hline Aulacoseiragranulata & 3,0 & 4,1 & 2,7 & 2,3 & 1,5 & 3,1 & 2,1 & 1,3 \\
Aulacoseira sp.2 & 1,9 & 1,2 & 1,0 & 0,8 & 1,3 & 1,0 & 1,2 & 1,8 \\
Aulacoseira sp.3 & 2,2 & 1,3 & 0,0 & 1,1 & 0,6 & 0,7 & 1,8 & 0,5 \\
Chroococcus minutus & 2,2 & 4,4 & 2,5 & 2,7 & 4,9 & 3,1 & 4,3 & 3,3 \\
Cryptomonas tetrapyrenoidosa & 0,5 & 0,8 & 1,2 & 0,8 & 1,2 & 1,1 & 2,0 & 1,6 \\
Dolichospermum planctonicum & 3,3 & 5,7 & 2,6 & 3,0 & 5,0 & 2,2 & 3,9 & 2,3 \\
Lepocincles sp.1 & 77,0 & 78,0 & 86,2 & 82,4 & 76,5 & 82,2 & 74,0 & 81,4 \\
Microcystis aeruginosa & 0,0 & 0,0 & 0,0 & 2,6 & 0,0 & 2,7 & 3,8 & 1,4 \\
\hline
\end{tabular}


Tabela 6: Espécies descritoras da comunidade de algas e cianobactérias com base na porcentagem de contribuição em biovolume, nos filtros ecológicos (siglas conforme Tabela 4), na segunda contaminação.

\begin{tabular}{|c|c|c|c|c|c|c|c|c|}
\hline \multirow[b]{2}{*}{ Espécies descritoras (antes) } & \multicolumn{8}{|c|}{$\%$} \\
\hline & C2a & P2a & D2a & $\mathbf{N 2 a}$ & I2a & M2a & B2a & Mix2a \\
\hline Aulacoseira granulata & 6,2 & 2,8 & 2,2 & 5,6 & 2,3 & 3,0 & 2,7 & 8,6 \\
\hline Aulacoseira sp.2 & 5,8 & 3,6 & 2,5 & 3,7 & 2,4 & 3,9 & 3,6 & 7,1 \\
\hline Aulacoseira sp. 3 & 0,0 & 1,0 & 2,0 & 3,4 & 1,5 & 1,4 & 1,7 & 3,3 \\
\hline Chroococcus minutus & 9,6 & 3,9 & 3,0 & 5,0 & 3,6 & 3,8 & 4,1 & 3,8 \\
\hline Dolichospermum planktonicum & 16,1 & 5,6 & 5,1 & 11,0 & 5,4 & 5,9 & 5,6 & 6,6 \\
\hline Gomphonema gracile & 0,0 & 1,6 & 1,1 & 1,3 & 2,0 & 1,0 & 1,2 & 2,9 \\
\hline Lepocincles sp. 1 & 44,0 & 70,5 & 72,4 & 61,8 & 18,3 & 68,7 & 76,7 & 59,1 \\
\hline Microcystis aeruginosa & 0,0 & 4,8 & 0,7 & 1,7 & 3,2 & 6,0 & 0,0 & 2,3 \\
\hline Spyro & 0,0 & 0,0 & 0,0 & 0,0 & 55,3 & 0,0 & 0,0 & 0,0 \\
\hline Espécies descritoras (96 horas após) & $\mathbf{C} 2 \mathrm{~b}$ & P2b & D2b & $\mathbf{N} 2 \mathbf{b}$ & $\mathbf{I 2 b}$ & M2b & B2b & Mix2b \\
\hline Aulacoseiragranulata & 0,0 & 2,8 & 0,7 & 1,3 & 0,3 & 1,7 & 0,8 & 3,8 \\
\hline Aulacoseira sp.2 & 20,6 & 1,2 & 1,4 & 0,6 & 0,9 & 3,4 & 0,6 & 2,0 \\
\hline Chroococcus minutus & 13,9 & 9,5 & 8,9 & 12,1 & 3,1 & 7,1 & 2,6 & 8,1 \\
\hline Dolichospermum planktonicum & 21,6 & 37,5 & 36,2 & 43,1 & 12,0 & 26,4 & 9,1 & 45,5 \\
\hline Gomphonema gracile & 0,0 & 1,5 & 0,6 & 1,0 & 0,3 & 4,9 & 1,3 & 1,2 \\
\hline Lepocincles sp.1 & 0,0 & 33,6 & 31,9 & 24,7 & 8,4 & 35,5 & 14,8 & 0,0 \\
\hline Microcystis aeruginosa & 0,0 & 0,0 & 7,0 & 0,0 & 2,8 & 5,2 & 0,0 & 22,3 \\
\hline Spyrogyra sp. & 0,0 & 0,0 & 0,0 & 0,0 & 67,4 & 0,0 & 66,9 & 0,0 \\
\hline
\end{tabular}

Tabela 7: Espécies descritoras da comunidade de algas e cianobactérias com base na porcentagem de contribuição em biovolume, nos filtros ecológicos (siglas conforme Tabela 4), na terceira contaminação.

\begin{tabular}{|c|c|c|c|c|c|c|c|c|}
\hline \multirow[b]{2}{*}{ Espécies descritoras (antes) } & \multicolumn{8}{|c|}{$\%$} \\
\hline & C3a & P3a & D3a & N3a & I3a & M3a & B3a & Mix3a \\
\hline Aphanocapsa holsatica & 75,0 & 0,0 & 0,0 & 0,0 & 0,0 & 0,0 & 0,0 & 0,0 \\
\hline Aulacoseira granulata & 0,0 & 0,7 & 1,9 & 0,0 & 6,0 & 2,2 & 1,9 & 0,0 \\
\hline Aulacoseira sp.2 & 0,0 & 1,9 & 1,9 & 0,3 & 9,5 & 0,9 & 0,8 & 2,1 \\
\hline Aulacoseira sp. 3 & 5,6 & 0,0 & 1,5 & 2,0 & 0,0 & 0,0 & 0,0 & 1,2 \\
\hline Chroococcus minutus & 11,1 & 18,9 & 15,0 & 16,8 & 9,8 & 20,5 & 9,1 & 12,2 \\
\hline Coenocystis quadriguloides & 0,5 & 1,4 & 1,7 & 2,7 & 0,5 & 2,0 & 0,8 & 1,2 \\
\hline Cryptomonas marssonii & 0,0 & 1,7 & 2,3 & 2,9 & 0,6 & 1,4 & 1,1 & 2,2 \\
\hline Cyclotela meneghiniana & 3,5 & 4,2 & 10,4 & 4,2 & 2,2 & 4,4 & 2,6 & 2,1 \\
\hline Dolichospermum planktonicum & 0,0 & 6,3 & 9,0 & 12,3 & 1,9 & 7,5 & 4,0 & 7,2 \\
\hline Lepocincles sp. 1 & 0,0 & 48,0 & 41,7 & 25,7 & 2,4 & 44,3 & 17,4 & 52,9 \\
\hline Microcystis aeruginosa & 0,0 & 0,0 & 0,0 & 18,0 & 15,4 & 2,5 & 3,4 & 6,1 \\
\hline Microcystis protocystis & 2,4 & 1,7 & 2,3 & 0,4 & 1,8 & 3,0 & 1,8 & 1,7 \\
\hline Radiococcus fotti & 0,0 & 4,4 & 5,0 & 4,1 & 2,4 & 2,0 & 1,3 & 3,8 \\
\hline Spyrogyra sp. & 0,0 & 0,0 & 0,0 & 0,0 & 38,0 & 0,0 & 49,3 & 0,0 \\
\hline Espécies descritoras (96 horas após) & C3b & P3b & D3b & N3b & I3b & M3b & B3b & Mix3b \\
\hline Aulacoseira granulata & 4,3 & 2,0 & 2,3 & 1,8 & 0,0 & 1,5 & 1,4 & 2,6 \\
\hline Chroococcus minutus & 4,4 & 8,4 & 8,7 & 16,4 & 1,0 & 13,3 & 13,5 & 21,0 \\
\hline Cryptomonas tetrapyrenoidosa & 2,2 & 1,4 & 1,9 & 4,8 & 0,1 & 3,9 & 2,5 & 5,2 \\
\hline Cyclotela meneghiniana & 0,0 & 2,1 & 1,4 & 5,8 & 0,4 & 3,1 & 3,4 & 5,9 \\
\hline Dolichospermum planktonicum & 5,2 & 3,5 & 5,6 & 10,4 & 0,6 & 4,2 & 8,2 & 10,6 \\
\hline Lepocincles sp1 & 60,7 & 63,7 & 66,5 & 26,6 & 3,4 & 50,6 & 36,3 & 16,6 \\
\hline Microcystis aeruginosa & 14,1 & 6,0 & 0,0 & 0,0 & 0,0 & 0,0 & 0,0 & 0,0 \\
\hline Radiococcus fotti & 4,7 & 4,4 & 4,9 & 9,6 & 0,6 & 11,3 & 12,3 & 14,6 \\
\hline Spyrogyra sp. & 0,0 & 0,0 & 0,0 & 0,0 & 92,1 & 0,0 & 0,0 & 0,0 \\
\hline
\end{tabular}


O índice de diversidade baseado no biovolume (Figura 5), variou entre 0,65 bits.ind $^{-1} \mathrm{e}$ 3,72 bits.ind $^{-1}$. O valor médio do índice de diversidade considerando todas as contaminações no tempo de coleta antes da contaminação foi $\mathrm{H}^{\prime}=2,39$ bits.ind $^{-1}$. Já para as coletas realizadas após a contaminação o valor médio para todos os filtros foi de $\mathrm{H}^{\prime}=2,23$, mostrando que não houve diferença significativa $(\mathrm{p}=0,72)$ no índice de diversidade de espécies identificadas nos filtros após a contaminação dos mesmos.

O maior valor do índice de diversidade $\left(3,72\right.$ bits.ind $\left.^{-1}\right)$ e o menor $\left(0,65\right.$ bits.ind $\left.^{-1}\right)$ ocorreram na terceira contaminação, no tempo de coleta após 96 horas da contaminação, sendo o maior valor detectado no filtro contaminado com naproxeno e o menor valor no filtro contaminado com ibuprofeno.

A diversidade (H') média dos filtros foi aumentando, conforme o tempo de operação dos filtros, sendo os valores médios: $H^{\prime}=1,84$ bits.ind $^{-1}$ na primeira contaminação, $H^{\prime}=2,40$ na segunda contaminação e $\mathrm{H}^{\prime}=2,69$ na terceira contaminação. Este cálculo mostrou e reforçou o fato já discutido anteriormente que a comunidade de algas e cianobactérias se desenvolveu, aumentou em número de indivíduos e apresentou mudanças de composição ao longo do tempo de operação dos filtros ecológicos.

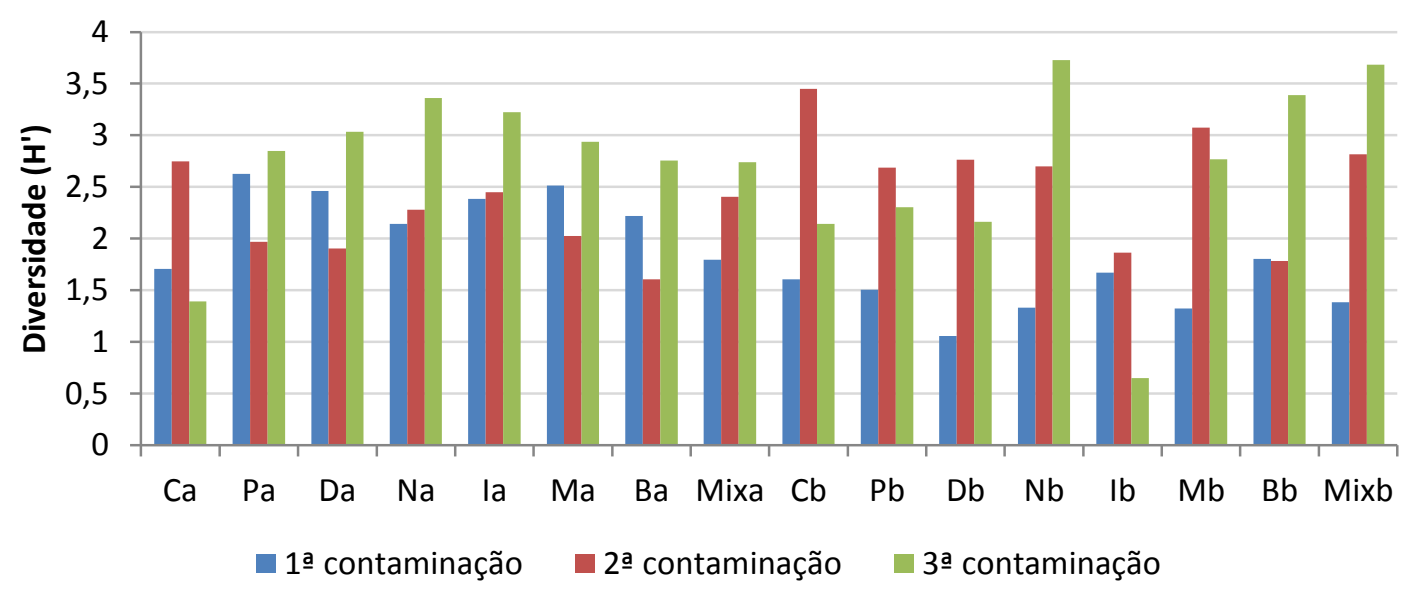

Figura 5: Valores do índice de diversidade (H': bits.ind-1) estimados com base no biovolume nas três contaminações e em cada filtro, antes (a) e após a contaminação (b), sendo que primeira letra refere-se ao tipo de tratamento aplicado, de acordo com a Tabela 4.

A análise das coordenadas principais ( $\mathrm{ACOP}$ ) foi realizada primeiramente, a partir de matrizes de biovolume de todas as espécies de algas e cianobactérias identificadas nas três contaminações, e após selecionadas as espécies significativas $(r \geq 0,5)$ das correlações, outra ACoP foi gerada (Figura 6). 
A análise resumiu $65,4 \%$ da variabilidade conjunta dos dados em seus dois primeiros componentes (Figura 6). Observa-se o agrupamento das contaminações separadamente, e dentro de cada contaminação, observa-se a separação em "a"e "b", ou seja, antes e 96 horas após a contaminação, respectivamente.

No lado positivo do eixo 1, ordenam-se filtros na primeira contaminação, sendo que estas unidades estão associadas aos maiores biovolumes das espécies com valores de correlações positivas do eixo 1 (Tabela 8), sendo as de maiores valores as espécies Dictyosphaerium pulchellum, Desmodesmus intermedius e Cryptomonas obovata.

No lado negativo do eixo 1 ordenaram-se os filtros referentes a terceira contaminação, onde as espécies Coenocystis quadriguloides e Eutetramorus fotti tiveram o maior valor de correlação $(r=-0,854)$. No lado negativo do eixo 2 ordenaram-se os filtros referentes a segunda contaminação. O filtro controle antes da terceira contaminação dispersou-se dos demais filtros da mesma contaminação, indicando que o biovolume das espécies encontradas neste filtro não se assimila com os demais, assim como ocorreu no filtro antes da aplicação do ibuprofeno na primeira contaminação.

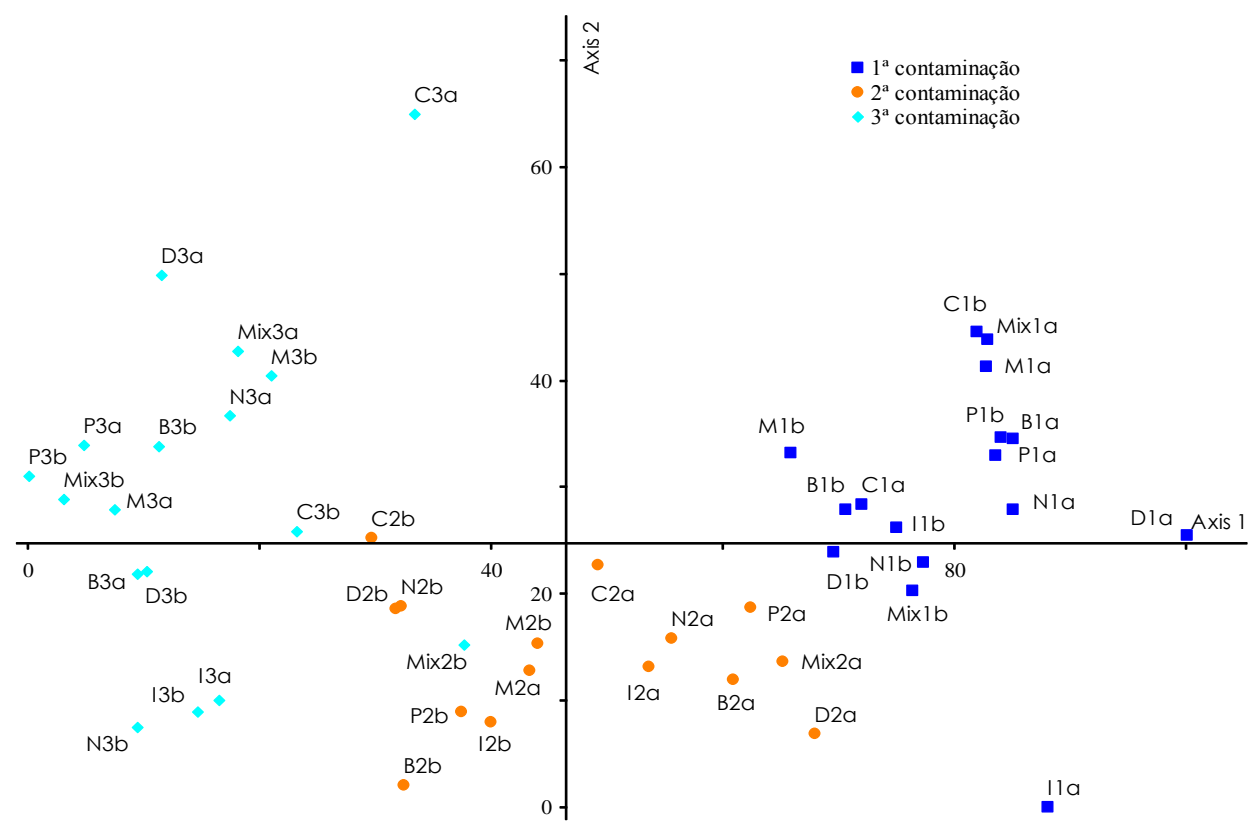

Figura 6: Gráfico de ACoP (Análise de Coordenadas Principais) das espécies significativas em todos os filtros (primeira letra refere-se ao tipo de tratamento aplicado, de acordo com a Tabela 4), nas três contaminações $(1=$ primeira contaminação; $2=$ segunda contaminação; $3=$ terceira contaminação) realizadas e nos diferentes tempos de coleta $(a=$ antes da contaminação; $b=96$ horas após a contaminação). 
Tabela 8: Coeficiente de correlação de Pearson entre as espécies significativas identificadas nos filtros ecológicos, nas três contaminações, nos dois primeiros eixos de ordenação $(n=48)$.

\begin{tabular}{lrr}
\hline & \multicolumn{2}{c}{ Correlação } \\
\cline { 2 - 3 } Táxons & Eixo 1 & Eixo 2 \\
\hline Aphanocapsa cf. conferta & $-0,568$ & 0,022 \\
Aphanocapsa elachista & $-0,524$ & 0,011 \\
Aphanocapsa sp.1 & $-0,596$ & 0,182 \\
Aphanothece sp. 2 & $-0,658$ & 0,112 \\
Aulacoseira sp. 2 & 0,539 & 0,387 \\
Chlorella minutssima & $-0,551$ & $-0,046$ \\
Chromulina sp. 1 & $-0,593$ & $-0,048$ \\
Closterium sp.1 & 0,692 & $-0,075$ \\
Coelasphaerium minutissimum & $-0,726$ & 0,159 \\
Coenocystisquadriguloides & $-0,854$ & 0,041 \\
Cryptomonasobovata & 0,722 & 0,236 \\
Desmodesmus brasiliensis & $-0,729$ & $-0,274$ \\
Desmodesmus intermedius & 0,791 & 0,206 \\
Dictyosphaerium pulchellum & 0,835 & 0,068 \\
Eutetramorus fottii & $-0,854$ & 0,033 \\
Eutetramorus planctonicus & $-0,682$ & 0,005 \\
Fragilaria sp. & 0,408 & $-0,530$ \\
Geitlerinema sp. 1 & $-0,770$ & $-0,056$ \\
Gomphonema gracile & 0,374 & $-0,559$ \\
Kirchneriella rosellata & $-0,777$ & 0,346 \\
Monoraphidium arcuatum & $-0,629$ & $-0,304$ \\
Monoraphidium irregulare & $-0,415$ & $-0,576$ \\
Monoraphidium minutum & $-0,636$ & $-0,100$ \\
Peridinium sp. & 0,537 & $-0,024$ \\
Planktolyngbya limnetica & $-0,688$ & $-0,397$ \\
Planktolyngbya sp. 1 & 0,519 & 0,136 \\
Pseudodidymocystis fina & $-0,750$ & $-0,035$ \\
Radiococcus planktonicus & $-0,683$ & 0,156 \\
Synechocystis aquatilis & $-0,589$ & $-0,013$ \\
Trachelomonas volvocinopsis & 0,537 & 0,165 \\
\hline \% de explicabilidade dos eixos & 55,060 & 10,411 \\
\hline & & \\
& &
\end{tabular}

Foram realizadas análises das coordenadas principais (ACoP) para cada contaminação separadamente (Figuras 7; 8 e 9).

$\mathrm{Na}$ ACoP referente a primeira contaminação (Figura 7), a análise resumiu 58,76\% da variabilidade conjunta dos dados em seus dois primeiros componentes. A ordenação dos filtros antes da contaminação (tempo zero hora) está no lado positivo do eixo 1, sendo comum a estes as espécies Dolichospermum planctonicum, Eutetramorus tetrasporus e Planktolyngbya sp. 1. O filtro controle antes da contaminação não se agrupou com os demais filtros, indicando a separação entre estes filtros.

No lado negativo do eixo 1 ordenaram-se os filtros no tempo de coleta de 96 horas após a contaminação, onde observa-se similaridade entre os filtros onde aplicou-se diclofenaco (D1), paracetamol (P1) e o filtro controle (C1); assim como houve similaridade 
entre os filtros em que aplicou-se os produtos de cuidados pessoais (metilparabeno - M1 e benzofenona-3 - B1) com o filtro Mix dos compostos.

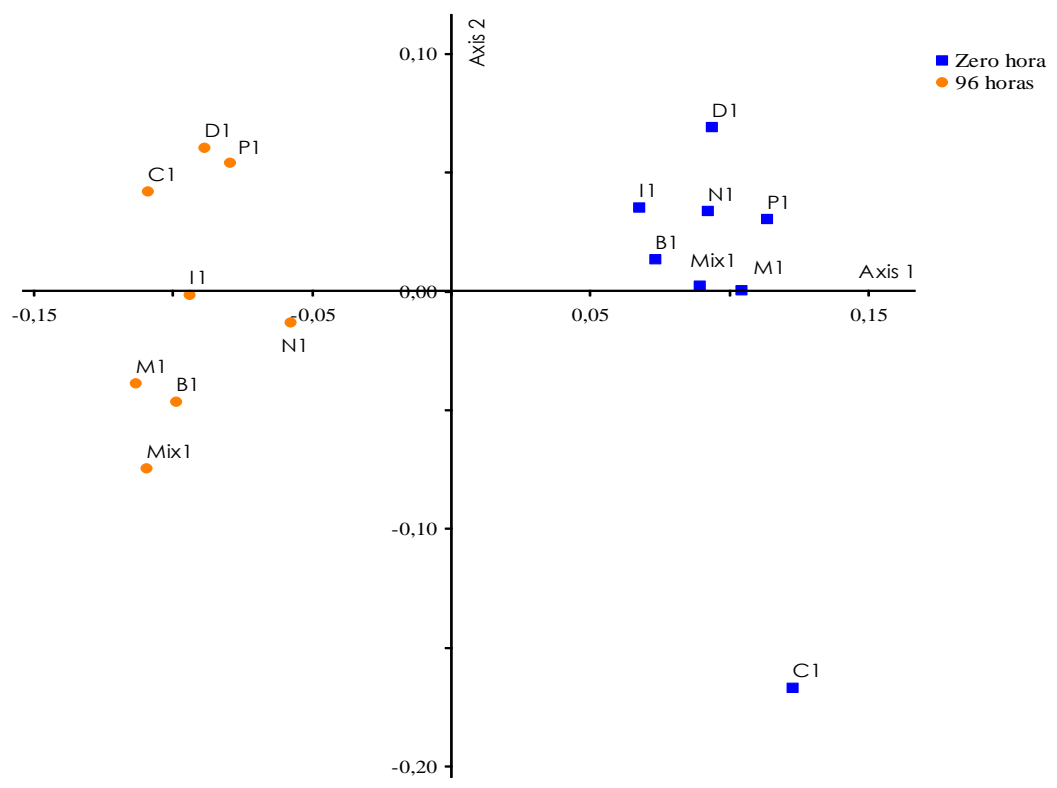

Figura 7: Gráfico de ACoP (Análise de Coordenadas Principais) das espécies significativas em todos os filtros (primeira letra refere-se ao tipo de tratamento aplicado, de acordo com a Tabela 4), na primeira contaminação realizada e nos diferentes tempos de coleta.

Tabela 9: Coeficiente de correlação de Pearson entre as espécies significativas identificadas nos filtros ecológicos, na primeira contaminação, nos dois primeiros eixos de ordenação $(n=16)$.

\begin{tabular}{lrr}
\hline & \multicolumn{2}{c}{ Correlação } \\
\cline { 2 - 3 } Táxons & Eixo 1 & \multicolumn{1}{c}{ Eixo 2 } \\
\hline Aphanocapsa delicatissima & $-0,560$ & 0,566 \\
Aphanocapsa incerta & $-0,741$ & 0,329 \\
Aphanothece sp.1 & $-0,792$ & 0,357 \\
Aulacoseira granulata & $-0,601$ & 0,663 \\
Aulacoseira sp.2 & $-0,737$ & $-0,172$ \\
Chlorella minutissima & $-0,797$ & $-0,234$ \\
Chlorella vulgaris & $-0,194$ & 0,695 \\
Chroococcus minor & $-0,687$ & 0,197 \\
Chroococcus minutus & $-0,929$ & 0,189 \\
Closterium sp.1 & 0,113 & 0,507 \\
Cryptomonas brasiliensis & $-0,389$ & 0,700 \\
Cryptomonas erosa & $-0,681$ & 0,375 \\
Cryptomonas marssonii & $-0,495$ & 0,693 \\
Cryptomonasobovata & 0,431 & 0,708 \\
Cryptomonas tetrapyrenoidosa & $-0,982$ & $-0,053$ \\
Dictyosphaerium ehrembergianum & $-0,826$ & 0,199 \\
Dictyosphaerium pulchellum & $-0,633$ & 0,480 \\
Dolichospermum planctonicum & 0,707 & 0,406 \\
Eutetramorus tetrasporus & 0,602 & 0,445 \\
Gymnodinium sp. & $-0,740$ & $-0,257$ \\
Kirchneriella lunaris & $-0,217$ & $-0,627$ \\
Lepocinclis sp. 1 & $-0,947$ & $-0,045$ \\
\hline
\end{tabular}




\section{Continuação da Tabela 9...}

\begin{tabular}{lrr}
\hline Mallomonas sp.2 & $-0,770$ & 0,067 \\
Melosira sp. & $-0,699$ & 0,057 \\
Monoraphidium arcuatum & $-0,637$ & $-0,106$ \\
Monoraphidium contortum & $-0,251$ & 0,590 \\
Monoraphidium irregulare & $-0,572$ & $-0,317$ \\
Monoraphidium komarkovae & $-0,677$ & 0,218 \\
Monoraphidium minutum & $-0,979$ & $-0,036$ \\
Monoraphidium tortile & $-0,850$ & $-0,014$ \\
Ochromonas ovalis & $-0,540$ & $-0,439$ \\
Oocystis sp.1 & $-0,537$ & $-0,442$ \\
Peridinium sp. & $-0,548$ & 0,287 \\
Planktolyngbya sp. 1 & 0,754 & 0,375 \\
Pleurataenium sp. 1 & 0,329 & $-0,743$ \\
Pseudanabaena mucicola & $-0,726$ & 0,520 \\
\hline \% de explicabilidade dos eixos & 43,005 & 15,760 \\
\hline
\end{tabular}

$\mathrm{Na}$ ACoP referente a segunda contaminação (Figura 8), a análise resumiu 50,9 \% da variabilidade conjunta dos dados em seus dois primeiros componentes. Os filtros antes da contaminação (tempo zero hora) estão ordenamento dos no lado positivo do eixo 1 , e o conjunto de filtros 96 horas após a contaminação ordenando-se no lado negativo do eixo 1 , assim como ocorreu na primeira contaminação.

Entre o agrupamento dos filtros antes da contaminação (eixo 1), as espécies com maiores valores de correlação foram Aulacoseira sp.2 e Aulacoseira sp.3, ambas pertencentes a classe Bacillariophyta. O filtro controle antes da contaminação não se agrupou com os demais filtros, mostrando a falta de similaridade com os demais filtros.

No lado negativo do eixo 1 ordenaram-se os filtros no tempo de coleta de 96 horas após a contaminação, com agrupamento entre os filtros onde se aplicou benzofenona-3 (B2) e Ibuprofeno (I2); e entre os filtros com aplicação de naproxeno (N2) e o mix dos compostos (Mix2). O filtro controle (C2), assim como para o tempo de zero hora, não se agrupou com os demais filtros. 


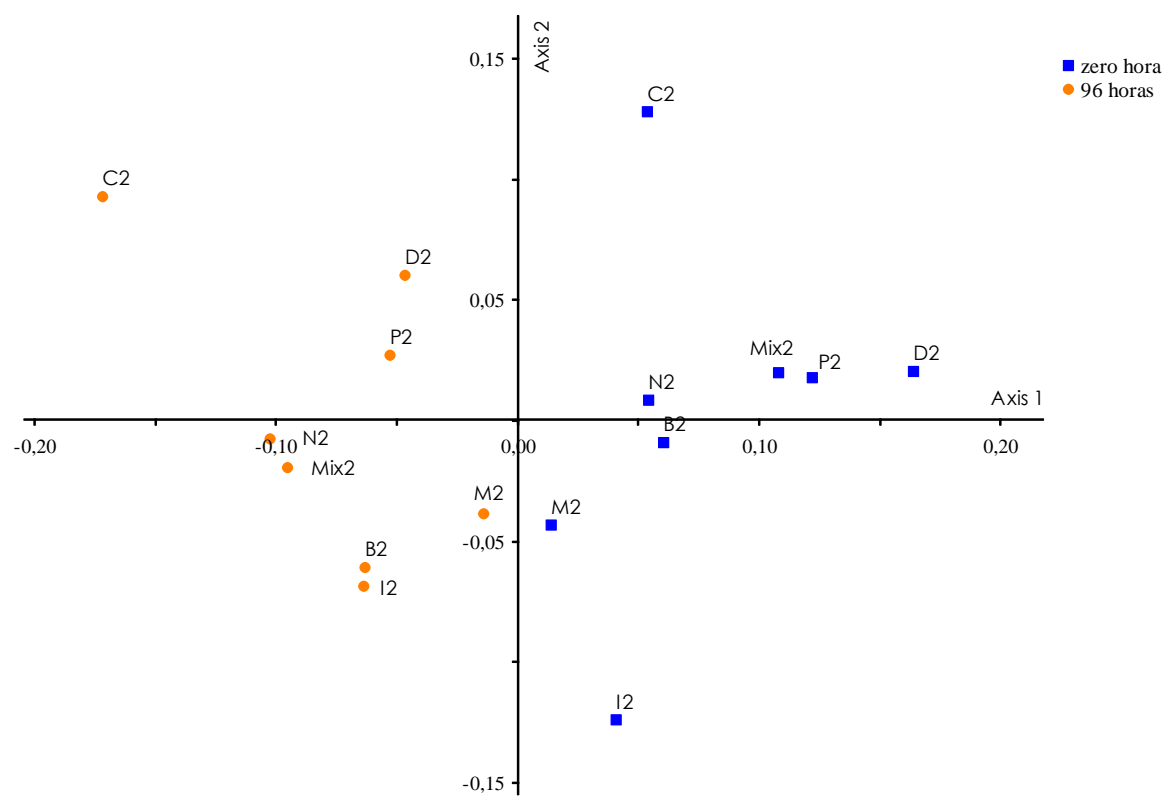

Figura 8: Gráfico de ACoP (Análise de Coordenadas Principais) das espécies significativas em todos os filtros (primeira letra refere-se ao tipo de tratamento aplicado, de acordo com a Tabela 4), na segunda contaminação realizada e nos diferentes tempos de coleta.

Tabela 10: Coeficiente de correlação de Pearson entre as espécies significativas identificadas nos filtros ecológicos, na segunda contaminação, nos dois primeiros eixos de ordenação $(n=16)$.

\begin{tabular}{lrr} 
& \multicolumn{2}{c}{ Correlação } \\
\cline { 2 - 3 } Táxons & Eixo 1 & Eixo 2 \\
\hline Achnanthidium minutissimum & 0,424 & $-0,691$ \\
Aphanocapsa delicatissima & 0,650 & 0,013 \\
Aphanocapsa incerta & 0,568 & $-0,122$ \\
Aulacoseira sp.2 & 0,813 & $-0,106$ \\
Aulacoseiragranulata & 0,720 & $-0,351$ \\
Aulacoseira sp.3 & 0,776 & $-0,313$ \\
Bulbochaete sp. & $-0,342$ & $-0,691$ \\
Characiopsis sp. 1 & $-0,758$ & $-0,423$ \\
Chlamydomonas sp. 1 & $-0,006$ & $-0,686$ \\
Chlorella minutissima & $-0,702$ & $-0,190$ \\
Chlorella vulgaris & $-0,163$ & $-0,588$ \\
Chroococcus minor & 0,375 & $-0,748$ \\
Chroococcus minutus & 0,697 & $-0,367$ \\
Closterium sp.1 & 0,746 & 0,006 \\
Coenocystisquadriguloides & 0,715 & $-0,334$ \\
Cosmariumhumile & 0,117 & $-0,531$ \\
Cryptomonas brasiliensis & 0,653 & $-0,092$ \\
Cryptomonas erosa & 0,733 & 0,511 \\
Cryptomonas tetrapyrenoidosa & 0,546 & 0,002 \\
Desmodesmus brasiliensis & 0,173 & $-0,525$ \\
Desmodesmus communis & 0,578 & 0,124 \\
Dictyosphaerium pulchellum & 0,752 & 0,247 \\
Discostella stelligera & $-0,133$ & $-0,584$ \\
Eutetramorus planctonicus & 0,126 & $-0,579$ \\
Fragilaria sp. & 0,371 & $-0,710$ \\
Geitlerinema sp. 1 & $-0,752$ & 0,113 \\
Gomphonema gracile & 0,398 & $-0,728$ \\
\hline & &
\end{tabular}


Continuação da Tabela 10...

\begin{tabular}{lrr}
\hline Gomphonema sp. 1 & 0,117 & $-0,531$ \\
Lepocincles sp. 1 & 0,695 & $-0,224$ \\
Mallomonas sp.1 & 0,606 & 0,122 \\
Melosira sp. & 0,569 & $-0,222$ \\
Mougeotia sp. & 0,262 & $-0,509$ \\
Navicula sp. & 0,603 & 0,118 \\
Oedogonium sp. & 0,587 & $-0,111$ \\
Oocystis sp.1 & 0,652 & $-0,205$ \\
Phormidium sp.1 & 0,741 & $-0,321$ \\
Pseudanabaena mucicola & 0,706 & $-0,193$ \\
Radiococcus planktonicus & 0,235 & 0,569 \\
Radiocystisfernandoi & 0,509 & $-0,011$ \\
Spirogyra sp. & $-0,150$ & $-0,679$ \\
Staurastrum sp. 1 & 0,114 & $-0,525$ \\
Synechocystis aquatilis & $-0,728$ & $-0,315$ \\
\hline \% explicabilidade dos eixos & 34,941 & 15,991 \\
\hline
\end{tabular}

A ACoP referente a terceira contaminação (Figura 9), resumiu 51,02\% da variabilidade conjunta dos dados em seus dois primeiros componentes. Os dois primeiroeixos foram estatisticamente significativos $(\mathrm{p}<0,05)$.

Os filtros antes da contaminação (tempo zero hora) estão agrupados no lado negativo do eixo 2, associados aos biovolumes das espécies Chroococcus minor, Gomphonema gracile, Fragilaria sp., Achnanthidium minutissimum, Bulbochaete sp., Chlamydomonas sp. 1, Spirogyra sp. (espécies com maiores valores de correlação negativa no eixo) e aos filtros contaminados com naproxeno, diclofenaco e mix dos compostos (N3, D3 e Mix3). O filtro controle não se agrupou com os demais no mesmo tempo (zero hora), e esteve associado ao lado negativo do eixo 1. A espécie com maior valor de correlação observado para tal ordenamento foi Chroococcus minor.

O conjunto de filtros 96 horas após a contaminação ordenaram-se parte no lado positivo do eixo 1, e parte no lado positivo do eixo 2, com maior peso na ordenação do eixo pelo biovolume das espécies dos filtros contaminados com ibuprofeno, naproxeno e mix dos compostos (I3, N3, Mix3), respectivamente. Também se observa que os filtros em que foram aplicados os produtos de cuidados pessoais (B3 e M3) encontram-se próximos entre si no gráfico, 96 horas após a contaminação, assim como ocorreu na primeira contaminação (Figura 9). 


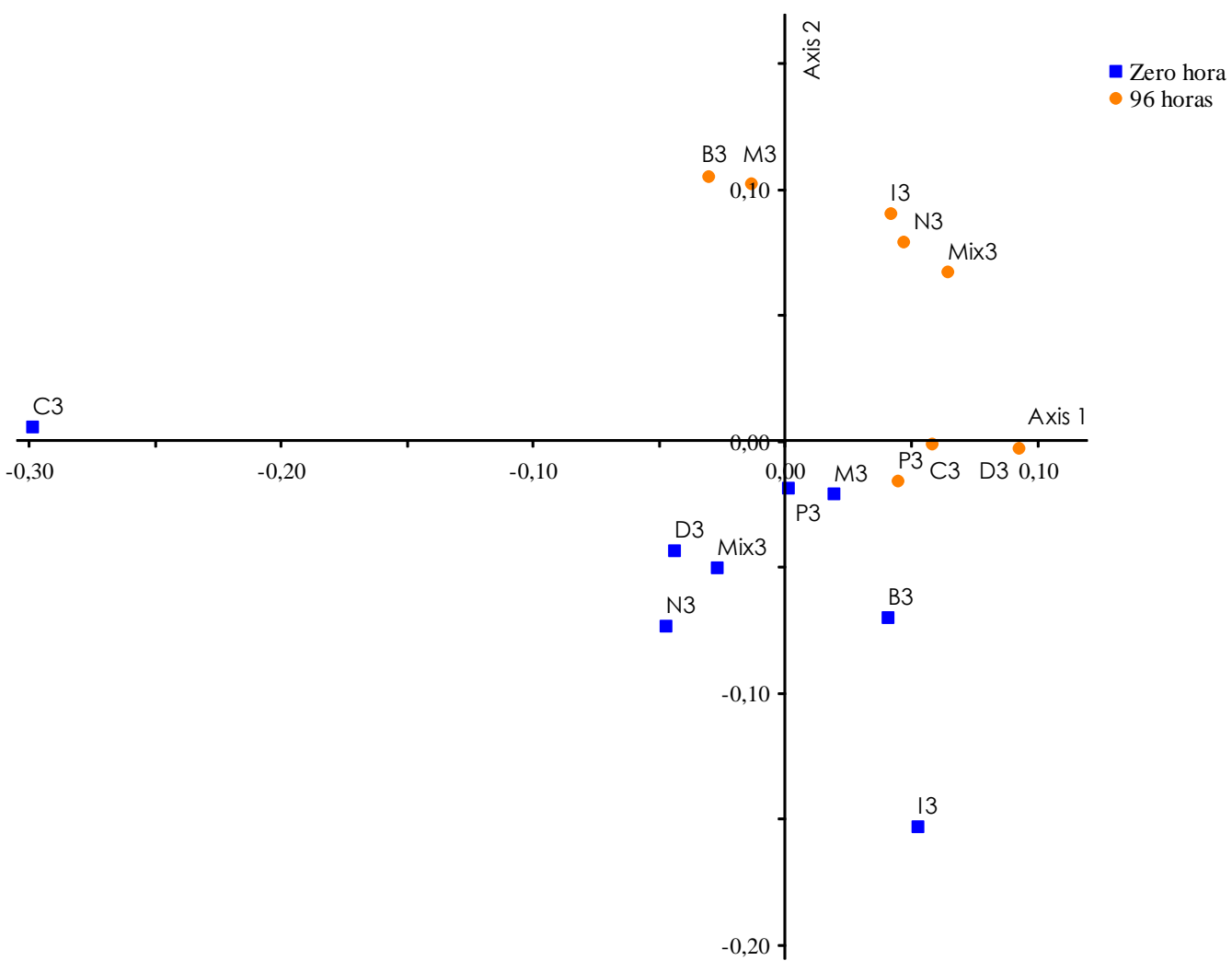

Figura 9: Gráfico de ACoP (Análise de Coordenadas Principais) das espécies significativas em todos os filtros (primeira letra refere-se ao tipo de tratamento aplicado, de acordo com a Tabela 4), na terceira contaminação realizada e nos diferentes tempos de coleta.

Tabela 11: Coeficiente de correlação de Pearson entre as espécies significativas identificadas nos filtros ecológicos, na terceira contaminação, nos dois primeiros eixos de ordenação $(n=16)$.

\begin{tabular}{lrr}
\hline & \multicolumn{2}{c}{ Correlação } \\
\cline { 2 - 3 } Táxons & Eixo 1 & Eixo 2 \\
\hline Aphanocapsa delicatissima & 0,886 & 0,166 \\
Aphanocapsa elachista & 0,360 & 0,565 \\
Aphanocapsa holsatica & $-0,763$ & $-0,554$ \\
Aphanocapsa sp.1 & 0,150 & 0,746 \\
Aphanothece sp. 1 & 0,280 & 0,588 \\
Aphanothece sp. 2 & 0,463 & 0,120 \\
Aulacoseiragranulata & 0,569 & $-0,018$ \\
Aulacoseira sp.2 & 0,881 & $-0,106$ \\
Aulacoseira sp.3 & $-0,756$ & 0,076 \\
Characiopsis sp. 1 & $-0,619$ & 0,435 \\
Chlamydomonas sp. 2 & 0,224 & 0,697 \\
Chlorella vulgaris & 0,884 & $-0,018$ \\
Chromulina sp.1 & 0,480 & $-0,444$ \\
Chromulina sp.2 & 0,561 & 0,137 \\
Chroococcus limneticus & 0,507 & 0,008 \\
Chroococcus minor & 0,872 & $-0,706$ \\
Chrysophyceae não identificada & 0,156 & $-0,559$ \\
Cryptomonas brasiliensis & $-0,197$ & 0,627 \\
Cryptomonas marssonii & 0,844 & 0,818 \\
Cryptomonas tetrapyrenoidosa & 0,565 & 0,018 \\
\hline
\end{tabular}


Continuação da Tabela 11...

\begin{tabular}{lrr}
\hline Cyanophyceae filamentosa não identificada & 0,061 & 0,043 \\
Desmodesmus brasiliensis & 0,915 & 0,131 \\
Dictyosphaerium ehrembergianum & 0,030 & 0,521 \\
Discostella stelligera & 0,511 & $-0,060$ \\
Dolichospermum planctonicum & 0,879 & 0,750 \\
Euglenophyta não identificada & 0,868 & 0,559 \\
Eutetramorus fottii & 0,881 & 0,111 \\
Fragilaria sp. & 0,548 & $-0,187$ \\
Geitlerinema sp. 1 & 0,525 & 0,649 \\
Geitlerinema sp. 2 & 0,240 & 0,042 \\
Gomphonema sp.1 & 0,156 & $-0,559$ \\
Mallomonas sp.3 & 0,029 & 0,522 \\
Melosira sp. & 0,884 & 0,013 \\
Microcystis aeruginosa & 0,211 & $-0,007$ \\
Monoraphidium arcuatum & 0,760 & $-0,220$ \\
Monoraphidium contortum & 0,531 & $-0,170$ \\
Monoraphidium irregulare & 0,675 & 0,101 \\
Monoraphidium tortile & 0,837 & 0,082 \\
Ochromonas ovalis & 0,156 & $-0,559$ \\
Oedogonium sp. & 0,156 & $-0,559$ \\
Oocystis sp.1 & 0,074 & 0,675 \\
Pseudanabaena mucicola & $-0,544$ & 0,772 \\
Pseudodidymocystis planctonica & 0,166 & 0,851 \\
Radiococcus planktonicus & 0,933 & 0,056 \\
Rhodomonas lacustris & 0,285 & 0,044 \\
Synechocystis aquatilis & 0,444 & 0,549 \\
Tetraediella spinigera & 0,156 & 0,559 \\
Tetrastrum komarekii & 0,080 & 0,517 \\
\hline \% de explicabilidade dos eixos & 30,891 & 20,138 \\
\hline & &
\end{tabular}

\section{Análise integrada dos fatores abióticos e bióticos com base no biovolume}

A avaliação da relação dos fatores abióticos e bióticos foi realizada pela análise de correspondência canônica (ACC) a partir das matrizes de biovolume da totalidade das espécies significativas de algas e cianobactérias das três contaminações realizadas e de seis variáveis ambientais da água dos filtros ecológicos. Os autovalores para o eixo $1(\lambda=0,29)$ e 2 $(\lambda=0,09)$ explicaram conjuntamente $40,7 \%$ da variabilidade dos dados. O teste de Monte Carlo revelou que os dois primeiros eixos foram estatisticamente significativos $(\mathrm{p}<0,05)$. As correlações espécie-ambiente foram elevadas para o eixo $1(\mathrm{r}=0,90)$ e $2(\mathrm{r}=0,88)$ e significativa para os dois eixos da $\operatorname{ACC}(\mathrm{p}=0,001)$, indicando forte relação entre a distribuição das variáveis ambientais e as espécies descritoras em questão (Tabela 12). 
Tabela 12: Síntese dos resultados da Análise de Correspondência Canônica (ACC) realizada a partir de 6 variáveis ambientais e 37 espécies significativas $(n=48)$.

\begin{tabular}{lrr}
\hline & Eixo 1 & Eixo 2 \\
\cline { 2 - 3 } Autovalores $(\lambda)$ & 0,290 & 0,090 \\
Porcentagem de Variância explicada (\%) & 30,700 & 10,000 \\
Porcentagem de Variância acumulada & 30,700 & 40,800 \\
Correlação de Pearson (espécie-ambiente) & 0,900 & 0,880 \\
Teste de Monte Carlo (p) Autovalores & 0,001 & 0,001 \\
Teste de Monte Carlo (p) Correlações espécies-ambiente & 0,001 & 0,001 \\
\hline
\end{tabular}

Tabela 13: Coeficiente canônico e correlações "intra-set" das seis variáveis ambientais com os eixos 1 e 2 da ACC, realizada com as 37 espécies significativas dos filtros ecológicos $(n=48)$.

\begin{tabular}{lrrrr}
\hline & \multicolumn{2}{c}{$\begin{array}{c}\text { Coeficiente } \\
\text { Canônico }\end{array}$} & \multicolumn{2}{c}{$\begin{array}{c}\text { Coeficiente de } \\
\text { Correlação "intra-set" }\end{array}$} \\
\cline { 2 - 5 } Variáveis & \multicolumn{1}{c}{ Eixo 1 } & \multicolumn{1}{c}{ Eixo 2 } & \multicolumn{1}{c}{ Eixo 1 } & Eixo 2 \\
\hline Temperatura (Temp) & $-0,234$ & $-0,725$ & $-0,212$ & $-0,643$ \\
Oxigênio Dissolvido (OD) & 0,564 & $-0,339$ & 0,511 & $-0,301$ \\
pH & 0,031 & $-0,335$ & 0,028 & $-0,297$ \\
Nitrogênio Total (NT) & 0,817 & 0,511 & 0,741 & 0,453 \\
Fósforo Total (PT) & 0,228 & 0,541 & 0,206 & 0,479 \\
Clorofila-a (Cloro a) & $-0,762$ & 0,244 & $-0,691$ & 0,216 \\
\hline
\end{tabular}

As correlações "intra-set" e o coeficiente canônico (Tabela 13) indicam que o nitrogênio total (NT) e o oxigênio dissolvido (OD) foram as variáveis de maior peso na ordenação do lado positivo do eixo 1 , com $r=0,817$ e $r=0,564$, respectivamente. Também se observa o agrupamento das amostras dos filtros na contaminação, incluindo o filtro controle, com separação das amostras realizadas antes e após a contaminação dos filtros. Estão associados a este lado do eixo, com maiores valores de biovolumes de Desmodesmus intermedius $(\mathrm{r}=0,877)$, Dictyosphaerium pulchellum $(\mathrm{r}=0,705)$ e Cryptomonas obovata $(\mathrm{r}=$ 0,698).

No lado negativo do eixo 1 ordenam-se os filtros das amostras da terceira contaminação, com alguns da segunda contaminação, como B2b e P2b; associadas aos maiores biovolumes e Coenocystis quadriguloides $(\mathrm{r}=-0,795)$, Eutetramorus fotti $(\mathrm{r}=-0,729)$ e Pseudodidymocystis fina $(\mathrm{r}=-0,722)$, associadas aos valores de clorofila-a (Cloro a) ( $\mathrm{r}=$ 0,762) (Figura 10 e Tabela 13 e 14).

Em relação ao lado positivo do eixo 2 da análise ACC (Figura 10) destaca-se a ordenação das amostrasdos filtros na segunda contaminação, onde a variável fósforo total (PT) apresentou o maior peso de ordenação ( $\mathrm{r}=0,541)$ (Tabela 13), sendo Monoraphidium minutum $(\mathrm{r}=0,609)$, Chlorella minutíssima $(\mathrm{r}=0,551)$ e Monoraphidium irregulare $(\mathrm{r}=0,537)$ 
as espécies com maiores valores de correlações nos eixos e portanto, melhor associadas as unidades amostrais neste lado do eixo (Tabela 14). No lado negativo do eixo 2 a temperatura da água (Temp) apresentou maior peso na ordenação do eixo $(r=-0,725)$, com a ordenação de alguns filtros da terceira contaminação, como o filtro controle antes da contaminação (C3a) e o filtro paracetamol antes da contaminação (P3a).

Espécies diferentes, em maioria da classe Chlorophyceae, foram as que tiveram maiores valores de correlação com os eixos (Tabela 14), assim como ocorreu para bactérias em outros trabalhos. De acordo com Haig et al., (2015), as composições de comunidades microbianas de filtros lentos de areia são significativamente diferentes, dependendo do estado (operacional ou drenado), idade do filtro, a localização da amostra, mês de coleta das amostras, as distâncias do afluente e efluente, e as profundidades a que as amostras foram coletadas.

O efeito tempo de operação do filtro (carreiras de filtração) influenciou o agrupamento das espécies em relação ao biovolume, separando as contaminações realizadas. Porém os efeitos dos contaminantes neste estudo foram inconclusivos.

Tabela 14: Coeficiente de correlação de Pearson entre as variáveis biológicas (37 espécies significativas) e as variáveis abióticas, nos dois primeiros eixos de ordenação $(n=48)$.

\begin{tabular}{lrr}
\hline & \multicolumn{2}{c}{ Correlação } \\
Táxons & Eixo 1 & Eixo 2 \\
\hline Chlorella minutissima & $-0,523$ & 0,551 \\
Coenocystisquadriguloides & $-0,795$ & $-0,068$ \\
Desmodesmus brasiliensis & $-0,712$ & 0,255 \\
Dictyosphaerium pulchellum & 0,705 & $-0,012$ \\
Kirchneriella rosellata & $-0,639$ & $-0,361$ \\
Monoraphidium arcuatum & $-0,591$ & 0,505 \\
Monoraphidium irregulare & $-0,455$ & 0,537 \\
Monoraphidium minutum & $-0,620$ & 0,609 \\
Oocystis sp.1 & $-0,205$ & 0,547 \\
Pseudodidymocystis fina & $-0,722$ & 0,154 \\
Desmodesmus intermedius & 0,877 & $-0,198$ \\
Eutetramorus planctonicus & $-0,611$ & $-0,107$ \\
Eutetramorus fottii & $-0,729$ & $-0,165$ \\
Radiococcus planktonicus & $-0,593$ & $-0,344$ \\
Chromulina sp. 1 & 0,523 & $-0,196$ \\
Cryptomonasobovata & 0,698 & $-0,424$ \\
Aphanocapsa cf. conferta & $-0,561$ & $-0,193$ \\
Aphanothece sp. 2 & $-0,513$ & $-0,284$ \\
Coelosphaerium minutissimum & $-0,631$ & $-0,270$ \\
Planktolyngbya limnetica & $-0,666$ & 0,269 \\
Synechocystis aquatilis & $-0,577$ & $-0,199$ \\
Geitlerinema sp. 1 & $-0,637$ & $-0,027$ \\
Closterium sp.1 & 0,622 & 0,023 \\
\hline \% explicabilidade dos eixos & 30,700 & 10,000 \\
\hline
\end{tabular}




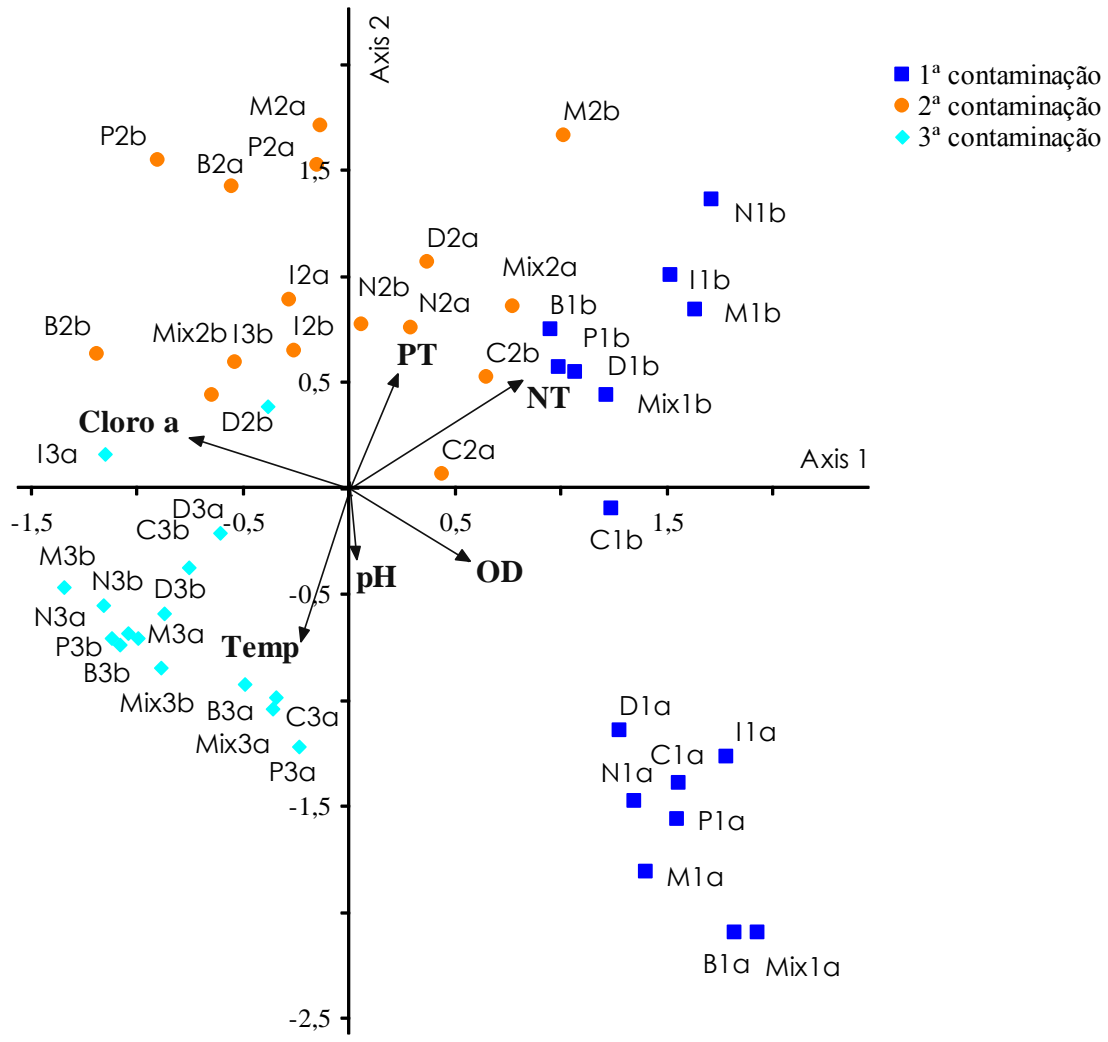

Figura 10: Gráfico biplot da ACC (eixos 1 e 2) das unidade amostrais referentes as três contaminações, em função das coletas realizadas nos filtros ecológicos de acordo com o tratamento (abreviações na Tabela 4) das espécies significativas da comunidade de algas e cianobactérias e as variáveis dos parâmetros de qualidade da água estudadas.

\section{Conclusões}

Os filtros ecológicos apresentaram uma flora de algas e cianobactérias bem diversificada, no que diz respeito a sua composição taxonômica, com representantes de Chlorophyceae e Cyanobacteria com elevados número de táxons e abundâncias.

Com este trabalho, observou-se que houve um efeito na comunidade de algas e cianobactérias diante da presença dos produtos farmacêuticos e de cuidados pessoais na água a ser tratada pelos filtros ecológicos, porém, não foram evidenciadas as diferenças com a aplicação dos PFCPs isoladamente ou em mistura dos seis compostos, talvez pelo fato dos mesmos já estarem presentes na água do Reservatório do Lobo, como relatado no Capítulo 2.

O efeito tempo (número de carreiras de filtração) também influenciou nos resultados de densidade, e consequentemente biovolume; riqueza, espécies descritoras, e composição da comunidade de algas e cianobactérias presentes nos filtros ecológicos de um modo geral.

As espécies que foram consideradas como descritoras em comum para todas as contaminações e tempos de coleta foram: a diatomácea Aulacoseira granulata, as 
cianobactérias Chroococcus minutus, Dolichospermum planctonicum e Microcystis aeruginosa. A espécie que mais contribuiu durante o período, com maior porcentagem, foi Lepocincles sp. (Euglenophyceae). A ocorrência/abundância e frequência destas espécies indicam uma possível tolerância das mesmas aos PFCPs aplicados.

Também foi observado o efeito tempo de coleta (antes e 96 horas após a contaminação dos filtros) nas ACoPs geradas, tanto na análise que considerou todas as contaminações e seus respectivos tempos de coleta, como nas análises específicas para cada contaminação, onde observa-se a ordenação de diferentes grupos antes e 96 horas após a contaminação de cada filtro.

Houve correlação dos fatores abióticos com os biovolumes das espécies significativas presentes nos filtros em todas as contaminações, conforme a análise de ACC, com maiores valores de correlações de nitrogênio total (NT) para o eixo 1 no lado positivo, com as espécies Desmodesmus intermedius, Cryptomonas obovata, Dictyosphaerium pulchellum, Closterium sp.1, e Chromulina sp. 1; do fósforo total (PT) para o eixo 2 no lado positivo, com as espécies Monoraphidium minutum, Chlorella minutíssima, Oocystis sp.1, Monoraphidium irregulare, Monoraphidium arcuatum; e da clorofila-a (Cloro a) no eixo 1 no lado negativo, com os biovolumes das espécies Coenocystis quadriguloides, Eutetramorus fottii, Desmodesmus brasiliensis, Pseudodidymocystis fina, Kirchneriella rosellata, Planktolyngbya limnetica.

\section{Referências}

ABNT - ASSOCIAÇÃO BRASILEIRA DE NORMAS TÉCNICAS. Ecotoxicologia Aquática Toxicidade crônica - Método de ensaio com algas (Chlorophyceae) NBR12648. Rio de Janeiro, 2011.

AZEVEDO, M.T.P., NOGUEIRA, N.M.C.; SANT'ANNA, C.L. Criptógamos do Parque Estadual das Fontes do Ipiranga, São Paulo, SP. Algas, 8: Cyanophyceae. Hoehnea. v. 23(1), p. 1-38, 1996.

AZEVEDO, M.T.P.; SANT'ANNA, C.L. Coelosphaerium evidentermarginatum, a new planktonic species of Cyanophyceae/Cyanobacteria from São Paulo State, Southeastern Brazil. Algological Studies. v. 94, p.35-43, 1999.

AZEVEDO, M.T.P.; SANT'ANNA, C.L. Sphaerocavum, a new genus of planktic Cyanobacteria from continental water bodies in Brazil. Algological Studies. v. 109, p.79-92, 2003.

BENSON-EVANS, K.; ANTOINE, R.; ANTOINE, S. Studies of theWater Quality and Algae of Llangorse Lake. Aquatic Conservation. v. 9, p. 425-439,1999. 
BERNHARDT, H.; CLASEN, J. Flocculation of Micro-Organisms. Journal of Water Supply Research T. v. 40, p. 76-87, 1991.

BOUVY, M., FALCÃO, D., MARINHO, M., PAGANO, M. \& MOURA, A.Occurrence of Cylindrospermopsis (Cyanobacteria) in 39 Brazilian tropical reservoirs during the 1998 drought. Aquatic Microbial Ecology. v. 23, p. 13-27, 2000.

CALIJURI. M.C.. TUNDISI. J.G. Limnologia comparada das represas do Lobo (Broa) e Barra Bonita - Estado de São Paulo: mecanismos de funcionamento e bases para o gerenciamento. RJ. Revista Brasileira de Biologia v. 50, p. 893-913, 1990.

CALVO-BADO, L.; PETTITT, T.; PARSONS, N.; PETCH, G.; MORGAN, J.; Spatial and temporal analysis of the microbial community in slow sand filters used for treating horticultural irrigation water. Applied and environmental microbiology. v. 69, p. 2116-2125, 2003.

CAMPOS, L.C. Modelling and Simulation of the Biological and Physical Processes of Slow Sand Filtration. PhD. Thesis, University of London, UK, 2002.

CASTRO, A.A.J., BICUDO, C.E.M. \& BICUDO, D.C. Criptógamos do Parque Estadual das Fontes do Ipiranga, São Paulo, SP. Algas 2: Cryptophyceae. Hoehnea. v.18, p.87-106, 1991.

COMAS, A.G.Las Chlorococcales dulciacuicolas de Cuba. In: L.K. Hamburg \& S. Giessen (Eds.). Blibliotheca Phycologica. Sttutgart, Gustav Fisher Verlag, 1996.

DIAS JR., C. Estudo do fitoplâncton em um reservatório de águas ácidas na região litorânea do Espírito Santo (Reservatório Águas Claras, Aracruz, ES). Tese. (Doutorado em Ecologia). Universidade Federal de São Carlos, São Carlos - SP, 1998.

DI BERNANRDO, L. Métodos e técnicas de tratamento de água. Rio de Janeiro: ABES, 1993.

FERNANDES, V.O., OLIVEIRA, B.C.L.B. \& SOUZA, B.A.Ecologia de cianobactérias: fatores promotores e consequências das florações. Oecologia Brasiliensis. v. 13, p. 247-258, 2009.

FONSECA, B.M., FERRAGUT, C., TUCCI, A., CROSSETTI, L.O., FERRARI, F., BICUDO, D.C., SANT'ANNA, C.L., BICUDO, C.E.M.. Biovolume de cianobactérias e algas de reservatórios tropicais do Brasil com diferentes índices tróficos. Hoehnea. v. 41, p. 9-30, 2014.

GODINHO, L.R. Família Scenedesmaceae no Estado de São Paulo: Levantamento florístico. Tese de Doutorado. Instituto de Botânica da Secretaria de Meio Ambiente do Estado de São Paulo. São Paulo, 2009. 
GODINHO, L.R.; COMAS, A.; BICUDO, C.E.M. Criptógamos do Parque Estadual das Fontes do Ipiranga, São Paulo, SP. Algas, 30: Chlorophyceae (família Scenedesmaceae). Hoehnea v. 37, p. $513-$ $553,2010$.

GOLTERMAN, H.L., CLYNO, R.S.; OHSNTAD, M.A.M. Methods for chemical analysis of fresh water. Blackwell, Boston., p. 214. 1978.

HAIG, S.J., COLLINS, G., DAVIES, R.L., DOREA, C.C., QUINCE, C. Biological aspects of slow sand filtration: past, present and future. Water Science and Technology. v. 11, p. 468-472, 2011.

HAIG, S-J.; QUINCE, C.; DAVIES, R.L.; DOREA, C.C.; COLLINS, G. The relationship between microbial community evenness and function in slow sand filters. MBio v. 6(5), p. e00729-15, 2015.

HENDERSON, R.; CHIPS, M.; CORNWELL.; HITCHINS, P.; HOLDEN, B.; HURLEY, S.; PARSONS, S.A.; WETHERILL, A.; JEFFERSON, B. Experiences of algae in UK waters: a treatment perspective. Water and Environment Journal. v. 22, p. 184-192, 2008.

HESPANHOL, I. "Filtração lenta." Técnicas de Abastecimento de Água 2. p. 229-273, 1987.

HILLEBRAND, H., DÜRSELEN, C.D., KIRSCHTEL, D., POLLINGHER, U., ZOHARY, T.Biovolume calculation for pelagic and benthic microalgae. Journal of Phycology. v. 35, p. 403-424, 1999.

HOFFMANN, L., KOMÁREK, J. \& KASTOVSKÝ, J.System of cyanoprokaryotes (cyanobacteria) state in 2004. Algological Studies. v. 117, p. 95-115, 2005.

HWANG, H.G.; KIM, M.S.; SHIN, S.M.; and HWANG, C.H. Risk Assessment of the Schmutzdecke of Biosand Filters: Identification of an Opportunistic Pathogen in schmutzdecke Developed by an Unsafe Water Source. Internationa. Journal of Environment Research Public Health. v. 11, p. 2033-2048, 2014.

INAG, IP. "Manual para a Avaliação da Qualidade Biológica da Água em Lagos e Albufeiras segundo a Directiva Quadro da Água-Protocolo de Amostragem e análise para o Fitoplâncton." Ministério do Ambiente, do Ordenamento do Território e do Desenvolvimento Regional. Instituto da Água, IP (2009).

KOMÁREK, J. \& ANAGNOSTIDIS, K.Cyanoprokaryota 2. Teil: Oscillatoriales.In: B. Büdel, L. Krienitz, G. Gärtner \& M. Schagerl (eds). Süsswasserflora von Mitteleuropa 19. Elsevier Spektrum Akademischer Verlag, München, pp. 1-759, 2005.

KOMÁREK, J. \& ANAGNOSTIDIS, K.Cyanoprokaryota. 1. Teil Chroococcales. In: H. Ettl, G. Gärtner, H. Heying \& D. Möllenhauer (eds.). Süsswasserflora von Mitteleuropa 19. Gustav Fischer Verlag, Stuttgar, p. 1-548, 1999. 
KOMÁREK, J. \& ANAGNOSTIDIS, K.Modern approach to the classification system of cyanophytes. Nostocales 4. Algological Studies. v. 56, p. 247-345, 1989.

KOMÁREK, J.; AZEVEDO, M.T.P. Geitlerinema unigranulatum, a commom tropical cyanoprokaryote from freshwater reservoirs in Brazil. Algological Studies. v. 99, 52p. 2000.

KOMÁREK, J.; FOTT, B. Das Phytoplankton des S̈̈_wassers. Systematik und Biologie. 7. Teil, 1. Hälfte. Chlorophyceae (Grünalgen) Ordnung: Chlorococcales. E. Schweizerbart'sche Verlagsbuchhandlung (Nägele u. Obermiller). Stuttgart, 1044p, 1983.

KOMÁRKOVA-LEGNEROVÁ, J. \& CRONBERG, G.Planktic blue-green algae from lakes in South Scania, Sweden. Part I. Chroococcales. Algological Studies v. 72, p. 13-51, 1994.

LUND, J.W.G., KIPLING, C. \& LECREN, E.D.The invert microscope method of estimating algal numbers and the statistical basis of estimations by counting. Hydrobiologia. v. 11, p. 143-170, 1958.

MACKERETH, J.F.H., HERON, J.; TALLING, J.F. Water analysis: some revised methods for limnologists. Freshwater Biological Association. v.36, p. 121, 1978.

MCCUNE, B. \& MEFFORD, M. J.PC-ORD. Multivariate Analysis of Ecological Data. Version 6.0. MjM. Software design, Gleneden Beach, Oregon, U.S.A, 2011.

MERCANTE, C.T.J., CARMO, C.F., RODRIGUES, C.J., OSTI, J.A.S., MAINARDES-PINTO, C.S.,VAZDOS-SANTOS, A.M.,TUCCI A. \& DI GENARO, A. Limnologia de viveiro de criação de tilápias do nilo: avaliação diurna visando boas práticas de manejo. Bol. Inst. Pesca, Sao Paulo, v. 37, p. $73-84,2011$.

NAKAMOTO, N. Food chain is the key in ecological purification system: new concept and new name of slow sand filter. In: Nobutada Nakamoto, Nigel Graham, M. Robin Collins and Rolf Gimbel.

(Org.). Progress in slow sand and alternative biofiltration process. 1ed.: IWA publishing, v. 5, cap 9, p. 77-84, 2014.

NAKAMOTO, N. Produza você mesmo uma água saborosa - sistema de purificação ecológica revendo a tecnologia de produção de água potável.São Paulo: Ferrari. 210 p., 2008.

NAKAMOTO, N.; KATO, H. Devellopment paterno f filamentous diatom and its condition related with midge larvae in slow sand filter. In. Recent Progress in Slow Sand and Alternative Biofiltration Processes. Gimble, R.; N.J.D. Graham and R. Collins (Eds.), IWA, p. 68-73, 2006.

NAKAMOTO, N.; YAMAMOTO, M.; SAKAI.; NOZAKI.; IWASE, N.; YASUDA, M..; KITADA, T. Role of filamentous diatom as an automatic purifier in a slow sand filter. In Advances in Slow sand and alternative biological filtration. N.J.D. Graham and Collins (Eds.), John Wiley \& Sons, U.K. p. 139 -148, 1996. 
NOGUEIRA, I.S.Chlorococcales sensu lato (Chlorophyceae) do município do Rio de Janeiro e arredores, Brasil: inventario e considerações taxonômicas. Dissertação de Mestrado, Universidade Federal do Rio de Janeiro, Rio de Janeiro, 1991.

NUSCH, E. A. Comparison of different methods for chlorophyll and phaeopigment determination. Arch.Hydrobiology Brih. Ergebn. Limnology, v. 14, p. 14-36, 1980.

OSTI, J.A.S.Características limnológicas e do fitoplâncton de viveiro de criação de tilápia-do-nilo e de wetlands construídas para o tratamento do efluente.Tese de Doutorado, Universidade Estadual Paulista, Jaboticabal, 2013.

PADISÁK, J. Cylindrospermopsis raciborskii (Woloszynnska) Seenayya et Subba Raju, an expanding, highly adaptive cyanobacterium: worldwide distribution and review of its ecology. Archiv für Hydrobiology, v. 107, p. 563-593, 1997.

POMATI, F.; NETTING, A.G.; CALAMARI, D.; NEILAN, B.A. Effects of erythromycin, tetracycline and ibuprofen on the growth of Synechocystis sp. and Lemna minor. Aquatic Toxicology. v. 67, p. 387-396, 2004.

RAMOS, G.J.P.; BICUDO, C.E.M.; GÓES-NETO, A.; MOURA, C.W.N. Monoraphidium and Ankistrodesmus (Chlorophyceae, Chlorophyta) from Pantanal dos Marimbus, Chapada Diamantina, Bahia State, Brazil. Hoehnea v. 39(3), p. 421-434, 2012.

REYNOLDS, C. S. Phytoplankton associations and their periodicity in stratifying lake systems. Holartic Ecol.v.3, p. 141-159, 1980.

RODRIGUES, L.L., SANT'ANNA, C.L. \& TUCCI, A. Chlorophyceae das represas Billings (Braço Taquacetuba) e Guarapiranga, SP, Brasil. Revista Brasileira de Botânica v. 33, p. 247-264, 2010.

ROSINI, E. F. respostas da comunidade fitoplanctônica à implantação de sistema de piscicultura em tanque-rede no parque aquícola do rio ponte pensa, reservatório de Ilha Solteira, SP, Brasil. Tese de doutorado. Instituto de Botânica da Secretaria do Meio Ambiente 203p., 2015.

ROSINI, E.F., SANT'ANNA, C.L. \& TUCCI, A.Cyanobacteria de pesqueiros da região metropolitana de São Paulo, Brasil. Rodriguésia v. 64, p. 399-417, 2013.

ROSINI, E.F.; SANT'ANNA, C.L.; TUCCI, A. Chlorococcales (exceto Scenedesmaceae) de pesqueiros da Região Metropolitana de São Paulo, SP, Brasil: levantamento florístico. Hoehnea v. 39(1), p. 11-38, 2012.

ROUND, F.E. The taxonomy of the Chlorophyta, 2. British Phycological Journal v. 6, p. 235-264, 1971. 
ROUND, F.E., CRAWFORD, R.M. \& MANN, D.G. The diatoms - Biology and Morphology of the Genera.Cambridge University Press. Cambridge, 1990.

SANT'ANNA, C.L.Chlorococcales (Chlorophyceae) do Estado de São Paulo, Brasil. Bibliotheca Phycologica v. 67, p. 1-348, 1984.

SANT'ANNA, C.L., AZEVEDO, M.T.P., SENNA, P.A.C., KOMÁREK, J. \& KOMÁRKOVÁ, J.2004. Planktic Cyanobacteria from São Paulo State, Brazil: Chroococcales. Revista Brasileira de Botânica v. 27, p. 213-227, 2004.

SANT'ANNA, C.L., GENTIL, R.C., \& SILVA, D. Comunidade fitoplanctônica de pesqueiros da região metropolitana de São Paulo.In: K.E. Esteves \& C.L.Sant'Anna (org.). Pesqueiros sob uma visão integrada de meio ambiente saúde pública e manejo. Rima, São Paulo, p. 49-62, 2006.

SHANNON, C.E. \& WEAVER, W. The mathematical theory of communication. University of Illinois Press, Urbana, 1963.

SUN , J.; LIU, D. Geometric models for calculating cell biovolume and surface area for phytoplankton. Journal of Plankton Research. v. 25, p. 1331-1346, 2003.

TELL, G. \& CONFORT, V.Euglenophyta pigmentadas de la Argentina.Bibliotheca Phycologica 75, 1996.

TUCCI, A.Sucessão da comunidade fitoplanctônica de um reservatório urbano e eutrofico, São Paulo, SP, Brasil. Tese de Doutorado, Universidade Estadual Paulista, Rio Claro, 2000.

TUCCI, A., SANT'ANNA, C.L. GENTIL, R.C. \& AZEVEDO, M.T.P. Fitoplâncton do Lago das Garças, São Paulo, Brasil: um reservatório urbano eutrófico. Hoehnea v. 33, p. 147-175, 2006.

UTERMÖHL, H.Zur Vervollkommung der quantativen phytoplancton-methodik. Mitteilungen Internationale Vereinigung für Theoretische und Angewandte Limnologie. v. 9: 1, 38p., 1958.

VALENTIN, J.L. Ecologia Numérica: Uma introdução à análise multivariada de dados ecológicos. Ed. Interciência, Rio de Janeiro. 117, 2000.

VAN DEN HOEK, C., MANN, D.G.; JAHNS, H.M. Algae. An introduction to phycology. Cambridge University Press, Cambridge, 1995.

WAKELIN, S. A.; PAGE, D.W.; PAVELIC, P.; GREGG, A. L.; DILLON, P. J. Rich microbial communities inhabit water treatment biofilters and are differentially affected by water type and sampling depth. Water Science and Technology: water supply. v. 10, p. 145-156, 2010. 
WAKELIN, S., PAGE, D., DILLON, P., PAVELIC, P., ABELL, G.C.J., GREGG, A.L., BRODIE, E., DESANTIS, T.Z., GOLDFARB, K.C., ANDERSON, G. Microbial community structure of a slow sand filter Schmutzdecke: a phylogenetic snapshot based on rRNA sequence analysis. Water Science Technology. v. 11, p. 426-436, 2011.

WEBER, C.I.Plankton. In: National Environmental Research Center Office of Research and Development U. S. Environmental Protection Agency Cincinnati (ed.). Biological field and laboratory methods for measuring the quality of surface water and effluents. p.1-17, 1973.

WETZEL, R.G. \& LIKENS, G.E.Limnological Analyses. 3 ed. Springer-Verlang, New York, 2000. 
Capítulo 4

Efeito da contaminação por produtos farmaceuticos e de cuidados pessoais no biofilme

de filtros ecológicos para uso doméstico

\section{Resumo}

A remoção dos produtos farmacêuticos para cuidados pessoais (PFCPs) da água geralmente são melhores por oxidação avançada que não é acessível em países de baixa renda. A biodegradação tem sido sugerida como um dos mecanismos responsáveis pela remoção de contaminantes orgânicos da água, e a filtração ecológica tem mostrado remover compostos anti-inflamatórios. Seus baixos custos de manutenção e operação a torna uma tecnologia atrativa para o tratamento de água em muitas partes do mundo. Além disso, filtros ecológicos podem ser utilizados a nível doméstico ou em grande escala. O biofilme (ou schmutzdecke) desenvolvido no topo da areia e em camadas superiores da areia é reconhecido como sendo responsável pela purificação da água. No entanto, é possível que os PFCPs possam afetar o desenvolvimento do biofilme e a comunidade microbiana dentro dos filtros e, consequentemente, o desempenho do filtro. Este estudo investigou dois filtros ecológicos domésticos operados com e sem contaminação por seis PFCPs (paracetamol, diclofenaco, naproxeno, ibuprofeno, metilparabeno e benzofenona-3). Onze parâmetros foram monitorados na água afluente e efluente, além do sequenciamento genético de bactérias e a determinação da biomassa do biofilme. Os resultados demonstraram que o desempenho dos filtros ecológicos domésticos não foi afetado pela presença dos PFCPs na água. Não houve diferença significativa entre filtros para remoção de coliformes totais e de $E$. coli, mas não houve diferença considerável entre os tempos de coleta. A biomassa teve aumento considerável com o tempo, em ambos os filtros, sendo que não houve diferença significativa entre os filtros. No entanto, verificou-se que mais espécies de bactérias estavam presentes no período sem contaminação do que durante o período de contaminação. Bacillus anthracis e Exiquobacterium sp. parecem ser resistente aos compostos PFCPs.

Palavras-chave: filtros domésticos, compostos farmacêuticos e de cuidados pessoais, biomassa, biofilme, sequenciamento genético de bactérias. 


\begin{abstract}
The removal of pharmaceutical personal care products (PPCPs) from water are usually enhanced by advanced oxidation which is not affordable in low income countries. Biodegradation has been suggested as one of the mechanisms responsible for the removal of organic trace contaminants from water, and ecological filters have been found capable of removing anti-inflammatory compounds. Its low maintenance costs and easy operation make ecological filtration an attractive technology for treating water in many parts of the world. In addition, ecological filters can be used at large scale and household level. The biolayer (i.e.schmutzdecke) developed on the top of the sand and within the upper layers of the sand is acknowledged to be responsible for the purification of the water. However, it is possible that the PPCPs may affect the schmutzdecke development and microbial community within the filters, and consequently the performance of the filter. This study investigated two household ecologogical filters operated with and without contamination by six PPCPs (i.e.paracetamol, diclofenac, naproxen, ibuprofen, methylparaben and benzophenone-3). Eleven parameters were monitored in the affluent and effluent water, including bacteria gene speciation and schmutzdecke biomass determination. Results demonstrated that the household ecological filters performance was not affected by the presence of PPCPs in the water. There was no significant difference between filters for total coliforms and E.coli removals, but there was considerable difference between sampling times. Biomass considerably increased with time in both filters and there was no siginifcant difference between filter biomass. However, it was found that more bacteria species were present in the period with no contamination than during the contamination period. Bacillus anthracis and Exiquobacterium sp. showed to be resistant to the PPCPs compounds.
\end{abstract}

Keywords: Household filters, pharmaceutical and personal care compounds, biomass, biofilm, bacteria sequencing. 


\section{Introdução}

Apesar dos esforços de alcançar o Objetivo de Desenvolvimento do Milênio (ODM 7) na água potável, globalmente cerca de 1,9 bilhões de pessoas usam fontes de água contaminada com patógenos (WHO, 2016). Além de patógenos, em todo mundo os compostos químicos são encontrados em águas superficiais e subterrâneas com concentração em níveis de $\mathrm{ng} \mathrm{L}^{-1}$ a mg L $\mathrm{m}^{-1}$ (SUI et al., 2015). Dentre estes compostos estão antibióticos, anti-inflamatórios, analgésicos, esteroides, antidepressivos, antipiréticos, estimulantes, agentes antimicrobianos, perfumes, cosméticos, e muitos outros produtos farmacêuticos e de cuidados pessoais (PFCPs). O trabalho realizado por Chan et al., (2014) mostra como é alarmante a presença de fármacos em água, e os autores descrevem que fármacos foram encontrados em 14 das 17 comunidades investigadas.

Os PFCPs são biologicamente ativos e foram desenvolvidos para atuar em vias específicas em seres humanos e animais (BOXALL et al., 2012); podendo exercer a sua atividade mesmo quando em baixa concentração (VULLIET e CREN-OLIVA, 2011), e, potencialmente, ter um impacto no abastecimento de água potável (Jones et al., 2005). Os efeitos adversos causados por compostos farmacêuticos incluem toxicidade em organismos aquáticos, desenvolvimento de resistência em bactérias patogênicas, genotoxicidade e desregulações endócrinas (KUMMERER, 2008).

O processo convencional de tratamento de água usualmente utiliza coagulação com sulfato de alumínio ou sais de metais a base de ferro, seguido de floculação, sedimentação, filtração, e desinfecção. Este processo atinge altas remoções de microrganismos, mas uma remoção muito modesta de carbono orgânico dissolvido (COD) (RIGOBELLO et al., 2013). Os tratamentos de água avançados utilizando oxidação e carvão ativado geralmente melhoram a remoção de COD.

Um exemplo de que o tratamento convencional não remove totalmente os PFCPs pode ser visto no trabalho desenvolvido por Qiao et al., (2011), que investigaram a ocorrência e o destino de PFCPs na água potável e relatam que dos 15 PFCPs encontrados em concentrações de 0 a $36 \mathrm{ng} \mathrm{L}^{-1}$ em água de nascente, 12 deles ainda estavam presentes na água após o tratamento, em concentração de 0 a $20 \mathrm{ng} \mathrm{L}^{-1}$. Observa-se em dados da literatura que os processos convencionais de tratamento de água removem em média 30\% a 50\% dos PFCPs.

Os processos de tratamento de água avançados foram mais eficientes na remoção de PFCPs, com reduções de aproximadamente $50 \%$ a 90\%. Porém, um dos inconvenientes dos processos é o seu elevado custo. Isso faz com que a remoção de PFCPs não seja viável nos 
países em desenvolvimento onde os recursos financeiros são limitados. Assim, é necessária uma alternativa de tratamento eficiente e de baixo custo.

A biodegradação tem sido sugerida como um dos mecanismos responsáveis para a remoção de contaminantes orgânicos (HALLE, 2009; QIAO et al., 2011, BERTELKAMP et al., 2014). A filtração Ecológica (terminologia moderna para filtração lenta) mostrou ser um processo eficiente para remover alguns anti-inflamatórios, tais como diclofenaco, naproxeno e ibuprofeno (ERBA et al., 2014). Portanto, a filtração ecológica parece uma alternativa viável, uma vez que é de fácil operação e manutenção - não requer coagulante e pode ser usada em grandes escalas ou pequenas, como filtros domésticos.

Um exemplo de filtro lento de areia em escala domiciliar é o Biosand household filter, que nada mais é do que o filtro ecológico, mas em escala domiciliar com operação intermitente. Desde 2012 mais de 400.000 biofiltros de areia foram implementadas por governos, agências de desenvolvimento, organizações não-governamentais, organizações comunitárias e empresas de iniciativa privada em mais de 60 países, atendendo a mais de 2,5 milhões de pessoas (CAWST, 2012).

A escala domiciliar dos filtros supre as necessidades de pequenas populações e/ou de famílias que não possuem água potável disponível, deixando as famílias em situação de independência dos sistemas públicos.

A alta eficiência do tratamento de água alcançado por filtração ecológica é parcialmente explicado pela baixa taxa de filtração $\left(0,1\right.$ a $\left.0,4 \mathrm{mh}^{-1}\right)$ e pela espessura fina da areia utilizada como meio filtrante $(0,1$ a $0,3 \mathrm{~mm})$. Mas também é atribuída a processos biológicos que ocorrem principalmente na camada superficial da areia do filtro (schmutzdecke, ou biofilme) (HUISMAN e WOOD, 1974). Nakamoto (2014) explica também a importância do biofilme no sistema de tratamento, enfatizando a importância da camada biológica no topo da camada de areia.

Recentemente, muitos estudos têm focado na investigação do biofilme dos filtros ecológicos, mais especificamente da comunidade microbiana presente no biofilme (CAMPOS et al., 2002; ROOKLIDGE et al., 2005; UNGER e COLLINS, 2008; WAKELIN et al., 2011; HWANG, et al., 2014; HAIG et al., 2014, 2015), mas não há registros de investigações do efeito de compostos farmacêuticos e de cuidados pessoais no desenvolvimento de biofilme. No entanto alguns estudos demonstraram que há efeitos dos compostos farmacêuticos em espécies de bactérias presentes nos biofilmes aquáticos. Entre os efeitos descritos podem ser citados supressão da biomassa, da respiração e da fotossíntese (ROSI-MARSHALL et al., 2013), o aumento da resistência a fármacos (DRURY et al., 2013), e a toxicidade (HARADA 
et al., 2008). Mais recentemente, Rosi-Marshall et al., (2015) realizaram uma revisão literária sobre os efeitos ecológicos de drogas ilícitas nos organismos aquáticos e concluiram que uma grande variedade de organismos aquáticos, como bactérias e algas têm receptores que os tornam potencialmente sensíveis a estes compostos. Portanto, os PFCPs podem afetar o desenvolvimento da comunidade microbiana do biofilme de filtros lentos de areia e, consequentemente, influenciar no desempenho do filtro.

Neste trabalho foi investigado o desenvolvimento do biofilme, incluindo espécies de bactérias e o crescimento da biomassa, em filtros ecológicos domésticos para o tratamento de água contaminada por PFCPs, a fim de investigar a influencia da contaminação no desempenho dos filtros e do efeito no biofilme.

\section{Materiais e Métodos}

\section{1. Água bruta utilizada e descrição dos filtros}

A água bruta filtrada pelos filtros foi coletada em um lago localizado no Regents Park em Londres, Inglaterra. Duas vezes por semana, 100 L de água foram coletados para ser filtrados pelos filtros domésticos no Laboratório de Engenharia Ambiental da University College London. Um volume de $24 \mathrm{~L}$ de água foi filtrado em cada filtro, em cada carreira de filtração. Os filtros domésticos foram operados de maneira intermitente. $O$ trabalho experimental foi dividido em duas fases, o que resultou em um total de 21 filtrações na fase 1, e 12 filtrações na fase 2 (Tabela 1).

Dois filtros domésticos (Household filters) (Figura 1 e Figura 2) foram usados para este estudo. Os filtros eram compostos de $50 \mathrm{~mm}$ de cascalho grosso, $50 \mathrm{~mm}$ de cascalho de tamanho médio, e $400 \mathrm{~mm}$ de areia. O tamanho efetivo $\left(\mathrm{D}_{10}\right)$ da areia foi de $0,210 \mathrm{~mm}$, com coeficiente de uniformidade de 1,40. Tais valores estão dentro do tamanho de grão entre 0,15 $\mathrm{mm}$ e $0,30 \mathrm{~mm}$ e coeficiente de uniformidade inferior a 4 para utilização em filtração lenta de areia (HUISMAN e WOOD, 1974). A equação utilizada para calcular o coeficiente de uniformidade foi: $\mathrm{CU}=\mathrm{D}_{60} / \mathrm{D}_{10}$.

Para investigar o efeito do tempo de detenção hidráulica na qualidade da água, foram coletadas amostras de acordo com tempos de detenção hidráulicos determinados por Campos e Outhwaite, (2014), que estão resumidas na Tabela 2. 
Durante a fase 1 , os filtros foram operados com torneira de modo que a filtragem da água foi interrompida por duas vezes durante um período de 2 horas. Durante a fase 2, os filtros foram operados sem torneira sendo o tempo de filtração igual a 90 minutos (Tabela 2). Além disso, na fase 1, o filtro 2 (F2) foi contaminado com uma mistura de produtos farmacêuticos e de cuidados pessoais, e o filtro 1 (F1) correspondeu ao filtro de controle.

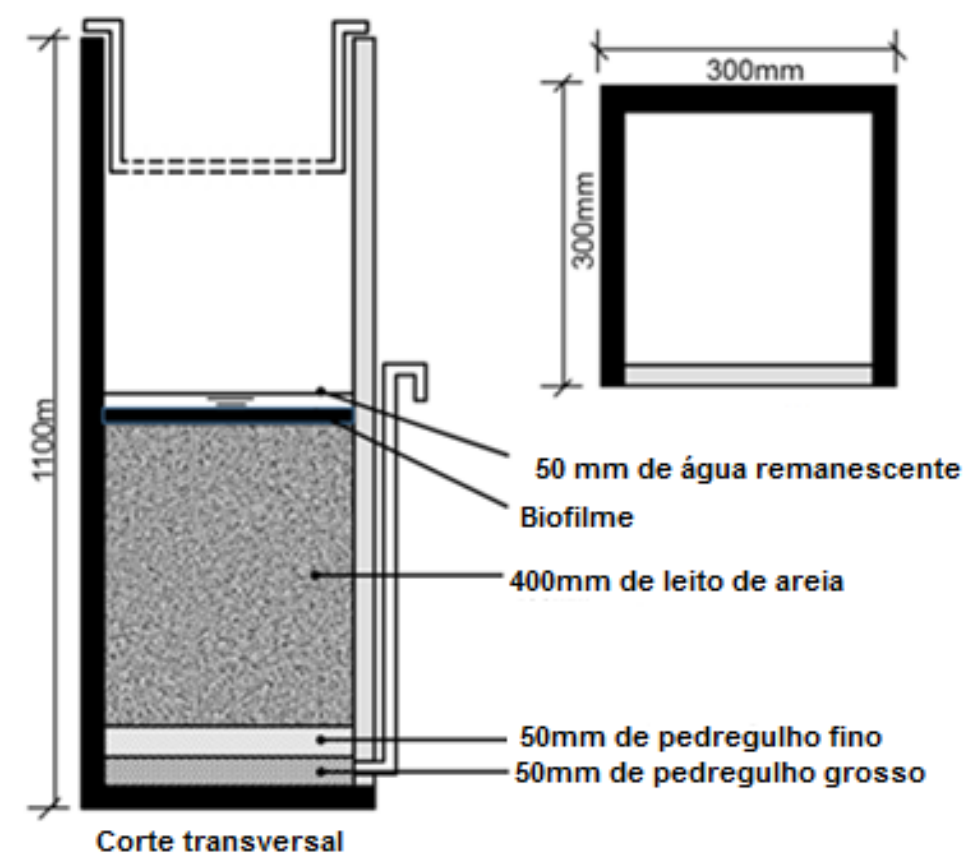

Figura 1: Modelo de um filtro ecológico doméstico em planta e seção transversal.

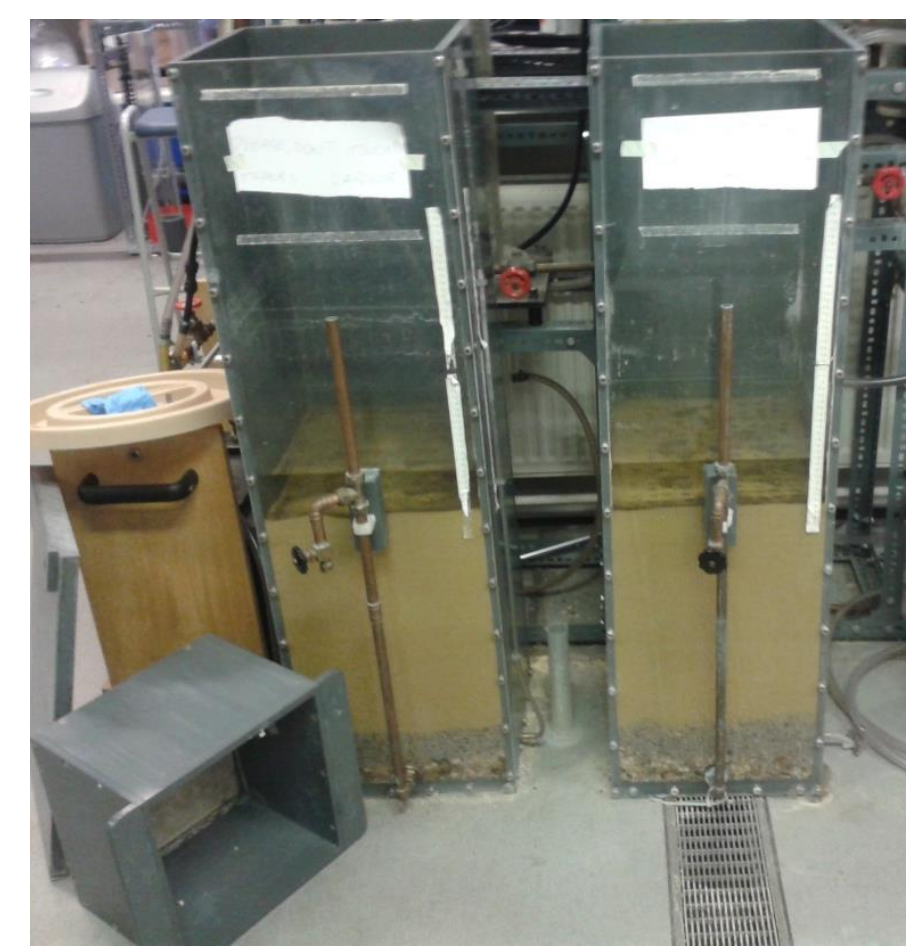

Figura 2: Filtros domésticos utilizados. 
Tabela 1: Descrição das filtrações realizadas na fase 1 e fase 2.

\begin{tabular}{lcc}
\hline \multicolumn{1}{c}{ Procedimento } & Fase 1 & Fase 2 \\
\hline Período de maturação & 10 filtrações (20 dias) & - \\
Filtrações & 1 a 21 & 22 a 33 \\
Número de filtrações & 21 & 12 \\
Contaminações com PFCPs & À partir da $11^{\text {a }}$ filtração no F2 & - \\
\hline
\end{tabular}

Tabela 2: Sistema de operação dos filtros ecológicos domésticos nas fases 1 e 2.

\begin{tabular}{cccc}
\hline Amostras & Descrição & Fase 1 com torneira & Fase 2 sem torneira \\
\hline S1 & $\begin{array}{c}\text { Representa a água } \\
\text { proveniente da } \\
\text { filtração anterior }\end{array}$ & $\begin{array}{c}\text { Apónitos do } \\
\text { torneira foiltração. A } \\
\text { após 2 horas do início } \\
\text { da filtração. }\end{array}$ & $\begin{array}{c}\text { Após 10 minutos do } \\
\text { início da filtração }\end{array}$ \\
\hline Período de pausa & $\begin{array}{c}\text { A torneira foi fechada } \\
\text { 2 horas após início da } \\
\text { filtração e aberta após } \\
\text { duas horas. }\end{array}$ & \\
\hline S2 & Representa a água da & $\begin{array}{c}\text { Após 4h30 minutos } \\
\text { da adição de água nos } \\
\text { filtração do dia }\end{array}$ & $\begin{array}{c}\text { Após 90minutos do } \\
\text { início da filtração }\end{array}$ \\
\hline
\end{tabular}

\subsection{Solução de produtos farmacêuticos e de cuidados pessoais adicionada a água bruta}

Durante a fase 1, a água afluente do filtro 2 (F2) foi contaminada com uma mistura de 6 diferentes produtos farmacêuticos e de cuidados pessoais (PFCPs), a saber: paracetamol, diclofenaco, naproxeno, ibuprofeno, metilparabeno e benzofenona-3, na concentração de $2 \mu \mathrm{g} \mathrm{L} \mathrm{L}^{-1}$, enquanto o filtro 1 (F1) operou como controle, ou seja, sem adição dos PFCPs.

Os padrões do paracetamol (4-acetaminofenol), diclofenaco sódico, naproxeno, ibuprofeno, metilparabeno (metil 4-hidroxibenzoato) e benzofenona-3 (2-hidroxi-4metoxibenzofenona) utilizados foram todos com pureza de $\geq 99 \%$ provenientesda SigmaAldrich. Informações adicionaisde cada composto estão na Tabela 1 do Capítulo 2 . A quantificação destes compostos em água não foram consideradas neste estudo.

\subsection{Coleta de amostras de água}

Para a análise dos parâmetros de qualidade da água, $100 \mathrm{~mL}$ de água afluente e efluente foram coletados em triplicata durante a fase 1 e fase 2 em cada filtração efetuada. $\mathrm{Na}$ fase 1, uma vez iniciada a filtração, as coletas das amostras de água foram feitas com 10 
minutos após início da filtração (S1) que representa a água remanescente no filtro da filtração anterior, e 4 horas e 30 minutos depois da filtração (S2), que representa a água da filtração do dia. Na fase 2 as amostras foram coletadas em S1 (10 min), e S2 (90 min) representando água a partir do mesmo dia de filtração.

\subsection{Variáveis de qualidade da água}

Foram aferidos as seguintes variáveis de qualidade da água: turbidez (NTU), Oxigénio Dissolvido (OD) $\left(\mathrm{mg} \mathrm{L}^{-1}\right)$, absorbância ultravioleta específica $(254 \mathrm{~nm}), \mathrm{pH}$, temperatura $\left({ }^{\circ} \mathrm{C}\right)$, condutividade elétrica $\left(\mathrm{mg} \mathrm{L}^{-1}\right)$, Carbono Orgânico Total (COT), expresso em $\mathrm{mg} \mathrm{L}^{-1}$, nitrito $\left(\mathrm{mg} \mathrm{L}^{-1}\right)$, nitrato $\left(\mathrm{mg} \mathrm{L}^{-1}\right)$, e fosfato $\left(\mathrm{mg} \mathrm{L}^{-1}\right)$. A determinação de cada variável seguiu os métodos da APHA (2005), com exceção de fosfato, nitrito, nitrato e que foram determinados por cromatografia de íons (CI), utilizando-se o cromatógrafo de íons KS-1100, Thermo Scientific ${ }^{\mathrm{TM}}$ Dionex $^{\mathrm{TM}}$.

$\mathrm{Na}$ cromatografia de íons a coluna utilizada foi Thermo Scientific ${ }^{\mathrm{TM}}$ Dionex $^{\mathrm{TM}}$ IonPac ${ }^{\mathrm{TM}} \mathrm{AS} 23,4 \times 250 \mathrm{~mm}$ de carbonato de troca aniônica como eluente. A análise no modo aniônica foi realizada de acordo com as recomendações do fabricante, utilizando uma fase móvel de 4,5 mM de $\mathrm{Na}_{2} \mathrm{CO}_{3}$. A taxa de fluxo foi de $1 \mathrm{~mL} \mathrm{~min}{ }^{-1}$, com um tempo total da análise de 30 minutos e a temperatura mantida em $30{ }^{\circ} \mathrm{C}$. A análise de cátions foi efetuada utilizando a coluna IonPac ${ }^{\circledR} \mathrm{CS} 16$ - $5 \mu \mathrm{m}(0,5$ x $250 \mathrm{~mm})$ com ácido metanossulfonico a 30 $\mathrm{mM}$ como eluente. A taxa de fluxo estabelecida também foi de $1 \mathrm{~mL} \mathrm{~min}^{-1}$, com um tempo total de análise de 25 minutos, e temperatura mantida a $40^{\circ} \mathrm{C}$. A detecção de picos de íons em ambas as condições foi realizada por meio de medições de condutividade suprimida a 25 $\mathrm{mA}$. Os espectros foram analisados por meio de um conjunto de normas e software fornecidos pela Dionex.

Foi avaliada a remoção de coliformes totais e Escherichia coli pelos filtros utilizando o kit m-ColiBlue24® de acordo com as instruções do fabricante.

\subsection{Análise microbiológica do biofilme}

Foram coletadas duas amostras do biofilme (10 gramas cada) no final da fase 1 e da fase 2 em triplicata. Os pontos de coleta foram selecionados aleatoriamente no biofilme dos filtros. 
Após coletadas, as amostras foram misturadas em vortex com Solução Fosfato Salino tamponada - PBS (Phosphate-buffered salin). Foram feitas diluições em série (1:10) e as amostras diluídas foram plaqueadas em agar R2A, recomendado para bactérias em água, especialmente de água potável (Oxoid, Reino Unido), a $25{ }^{\circ} \mathrm{C}$ durante 48 horas. Foram isoladas colônias com diferentes morfologias.

O DNA (DeoxyriboNucleic Acid) de cada espécie isolada foi extraído utilizando o QIAamp DNA Mini Kit ${ }^{\circledR}$ (Qiagen, UK), e amplificado por meio de PCR (Polymerase Chain Reaction) utilizando o equipamento 7500 Real Time PCR System.

A concentração do DNA extraído foi mensurado por meio do equipamento Nanodrop 2000 (Thermo fisher, UK), e os valores dos extraídos foram medidos na faixa de 260-280nm, e estiveram entre 1,70 a 2,2, que é o indicado.

O DNA extraído foi amplificado utilizando o gene 16S rRNA, com primers universais 27F (5'AGAGTTTGATCCTGGCTCAG-3') e 1492R (5'GGTTACCTTGTTACGACTT-3'), provenientes da Sigma Aldrich, UK. (LANE et al., 1985).

Foi construída uma curva de calibração (Figura A.2 - Anexos) com um mix de 20 amostras a serem sequenciadas selecionadas aleatoreamente, a fim de possibilitar o cálculo do número de amplificações realizadas para cada amostra. Para a construção da curva, foram feitas diluições de $10^{-1}$ a $10^{-5}$ em triplicata. O DNA amplificado foi purificado utilizando o kit de purificação QIAquick PCR (Qiagen, UK).

\subsection{Sequenciamento e análise dos dados}

O sequenciamento do $16 \mathrm{~S}$ rRNA dos amplicons foi conduzido pela Eurofins Genomics, Reino Unido.

As sequências foram editadas e alinhadas com o uso dos softwares EDISEQ e Megalign. Para cada cepa isolada, o vizinho filogenético mais próximo foi encontrado segundo a ferramenta "Basic Local Alignment search" (BLAST) do NCBI (National Centre for Biotechnology Information, Bethesda, MD, USA). As cepas isoladas foram organizadas na Tabela 4, que mostra que o que foi encontrado em cada amostra do filtro durante a fase 1 e fase 2. A Tabela 4 foi então utilizada para executar a análise de componente principal (PCA). O PCA foi realizado utilizando Multiple Variable Statistical Package (Kovach Computing Services, UK). 


\subsection{Análises da biomassa}

Três amostras contendo 100 gramas cada foram coletadas aleatoriamente na superfície de areia de cada filtro (biofilme mais areia), para a análise no final da fase 1 e uma vez por semana, após três filtragens por semana, na fase 2. A biomassa durante a fase 1 foi medida apenas uma vez no final das 21 filtragens. Foram coletadas seis amostras no total. Não era possível retirar mais amostras de areia dos filtros para efetuar mais análises por se tratar de filtros pequenos e a retirada excessiva de areia poderia afetar o desempenho dos filtros uma vez que o biofilme é um componente essencial para a purificação de água por filtração ecológica. As amostras foram armazenadas em $-80{ }^{\circ} \mathrm{C}$ em frascos com glicerol a $10 \%$ antes da determinação da biomassa através do processo de fumigação (CAMPOS et al., 2002).

\section{Resultados e Discussões}

\subsection{Análises das variáveis de qualidade da água}

As análises das variáveis de qualidade da água mostraram que os filtros domésticos se enquadraram nos parâmetros de qualidade de água estabelecidos pela diretiva da União Europeia: 98/83/CE (1998), com exceção de coliformes totais e E. coli, que excederam o limite em alguns dias de filtragem (Figura $3 \mathrm{~b}$ e $3 \mathrm{~d}$ ). Ambos os filtros apresentaram excelente remoção de coliformes totais e E. coli (> 99\%) no tempo de coleta S1 (Figura 3a e 3c). Antes da análise, a água bruta foi diluída na proporção de 1:10 para a contagem.

A Tabela 3 mostra os resultados médios de todos os parâmetros de qualidade da água aferidos em diferentes tempos de coleta, de acordo com as fases 1 e 2 . As relações entre afluente e efluente dos filtros, em relação aos parâmetros de qualidade da água foram examinadas usando teste-t, e o valor foi considerado significativo quando $\mathrm{P} \leq 0,05$.

Pode-se visto que F1 (controle) e F2 (contaminado) apresentaram diferenças significativas entre afluente e efluente em relação aos mesmos parâmetros. Isto indica que os filtros tivera um comportamento semelhante e a contaminação por PFCPs pareceu não afetar o desempenho da remoção dos parâmetros físico-químicos. No entanto, a pausa do fluxo causada por fechamento da torneira na fase 1 pareceu melhorar a remoção de turbidez e absorbância, enquanto a diferença de oxigénio dissolvido entre afluente e efluente foi significativa $(\mathrm{P}<0,05)$ com diferença de $7,81 \mathrm{mg} \mathrm{L}^{-1}$ para $9,93 \mathrm{mg} \mathrm{L}^{-1}$ e $3,80 \mathrm{mg} \mathrm{L}^{-1}$ em $\mathrm{F} 1$ e 
F2, respectivamente, devido à respiração microbiana. No entanto, estes níveis são superiores ao valor recomendado de $3 \mathrm{mg} \mathrm{L}^{-1}$ para filtros lentos de areia (Huisman e Wood, 1974). Os níveis de nitratos aumentaram significativamente $(\mathrm{P}<0,05)$ de $0,29 \mathrm{mg} \mathrm{L}^{-1}$ para $2,40 \mathrm{mg} \mathrm{L}^{-1}$ e $2,28 \mathrm{mg} \mathrm{L}^{-1}$, enquanto o fosfato moderadamente aumentado de $8,61 \mathrm{mg} \mathrm{L}^{-1}$ para $11,53 \mathrm{mg} \mathrm{L}^{-1}$ e 11,36 $\mathrm{mg} \mathrm{L}^{-1}$ em F1 e F2, respectivamente, na fase 1 para o tempo de coleta S1. Este aumento de nitrito e fosfatos pode ser devido à respiração algas que converte fósforo orgânico para inorgânico e nitrogênio de algas para nitrogênio inorgânico (BROWN e BARNWELL, 1987).

Observa-se também que a qualidade da água do lago do Regents Park tinham níveis mais elevados de condutividade elétrica da água, STD, e fosfato na fase 2 do que na fase 1 (Tabela 3). Isso se deveu ao fato de que a fase 2 ocorreu durante o verão, e além disso, foi observada a presença bloom de algas (Figura A.3 - Anexos). Consequentemente, a eficiência de remoção dos filtros na fase 2 foi menor do que na fase 1. Contudo uma outra razão pode ter sido o fato 3 amostras contendo schmutzdecke e alguns centímetros de areia foram coletadas a cada duas outras semanas durante a fase 2 para a determinação de biomassa.

Em adicional, foi feito o teste-t para examinar as relações entre F1 e F2 e S1 e S2, para verificar se havia diferença ou não entre filtros e tempos de coletas. A significância foi considerada quando $\mathrm{P} \leq 0,05$.

Não houve diferença significativa entre os filtros e entre os tempos de coleta, em ambas as fases, para temperatura, condutividade elétrica, STD, pH, turbidez, COT, nitrato e fosfato ( $\mathrm{P}=0,1$ a 0,9$)$. Estes resultados confirmam que o efeito do aumento do tempo de residência após a maturação do filtro não afeta o desempenho do filtro (CAMPOS e OUTHWAITE, 2014). Os resultados também mostram que a presença de PFCPs no afluente não afetou a eficiência do F2 (contaminado) na remoção de turbidez, coliformes totais e $E$. coli durante a fase 1 (remoção > 90\%).

No entanto, houve diferença considerável entre e nas fases 1 e 2, para os parâmetros: absorbância, nitrito e OD. Houve diferença significativa da absorbância da água no F1, entre os tempos de coleta S1 e S2 (P=0,006) na fase 1, operado com torneira, e pausa. Entretanto, não houve diferença significativa entre os filtros na fase 1 . Isto indica que o aumento do tempo de detenção aumenta o crescimento da biomassa ( $\mathrm{P}=0,79$ para $\mathrm{S} 1$ e $\mathrm{P}=0,11$ para $\mathrm{S} 2)$ e melhora a remoção de absorbância. Há melhora na eficiência dos filtros lentos de areia domésticos em relação aos parâmetros de qualidade de água conforme o amadurecimento dos filtros, fato este que tem sido relatado em vários trabalhos (KAISER et al., 2002; NGAI et al.; 2007, MWABI et al., 2012). 
Em relação ao nitrito, uma diferença significativa ocorreu apenas na fase 2 para ambos os filtros operados sem torneira, nos tempos de coleta $\mathrm{S} 1(\mathrm{P}=0,01)$ e $\mathrm{S} 2(\mathrm{P}=0,008)$. Na fase 2, a concentração de nitrato no efluente dos filtros foi maior do que na fase 1 . Como a amostragem do biofilme foi feita semanalmente, pode ter ocorrido um aumento da decomposição de algas, pois houve também diminuição de OD (Tabela 3).

Não houve diferença significativa de $\mathrm{OD}$ na fase 1 entre os filtros $(\mathrm{P}=0,70)$, porém foi observada uma diferença significativa entre os tempos de coleta, sendo que o OD em S1 esteve bem abaixo do que em S2. Esta diferença foi mais significativa do filtro F2 contaminado $(P=0,0009)$ do que no filtro F1 $(P \leq 0,05)$. A concentração média de OD foi F1_S1 (4,93 mg L $\left.{ }^{-1}\right), F 1 \_S 2\left(6,28 \mathrm{mg} \mathrm{L}^{-1}\right)$ e F2_S1 (3,80 mg L $\left.{ }^{-1}\right), \mathrm{F} 2 \_\mathrm{S} 2\left(6,09 \mathrm{mg} \mathrm{L}^{-1}\right)$. Isto foi causado provavelmente pela pausa do fluxo com o fechamento da torneira e, consequentemente, S1 - ou seja, a água remanescente no filtro da filtragem anterior apresentou o menor OD, causada pelo aumento do tempo de detenção. Isso indica que o biofilme pode ter começado a decair devido à menor concentração de OD dissolvido na água causado pelo tempo da pausa (LEA, 2014).

Um comportamento semelhante ocorreu com o OD aferido na fase 2, pois não houve diferença significativa entre os filtros F1 e F2 em S2. Entretanto, houve diferença significativa entre o OD nos efluentes de ambos os filtros no tempo de coleta $\mathrm{S} 1$, com valor médio aferido no efluente do F1 (3,65 $\left.\mathrm{mg} \mathrm{L}^{-1} ; \mathrm{P}=0,003\right)$ maior do que em $\mathrm{F} 2\left(1,67 \mathrm{mg} \mathrm{L}^{-1}, \mathrm{P}=0,0009\right)$. Pode-se observar também uma diferença significativa entre os tempos de coleta para ambos os filtros ( $\mathrm{P}<$ 0,001 para o F1 e para o F2). Independentemente do modo de operação do filtro, a água remanescente nos filtros por mais de 24 horas provoca baixa quantidade de OD no efluente. Isto leva a baixa atividade dos microrganismos que necessitam do oxigênio para suas atividades básicas. 
Tabela 3: Valores médios dos parâmetros de qualidade de água aferidos durante as fases 1 e 2, e seus respectivos valores de $\mathrm{P}$, mostrando a relação entre afluente e efluente dos filtros.

\begin{tabular}{|c|c|c|c|c|c|c|c|c|c|}
\hline & \multicolumn{9}{|c|}{ Fase 1 - Filtrações de 1 a 21} \\
\hline & Afluente & $\begin{array}{c}\text { Efluente } \\
\text { F1_S1 }\end{array}$ & Teste-t & $\begin{array}{c}\text { Efluente } \\
\text { F2_S1 }\end{array}$ & Teste-t & $\begin{array}{c}\text { Efluente } \\
\text { F1_S2 }\end{array}$ & Teste-t & $\begin{array}{c}\text { Efluente } \\
\text { F2_S2 }\end{array}$ & Teste-t \\
\hline Temperatura $\left({ }^{\circ} \mathrm{C}\right)$ & 20,06 & 21,24 & $P=0,06$ & 21,50 & $\mathrm{P}<0,05$ & 21,21 & $P=0,05$ & $-21,48$ & $\mathrm{P}<0,05$ \\
\hline Condutividade elétrica $\left(\mu \mathrm{S} \mathrm{cm}^{-1}\right)$ & 57,78 & 56,09 & $P=0,59$ & 57,61 & $P=0,96$ & 58,71 & $P=0,66$ & 60,64 & $P=0,17$ \\
\hline $\mathrm{STD}\left(\mathrm{mg} \mathrm{L}^{-1}\right)$ & 20,04 & 26,83 & $P=0,61$ & 26,92 & $P=0,63$ & 29,93 & $P=0,25$ & 30,63 & $P=0,11$ \\
\hline $\mathrm{pH}$ & 8,26 & 7,85 & $\mathrm{P}<0,05$ & 7,91 & $\mathrm{P}<0,05$ & 8,00 & $P=0,09$ & 8,07 & $P=0,21$ \\
\hline Oxegênio dissolvido $\left(\mathrm{mg} \mathrm{L}^{-1}\right)$ & 7,81 & 4,93 & $\mathrm{P}<0,05$ & 3,80 & $\mathrm{P}<0,05$ & 6,31 & $\mathrm{P}<0,05$ & 6,15 & $\mathrm{P}<0,05$ \\
\hline Turbidez (NTU) & 6,94 & 1,76 & $\mathrm{P}<0,05$ & 2,08 & $P=0,06$ & 0,78 & $\mathrm{P}<0,05$ & 0,82 & $\mathrm{P}<0,05$ \\
\hline Absorbância (254nm) & 0,21 & 0,14 & $\mathrm{P}<0,05$ & 0,16 & $\mathrm{P}<0,05$ & 0,19 & $P=0,19$ & 0,18 & $P=0,06$ \\
\hline $\operatorname{COT}\left(\mathrm{mg} \mathrm{L}^{-1}\right)$ & 58,37 & 49,32 & $P=0,22$ & 39,89 & $\mathrm{P}<0,05$ & 43,67 & $P=0,08$ & 54,06 & $P=0,74$ \\
\hline Nitrito $\left(\mathrm{mg} \mathrm{L}^{-1}\right)$ & 0,29 & 2,40 & $\mathrm{P}<0,05$ & 2,28 & $\mathrm{P}<0,05$ & 2,42 & $\mathrm{P}<0,05$ & 2,33 & $\mathrm{P}<0,05$ \\
\hline Nitrato $\left(\mathrm{mg} \mathrm{L}^{-1}\right)$ & 17,94 & 17,22 & $P=0,92$ & 16,21 & $P=0,81$ & 17,51 & $P=0,95$ & 18,76 & $P=0,91$ \\
\hline \multirow[t]{3}{*}{ Fosfato $\left(\mathrm{mg} \mathrm{L}^{-1}\right)$} & 8,61 & 11,53 & $P=0,41$ & 11,36 & $P=0,44$ & 11,24 & $P=0,40$ & 11,29 & $P=0,50$ \\
\hline & \multicolumn{9}{|c|}{ Fase 2 - Filtrações de 22 a 33} \\
\hline & Afluente & $\begin{array}{c}\text { Efluente } \\
\text { F1_S1 }\end{array}$ & Teste-t & $\begin{array}{c}\text { Efluente } \\
\text { F2_S1 }\end{array}$ & Teste-t & $\begin{array}{c}\text { Efluente } \\
\text { F1_S2 }\end{array}$ & Teste-t & $\begin{array}{c}\text { Efluente } \\
\text { F2_S2 }\end{array}$ & Teste-t \\
\hline Temperatura $\left({ }^{\circ} \mathrm{C}\right)$ & 19,90 & 20,09 & $P=0,67$ & 20,24 & $P=0,46$ & 19,88 & $P=0,97$ & 19,82 & $P=0,87$ \\
\hline Condutividade elétrica $\left(\mu \mathrm{S} \mathrm{cm}^{-1}\right)$ & 1040,27 & 1033,30 & $P=0,77$ & 1037,41 & $P=0,88$ & 1005,60 & $P=0,21$ & 1016,10 & $P=0,30$ \\
\hline $\operatorname{STD}\left(\mathrm{mg} \mathrm{L}^{-1}\right)$ & 527,57 & 519,02 & $P=0,49$ & 520,66 & $P=0,52$ & 509,78 & $P=0,24$ & 511,57 & $P=0,20$ \\
\hline $\mathrm{pH}$ & 7,84 & 7,81 & $P=0,76$ & 7,76 & $P=0,50$ & 7,92 & $P=0,49$ & 7,95 & $P=0,38$ \\
\hline Oxegênio dissolvido $\left(\mathrm{mg} \mathrm{L}^{-1}\right)$ & 5,77 & 3,65 & $\mathrm{P}<0,05$ & 1,67 & $\mathrm{P}<0,05$ & 6,06 & $P=0,52$ & 6,31 & $P=0,26$ \\
\hline Turbidez (NTU) & 6,55 & 1,23 & $\mathrm{P}<0,05$ & 1,35 & $\mathrm{P}<0,05$ & 1,83 & $P=0,06$ & 1,80 & $P=0,06$ \\
\hline Absorbância (254nm) & 0,27 & 0,23 & $\mathrm{P}<0,05$ & 0,23 & $P=0,54$ & 0,23 & $\mathrm{P}<0,05$ & 0,22 & $\mathrm{P}<0,05$ \\
\hline $\operatorname{COT}\left(\mathrm{mg} \mathrm{L}^{-1}\right)$ & 62,72 & 56,22 & $P=0,21$ & 56,19 & $P=0,21$ & 57,88 & $P=0,15$ & 56,40 & $P=0,23$ \\
\hline Nitrito $\left(\mathrm{mg} \mathrm{L}^{-1}\right)$ & 0,61 & 1,09 & $P=0,11$ & 1,23 & $P=0,06$ & 0,36 & $\mathrm{P}=0,17$ & 0,33 & $\mathrm{P}=0,15$ \\
\hline Nitrato $\left(\mathrm{mg} \mathrm{L}^{-1}\right)$ & 1,49 & 3,97 & $\mathrm{P}<0,05$ & 3,50 & $\mathrm{P}<0,05$ & 4,22 & $\mathrm{P}<0,05$ & 3,81 & $\mathrm{P}<0,05$ \\
\hline Fosfato $\left(\mathrm{mg} \mathrm{L}^{-1}\right)$ & 127,90 & 100,81 & $P=0,69$ & 105,06 & $\mathrm{P}=0,74$ & 105,45 & $\mathrm{P}=0,75$ & 91,18 & $P=0,59$ \\
\hline
\end{tabular}


Considerando o valor de P calculado para a remoção de coliformes totais (Figuras 3a e 3b), na fase 1 não houve diferença significativa entre os filtros F1 e F2, mas houve diferença significativa entre os tempos de coleta $\mathrm{S} 1$ e $\mathrm{S} 2$ ( $\mathrm{P}=0,0041$ para o $\mathrm{F} 1 ; \mathrm{P}=0,0042$ para o $\mathrm{F} 2$ ).

Os coliformes totais foram mais bem removidos em S1 (F1=89,2\%; F2=91,1\%) do que em S2 $(\mathrm{F} 1=68,7 \%, \mathrm{~F} 2=72,1 \%)$. Estes resultados estão de acordo com Campos e Outhwaite, (2014). Embora a hipótese fosse de que o aumento do tempo de retenção melhoraria a remoção de coliformes totais, a remoção melhorou com o aumento do numero de filtragens. Por exemplo, na fase 2, não houve diferença significativa entre F1 e F2 e nem entre os tempos de coleta S1 e S2. No entanto, em todos os casos na fase 2, a média de remoção de coliformes totais foi $>85 \%$. A diferença entre os tempos de coleta deixou de existir quando mais filtragens foram efetuadas.

Em relação à remoção de E. coli houve diferença significativa apenas entre os tempos de coleta no F2 (P = 0,0048), durante a fase 1, onde a remoção média foi de 97,6\% em S1 e $47,8 \%$ em S2.

Na fase 2, não houve diferença significativa entre F1 e F2 nem entre os tempos de coleta S1 e S2, sendo que a remoção de E. coli foi > 87\% para todos os casos. Tanto a remoção de coliformes totais como de $E$. coli foram variáveis nas fases 1 e 2 para F1 e F2 e para o tempo de coleta S2 (a água coletada no efluente referiu-se a água adicionada nos filtros no mesmo dia) embora as remoções tenham se tornado constantes após a $16^{\text {a }}$ filtração.

No geral, as remoções de coliformes totais e E. coli estão de acordo com trabalhos publicados sobre filtros lentos de areia para uso doméstico (NGAI et al., 2007; MWABI et al., 2012).

Como pode ser visto na Figura 4, a concentração de COT no efluente dos filtros variou na fase 2 se comparada com a fase 1, onde ocorreu um perfil mais constante das concentrações. Isto ocorreu provavelmente devido à contaminação PFCPs. Não foram observadas diferenças significativas de COT nos efluentes entre F1 e F2. Estes resultados estão de acordo com Campos et al., (2002).

Não houve diferença significativa de COT entre os filtros em $\mathrm{S} 1(\mathrm{P}=0,30$ para a fase 1; $\mathrm{P}=0,99$ para a fase 2) e nem em S2 ( $\mathrm{P}=0,44$ para a fase $1 ; \mathrm{P}=0,80$ para a fase 2 ) (Figura 3). Também não houve diferença significativade COT entre os tempos de coleta em F1 (P = $0,49$ para a fase $1 ; \mathrm{P}=0,78$ para a fase 2$)$ e nem em $\mathrm{F} 2(\mathrm{P}=0,31$ para a fase $1 ; \mathrm{P}=0,97$ para a fase 2). 
(a)

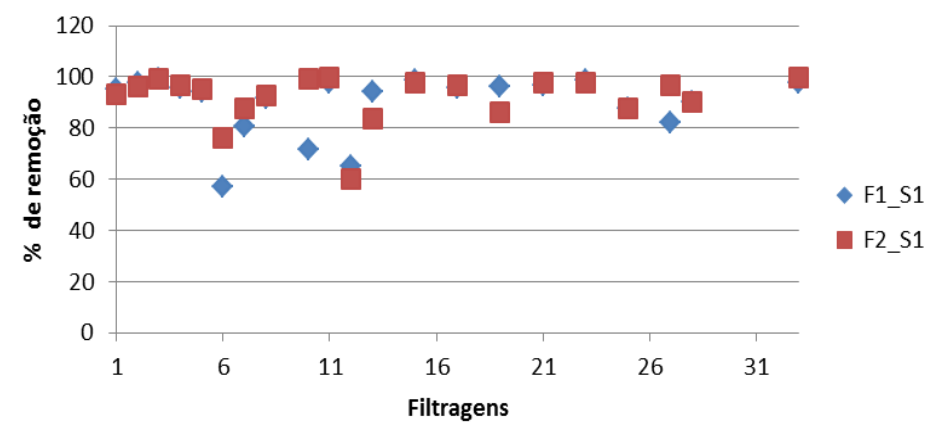

(c)

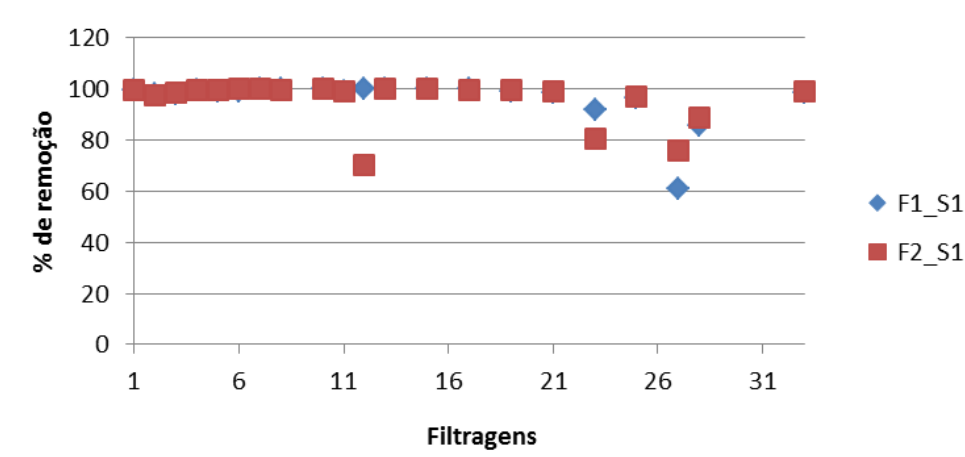

(b)

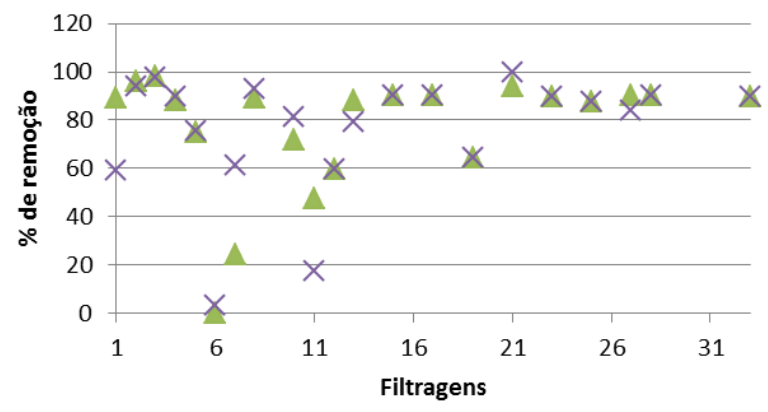

(d)

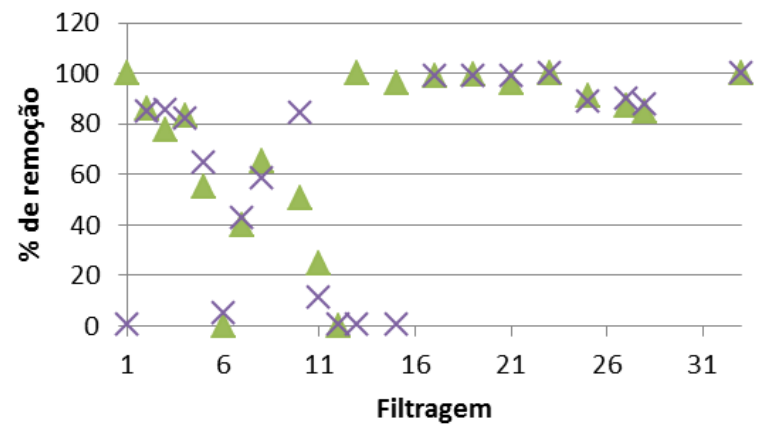

Figura 3: Remoção de coliformes totais na fase 1(filtrações de 1 a 21) e na fase 2 (filtrações de 22 a 33) nos tempos de coleta (a) S1 e (b) S2; e remoção de E. coli nos tempos de coleta (c) S1 e (d) S2.

(a)

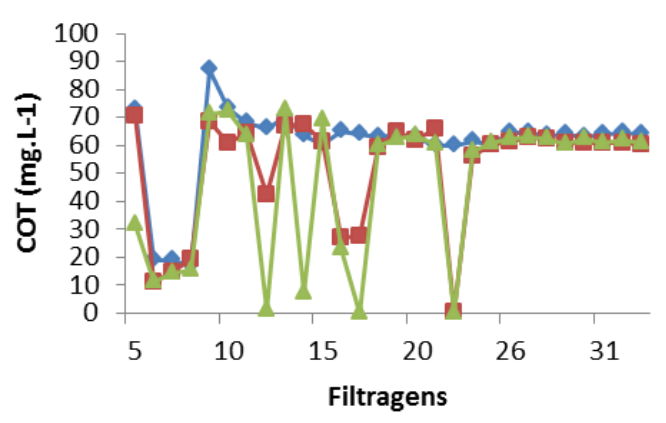

(b)

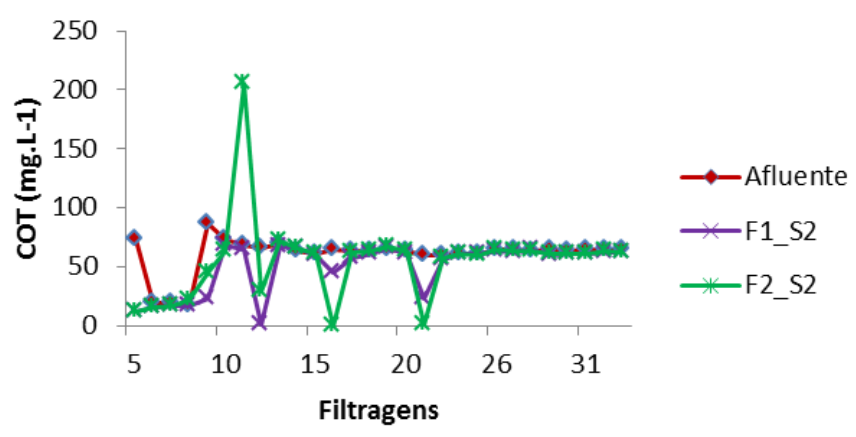

Figura 4: Remoção de COT na fase 1 (filtragens de 1 a 21) e na fase 2 (filtragens de 22 a 33) nos tempos de coleta (a) S1 e (b) S2.

\subsection{Comparação da composição bacteriana em filtros ecológicos domésticos, em dois modos operacionais diferentes.}

As amostras do biofilme foram coletadasem ambos os filtros, em três locais aleatórios, a fim de comparar a comunidade de bactérias que se desenvolveu nos dois filtros, na fase $1 \mathrm{e}$ na fase 2 (Tabela 4). Os pontos de coleta do biofilme de F1 durante a fase 1 correspondem a 
F1.1 a F1.3; para F2 correspondem a F2.4 a F2.6. Na fase 2, as coletas feitas no F1 correspondem a F1.7 a F1.9, e para o F2 correspondem a F2.10 para F2.12.

O resultado do BLAST para cada cepa está distribuído em presença e ausência para cada ponto de coleta, na Tabela 4. Para tal, a primeira opção do BLAST foi tomada, com similaridade de 99,9\% para cada cepa.

De acordo com outros estudos que investigaram a comunidade bacteriana presente no biofilme de filtros lentos de areia, a comunidade foi considerada rica em espécies no biofilme (PETRY-HANSEN et al., 2006; WAKELIN et al., 2010, 2011), mas muitas cepas não puderam ser isoladas (HUGENHOLTZ et al., 1998; CALVO-BADO et al., 2003a), e o material utilizado no filtro foi um fator-chave para determinar a ocorrência de espécies microbianas (WAKELIN et al., 2010). Com base no método de filtração adotado neste estudo, no total (fase 1 e 2), foi possível identificar 22 espécies de bactérias nas amostras de biofilme coletadas durante esta pesquisa, três não puderam ser isoladas - As cepas S8, S15, S18 (Tabela 4).

Tabela 4: Presença e ausência de cada cepa de bactéria em seus respectivos ponto de coleta, nas fases

1 e 2 .

\begin{tabular}{|c|c|c|c|c|c|c|c|c|c|c|c|c|c|}
\hline \multirow[b]{2}{*}{ Cepa } & \multirow[b]{2}{*}{$\begin{array}{l}\text { Vizinho filogenético mais } \\
\text { próximo }\end{array}$} & \multicolumn{6}{|c|}{ Fase 1 (Pontos de coleta) } & \multicolumn{6}{|c|}{ Fase 2 (Pontos de coleta) } \\
\hline & & F1.1 & F1.2 & $\mathrm{F} 1.3$ & $\mathrm{~F} 2.4$ & $\mathrm{~F} 2.5$ & $\mathrm{~F} 2.6$ & F1.7 & F1.8 & F2.9 & $\mathrm{F} 2.10$ & F2.11 & F2.12 \\
\hline S1 & Bacillus anthracis & $\mathrm{X}$ & $\mathrm{X}$ & $\mathrm{X}$ & $\mathrm{X}$ & $\mathrm{X}$ & $\mathrm{X}$ & & & & & $\mathrm{X}$ & \\
\hline S2 & Bacillus pumilus & & $\mathrm{X}$ & $\mathrm{X}$ & & & & & & & & & \\
\hline S3 & Enterobacterium bacterium & $\mathrm{X}$ & & $\mathrm{X}$ & & & & & & & & & \\
\hline S4 & Exiquobacterium sp. & $\mathrm{X}$ & & $\mathrm{X}$ & $\mathrm{X}$ & & & $\mathrm{X}$ & $\mathrm{X}$ & & & & \\
\hline S5 & Bacillus mycoides & & & & & $\mathrm{X}$ & & & & & & & \\
\hline S6 & Serratia ureilytica & & & & & $\mathrm{X}$ & & & & & & & \\
\hline S7 & Chryscobacterium sp. & & & & & $\mathrm{X}$ & & & & & & & \\
\hline S8 & Espécie não isolada & & & & & $\mathrm{X}$ & & & & & & & \\
\hline S9 & Stemotrophomonas rhizophila & & & & $\mathrm{X}$ & & & & & & & & \\
\hline $\mathrm{S} 10$ & Bacillus sp. & & & & $\mathrm{X}$ & & $\mathrm{X}$ & & & & & & \\
\hline S11 & Pseudomonas $s p$ & & & & & & & $\mathrm{X}$ & & $\mathrm{X}$ & $\mathrm{X}$ & & $\mathrm{X}$ \\
\hline S12 & Aeromonas sp. & & & & & & & $\mathrm{X}$ & $\mathrm{X}$ & & & & \\
\hline S13 & Bacillus toyonensis & & & & & & & & & & & & \\
\hline S14 & Bacillus megaterium & & & & & & & & & $\mathrm{X}$ & & & \\
\hline S15 & Espécie não isolada & & & & & & & & & $\mathrm{X}$ & & & \\
\hline S16 & Pseudomonas putida & & & & & & & & & & $\mathrm{X}$ & & \\
\hline S17 & Tolumonas osonensis & & & & & & & & & & & $\mathrm{X}$ & \\
\hline S18 & Espécie não isolada & & & & & & & & & & & $\mathrm{X}$ & $\mathrm{X}$ \\
\hline S19 & Bacillus Thuringiensis & & & & & & & & & & & $\mathrm{X}$ & \\
\hline S20 & Enterobacter ludeigii & & & & & & & & & & & $\mathrm{X}$ & \\
\hline S21 & Stenotrophomonas mattophilia & & & & & & & & & & & & $\mathrm{X}$ \\
\hline S22 & Delftia sp. & & & & & & & & & & & & $\mathrm{X}$ \\
\hline
\end{tabular}


Duas espécies, de nome Bacillus anthracis, e Exiquobacterium sp., foram encontradas no F1 (controle) e F2 (filtro contaminado) durante a fase 1. Isto sugere que estas espécies parecem ser resistentes aos PFCPs aplicados no F2. As espécies Bacillus pumilus e Enterobacterium bacterium estavam presentes apenas em F1 durante a fase 1, enquanto as demais seis espécies estiveram presentes apenas em F2 (a saber: Bacillus mycoides, Serratia ureilytica, Chryscobacterium sp, espécie não isolada, Stemotrophomonas rhizophila, Bacillus sp - Cepas S5 a S10) (Tabela 4). As espécies de bactérias presentes no biofilme do F1 foram diferentes das presentes no biofilme do F2 na fase 1, no entanto, para confirmar se esta diferença relaciona-se com a presença dos produtos farmacêuticos e de cuidados pessoais no afluente do F2, mais testes devem ser conduzidos.

$\mathrm{Na}$ fase 2, sem contaminação da água afluente ao F2 com PFCPs, 12 diferentes espécies foram observadas, sendo que 10 foram identificadas e dois não puderam ser isoladas, que é mais do que na fase 1. Do total, apenas duas espécies que estavam presentes na fase 1 permaneceram na a fase 2 (Bacillus anthracis, e Exiquobacterium sp.). As outras 10 espécies eram diferentes, de modo que estes resultados indicam que a comunidade de bactérias na fase 1 foi diferente das encontradas na fase 2. No entanto, não significa necessariamente que essa diferença está relacionada com o modo de operação dos filtros, mas pode estar associada à idade dos filtros. De acordo com Haig et al., (2015), a composição da comunidade microbiana em filtros lentos de areia foi significativamente diferente, dependendo de vários fatores, tais como: localização da amostra, mês da coleta de amostra, profundidades em que as amostras foram coletadas, sendo a idade do filtro o parâmetro mais importante em explicar as mudanças na comunidade microbiana. Além disso, a diversidade de espécies de bactérias que colonizam o biofilme e sua composição dependem da qualidade da água afluente aos filtros. Um exemplo disso pode ser visto ao comparar o trabalho feito por Calaway et al., (1952) e Brink, (1967) que utilizaram águas residuais, com uma carga mais elevada de nutrientes. Os autores encontraram baixa diversidade de bactérias. Bahgat et al., (1999) encontraram maior diversidade de espécies de bactérias no biofilme de filtros lentos de areia abastecidos com água de esgoto que passou por tratamento primário, do que a diversidade descrita por Wakeling et al. (2011) que usou a água da chuva como afluente.

As espécies Bacillus anthracis e Exiquobacterium sp. que estiveram presentes nas fases 1 e 2 eram as mesmas que apresentaram resistência a compostos farmacêuticos e de cuidados pessoais, quando compara-se as bactérias isoladas em F1 e F2 durante a fase 1 (Tabela 4), o que sugere a capacidade destas espécies para a adaptação e a resistência à contaminação, além do fator do tempo de operação. 
A análise dos componentes principais (PCA), que considerou a fase 1 e 2 e o local de amostragem do biofilme em cada filtro (Tabela 4), resumiu 64,1\% da variabilidade conjunta dos dados nos dois primeiros eixos (Figura 5). No lado positivo do eixo 2 (eixo X), estão agrupados os pontos referentes aos pontos de coleta de biofilme no F1 e F2 na fase 1. Isto indica que estas amostras são semelhantes entre si, e que não houve diferença entre os filtros controle e contaminado.

No lado negativo do eixo 1 estão algumas amostras de biofilme relacionadas com F1 e F2 coletadas na fase 2 (F1.7, F1.9, F2.10 e F2.12), mostrando similaridade entre as amostras destes pontos.

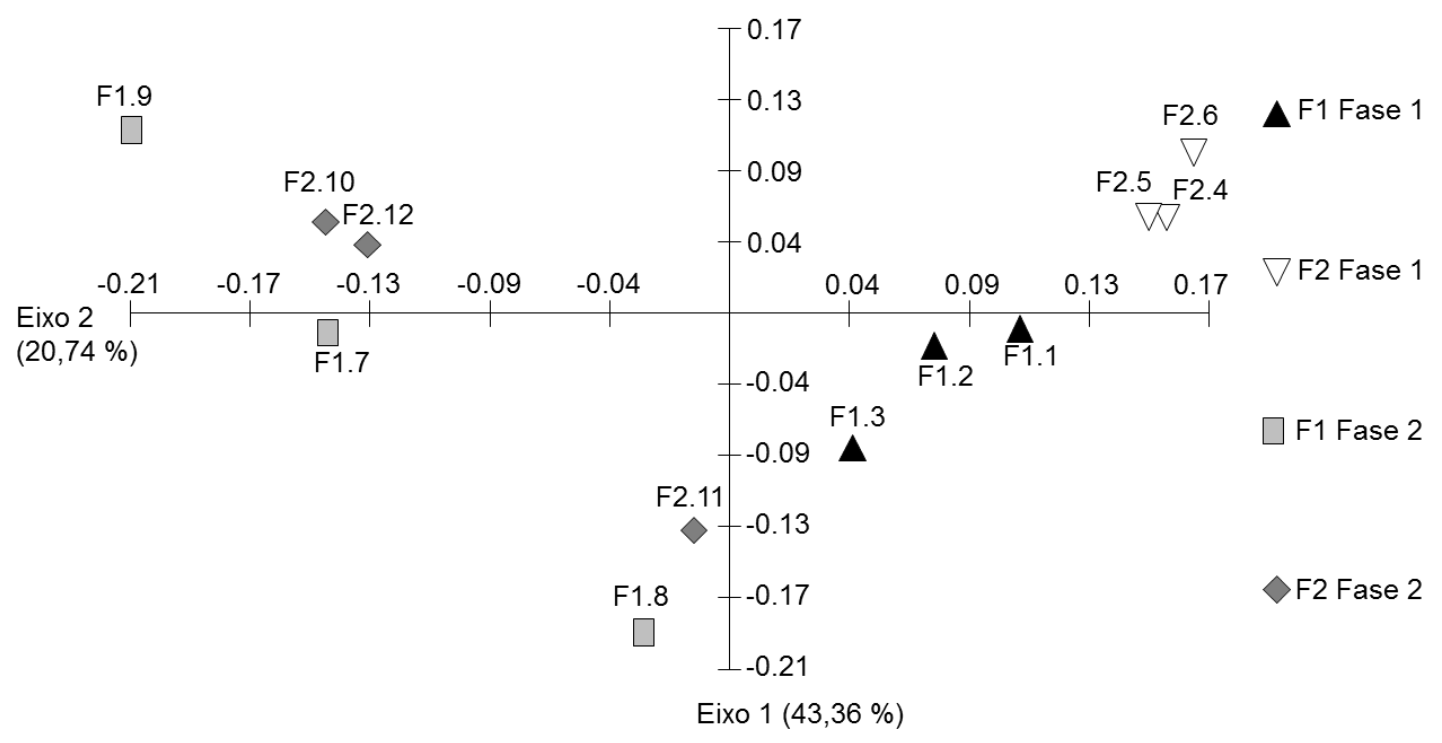

Figura 5: Gráfico de PCA (Análise dos Principais componentes) para as amostras das cepas isoladas em cada ponto de coleta de cada filtro, na fase 1 e 2 .

No lado negativo do eixo 1 estão agrupadas F1.8 e F2.11, coletadas na fase 2. Observa-se similaridade entre F1.7 e F1.9; F2.10 e F.12; F1.8 e F2.11 na fase 1. As similaridades citadas mostra que houve semelhança entre alguns locais aleatórios de amostragem do biofilme, em ambas as fases. No entanto, a comunidade de bactérias na fase 1 foi diferente da presente na fase 2, pois F1.1, F1.2, F1.3, F2.4, F2.5 e F2.6 (todos pontos de coleta durante a fase 1) agruparam-se no lado direito do gráfico, em contraste com F1.7, F1.8, F1.9, F2.10, F2.11 e F2.12 (fase 2) agrupados no lado esquerdo do gráfico da PCA (Figura 4). 


\subsection{Biomassa}

A concentração de biomassa aumentou significativamente com o tempo de operação e foi resumida por uma função de crescimento exponencial ( $\mathrm{P}<0,0001$ para $\mathrm{F} 1, \mathrm{P}<0,001$ para F2) em ambos os filtros, mas não houve diferença significativa entre eles $(P=0,76)$. No entanto, durante a fase 1 (21 filtrações), a concentração de biomassa (F1 = 46,45 $\mathrm{g} \mathrm{C} \mathrm{g}^{-1}$; F2 = $\left.50,08 \mathrm{~g} \mathrm{C} \mathrm{g}^{-1}\right)$ foi menor do que a média na fase $2\left(\mathrm{~F} 1=94,96 \mathrm{~g} \mathrm{C} \mathrm{g}^{-1} ; \mathrm{F} 2=90,93 \mathrm{~g} \mathrm{C} \mathrm{g}^{-1}\right)$ (Figura 6) em ambos os filtros. Esses valores são maiores do que os observados por Campos et al., (2002) em filtros lentos de areia de grande escala, e isto pode ser devido à qualidade da água afluente.

Neste estudo foi utilizada a água bruta do lago do Regent's Park, enquanto que Campos et al., (2002) coletaram amostras do schmutzdecke de filtros lentos de areia em grande escala, que fazia parte de um tratamento de água avançado envolvendo pré-tratamento pelo reservatório, pré-ozonização, flotação, filtração rápida, ozonização intermediária e carvão granular ativado. Também durante a fase 2 (12 filtrações), uma floração de algas foi observada no lago do Regent's Park, e isso explica o considerável aumento da biomassa da fase 1 (21 filtrações) para a fase 2 (12 filtrações). É importante notar que os filtros não foram limpos entre as fases 1 e 2 , e a ocorrência do desenvolvimento de perda de carga não foi significativa durante o tempo de operação.

Durante a fase 1 o filtro F2, que recebeu a contaminação por PPCPs, apresentou maior valor de biomassa no final das carreiras de filtração, do que o F1 (controle). Isto está de acordo com os resultados de sequenciamento genético de bactérias realizado (Figura 5), em que maior número de espécies foram isoladas e identificadas em F2 filtro durante a fase 1.

(a)

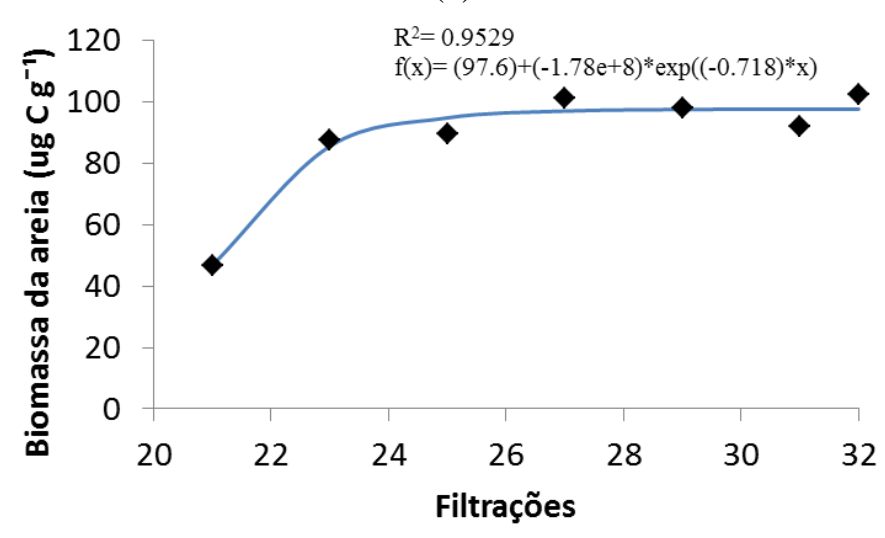

(b)

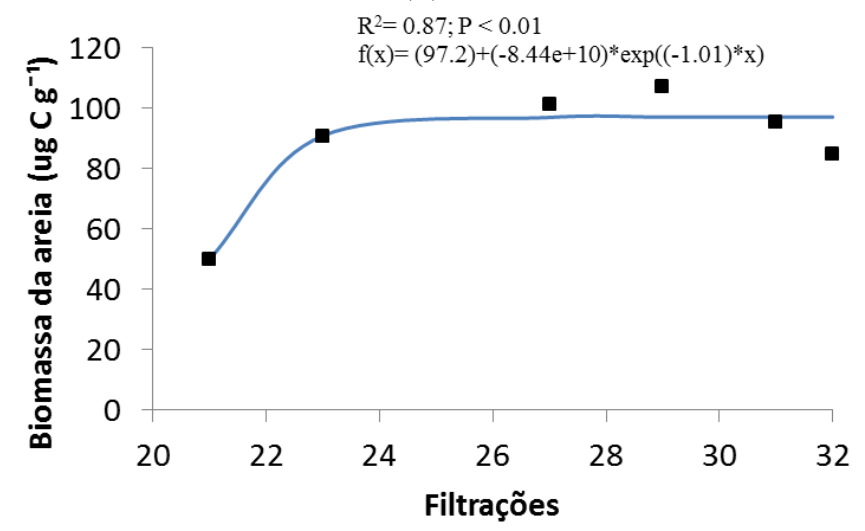

Figura 6: Gráfico da concentração de biomassa: a) no filtro 1 (F1) e b) no filtro 2 (F2). 


\section{Conclusões}

O desempenho dos filtros ecológicos de uso doméstico não foi afetado pela presença de $2 \mu \mathrm{g} \mathrm{L}^{-1}$ de PFCPs na água afluente. Para remoção de coliformes totais e de E. coli na fase 1, não houve diferença significativa entre filtros F1 e F2, mas não ocorreu diferença considerável entre os tempos de coleta (S1 e S2).

Maior tempo de retenção de água no filtro (S1) gerou melhores remoções de coliformes totais e E. coli, do que na coleta S2 referente a água filtrada no mesmo dia. No entanto, a água remanescente e parada nos filtros por mais de 24 horas causou baixa quantidade de OD na água efluente, causadas devido a respiração microbiana, porém os valores de efluentes foram acima do mínimo $\left(3 \mathrm{mg} \mathrm{L}^{-1}\right)$ recomendado por Huisman e Wood (1974).

Foram sequenciados maior número de espécies de bactérias na fase 2 (operação normal) do que na fase 1 , que recebeu contaminação por PFCPs e teve operação com torneira e pausas. As espécies Bacillus anthracis, e Exiquobacterium sp., pareceram ser resistentes aos compostos aplicados ao F2, na concentração de $2 \mu \mathrm{g} \mathrm{L}^{-1}$, pois ambos foram encontrados no filtro F1 (controle) e no F2 (filtro contaminado) durante a fase 1 (1-21 filtrações). As demais espécies de bactérias sequenciadas foram diferentes no F1 e no F2.

Na fase 2 (22-33 filtrações), sem contaminação por PFCPs e sem pausa do fluxo, 12 espécies foram isoladas e sequenciadas, mas apenas 2 espécies estavam presentes na fase 1 , ou seja, Bacillus anthracis, e Exiquobacterium sp. As outras 10 espécies foram diferentes, de modo que estes resultados indicam que a comunidade de bactérias presente no biofilme dos filtros no final da fase 1 foi diferente da presente nos filtros no final da fase 2. Isto pode ser relacionado com a idade dos filtros, embora a diferença entre a comunidade de bactérias entre os filtros e as fases não afetou a qualidade da água tratada pelos filtros.

A concentração de biomassa nos filtros aumentou significativamente com o tempo e foi resumida por uma função exponencial de crescimento em ambos os filtros, mas não houve nenhuma diferença significativa entre eles.

Durante a fase 1, o filtro F2 (contaminado) mostrou concentração de biomassa ligeiramente mais elevada no final das filtraçõesno F1 (controle). Isto está de acordo com o sequenciamento genético de bactérias realizado (Figura 5), em que maior número de espécies foram isoladas e identificadas no F2 durante a fase 1; todavia, o efeito dos PFCPs sobre a biomassa não é determinante neste estudo.O biofilme do filtro ecológico para uso doméstico, 
assim como ocorre para os de grande escala, é parte fundamental e complexa do processo de filtração.

\section{Referências Bibliográficas}

APHA. Standard Methods for the Examination of Water \& Wastewater: 21 st ed., American Technical Publishers, New York, USA, 2005.

BAHGAT, M., DEWEDAR, A., \& ZAYED, A. Sand-filters used for wastewater treatment: buildup and distribution of microorganisms. Water Research, v. 33(8), p. 1949-1955, 1999.

BERTELKAMP, C. REUNGOAT, J., CORNELISSEN, E.R., SINGHAL, N., REYNISSON, J., CABO, A.J., VAN DER HOEK, J.P., VERLIEFD, A.R.D. Sorption and biodegradation of organic micropollutants during river bank filtration: A laboratory column study. Water Research, v. 52, p. 231-241, 2014.

BLAST - Basic local Alignment Search Tool. Avaliable online: http://blast.ncbi.nlm.nih.gov (acesso em 25 de janeiro de 2015).

BOXALL, A. B.A., et al. Pharmaceuticals and Personal Care Products in the Environment: What Are the Big Questions? Environmental Health Perspectives, v. 120I9, p.1221-1229, 2012.

BRINK, N. Ecological studies in biological filters. Int. Revue Ges. Hydrobiology. v. 52, p. 51-122, 1967.

CALAWAY, W. T., CARROLL, W. R. \& LONG, S. K. Heterotrophic bacteria encountered in intermittent sand filtration of sewage. Sewage Ind. Wastes. v. 24, p. 642-653, 1952.

CALVO-BADO, L. A., PETTITT, T. R., PARSONS, N., PETCH, G. M., MORGAN, J. A. W.; WHIPPS, J. M. Spatial and temporal analysis of the microbial community in slow sand filters used for treating horticultural irrigation water. Applied and environmental microbiology, v. 69(4), p. 2116$2125,2003$.

CAMPOS, L.C. AND OUTHWAITE, R. Performance optimisation of household biosand filters. In: Progress in Slow Sand and Alternative Biofiltration Processes.Nakamoto, N., Graham, N., Collins, M.R., Gimbel, R., p.331-338, 2014.

CAMPOS, L.C.; SU, M.F.J.; GRAHAM, N.J.D.; SMITH, S.R. Biomass development in slow sand filters. Water research v. 36, p. 4543-4551, 2002.

CAWST -Centre for Affordable Water and Sanitation Technology. Annual Report; CAWST: Alberta, $\mathrm{AB}$, Canada, 1-32, 2012. 
CHAN, L., RECEVEUR, O. BATAL, M., DAVID, W., SCHWARTZ, H., ING, A., FEDIUK, K., BLACK, A, TIKHONOV, C. First Nations Food, Nutrition and Environment Study (FNFNES): Results from Ontario (2011/2012). Ottawa: University of Ottawa, p.229, 2014.

DRURY, B., SCOTT, J., ROSI-MARSHALL, E.J. KELLY, J.J. Triclosan exposure increases triclosan resistance and influences taxonomic composition of benthic bacterial communities. Environmental Science and Technology, v. 47, p. 8923-8930, 2013.

ERBA, C.M., TANGERINO, E.P., ISIQUE, W.D., CAMPOS, L.C. (2014). Removal of AntiInflamatory Compounds by Ecological Filtration. In: Progress in Slow Sand and Alternative Biofiltration Processes. Nakamoto, N., Graham, N., Collins, M.R., Gimbel, R. 1ed.: IWA publishing. v. 5(19), p. 147-152, 2014.

European Union Council Directive, 1998. 98/83/EC of 3 November 1998 relative to the quality of drinking water. Off. J. Eur. Commun., 330e332, 1998.

HAIG S-J, QUINCE C, DAVIES RL, DOREA CC, COLLINS G. The relationship between microbial community evenness and function in slow sand filters. mBio v. 6(5), p. e00729-15, 2015.

HAIG, S.J, COLLINS G, DAVIES, R.L, DOREA, C, AND QUINCE C. Biological aspects of slow sand filtration: past, presente and future. Water Science and Technology: Water Supply, v. 11(4), p. 468-472, 2011.

HAIG, S.J, QUINCE, C, DAVIES, R.L, DOREA, C.C, AND COLLINS, G. Replicationg the microbial community and water qaulity performance of full scale filters in laboratory-scale filters. Water Research v. 61, p. 141-151, 2014.

HALLE, C. Biofiltration in Drinking Water Treatment: Reduction of Membrane Fouling and Biodegradation of Organic Trace Contaminants. PhD Thesis, University of Waterloo, Canada, 2009.

HARADA, A., KOMORI, K., NAKADA, N., KITAMURA, K., SUZUKI, Y. Biological effects of PPCPs on aquatic lives and evaluation of river waters affected by different wastewater treatment levels. Water Science \& Technology_WST, v. 58(8), p.1541-1546, 2008.

HUGENHOLTZ, P., GOEBEL, B. M., PACE, N. R. Impact of culture-independent studies on the emerging phylogenetic view of bacterial diversity.Journal of bacteriology, v. 180(18), p. 4765-4774, 1998.

HUISMAN, L.; WOOD, W. Slow sand filtration. World Health Organization, Geneva, Switzerland, 1974.

HWANG, H.G, KIM, M.S, SHIN, S.M, AND HWANG, C.H. Risk Assessment of the Schmutzdecke of Biosand Filters: Identification of an Opportunistic Pathogen in schmutzdecke Developed by an Unsafe Water Source. Int. J. Environ. Res. Public Healthv. 11, p. 2033-2048, 2014. 
JONES, O.A.; LESTER, J.N.; VOULVOULIS, N. Pharmaceuticals: a threat to drinking water? Trends in Biotechnology. v. 23, p. 163-167, 2005.

KAISER, N.; LIANG, K.; MAERTENS, M.; SNYDER, R. Biosand Household Water Filter Evaluation 2001; Samaritan's Purse Canada: Calgary, Canada, 2002.

KÜMMERER, K. (Ed.). Pharmaceuticals in the environment: sources, fate, effects and risks. Springer Science \& Business Media, 2008.

LANE, D. J., B. PACE, G. J. OLSEN, D. A. STAHL, M. L. SOGIN, AND N. R. PACE. Rapid determination of 16S ribosomal RNA sequences for phylogenetic analyses. Proc. Natl. Acad. Sci. USAv. 82, p. 6955-6959, 1985.

LEA, M. Biological Sand Filters: Low-Cost Bioremediation Technique for Production of Clean Drinking Water. In Current Protocals in Microbiology, John Wiley \& Sons, 2014.

MWABI, J.K., MAMBA, B.B., MOMBA, M.N.B. Removal of Escherichia coli and Faecal Coliforms from Surface Water and Groundwater by Household Water Treatment Devices/Systems: A Sustainable Solution for Improving Water Quality in Rural Communities of the Southern African Development Community Region. Int. J. Environ. Res. Public Health.v. 9, p. 139-170, 2012.

NAKAMOTO, N. Food chain is the key in ecological purification system: new concept and new name of slow sand filter. In: Nobutada Nakamoto, Nigel Graham, M. Robin Collins and Rolf Gimbel. (Org.). Progress in slow sand and alternative biofiltration process. 1ed.: IWA publishing, v. 5(9), p. 77-84, 2014.

NGAI, T., SHRESTHA, R., DANGOL, B., MAHARJAN, M. AND MURCOTT, S. Design for Sustainable Development - Household drinking water filter for arsenic and pathogen treatment in Nepal, Journal of Environmental Science and Health Part A, v. 42, p. 1879 - 1888, 2007.

Petry-Hansen, H., Steele, H., Grooters, M., Wingender, J., \& Flemming, H. C. 17 Faecal contamination indicator organisms in slow sand filters. Recent Progress in Slow Sand and Alternative Biofiltration Processes, p. 143, 2006.

QIAO, T., YU, Z., ZHANG, X., AU, D. W. T. Occurrence and fate of pharmaceuticals and personal care products in drinking water in southern China. J. Environ. Monit., v. 13(11), p. 3097-3103, 2011.

RIGOBELLO, E. S., DANTAS, A.D., DI BERNARDO, L., VIEIRA, E.M. Removal of diclofenac by conventional drinking water treatment processes and granular activated carbon filtration.

Chemosphere v. 92, p. 184-191, 2013.

ROOKLIDGE, S. J., BURNS, E. R., \& BOLTE, J. P. Modeling antimicrobial contaminant removal in slow sand filtration. Water research, v. 39(2), p. 331-339, 2005. 
ROSI-MARSHALL, E., SNOW, D., BARTELT-HUNT, S.L., PASPALOF, A., TANK, J.L. A review of ecological effects and environmental fate of illicit drugs in aquatic ecosystems. J Hazard Mater., v. 282, p.18-25, 2015.

ROSI-MARSHALL, E.J., KINCAID, D.W., BECHTOLD, H.A., ROYER, T.V., ROJAS, M., KELLY, J.J. Pharmaceuticals suppress algal growth and microbial respiration and alter bacterial communities in stream biofilms. Ecol Appl., v. 23(3), p. 583-93, 2013.

SUI, Q., CAO, X., LU, S., ZHAO, W., QIU, Z., YU, G. Occurrence, sources and fate of pharmaceuticals and personal care products in the groundwater: A review. Emerging Contaminants, v.1(1), p. 14-24, 2015.

UNGER, M.; COLLINS, M. R. (2008). Assessing Escherichia coli removal in the schmutzdecke of slow-rate biofilters. American Water Works Association. Journal, v. 100(12), 60, 2008.

VULLIET, E., CREN-OLIVÉ, C. Screening of pharmaceuticals and hormones at the regional scale, in surface and groundwaters intended to human consumption. Environmental Pollution v. 159, p. 29292934, 2011.

WAKELIN, S. A.; PAGE, D.W.; PAVELIC, P.; GREGG, A. L.; DILLON, P. J. Rich microbial communities inhabit water treatment biofilters and are differentially affected by water type and sampling depth. Water Science and Technology: water supply. v.10, p. 145-156, 2010.

WAKELIN, S., PAGE, D., DILlON, P., PAVELIC, P., ABELL, G.C.J., GREGG, A.L., BRODIE, E., DESANTIS, T.Z., GOLDFARB, K.C., ANDERSON, G. Microbial community structure of a slow sand filter Schmutzdecke: a phylogenetic snapshot based on rRNA sequence analysis. Water Science Technology. v.11, p. 426-436, 2011.

WHO (2016). Results of round I: of the WHO International Scheme to Evaluate Household Water Treatment Technologies. Geneva: World Health Organization;

(http://www.who.int/household_water/scheme/household-water-treatment-report-round-1/en/, accessed 08/03/2016). 


\section{Conclusões gerais}

A partir da análise dos resultados obtidos com este estudo, estabeleceram-se as seguintes conclusões gerais:

- Apesar da contaminação do Reservatório do Lobo com grade concentração de coliformes fecais e Escherichia Coli, os 22 filtros ecológicos confeccionados apresentaram boa remoção destes contaminantes. Em média a turbidez e a cor aparente no efluente dos filtros ecológicos não estiveram nos padrões de potabilidade estabelecidos no Brasil em decorrência da qualidade da água a ser tratada. Para melhor desempenho e resultado no tratamento da água do Reservatório do Lobo por filtros ecológicos, a inclusão de um pré-tratamento é indicada.

- Considera-se aplicável o sistema de purificação ecológica para tratamento de água no Brasil, pois é uma alternativa com baixo custo, que fornece água tratada naturalmente, de fácil operação, não necessitando de mão de obra especializada. Pode ser utilizada em grande escala ou para uso doméstico. Além disso, foi descrito na literatura que levando em conta a área total ocupada por estações de tratamento que utilizam filtração rápida comparado com estações que usam filtração lenta, as estações praticamente se igualam.

- A ocorrência dos seis produtos farmacêuticos e de cuidados pessoais avaliados no Reservatório do Lobo reflete a contaminação como resultado das atividades antrópicas no entorno. Os produtos de cuidados pessoais (metilparabeno e benzofenona-3) estiveram presentes em todas as amostras de água coletadas e foram os compostos detectados em maior concentração no Reservatório do Lobo.

- Os filtros ecológicos apresentaram bons resultados na remoção dos PFCPs aplicados, sendo que os compostos farmacêuticos tiveram melhor remoção pelos filtros ecológicos do que os produtos de cuidados pessoais.

- Houve efeito na comunidade de algas e cianobactérias diante da presença dos produtos farmacêuticos e de cuidados pessoais na água a ser tratada pelos filtros ecológicos. As espécies Aulacoseira granulata, Chroococcus minutus, Dolichospermum planctonicum e Microcystis aeruginosa que foram consideradas como descritoras em comum para todas as contaminações e tempos de coleta. A espécie que mais contribuiu durante o período, com maior porcentagem, foi Lepocincles sp. 
(Euglenophyceae). A ocorrência, abundância e frequência destas espécies indicam uma possível tolerância das mesmas aos PFCPs aplicados.

- O desempenho dos filtros ecológicos de uso doméstico não foi afetado pela presença de $2 \mu \mathrm{g} \mathrm{L}^{-1}$ de produtos farmaceuticos e de cuidados pessoais na água afluente. As espécies de bactérias Bacillus anthracis, e Exiquobacterium sp., foram resistentes aos compostos aplicados.

- Apesar da presença dos contaminantes estudados não afetarem o desempenho dos filtros ecológicos na concentração em que foram aplicados, tanto em grande escala como os domésticos, foi observado efeito nas comunidades de algas e cianobactérias e bactérias, com modificações na composição destas comunidades do biofilme. 


\section{Considerações finais e recomendações}

Os fármacos e os produtos de cuidados pessoais fazem parte do cotidiano da população mundial e são importantes para o aumento da expectativa e qualidade de vida das pessoas. Porém fatores como os avanços do mercado farmacêutico, o uso indiscriminado, a facilidade na compra de grande parte destes, e a falta de tratamento dos resíduos de forma adequada geram a contaminação do ambiente aquático com estes produtos e as consequências para o meio ambiente e a saúde humana ainda não são conhecidas.

Além dos compostos originais, produtos de degradação do diclofenaco e da benzofenona-3 foram encontrados no Reservatório do Lobo, conforme os trabalhos da literatura que explicam que os compostos são degradados no ambiente por fotodegradação, biodegradação, dentre outros, e as consequências ainda são desconhecidas.

O monitoramento e conhecimento dos compostos presentes nos corpos dagua é de fundamental importância para que os estudos sejam conduzidos a fim de reduzir os impactos ambientais e na saúde humana.

Diante da presença destes e outros contaminantes na água de consumo, são importantes avaliações de métodos de tratamento da água. Neste estudo os filtros ecológicos apresentaram bons resultados na remoção do paracetamol, diclofenaco, naproxeno, ibuprofeno, metilparabeno e benzofenona-3.

O biofilme é o compartimento essencial do tratamento ecológico da água e com os resutados deste estudo, observou-se que houve um efeito nas comunidades de algas e cianobactérias e de bactérias diante da presença dos compostos estudados na água afluente aos filtros, referentes à composição das comunidades em espécie. Neste estudo, a concentração aplicada não afetou o desempenho dos filtros em tratar a água, mas acredita-se que a concentração em que foram aplicados não ocasionou grandes efeitos.

Como recomendações para trabalhos futuros, no caso do uso da água do Reservatório do Lobo para o tratamento ecológico da água, indica-se a inclusão de um pré-tratamento da água antes da mesma ser tratada por filtros ecológicos, como o pré-filtro de fluxo ascendente.

Para estudos dos produtos de degradação gerados pelos filtros ecológicos, recomendam-se ensaios com água que não esteja contaminada com produtos farmaceuticos e de cuidados pessoais ou outros compostos, para que seja possível a avaliação individual de cada composto gerado. 
Indica-se também que os compostos sejam adicionados na água afluente em maior concentração para que seja mais facilmente detectado pelo equipamento, ou o uso de LCMS/MS mais sensível.

Sugerem-se também como trabalhos futuros o estudo da concentração limite dos compostos que os filtros ecológicos conseguem tratar, para delimitar a aplicabilidade deste tratamento para águas contaminadas com os respectivos compostos.

Os efeitos dos compostos na comunidade biológica dos filtros precisa ser melhor investigada e de possíveis espécies que podem estar relacionadas com a biodegradação destes compostos, para que seja delimitada a aplicabilidade do sistema. 


\section{Anexos}

Tabela A.1. Resultado das análises de correlação (r) e de regressão entre os parâmetros aferidos no efluente dos filtros.

\begin{tabular}{|c|c|c|c|c|c|c|c|c|c|c|c|c|c|c|c|c|c|c|}
\hline & \multicolumn{2}{|c|}{ Temperatura } & \multicolumn{2}{|c|}{ TDS } & \multicolumn{2}{|c|}{$\begin{array}{c}\text { Condutividade } \\
\text { elétrica }\end{array}$} & \multicolumn{2}{|c|}{$\mathrm{pH}$} & \multicolumn{2}{|c|}{ Turbidez } & \multicolumn{2}{|c|}{ Cor aparente } & \multicolumn{2}{|c|}{$\begin{array}{c}\text { Cor } \\
\text { verdadeira }\end{array}$} & \multicolumn{2}{|c|}{ OD } & \multicolumn{2}{|c|}{$\begin{array}{c}\text { Coliformes } \\
\text { totais }\end{array}$} \\
\hline & $\mathrm{r}$ & $\mathrm{P}$ & $\mathrm{r}$ & $\mathrm{P}$ & $\mathrm{r}$ & $\mathrm{P}$ & $\mathrm{r}$ & $\mathrm{P}$ & $\mathrm{r}$ & $\mathrm{P}$ & $\mathrm{r}$ & $\mathrm{P}$ & $\mathrm{r}$ & $\mathrm{P}$ & $\mathrm{r}$ & $\mathrm{P}$ & $\mathrm{r}$ & $\mathrm{P}$ \\
\hline \multicolumn{19}{|l|}{ Temperatura } \\
\hline TDS & 0,27 & 0,14 & & & & & & & & & & & & & & & & \\
\hline Condutividade & 0,30 & 0,10 & 0,98 & $<0,001$ & & & & & & & & & & & & & & \\
\hline $\mathrm{pH}$ & 0,35 & $\mathbf{0 , 0 5}$ & 0,18 & 0,33 & 0,22 & 0,23 & & & & & & & & & & & & \\
\hline Turbidez & 0,07 & 0,71 & $-0,11$ & 0,55 & $-0,08$ & 0,63 & $-0,30$ & 0,10 & & & & & & & & & & \\
\hline Cor aparente & 0,11 & 0,53 & $-0,19$ & 0,30 & $-0,17$ & 0,34 & $-0,23$ & 0,20 & 0,93 & $<0,001$ & & & & & & & & \\
\hline Cor verdadeira & $-0,25$ & 0,21 & 0,18 & 0,38 & 0,21 & 0,29 & $-0,49$ & $\mathbf{0 , 0 1}$ & 0,40 & 0,04 & 0,35 & 0,08 & & & & & & \\
\hline OD & $-0,35$ & 0,23 & $-0,05$ & 0,84 & $-0,06$ & 0,84 & 0,49 & 0,08 & 0,31 & 0,29 & 0,35 & 0,23 & 0,52 & 0,06 & & & & \\
\hline Coliformes totais & $-0,33$ & 0,28 & $-0,12$ & 0,70 & $-0,10$ & 0,75 & $-0,18$ & 0,55 & 0,50 & 0,08 & 0,43 & 0,14 & 0,57 & 0,11 & $-0,08$ & 0,89 & & \\
\hline E.coli & $-0,14$ & 0,66 & 0,39 & 0,19 & 0,36 & 0,23 & 0,00 & 0,99 & $-0,01$ & 0,97 & $-0,02$ & 0,95 & $-0,14$ & 0,71 & $-0,37$ & 0,47 & 0,19 & 0,54 \\
\hline
\end{tabular}

$\mathrm{r}=$ coeficiente de correlação; $\mathrm{P}=$ significância. 
Figura A.1. Gráfico de distribuição particular da areia utilizada nos filtros ecológicos domésticos.

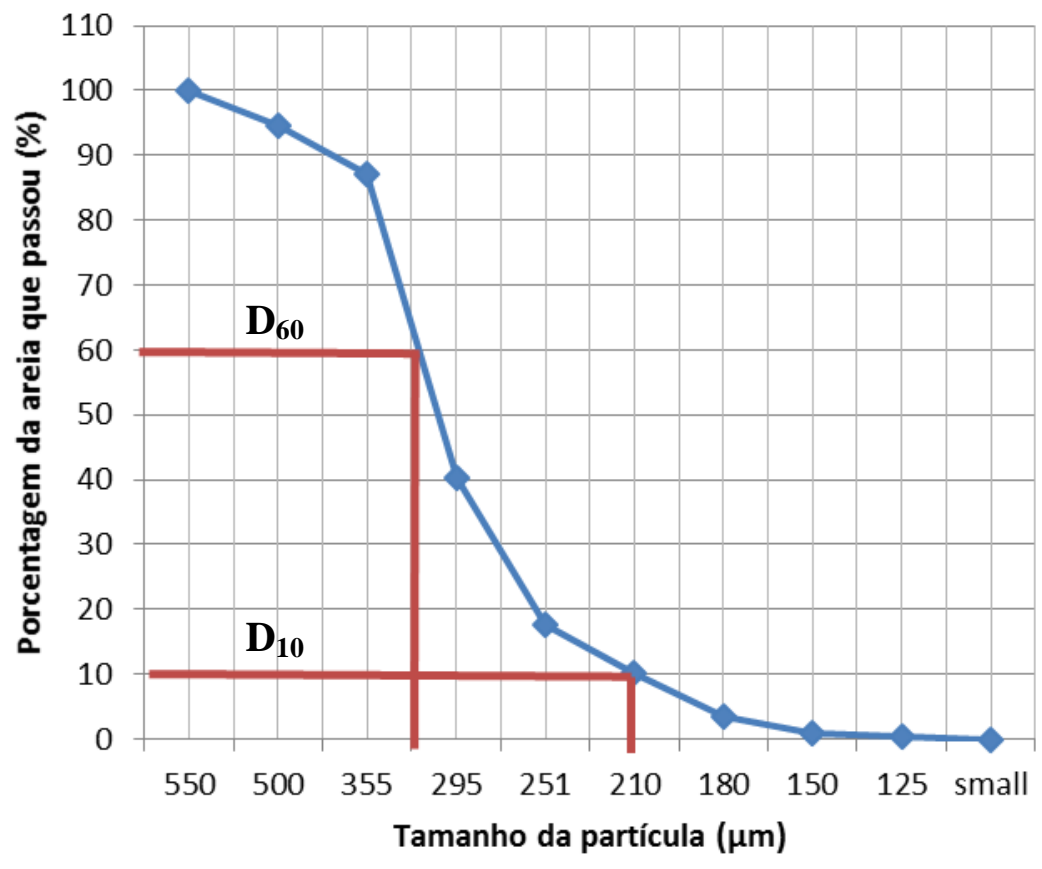

Figura A.2. Curva de calibração das amostras submetidas a PCR.

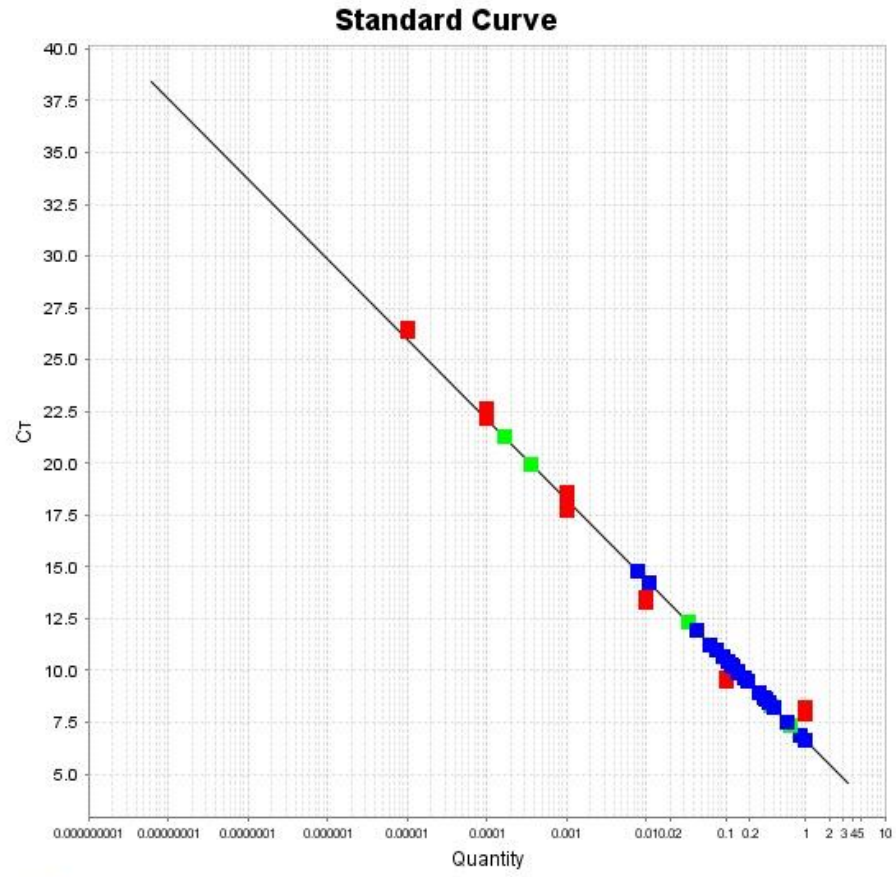

Standard $\square$ Unknown Unknown (Flagged) 
Figura A.3. Bloom de algas e cianobactérias no lago do Regents park.

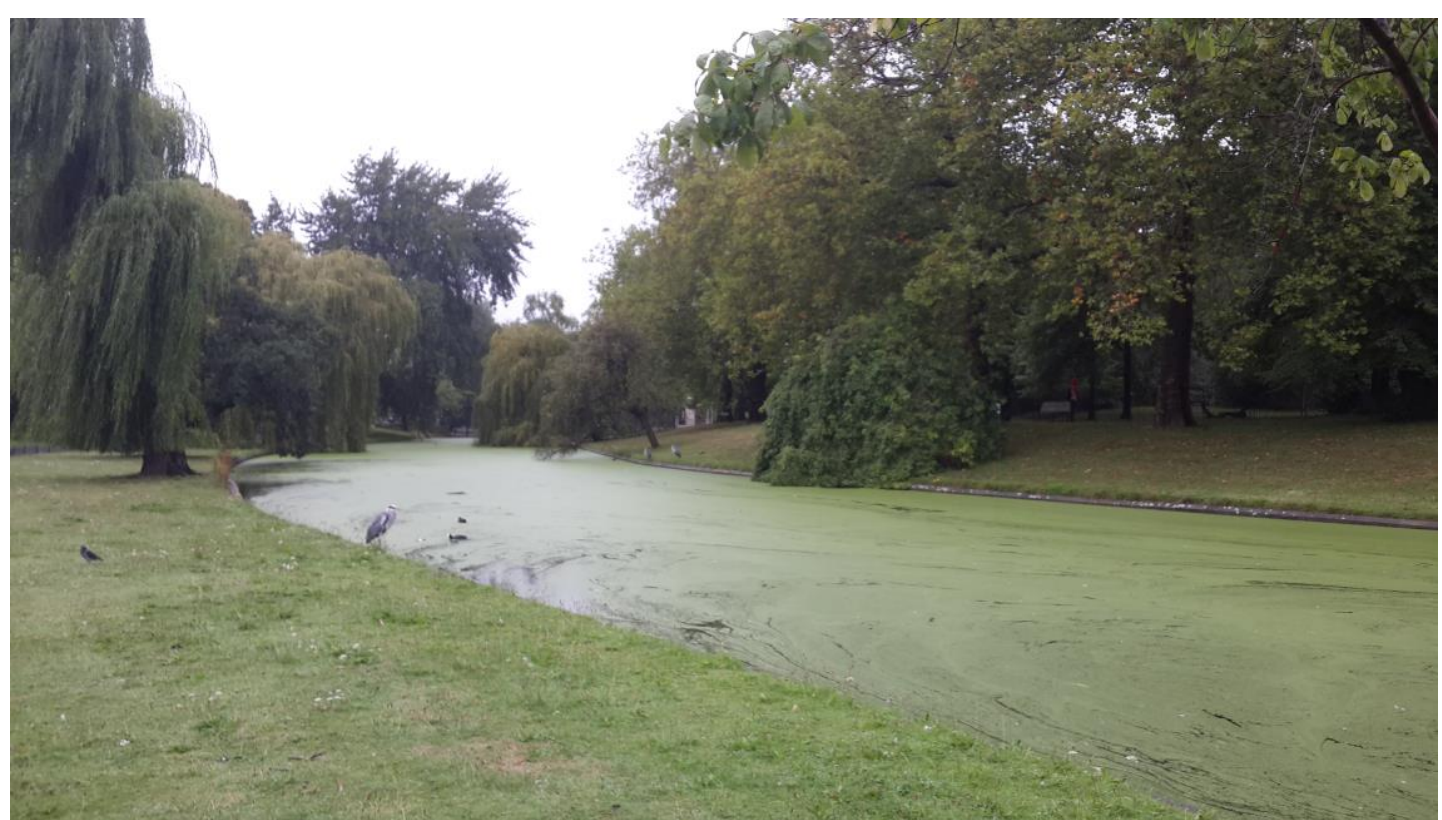

